Aus der Abteilung für Allgemeine Pflanzenpathologie und Pflanzenschutz des Departments für Nutzpflanzenwissenschaften der Georg-August-Universität Göttingen

\title{
Fusarium-Artenspektren an Halmbasis und Körnern von Weizen in unterschiedlichen Weizenfruchtfolgen
}

\author{
Dissertation \\ zur Erlangung des Doktorgrades \\ der Fakultät für Agrarwissenschaften \\ der Georg-August-Universität Göttingen
}

\author{
vorgelegt von \\ Marcel Tillmann \\ geboren in Dortmund
}

Göttingen, im März 2013 
D7

1. Referent: Prof. Dr. Andreas v. Tiedemann

2. Referent: Prof. Dr. Petr Karlovsky

Tag der mündlichen Prüfung: 03.05.2013 
„Wissenschaft:

Es ist nicht ihr Ziel, der unendlichen Weisheit eine Tür zu öffnen, sondern eine Grenze zu setzen dem unendlichen Irrtum.“

Bertholt Brecht 


\section{Inhalt}

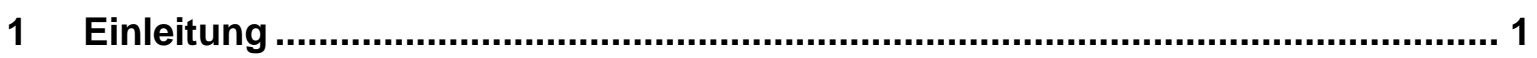

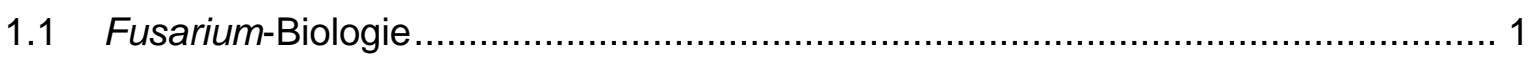

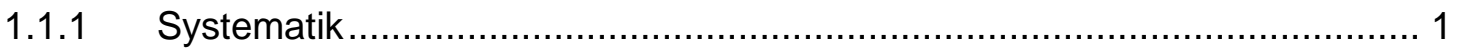

1.1.2 Epidemiologie von Fusarium an Weizen ................................................. 4

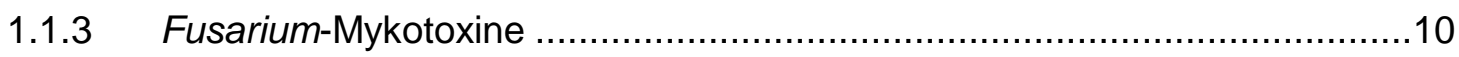

1.2 Agronomische Bedeutung von Fusarium an Weizen............................................14

1.3 Fusarium in Weizenfruchtfolgen.......................................................................

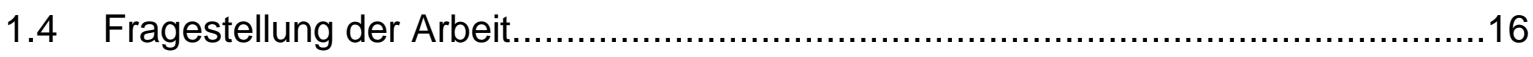

2 Material und Methoden ....................................................................................17

2.1 Medienkomponenten und Chemikalien …………………...............................17

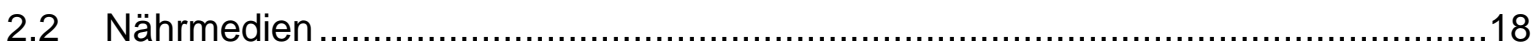

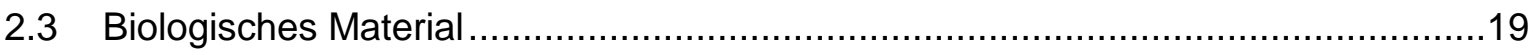

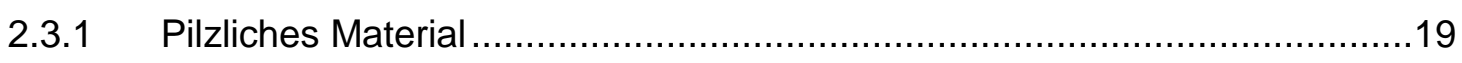

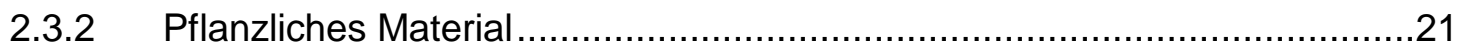

2.4 Saat-, Erntegut- und Halmsegmentsterilisation ……….........................................21

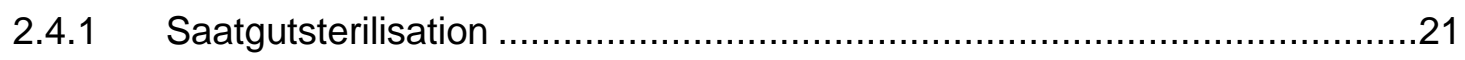

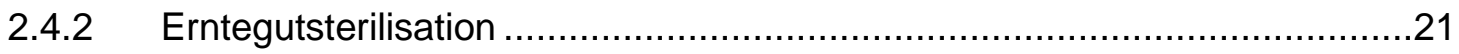

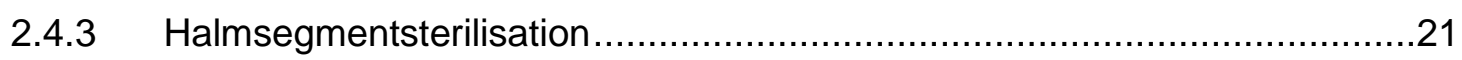

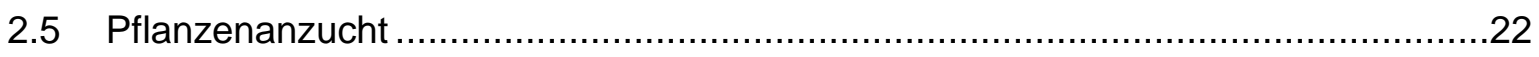

2.5.1 Versuche unter kontrollierten Bedingungen im Gewächshaus ....................22

2.5.2 Versuche unter kontrollierten Bedingungen in der Klimakammer ...............22

2.5.3 Versuche unter kontrollierten Bedingungen im Klimaschrank ....................22

2.6 Herstellung von Einzelsporenisolaten ………………........................................23

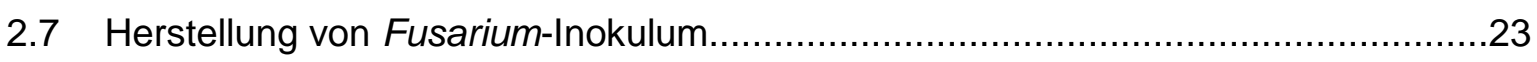

2.8 Anzucht von Fusarium-Arten in Flüssigkultur ………………………..................24

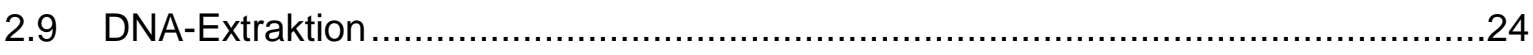

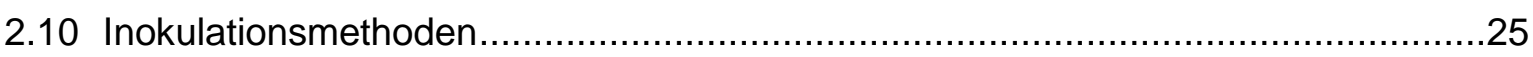


2.10.1 Inokulationsmethode für Feldversuche …..........................................25

2.10.2 Inokulationsmethode für Gewächshausversuche ...................................25

2.10.3 Inokulationsmethode für Kilmakammerversuche ....................................26

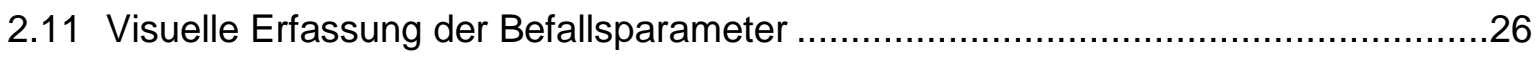

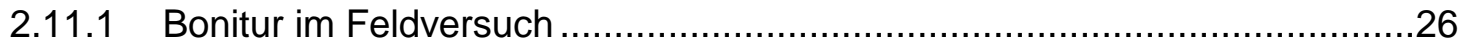

2.11.2 Bonitur Pathogenitätsversuche an der Ähre unter kontrollierten Bedingungen

2.11.3 Bonitur Pathogenitätsversuch an der Halmbasis unter kontrollierten

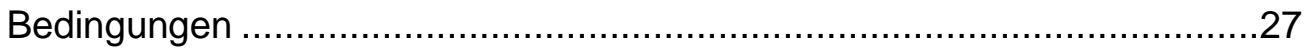

2.11.4 Visuelle Erfassung von Trockenstresssymptomen .................................28

2.11.5 Bonitur des In vitro-Pathogenitätstests unter kontrollierten Bedingungen....28

2.12 Tausendkorngewicht (TKG) und Ertragserfassung .28

2.12.1 Erfassung des Tausendkorngewichts von Erntegut aus dem FAENFeldversuch

2.12.2 Erfassung des Tausendkorngewichts von Erntegut aus Pathogenitätsversuchen 29

2.12.3 Erfassung des Kornertrags

2.13 Isolation und Identifikation des Fusarium-Spektrums an Halmbasis und Körnern von Weizen innerhalb des FAEN-Fruchtfolgeversuchs .29

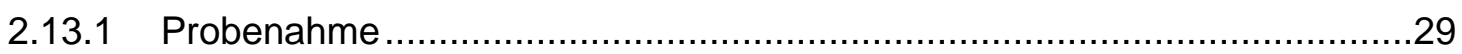

2.13.2 Isolation von Fusarium-Arten und Bestimmung der Kolonisierungsrate ......31

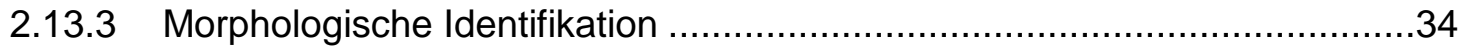

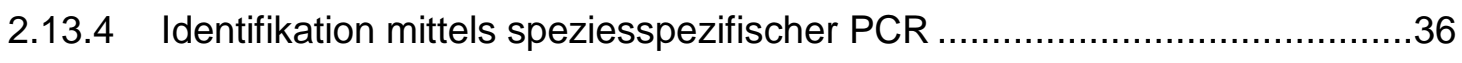

2.13.5 Identifikation mittels Restriktionsfragmentlängenpolymorphismus (RFLP) ..40

2.14 Analyse der Proben aus Freiland- und Gewächshausversuchen .... .43

2.14.1 Probenahme und Probenaufbereitung für Mykotoxinanalysen ..................43

2.14.2 Mykotoxinanalyse mittels HPLC-MS/MS .............................................44

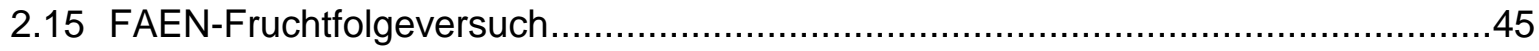

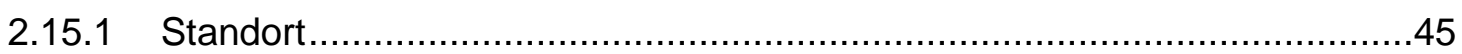

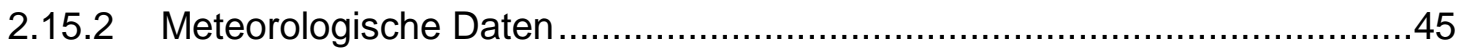




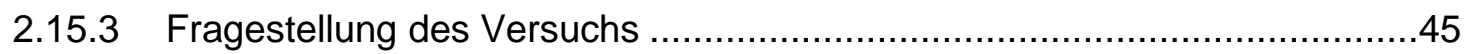

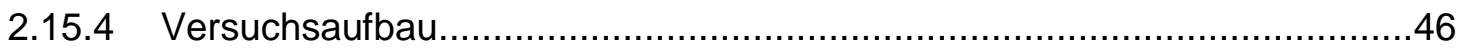

2.16 Pathogenitätsversuche mit Fusarium-Arten an Halmbasis und Ähre von Weizen ...48

2.16.1 Pathogenitätsversuch an der Ähre im Feld .........................................49

2.16.2 Pathogenitätsversuche unter kontrollierten Bedingungen an der Ähre ........51

2.16.3 Pathogenitätsversuch unter kontrollierten Bedingungen an der

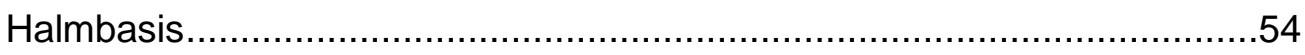

2.17 In vitro-Pathogenitätstests mit Fusarium-Arten an Weizen ..................................55

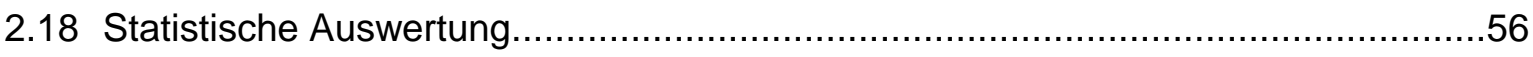

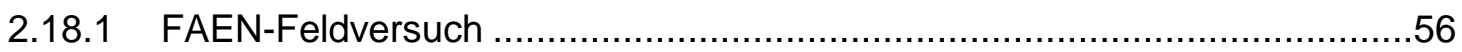

2.18.2 Pathogenitätsversuche an der Ähre in Freiland und Gewächshaus ............58

2.18.3 Pathogenitätsversuch an der Halmbasis unter kontrollierten

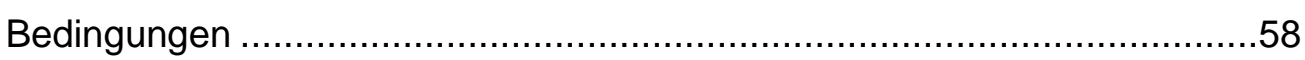

2.18.4 In vitro-Pathogenitätstest mit Fusarium-Arten an Weizen .........................59

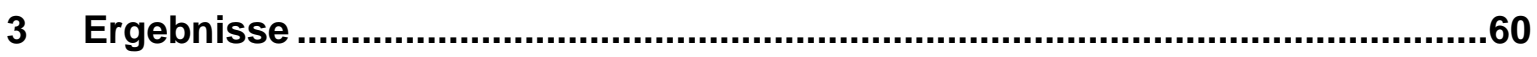

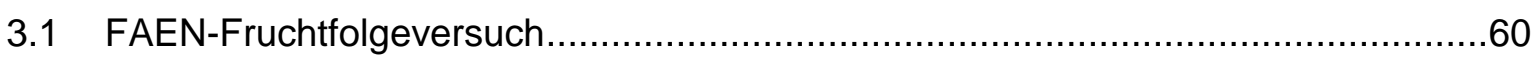

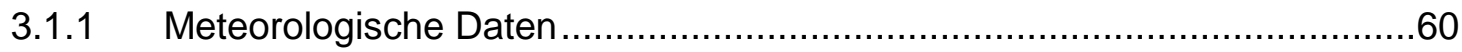

3.1.2 Befallshäufigkeit und Befallsstärke der Partiellen Weißährigkeit 2010

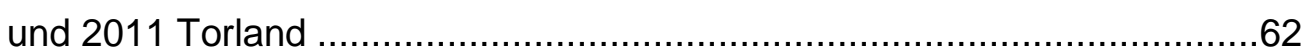

3.1.3 Deoxynivalenolgehalte des FAEN-Fruchtfolgeversuchs am Standort

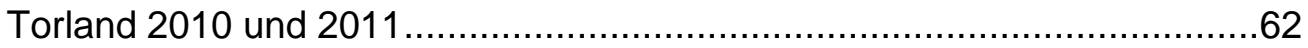

3.1.4 Einfluss der Versuchsfaktoren auf den Ertrag des FAEN-Fruchtfolgeversuchs am Standort Torland 2010 und 2011 .....................................64

3.1.5 Halmbasisbonitur zu BBCH 75-77 am Standort Torland 2011 ..................68

3.2 Fusarium-Artenspektren an Halmbasis und Körnern von Weizen ...........................70

3.2.1 Einfluss der Versuchsparameter auf das Fusarium-Artenspektrum an

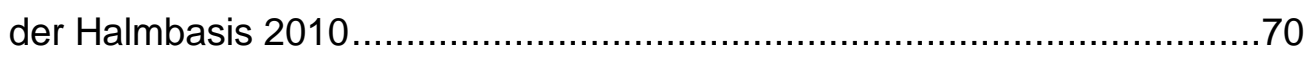

3.2.2 Einfluss der Versuchsparameter auf das Fusarium-Artenspektrum an

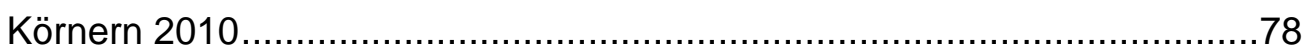

3.2.3 Vergleich der Fusarium-Artenspektren an Halmbasis und Körnern 2010 ....83 
3.2.4 Einfluss der Versuchsparameter auf das Fusarium-Artenspektrum an der Halmbasis 2011.

3.2.5 Einfluss der Versuchsparameter auf das Fusarium-Artenspektrum an Körnern 2011.

3.2.6 Vergleich der Fusarium-Artenspektren an den verschiedenen Pflanzenorganen 2011

3.2.7 Vergleich der Fusarium-Artenspektren der beiden Versuchsjahre 2010 und 2011

3.2.8 Varianzanalyse der Gesamtkolonisierungsraten an Halmbasis und Körnern 2010 und 2011

3.3 Pathogenität verschiedener Fusarium-Arten an der Ähre im Feldversuch.

3.3.1 Witterung zur Inokulation am 04.06.2011.

3.3.2 Visuelle Bonitur.

3.3.3 TKG

3.3.4 Mykotoxingehalte des Ernteguts

3.4 Pathogenität verschiedener Fusarium-Arten an der Ähre im Gewächshausversuch

3.4.1 Pathogenitätsversuch mit Einzelvarianten .........................................122

3.4.2 Pathogenitätsversuch mit Einzel- und Mischvarianten ...........................131

3.5 Pathogenitätsversuch mit Fusarium-Arten an der Halmbasis .............................139

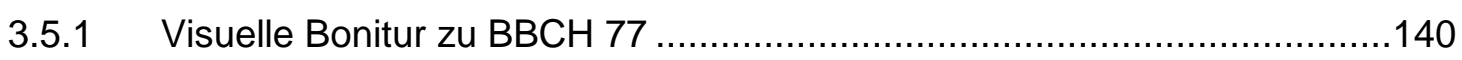

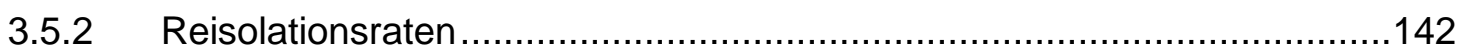

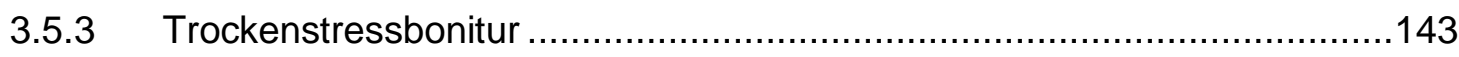

3.6 In vitro-Pathogenitätstest mit Fusarium-Arten an Weizen...................................145

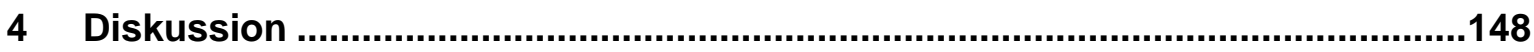

4.1 Fusarium-Artenspektren und Kolonisierungsraten an Halmbasis und Körnern von Weizen in Abhängigkeit der Versuchsfaktoren .........................................148

4.1.1 Einfluss des Versuchsjahres bzw. der Witterung .................................148

4.1.2 Einfluss des Probenahmezeitpunktes ................................................153

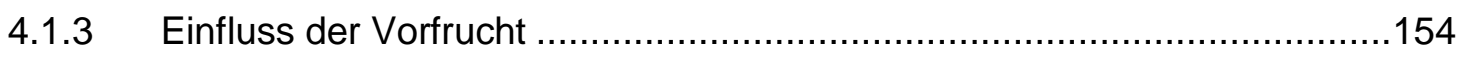

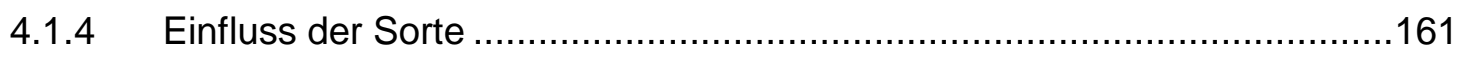




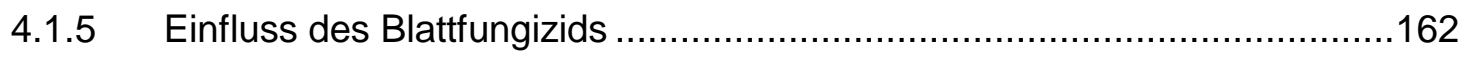

4.2 Pathogenität, Bedeutung und Risikobewertung der untersuchten Fusarium-

Arten an Halmbasis und Ähre von Weizen.....................................................164

4.2.1 Pathogenität, Bedeutung und Risikobewertung der untersuchten

Fusarium-Arten an der Halmbasis von Weizen .....................................164

4.2.2 Pathogenität, Bedeutung und Risikobewertung der untersuchten

Fusarium-Arten an der Ähre von Weizen ............................................168

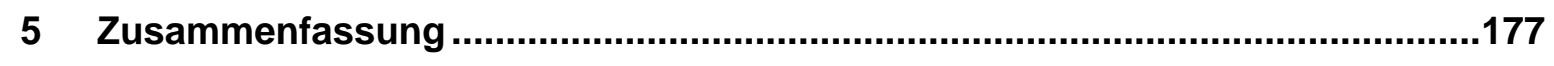

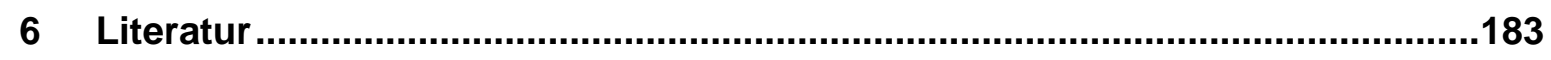

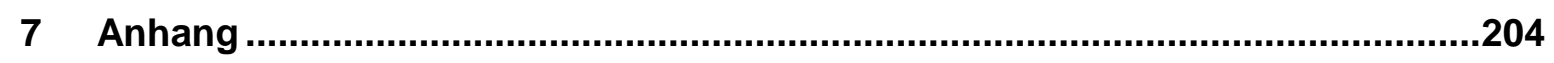




\section{Abkürzungen und Symbole}

Abb.

15-ADON

3-ADON

$\mathrm{BBCH}$

BEAU

bp

bzw.

${ }^{\circ} \mathrm{C}$

ca.

$\mathrm{cm}$

DNA

dNTP

DON

DON-3-G

dpi

ENN

et al.

FHB

g

ggf.

h

ha

$\mathrm{HB}$

HPLC-MS/MS

k.A.

$\mathrm{kg}$

$\mathrm{km}$

I

$\mathrm{m}$

$\mathrm{m}^{2}$

$\mathrm{mg}$

$\mu \mathrm{g}$
Abbildung

15-Acetyldeoxynivalenol

3-Acetyldeoxynivalenol

Kodierung der phänotypischen Entwicklungsstadien

von Getreide

Beauvericin

Basenpaar

beziehungsweise

Grad Celsius

circa

Zentimeter

Desoxyribonukleinsäure

Desoxy-Nucleotidtriphosphat

Deoxynivalenol

Deoxynivalenol-3-glucosid

days past inoculation

Enniatine

und andere

Fusarium Head Blight

Gramm

gegebenenfalls

Stunde

Hektar

Halmbasis

Hochdruckflüssigkeitschromatographie mit Tandem-

Massenspektrometrie

keine Angaben

Kilogramm

Kilometer

Liter

Meter

Quadratmeter

Milligramm

Mikrogramm 


\begin{tabular}{|c|c|}
\hline $\min$ & Minute \\
\hline $\mathrm{ml}$ & Milliliter \\
\hline$\mu l$ & Mikroliter \\
\hline $\mathrm{mm}$ & Millimeter \\
\hline $\mathrm{mM}$ & millimolar \\
\hline $\mathrm{mm}^{2}$ & Quadratmillimeter \\
\hline$\mu \mathrm{mol}$ & mikromol \\
\hline n.d. & nicht determiniert \\
\hline $\mathrm{nm}$ & Nanometer \\
\hline n.s. & nicht signifikant \\
\hline o.g. & oben genannt \\
\hline PCR & Polymerase-Kettenreaktion \\
\hline pmol & picomol \\
\hline rpm & Umdrehungen pro Minute \\
\hline s. & siehe \\
\hline $\mathrm{s}, \mathrm{sec}$ & Sekunde \\
\hline sp. & Spezies (Singular) \\
\hline spp. & Spezies (Plural) \\
\hline Tab. & Tabelle \\
\hline taq & Thermus aquaticus \\
\hline TKG & Tausendkorngewicht \\
\hline$U$ & Einheiten \\
\hline u.a. & unter anderem \\
\hline var. & Varietät \\
\hline vgl. & vergleiche \\
\hline Wdh. & Wiederholung \\
\hline z.B. & zum Beispiel \\
\hline ZEA & Zearalenon \\
\hline$\%$ & Prozent \\
\hline
\end{tabular}




\section{$1 \quad$ Einleitung}

\section{$1.1 \quad$ Fusarium-Biologie}

\subsubsection{Systematik}

Die Gattung Fusarium bildet einen großen Komplex mykotoxinbildender Schimmelpilze und wurde 1809 erstmals von Link eingeführt. Viele Arten innerhalb der Gattung werden taxonomisch den Deuteromyzeten zugeordnet, da sie keine Hauptfruchtform (Teleomorph) besitzen oder diese nicht bekannt ist. Ist eine teleomorphe Form vorhanden, so wird diese den Askomyzeten zugeordnet. Die Hauptfruchtformen von Fusarium werden heute in die Gattungen Cosmospora, Gibberella, Nectria, (Albonectria, Haematonectria), Monographella und Plectosporium eingeteilt (Samuels et al., 2001). Für lange Zeit stellte sich die Identifikation verschiedener Fusarium-Arten als sehr schwierig dar. Bis in die ersten Jahrzehnte des 20. Jahrhunderts waren bereits mehr als 1000 Arten beschrieben worden. Erst 1935 stand durch Wollenweber und Reinkings "Die Fusarien“ zum ersten Mal ein geordnetes, auf mykologischen Eigenschaften aufbauendes taxonomisches System mit 16 Sektionen, 65 Arten und 77 Varietäten sowie nur an bestimmten Pflanzenarten pathogene formae specialis zur Verfügung (Nelson, 1991). Snyder und Hansen entwickelten in den 1940er und 1950er Jahren dagegen ein auf lediglich neun Arten basierendes taxonomisches System, das jedoch heute auf breiter Basis als zu ungenau betrachtet wird (Leslie und Summerell, 2006). 
Tab. 1: Die 16 Sektionen des taxonomischen Sytems nach Wollenweber und Reinking (1935) und die Neueinteilung in neun Arten nach Snyder und Hansen zwischen 1940 und 1945 (Nelson, 1991).

\begin{tabular}{cc}
$\begin{array}{c}\text { Sektionen nach Wollenweber und } \\
\text { Reinking (1935) }\end{array}$ & $\begin{array}{c}\text { Arten nach Snyder und } \\
\text { Hansen }(1940-45)\end{array}$ \\
Eupinnotes & F. episphaeria \\
Macroconia & F. episphaeria \\
Spicarioides & F. rigidiuscula \\
Submicrocera & - \\
Pseudomicrocera & - \\
Arachmites & F. nivale \\
Sporotrichiella & F. tricinctum \\
Roseum & F. roseum \\
Arthrosporiella & F. roseum \\
Gibbosum & F. roseum \\
Discolor & F. roseum \\
Lateritium & F. lateritium \\
Liseola & F. moniliforme \\
Elegans & F. oxysporum \\
Martiella & Folani \\
Ventricosum & Folani \\
\hline
\end{tabular}

Auf Grund unterschiedlicher Meinungen, auf welche Weise eine taxonomische Ordnung der Gattung Fusarium erfolgen sollte, bildeten sich drei Gruppierungen: Die „lumpers“, die „moderates“ und die „splitters“ (Nelson et al., 1994). Wie die Namen bereits deutlich werden lassen, fassten Vertreter der „lumpers“ wie Messian und Cassini (1968, 9 Arten) oder Matuo (1972, 10 Arten) neben Snyder und Hansen (s.o.) Fusarium zu wenigen Arten zusammen. Eine weniger scharfe Einteilung erfolgte durch Vertreter der „moderates“, wie beispielsweise Gordon (1952), Booth (1971) und Nelson, Toussoun und Marasas (1983), welche sich für eine Gruppierung der Gattung in 26 bis 44 Arten aussprachen. Angehörige 
der „splitters“ waren neben Wollenweber und Reinking (1935, 65 Arten), Gerlach (1982, 78 Arten) oder auch Joffe (1974, 33 Arten) (Nelson et al., 1994).

Die auf den Forschungen von Wollenweber und Reinking basierende Arbeit von Gerlach und Nirenberg aus dem Jahr 1982 nimmt einen besonderen Stellenwert in der taxonomischen Erforschung von Fusarium ein. Dabei stützte sich die von ihnen vorgeschlagene taxonomische Einordnung vieler Fusarium-Arten auf ein morphologisches Artkonzept und erwies sich als sehr robust und größtenteils bis heute aktuell (Leslie und Summerell, 2006).

Mehrere Artkonzepte, die auf unterschiedlichen Strategien und Lösungsansätzen beruhen, sind mittlerweile entwickelt worden. Das oben genannte, auf individuellen physischen und physiologischen Eigenschaften verschiedener Arten aufbauende, morphologische Artkonzept, ist das älteste und ein bis heute weit verbreitetes (Leslie und Summerell, 2006). Dabei liegt der Fokus der taxonomischen Einordnung besonders auf der mikroskopischen Begutachtung der spezifischen Größe, Form und Septierung der Makrokonidien einer jeden Art (Moretti, 2009). Zudem spielt die Form von Apikal- und Basalzellen, Septierung sowie die Bildung von Chlamydosporen und Meso- und Mikrokonidien eine große Rolle (Burgess et al., 1994). Die Beschaffenheit und Ausbildung von Sporodochien sowie Phialiden als Sporenträger und die durch sie produzierten Sporenformen sind ebenfalls von Bedeutung (Leslie und Summerell, 2006). Auch die Berücksichtigung der Myzelmorphologie ist bei der morphologischen Artunterscheidung bedeutsam. In vielen Fällen lässt die Betrachtung der Myzelkolonie im Hinblick auf Form und Dichte, Pigmentierung des Myzels und des Agars, Bildung von Luftmyzel und der Geruch bereits eine grobe Einteilung der Art zu, wobei die teilweise hohe Variabilität der Myzelmorphologie innerhalb einer Art berücksichtigt werden muss. Oftmals ergeben sich jedoch Schwierigkeiten bei der Anwendung dieses Artkonzeptes. Eine Artdifferenzierung kann nur nach Inkubation des Pilzes auf bestimmten Medien erfolgen und Arten können auf Grund zu ähnlicher morphologischer Eigenschaften nicht unterschieden werden (Leslie und Summerell, 2006). Zudem neigen Isolate bestimmter Arten bzw. Artkomplexe, wie z. B. F. oxysporum SCHLECHTENDAHL EMEND. SNYDER \& HANSEN zu frühzeitiger Myzeldegeneration. Auch Mutationen von Fusarium in Kultur werden immer wieder beobachtet, wodurch die Identifikation erschwert werden kann.

Das morphologische Artkonzept stellt die Basis dar für zwei weitere Artkonzepte: Das biologische und das phylogenetische, welche beide für die Fusarium-Taxonomie zunehmend an Bedeutung gewinnen (Leslie und Summerell, 2006). Während das biologische Artkonzept Arten als Individuen betrachtet, die untereinander kreuzbar sind und möglicherweise einen gemeinsamen Genpool teilen, definiert das phylogenetische Artkonzept eine Art als eine Gruppe von Individuen, die denselben genetischen Ursprung besitzen und somit eine monophyletische Gruppe bilden (Summerell et al., 2003). 
Die Anwendung des biologischen Artkonzeptes auf die Gattung Fusarium gestaltet sich jedoch mitunter als schwierig, nicht zuletzt wegen der hohen Anzahl an anamorphen Arten mit rein asexueller Fortpflanzung (Leslie und Summerell, 2006). Das phylogenetische Artkonzept bedient sich moderner Molekulargenetik und hat in den letzten Jahren zu einer Diversifizierung innerhalb der Gattung Fusarium geführt. So konnten beispielsweise bei F. graminearum SCHWABE [teleomorph Gibberella zeae (SCHWEINITZ) PETCH] mittels Untersuchung der DNA-Sequenzen sechs verschiedener Gene aus verschiedenen $F$. graminearum-Isolaten, sieben phylogenetisch distinkte Linien identifizieren werden (O'Donnell et al., 2000). Eine von O'Donnell et al. (2004) durchgeführte Genealogical Concordance Phylogenetic Species Recognition (GCPSR)Analyse identifizierte dagegen 11 phylogenetische Linien, die die ursprünglichen sieben Linien enthielten und zusätzlich noch vier weitere beinhalteten: $F$. austroamericanum (Linie 1), F. meridionale (Linie 2), F. boothii (Linie 3), F. mesoamericanum (Linie 4), F. acaciae-mearnsii (Linie 5), F. asiaticum (Linie 6), F.graminearum (Linie 7), F. cortaderiae (Linie 8) sowie drei weitere Linien mit F. brasilicum und den später identifizierten Linien F. vorosii und F. gerlachii (Starkey et al., 2007).

Die vorliegende Arbeit basiert auf der innerhalb der klassischen Phytopathologie immer noch sehr verbreiteten morphologischen Artdifferenzierung mit Hilfe von mikroskopischer und makroskopischer Untersuchung sowie parallelem Abgleich mit Bestimmungsliteratur (Gerlach und Nirenberg, 1982; Burgess et al., 1994, Leslie und Summerell, 2006). Eine molekulare Methode für die Identifikation morphologisch nicht eindeutig bestimmbarer Arten liefert die Verwendung des in Eukaryoten ubiquitär vorkommenden, evolutionär hochkonservierten Translation Elongation Factor 1a-Gens (tef1a). Das von tef1 $\alpha$ codierte Enzym EF-1 $\alpha$ ist eine GTPase, welche während der Proteinsynthese den Transport geladener tRNA zu den Ribosomen katalysiert (Uetsuki et al., 1989; Negrutskii et al., 1998). Das Gen besitzt jedoch in den Intronbereichen eine hohe Anzahl an Sequenzpolymorphismen. Diese können nach Gewinnung genomischer DNA und Durchführung einer PCR zur Amplifizierung des tef1 $\alpha$-Genfragments mit Hilfe von RFLP eine Artdifferenzierung ermöglichen (Nitschke et al., 2009).

\subsubsection{Epidemiologie von Fusarium an Weizen}

Fusarium-Arten sind in der Lage, weltweit eine Vielzahl von Pflanzen zu befallen, darunter Getreidearten wie Weizen (Triticum aestivum L.) und Gerste (Hordeum vulgare L.) und rufen auch an vielen anderen Kulturpflanzen Krankheiten hervor, wie zum Beispiel die Kolben- und Stängelfäule an Mais (Zea mays L.) oder die „Bakanae Disease“ in Reis (Oryza sativa L.) (Desjardins, 2003). Fusarium kommt ubiquitär im Boden vor und überdauert dort abhängig von der Art entweder als Myzel mit saprophytischer 
Lebensweise oder als Chlamydosporen (Dauersporen) (Parry et al., 1994). An Getreide werden drei verschiedene, durch Fusarium-Infektion hervorgerufene Krankheiten beobachtet: „Fusarium Seedling Blight“, „Fusarium Crown Rot“ und „Root Rot“ sowie „Fusarium Head Blight“ (FHB) (Cook, 1980; Parry et al., 1995). Im deutschen Sprachraum ist „Fusarium Head Blight" auch als „Partielle Weißährigkeit“ bekannt. Zur Infektion des Getreides benötigt der Pilz Nährstoffquellen, auf denen er saprophytisch überdauern und Inokulum anreichern kann. Zahlreiche Fusarium-Arten, wie beispielsweise F. graminearum, bilden diese Inokulumquellen hauptsächlich auf Ernteresten, die auf dem Feld zurückgeblieben sind (Parry et al., 1994). Jedoch auch windvermittelter Askosporenoder Konidieneintrag in einen Bestand ist möglich (Parry et al., 1995).

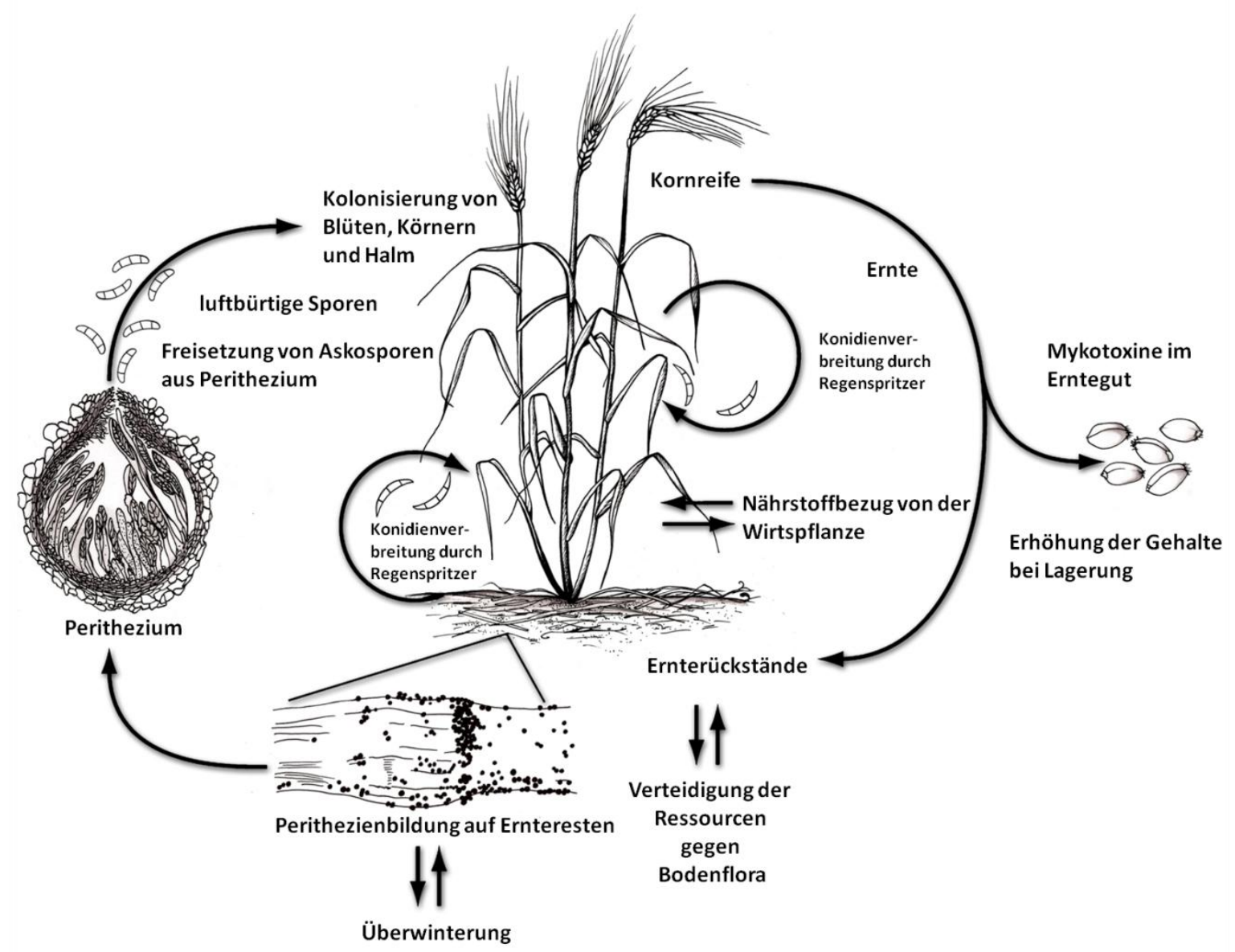

Abb. 1: Lebenszyklus von Fusarium graminearum (Teleomorph Gibberella zeae; verändert nach Trail, 2009). 


\section{Fusarium Head Blight}

An Weizen kommt ein diverses Spektrum an Fusarium-Arten vor, die zumeist als Komplex auftreten (Doohan et al., 2003; Xu et al., 2005). Vor allem in Europa wird „Fusarium Head Blight“ (FHB) mit einem aus 19 Fusarium-Arten bestehenden Komplex assoziiert (Liddell, 2003), wobei F. graminearum weltweit als Hauptverursacher von FHB und neben F. culmorum (W.G. SMITH) SACC. als die Art mit der höchsten Pathogenität gilt (Mesterházy, 1977; Wilcoxson et al., 1988; Brandfaß, 2006). Weitere wichtige Arten dieses Komplexes stellen F. avenaceum (FRIES) SACC. und F.poae (PECK) WollenWeber (Bottalico und Perrone, 2002) dar. Weniger pathogene Arten, die dennoch zum FHB-Artenspektrum gezählt werden, sind unter anderem F. cerealis (COOKE) SACC. (1886) syn. F. crookwellense L.W. BuRGESS, P.E. NELSON \& TOUSSOUN (1982), F. equiseti (CORDA) SACCARDO, F. sporotrichioides SHERBAKOFF und F. tricinctum (CORDA) SACCARDO sowie die seltener auftretenden Arten F. acuminatum ELL. \& KELLERM., F. subglutinans (Wollenweber \& ReINKING) NELSON, TOUSSOUn \& MARASAS, F. solani (MART.) SACC. var. solani, F. oxysporum, F. verticillioides (SACCARDO) NIRENBERG, F. semitectum BERK. \& RAV. und F. proliferatum (MATSUSHIMA) NIRENBERG (Bottalico und Perrone, 2002). Der Lebenszyklus der o.g. Arten verfügt über eine saprophytische und eine pathogene Phase (Sutton, 1982). Die Reproduktion zahlreicher Fusarium-Arten, unter innen die bereits erwähnten Arten F. culmorum und F. poae findet auf Grund einer fehlenden Hauptfruchtform asexuell statt, während F.graminearum auf Grund einer existierenden Hauptfruchtform neben asexueller auch zu sexueller Reproduktion befähigt ist (Sutton, 1982; Wagacha und Muthomi, 2007). Dementsprechend kann eine Infektion der Ähre, abhängig von der Fusarium-Art, durch Konidien oder Askosporen erfolgen.

Das Auftreten von FHB ist sehr stark von Umweltbedingungen wie Temperatur und Luftfeuchte, aber natürlich auch von der Sporendichte abhängig (Andersen, 1948). Dabei weisen verschiedene Arten unterschiedliche Umweltbedürfnisse für eine erfolgreiche Infektion auf. So konnten Xu et al. (2005) in einem vierjährigen Feldversuch in Ungarn, Irland, Italien und Großbritannien zeigen, dass F. poae in warmen, aber trockeneren Gebieten häufig auftrat, während $F$. avenaceum und F. culmorum im Gegensatz dazu in kühlen, feuchten Gebieten mit häufigen, aber kurzen Niederschlägen aufgefunden wurden. F. graminearum als wichtigstes FHB hervorrufendes Pathogen bevorzugte warme und feuchte Bedingungen. Eine Infektion der Weizenähre durch F. graminearum erfolgt daher bei relativ hohen Temperaturen über $25^{\circ} \mathrm{C}$, wobei das Temperaturoptimum bei $25-28^{\circ} \mathrm{C}$ liegt (Brennan et al., 2003) sowie ausgiebigen Niederschlägen zur Vollblüte (BBCH 61-65) (Pugh, 1933), da die Ähre zu diesem Zeitpunkt für eine Infektion am empfindlichsten ist (Sutton, 1982). Sowohl Konidien, als auch durch Perithezien ausgeschleuderte Askosporen werden durch Wind oder Regenspritzer zur Ähre 
transportiert (Jenkinson und Parry, 1994). Nach Ankunft der Sporen auf der Oberfläche der Ähre beginnt F. graminearum, ein Hyphengeflecht auf Deck- und Hüllspelzen der Ährchen auszubilden. Die Penetration des Ährengewebes erfolgt allerdings nicht auf der Außenseite der Ährchen, sondern nach Einwachsen des Myzels auf der Innenseite der Spelzen, wo sich ein dichtes Geflecht aus Hyphen bilden kann (Kang und Buchenauer, 2000a). Hier beginnt der Pilz durch leichter passierbare Eintrittspforten wie z.B. Stomata, das Ährengewebe zu penetrieren (Kang und Buchenauer, 2000a). Einen alternativen Infektionsweg stellen die Antheren dar (Dickson et al., 1921; Pugh, 1933), da der Pilz den Pollen als Nährstoffquelle für die Sporenkeimung nutzen kann (Diehl, 1984). Es folgt eine interzelluläre, im späteren Verlauf der Infektion auch intrazelluläre Ausbreitung des Pilzes zur Basis von Deck- und Hüllspelzen sowie des Fruchtknotens, welche in einer Besiedlung der Ährchenachse resultiert. Während des Infektionsprozesses produziert der Pilz zellwanddegradierende Enzyme wie Pektinasen, Xylanasen sowie Zellulasen, was die Zellwandpenetration erleichtert (Kang und Buchenauer, 2000b). F. graminearum dringt während der Infektion bis in das Leit- und Parenchymgewebe der Ährenspindel vor und breitet sich dort vor allem basipetal systemisch in der Ähre aus (Kang und Buchenauer, 2000a; Ribichich et al., 2000), sodass weitere Ährchen infiziert werden können. Bei anhaltenden feucht-warmen Bedingungen während der Kornbildungsphase können Starkinfektionen auftreten, wodurch der Pilz bis in das Pedunkel vordringen kann (Goswami und Kistler, 2004). Erste FHB-Symptome treten meist in der Mitte der Ähre auf (Bushnell et al., 2003), da in dieser Region die Weizenähre zu blühen beginnt (Kirby, 2002). Während sich nach der Vollblüte nach Infektion mit F. graminearum, braune, nekrotische Flecken an Deck- und Hüllspelzen bilden (Kang und Buchenauer 2000a), zeigt sich nach der systemischen Besiedlung der Ähre etwa zum Zeitpunkt der Milchreife (BBCH 71-75) das typische FHB-Symptom als ausgeblichene Ährchen oberhalb der Primärinfektion (Weinert und Wolf, 1995), was auf eine Unterbrechung von Wasser-, Nährstoff- und Assimilattransport in Xylem und Phloem der Ährenspindel durch die systemische Besiedlung des Pilzes zurückzuführen ist. 


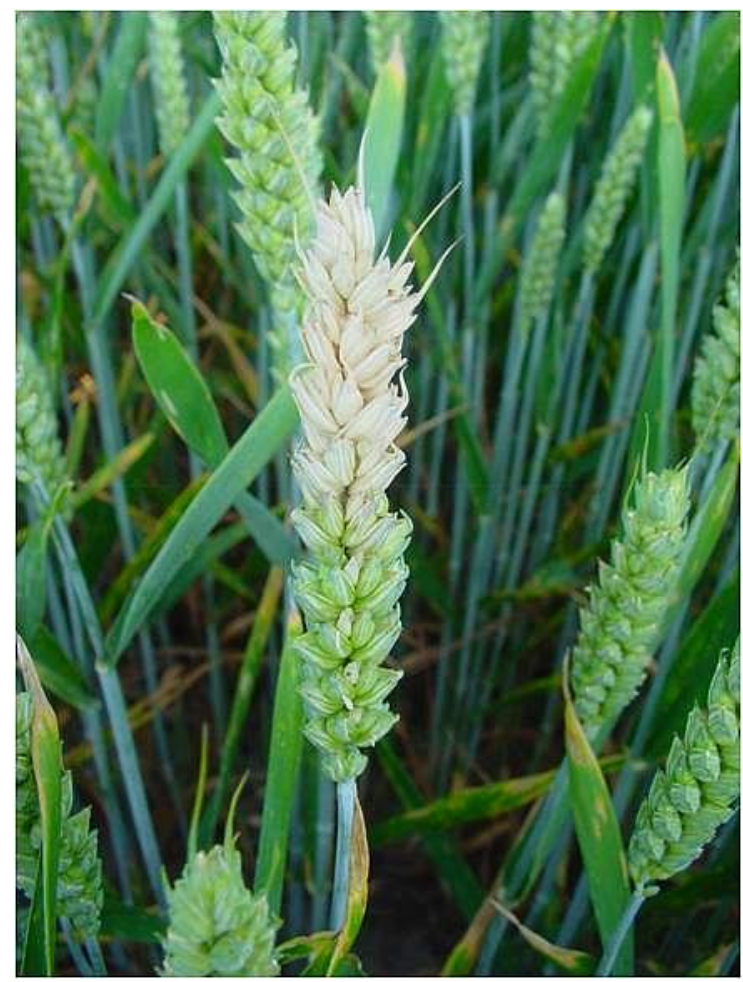

Abb. 2: „Fusarium Head Blight“, bzw. „Partielle Weißährigkeit“ an Winterweizen im Feld, hervorgerufen durch natürlichen Befall (Foto: M. Tillmann).

Eine mit F. graminearum infizierte Weizenähre bringt zum Zeitpunkt der Ernte bedingt durch die Nährstoffunterversorgung im oberen, ausgeblichenen Teil der Ähre kleine, endospermlose Kümmerkörner hervor. Der untere Teil der Ähre kann zur Ernte deutlich sichtbare, orangene Sporenmassen an den Ährchen aufweisen. Körner, die aus diesem Teil der Ähre gewonnen werden können, werden als Kümmerkörner, bzw. „scabby kernels“ bezeichnet. Diese Körner sind ebenfalls stark miniaturisiert, jedoch dazu mit Myzel bewachsen und können dadurch eine weißlich, pinke Farbe annehmen (Weinert und Wolf, 1995).

In Bezug auf die Resistenz gegenüber FHB existieren beträchtliche Unterschiede zwischen verschiedenen Weizensorten (Bai und Shaner, 2004). Studien von Mesterházy (2003) konnten zeigen, das FHB-Resistenz in Weizen nicht artspezifisch ist, sondern gegenüber allen Fusarium-Arten wirksam ist. Grundsätzlich wird zwischen Resistenztyp I und Resistenztyp II unterschieden (Schroeder und Christensen, 1963). Resistenz des Typs I ist gegenüber der initialen Infektion der Weizenähre durch Fusarium wirksam. Resistenztyp II unterbindet die systemische Ausbreitung des Pilzes in der Pflanze. Dieser Resistenzmechanismus geht mit Zellwandappositionen in der Rachis einher (Jansen et al., 2005). Später wurden neben diesen beiden Resistenztypen weitere definiert: Resistenz gegenüber der Infektion der Körner (Typ III), Toleranz gegenüber der Infektion (Typ IV) sowie Resistenz gegenüber Deoxynivalenol (DON)-Akkumulation (Typ V; Miller 
et al., 1985; Snijders und Perkowski, 1989; Mesterházy, 2002; Champeil et al., 2004, s. 1.1.3) durch Glykosylierung (Gareis, 1994).

\section{Fusarium Foot Rot}

„Fusarium Foot Rot“ (FFR), bzw. die sogenannte „Fusarium Fußfäule“ wird von einem Spektrum verschiedener Fusarium-Arten verursacht, welches vor allem durch F. culmorum und F. graminearum dominiert wird (Duben und Fehrmann, 1979; Cook, 1980; Clement und Parry, 1998). Eine weitere für den Fußbefall bedeutende Fusarium-Art stellt F. avenaceum dar (Krampe, 1926; Bennett, 1935; Duben, 1978; Smiley et al., 2005). FFR ist in den meisten Getreideanbaugebieten der Welt anzutreffen (Smiley et al., 2005).

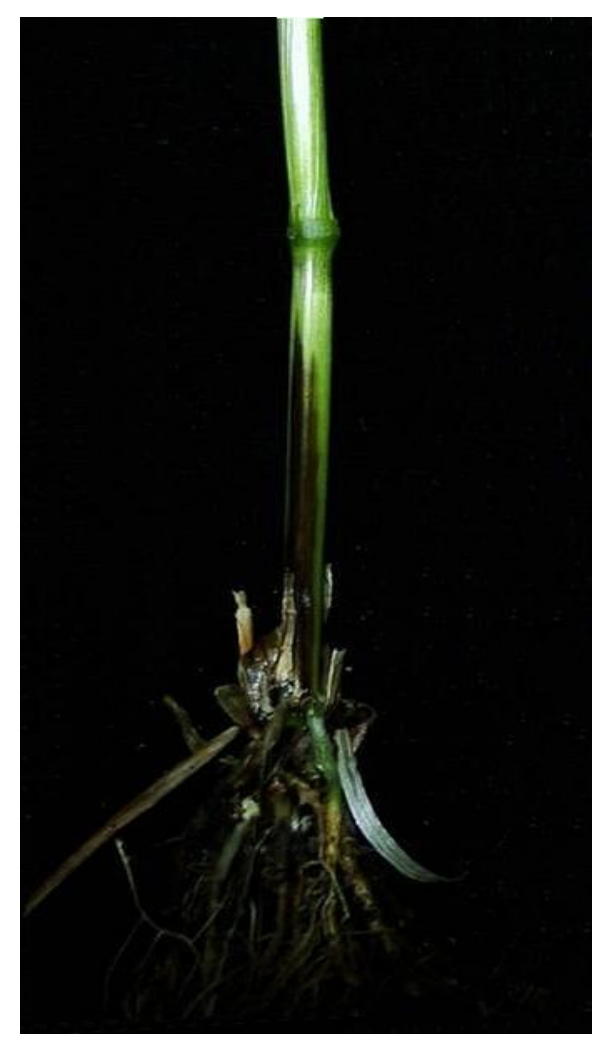

Abb. 3: „Fusarium Foot Rot“. Typische, schwarz-bräunliche, streifige Verfärbung der Halmbasis zu BBCH 77, hervorgerufen durch Inokulation mit F.culmorum (Foto: M. Tillmann).

Die Krankheit tritt vor allem auf, wenn zum Zeitpunkt des Auflaufens des Weizens im Herbst trockene und warme Bedingungen vorherrschen (Cook, 1980; Smiley et al., 2005). Als primäre Inokulumquelle gelten Vorfruchtreste (Abb. 1), die durch reduzierte Bodenbearbeitung auf dem Acker verblieben sind (Beck und Lepschy, 2000; Southwell et al., 2003). Typische Symptome sind als streifige, nekrotische, braun-schwarze 
Verfärbungen an der Krone sowie der Halmbasis (Cook, 1980; Hare und Parry, 1996) zu beobachten. Innerhalb des Fusarium-Artenspektrums, welches die Halmbasis befällt, gilt F. culmorum als die aggressivste Art (Clement und Parry, 1998). Als Inokulum dienen hauptsächlich Chlamydosporen und infizierte Ernterückstände (Cook, 1980). Während der initialen Infektion penetriert der Pilz zunächst die äußeren Blattscheiden hauptsächlich durch die Stomata und dringt horizontal bis zum Halm vor (Beccari et al., 2011). Zu späten Entwicklungsstadien kann die gesamte Halmbasis bis hin zum ersten Nodium durch Pilzmyzel kolonisiert sein (Clement und Parry, 1998) und starke Vermorschungen können entstehen (Smiley et al., 1996; Burgess et al., 2001).

Bisher konnten noch keine erfolgversprechenden Methoden zur Resistenztestung gegenüber bodenbürtigen Infektionen der Halmbasis von Weizen durch Fusarium etabliert werden (Cook, 1980), sodass gegenüber Fußbefall resistente Weizensorten nicht zur Verfügung stehen.

\subsubsection{Fusarium-Mykotoxine}

Neben den vier Schimmelpilzgattungen Alternaria, Aspergillus, Claviceps und Penicillium (Steyn et al., 1995) zeichnen sich auch die meisten Vertreter der Gattung Fusarium durch die Bildung warmblütertoxischer, dem pilzlichen Sekundärmetabolismus entstammender, chemischer Verbindungen aus. Diese Verbindungen werden als Mykotoxine bezeichnet. Viele Fusarium-Arten verfügen dabei oft über die Fähigkeit, aus mehreren verschiedenen Mykotoxinen bestehende Spektren zu bilden (Langseth et al., 1999). Innerhalb der Fusarium-Mykotoxine unterscheidet man zwischen verschiedenen Stoffgruppen. Von besonderer Bedeutung sind trizyklische Sesquiterpene, die Trichothecene, welche sich in Trichothecene des Typs A und Trichothecene des Typs B aufteilen (Ueno et al., 1985). Neben Fusarium bilden auch die Gattungen Mycothecium, Trichoderma, Trichothecium, Stachybotrys, Verticimonosporium und Cephalosporium Trichothecene (Ueno et al., 1985). Zu den Typ B Trichothecenen werden u.a. Deoxynivalenol (DON) und dessen Derivate 3-Acetyldeoxynivalenol (3-ADON) und 15-Acetyldeoxynivalenol (15-ADON) gezählt sowie Nivalenol (NIV) und Fusarenon X (FUS X). DON ist das am häufigsten auftretende Mykotoxin (Snijders, 1990). Die Mykotoxine Diacetoxyscirpenol (DAS), Monoacetoxyscirpenol (MAS), Neosolaniol (NEO) sowie das HT2- und das T2-Toxin sind den A-Trichothecenen zugehörig. Ihnen wird eine weitaus höhere Toxizität zugeschrieben, als den B-Trichothecenen (Krska et al., 2001). 
Tab. 2: Wichtige durch Vertreter der Gattung Fusarium produzierte Mykotoxine und deren Derivate.

\begin{tabular}{cccc}
\hline Trichothecene Typ A & Trichothecene Typ B & Cyclohexadepsipeptide & Andere \\
\hline Monoacetoxyscirpenol & Deoxynivalenol & Beauvericin & Avenacin Y \\
Diacetoxyscirpenol & 3-Acetydeoxynivalenol & Enniatine & Moniliformin \\
Neosolaniol & 15-Acetyldeoxynivalenol & & Zearalenon \\
T2-Toxin & Fusarenon X & \\
HT2-Toxin & Nivalenol & \\
\hline
\end{tabular}

Weitere wichtige Fusarium-Mykotoxine stellen sowohl Fumonisine, als auch Cyclohexadepsipeptide wie Beauvericin (BEAU), und die Enniatine (ENNI) A, A1, B, B1 und $B 2$ dar. Verschiedene Arten bilden zudem Moniliformin (MON) und Avenacin $Y$ (AVENA Y). Auch Zearalenon (ZEA) kann von verschiedenen Fusarium-Arten synthetisiert werden, darunter F. graminearum, F. culmorum und F. cerealis (Desjardins, 2006). Im Hinblick auf ihre Toxizität können Mykotoxine bei Mensch und Tier akute, chronische, mutagene und teratogene Intoxikationen hervorrufen (Pitt, 2000). Besonders Trichothecene werden mit akuten und chronischen Toxikosen in Verbindung gebracht. Ihre toxischen Eigenschaften basieren auf der Inhibition ribosomaler Proteinsynthese (Desjardins et al., 2007a). So führte in Russland in den 1940er Jahren der Verzehr von mit Trichothecenen kontaminierten Getreidekörnern bei ca. 100.000 Menschen zu einer „Alimentary Toxic Aleukia“ (Joffe, 1978), einhergehend mit dermalen Entzündungen, Erbrechen, Nekrosen der Mundhöhle, Bluten aus Mund und Nase sowie Störungen des zentralen Nervensystems (Bennett und Klich, 2003). In Japan wurde in der Mitte des letzten Jahrhunderts mehrfach eine als „Akakabi-byo“ bzw. „red mold disease“ bezeichnete Krankheit bei Mensch und Tier beobachtet (Desjardins et al., 2007a). Bei Schweinen zeigte sich in den USA dagegen durch Aufnahme von mit Deoxynivalenol (DON) kontaminiertem Futter eine reduzierte Nahrungsaufnahme und daraus resultierender Gewichtsverlust. Zu einem Hervorrufen dieser Symptome sind bereits Mengen zwischen 1 und $4 \mathrm{mg} / \mathrm{kg}$ DON ausreichend. Höhere Dosen von mehr als $10 \mathrm{mg} / \mathrm{kg}$ verursachten Durchfall und Erbrechen (Lepschy, 1991). Auf Grund dieser Symptome wird DON auch als Vomitoxin bezeichnet (Snijders, 1990; Visconti et al., 2004). Fumonisine werden mit Leukoenzephalomalazie bei Pferden in Verbindung gebracht. Beim Menschen kann der Verzehr von kontaminiertem Getreide zu 
Speiseröhrenkrebs und Geburtsfehlern führen (Desjardins et al., 2007a). Zearalenon, ein östrogenes, nichtsteroidales Mykotoxin (Desjardins, 2006), kann bei Schweinen zu östrogenen Syndromen führen, wie Vergrößerung des Uterus, Zysten an den Eierstöcken, Scham- und Gesäugeschwellungen sowie Fruchtbarkeitssörungen (Lepschy, 1991, 1992). Die toxigenen Eigenschaften der Cycloheptadepsipeptide Beauvericin und Enniatin scheinen gegenüber den o.g. Mykotoxinen gering zu sein. Toxische Wirkungen in Bezug auf Mensch und Tier sind jedoch nicht auszuschließen (Jestoi, 2008). Wätjen et al. (2009) postulierten hingegen, dass Enniatin A1, B und B1 durch Apoptoseinduktion möglicherweise eine antikanzerogene Wirkung haben könnten. Kuiper-Goodman (1998) bezeichnete Mykotoxine vor allen anderen Kontaminationsquellen als den höchsten Risikofaktor für die Ernährung von Mensch und Tier.

Seit dem 01. Juli 2006 gelten im Rahmen der EU-Verordnung (EG) Nr. 856/2005 europaweit eingeführte Grenzwerte für Fusarium-Mykotoxine in Getreide und deren Erzeugnissen. Für die Mykotoxine DON und ZEA ergibt sich daraus, dass unverarbeitetes Getreide nach anschließender Reinigung und Trocknung eine Höchstmenge von $1250 \mu \mathrm{g} / \mathrm{kg}$ DON und $100 \mu \mathrm{g} / \mathrm{kg}$ ZEA enthalten darf. Getreidemehl darf dagegen lediglich $750 \mu \mathrm{g} / \mathrm{kg}$ DON und $75 \mu \mathrm{g} / \mathrm{kg}$ ZEA aufweisen (Anonymus, 2005). Der Landwirt darf somit Getreidechargen, die Mykotoxingehalte über den gesetzlichen Grenzwerten enthalten, nicht in Umlauf bringen. Auch eine Vermischung mit unbelastetem Getreide ist unzulässig. Mykotoxinbelastungen im Getreide sind zudem so weit zu reduzieren, wie es die gute fachliche Praxis erlaubt. Die Vorhergehensweise bei der Stichprobenahme zur Analyse von Mykotoxinen in Getreide ist im Anhang I der Verordnung (EG) Nr. 401/2006 definiert.

DON ist in Verbindung mit durch Fusarium hervorgerufenen Krankheiten an Weizen, insbesondere FHB, das am häufigsten anzutreffende Mykotoxin. DON wird von drei Fusarium-Arten gebildet: F. graminearum, F. pseudograminearum (Aoki und O'Donnell, 1999) und $F$. culmorum. Bei allen drei Arten differenziert man zwischen unterschiedlichen Chemotypen. F. graminearum besitzt die Chemotypen 3-ADON, 15-ADON und NIV. Der 3-ADON Chemotyp produziert neben DON das DON-Derivat 3-ADON, Chemotyp 15-ADON synthetisiert DON sowie 15-ADON. Der NIV-Chemotyp bildet dagegen kein DON, sondern ausschließlich NIV (Ward et al., 2002). Für F.culmorum sind dagegen zwei Chemotypen bekannt. Zum einen der NIV-Chemotyp und zum anderen der 3-ADON Chemotyp (Jennings et al., 2004).

Weitere Trichothecen-Produzenten, welche zudem mit FHB assoziiert werden, sind F. cerealis, F. poae, F. sporotrichioides, F. langsethiae THORP \& NIRENBERG sowie F. equiseti. F. cerealis produziert ausschließlich NIV, F. poae und F. equiseti neben Equisetin und NIV ebenso das A-Trichothecen DAS, jedoch wurde in Einzelisolaten von 
F. poae auch die Produktion von stark toxischem T2 und HT2 nachgewiesen (Thrane et al., 2004). F. sporotrichioides und F. langsethiae sind im Gegensatz zu F. poae mit der Synthese von DAS, T2- und HT2-Toxin reine Typ A-Trichothecen-Bildner (Thrane et al., 2004). Zwei weitere, dem FHB-Artenkomplex angehörende Arten sind F. avenaceum und F. tricinctum. Diese Arten bilden keine Trichothecene, jedoch alle Formen von Enniatinen sowie MON (Uhlig et al., 2007). Die vor allem als Maispathogen bekannten FusariumArten F. proliferatum und F. verticillioides sind Fumonisin-Bildner (Desjardins, 2003).

Tab. 3: Einteilung verschiedener Arten der Gattung Fusarium anhand der von innen synthetisierten Mykotoxin-Stoffgruppen. (Nach Aoki und O'Donnell, 1999; Ward et al., 2002; Thrane et al., 2004; Uhlig et al., 2007).

\begin{tabular}{cccc}
\hline $\begin{array}{c}\text { Typ A-Trichothecen- } \\
\text { Bildner }\end{array}$ & $\begin{array}{c}\text { Typ B-Trichothecen- } \\
\text { Bildner }\end{array}$ & $\begin{array}{c}\text { Cyclohexadepsipeptid- } \\
\text { Bildner }\end{array}$ & $\begin{array}{c}\text { Fumonisin- } \\
\text { Bildner }\end{array}$ \\
F. equiseti & F. cerealis & F. avenaceum & F. proliferatum \\
F. langsethiae & F. culmorum & F. tricinctum & F. verticillioides \\
F. poae & F. equiseti & \\
F. sporotrichioides & F. graminearum & \\
& F. poae & \\
& F. pseudograminearum
\end{tabular}

Dem B-Trichothecen DON kommt eine wichtige Rolle im Ausbreitungsprozess von FHB zu (Bai et al., 2001), es wirkt jedoch nicht als Pathogenitätsfaktor. Der erste Schritt des DON-Synthesewegs wird von dem Enzym Trichodiene-Synthase katalysiert (Desjardins, 2006). Ein Ausschalten des für die Trichodiene-Synthase codierenden Gens (tri5) hat einen deutlichen Rückgang der Aggressivität von F. graminearum sowie F. culmorum zur Folge (Proctor et al., 1995) und zeigt die Bedeutung von DON für die Ausbreitung von FHB in der Pflanze (Desjardins et al., 1996), wobei DON die Bildung von Zellwandappositionen in der Rachis unterbindet (Jansen et al., 2005). Auch während des Besiedlungsprozesses der Halmbasis wird tri5 exprimiert (Beccari et al., 2011). So konnte von Mudge et al. (2006) nachgewiesen werden, dass F.graminearum während der Besiedlung der Halmbasis eine ähnlich hohe DON-Produktion aufwies, wie während der Entwicklung von FHB an der Ähre. DON scheint aber für den Infektionsprozess an der Halmbasis nicht von Bedeutung zu sein. 


\subsection{Agronomische Bedeutung von Fusarium an Weizen}

In Abhängigkeit von Inokulum und Witterung kann es unter natürlichen Befallsbedingungen durch einen Fusarium-Befall zu lokalem Auftreten von FHB im Weizen kommen, aber auch flächendeckende Epidemien mit erheblichen Ernteausfällen können entstehen. Neben einer Reduktion des Ertrages auf Grund von Kümmerkornbildung und damit einhergehender Verminderung der Verarbeitungs- und Saatgutqualität, ist vor allem die Kontamination des Ernteguts mit Mykotoxinen im Zuge von FHB ein wirtschaftlich bedeutender Faktor (Weinert und Wolf, 1995). FHB wurde an Weizen erstmals in den 1880er Jahren in England von W.G. Smith beschrieben und wird seit dem in vielen Teilen der Welt in Form von Epidemien beobachtet. Besonders in den großen Weizenanbaugebieten der USA tritt FHB immer wieder flächendeckend auf. In den 1980er Jahren verursachte eine FHB-Epidemie in verschiedenen Teilen des Landes mit 2,72 Mio. t eine Gesamtertragsreduktion für Weizen von 4\% (Boosalis et al., 1983). Nganje et al. (2001) bezifferte den durch FHB entstandenen wirtschaftlichen Schaden zwischen 1998 und 2000 für Weizen in den USA auf 663 Mio. US-Dollar.

An der Halmbasis kann ein durch Fusarium-Arten hervorgerufener Fußbefall durch die Verminderung des Tausendkorngewichts (TKG) und die Reduktion der Kornanzahl pro Ähre Ertragseinbußen herbeiführen (Kane et al., 1987). So berichtete Cook (1968) von einer Reduktion des Weizenertrags in Weizenanbaugebieten im Nordwesten der USA von $50 \%$ durch Befall mit F.culmorum. In Australien beobachtete Burgess et al. (1981) Ertragsminderungen im Weizen von 26\%, hervorgerufen durch eine Infektion mit F. pseudograminearum.

\subsection{Fusarium in Weizenfruchtfolgen}

Die in den letzten Jahren in steigendem Maße praktizierte Einengung der Fruchtfolge zu Gunsten weniger, ökonomisch bedeutsamer Kulturen wie Weizen, Mais und Raps stellt ein ernstzunehmendes Problem im Hinblick auf das Auftreten von Fusarium an Weizen dar. Eine unzureichend weite Fruchtfolge trägt dazu bei, dass sich Überdauerungsstrukturen in Form von saprophytischem Myzel oder Dauersporen (Chlamydosporen) im Boden oder auf besiedeltem Pflanzenmaterial bilden (siehe 1.1.2), wodurch die Wirtspflanze einem erhöhten Infektionsrisiko durch den Pilz ausgesetzt wird.

Bereits Atanasoff postulierte Anfang der 1920er Jahre, dass die Fruchtfolge einen wichtigen ackerbaulichen Anbaufaktor darstellt. Besonders im Hinblick auf Mais als Vorfrucht ist seitdem der fördernde Effekt auf den Befall mit Fusarium in Form von FHB bekannt. Der Pilz kann die sich nur langsam zersetzenden Maisreste und -stoppeln als 
Nährstoffressource nutzen (Sutton, 1982), dort überdauern (Beck und Lepschy, 2000), fruktifizieren und nachfolgend den Weizen infizieren.

Zur Bedeutung von Weizen als Vorfrucht sind die Aussagen recht widersprüchlich. Nach Snyder und Nash (1968) erhöht der Daueranbau von Weizen Befallshäufigkeit und -stärke von FHB. Krauthausen et al. (2003) konnte dagegen nach Untersuchung von Weizenproben aus Betrieben sowie Proben aus Landessortenversuchen des Landes Rheinland-Pfalz aus den Jahren 1999-2002 keinen erhöhten Befall von Winterweizen nach Vorfrucht Winterweizen nachweisen.

Die bisher als „Gesundfrucht" geltende Zuckerrübe wurde in aktuellen Untersuchungen als potenzieller Überträger von Fusarium auf Weizen als Nachfrucht eingestuft. Die Ergebnisse von Burlakoti et al. (2007) deuten darauf hin, dass durch F.graminearum infizierte Zuckerrüben möglicherweise als Inokulumquelle für eine Infektion des Weizens fungieren. Neben F.graminearum konnten Bosch und Mirocha (1992) acht weitere toxigene Fusarium-Arten aus Zuckerrübe isolieren, darunter in Reihenfolge der Häufigkeit des Vorkommens F. equiseti, F. acuminatum, F.culmorum, F. avenaceum und F. oxysporum. Dagegen wiesen Hanson et al. (2004) im Jahre 2001 in den westlichen Zuckerrübenanbaugebieten der USA nach Probenahme von Zuckerrüben, die das „Fusarium Yellow“-Symptom aufwiesen, F. oxysporum als häufigste Art in Zuckerrübe nach. Kürzlich konnten von Christ et al. (2011a) in Lagerversuchen mit Zuckerrüben in den Jahren 2006 und 2007 insgesamt 13 Fusarium-Arten isoliert werden, wobei ein besonders starker Befall durch F. redolens nachgewiesen wurde. Unter den 13 isolierten Arten waren insbesondere die dem FHB-Artenspektrum in Europa angehörenden Arten F.cerealis, F. culmorum, F. equiseti, F. graminearum und F. tricinctum (Parry et al., 1995) sowie die von den jeweiligen Arten synthetisierten Mykotoxine anzutreffen. Inokulationsversuche an Weizen mit aus Zuckerrübe isolierten Fusarium-Arten zur Prüfung der Aggressivität der verschiedenen Arten ergaben, dass vor allem F. graminearum, gefolgt von F. culmorum, F. cerealis, F. tricinctum und F. equiseti nach 21 dpi starke Symptome an der Ähre hervorrief, wogegen die Ähren nach Inokulation mit F. redolens und F. oxysporum weitestgehend symptomlos blieben (Christ et al., 2011b). Diese Ergebnisse verdeutlichen, dass von Zuckerrübe als Vorfrucht ein potenzielles Risiko für eine Infektion von Weizen als Nachfrucht ausgeht. Es sind jedoch weitere Studien zur möglichen Übertragung von Fusarium-Arten durch Zuckerrübe auf Weizen unter natürlichen Befallsbedingungen in Weizenfruchtfolgen notwendig, um ggf. eine Neubewertung der Vorfruchteigenschaften der Zuckerrübe vorzunehmen. 


\section{$1.4 \quad$ Fragestellung der Arbeit}

Neben den innerhalb der Gattung Fusarium als Leitpathogene an Weizen geltenden Arten F. graminearum und F.culmorum existiert noch ein weiteres Spektrum potenziell pathogener Fusarium-Arten, die zumeist als Komplex auftreten (Duben und Fehrmann, 1979; Clement und Parry, 1998; Liddell, 2003).

Im Rahmen des Verbundprojekts 3 „Qualitätsgerechte Pflanzenproduktion unter veränderten Rahmenbedingungen: Mykotoxine im Kontext von Produktion, Qualität und Verarbeitung" des Forschungsverbunds Agrar- und Ernährungswissenschaften Niedersachsen (FAEN), wurde daher in einem seit 2006 existierenden, dreifaktoriellen Fruchtfolgeversuch nahe Göttingen in den Jahren 2010 und 2011 das FusariumArtenspektrum an Winterweizen untersucht. Von besonderer Bedeutung war hierbei die Charakterisierung der Fusarium-Artenspektren an den beiden Pflanzenorganen Halmbasis und Korn in Abhängigkeit der Versuchfaktoren (i) Jahreseffekt/Witterung, (ii) Vorfrucht, (iii) Sortenwahl und (iv) Fungizidblattbehandlung. Die hier genannten Versuchsfaktoren gelten zusammen mit einer pfluglosen Bodenbearbeitung als ackerbauliche Risikofaktoren im Hinblick auf eine Infektion des Weizens mit Fusarium und der damit verbundenen Mykotoxinproblematik. Deren Relevanz für die Übertragungspfade und die Verbreitung von Fusarium-Arten in den verschiedenen Anbaufolgen sollte in dieser Arbeit herausgestellt werden.

Seit einigen Jahren ist bekannt, dass der Vorfrucht Zuckerrübe als Überträger von Fusarium eine mögliche Bedeutung zukommt. Auch die in Projektphase I dieses Verbundprojekts gewonnenen Ergebnisse weisen auf diesen Sachverhalt hin, sodass im Zuge dieser Arbeit ein besonderes Augenmerk auf der Vorfruchtwirkung bezüglich der epidemiologischen Übertragung von Fusarium-Arten auf Weizen als Nachfrucht gelegt wurde.

Die an Halmbasis und Körnern nach den verschiedenen Fruchtfolgegliedern gefundenen Fusarium-Spektren wurden miteinander verglichen und besonders häufig auftretende Arten in Freiland- Gewächshaus- und Klimakammerversuchen auf ihre Pathogenität an den beiden Pflanzenorganen, nach Art der Besiedlung, ihren Mykotoxinprofilen und möglichen Interaktionen als Erregerkomplex untersucht. Auf Basis der durch diese Arbeit gewonnenen Erkenntnisse soll ein Beitrag zur phytopathologischen und agronomischen Risikobewertung von Weizenfruchtfolgen hinsichtlich der an Halmbasis und Korn von Weizen vorkommenden Fusarium-Arten geleistet werden. 


\section{$2 \quad$ Material und Methoden}

\subsection{Medienkomponenten und Chemikalien}

Tab. 4: Liste der verwendeten Medienzusätze und Chemikalien sowie deren Hersteller.

\begin{tabular}{|c|c|}
\hline Substanz & Hersteller \\
\hline Agar-Agar & Roth, Karlsruhe \\
\hline Agarose NEEO & Applichem, Darmstadt \\
\hline Beschwerungspuffer & Fermentas, St. Leon-Rot \\
\hline Bioline Taq DNA-Polymerase $(5 \mathrm{U} / \mu \mathrm{l})$ & Bioline, Luckenwalde \\
\hline Calciumchlorid & Merck, Darmstadt \\
\hline Chloroform & Applichem, Darmstadt \\
\hline CTAB (N-Cetyl-N,N,N-trimethyl-ammoniumbromid) & Merck, Darmstadt \\
\hline dNTP-Mix (10 mM) & Fermentas, St. Leon-Rot \\
\hline dNTP-Mix 25 mM each & Fermentas, St. Leon-Rot \\
\hline DreamTaq DNA-Polymerase $(5 \mathrm{U} / \mu \mathrm{l})$ & Fermentas, St. Leon-Rot \\
\hline Dream taq Puffer (10x) & Fermentas, St. Leon-Rot \\
\hline EDTA & Roth, Karlsruhe \\
\hline Ethanol vergällt (>96\%) & Roth, Karlsruhe \\
\hline Ethidiumbromidlösung (1\%) & Applichem, Darmstadt \\
\hline Glukose & Merck, Darmstadt \\
\hline Isoamylalkohol & Applichem, Darmstadt \\
\hline Isopropanol & Roth, Karlsruhe \\
\hline Lysozym & Applichem, Darmstadt \\
\hline Magnesiumchlorid & Fermentas, St. Leon-Rot \\
\hline Magnesiumsulfat & Merck, Darmstadt \\
\hline Magnesiumsulfatheptahydrat (>99\%) & Roth, Karlsruhe \\
\hline 2-Mercaptoethanol & Fluka Bio Chemika \\
\hline Na-EDTA (Titriplex) & Merck, Darmstadt \\
\hline Natriumchlorid $(99,5 \%)$ & Roth, Karlsruhe \\
\hline Natriumhypochloridlösung (12\%) & Applichem, Darmstadt \\
\hline N-Lauroylsarcosin-Natriumsalz & Applichem, Darmstadt \\
\hline Phenol & Roth, Karlsruhe \\
\hline Primer (alle) & Invitrogen, Karlsruhe \\
\hline
\end{tabular}


Polyvinylpyrrolidon (K30)

Proteinase $\mathrm{K}$

Restriktionsendonuclease Bsh1236I

RNAse A

Saccharose (>99,9\%)

Silbernitrat

Silwet Gold

Sorbitol

Streptomycinsulfat

Taq-Polymerase (5U/ $\mu \mathrm{l})$

10x Taq Puffer inkl. 20 mM MgCl2

TBE-Puffer (10x)

TE-Puffer

Tris-Puffer $\mathrm{pH} 8$

Tris-EDTA

$\lambda$-Phagen-DNA, methyliert
Applichem, Darmstadt

Roth, Karlsruhe

Fermentas, St. Leon-Rot

Applichem, Darmstadt

Amresco Inc., Ohio,USA

Merck, Darmstadt

Spiess Urania, Hamburg

Applichem, Darmstadt

Duchefa, Haarlem

Fermentas, St. Leon-Rot

Fermentas, St. Leon-Rot

Applichem, Darmstadt

Applichem, Darmstadt

Fermentas, St. Leon-Rot

Applichem, Darmstadt

Sigma, Taufkirchen

\subsection{Nährmedien}

Kartoffel-Glukose-Agar (PDA)

$39 \mathrm{~g} / \mathrm{l} \quad$ Potato-Dextrose-Agar

ad. $1000 \mathrm{ml}$ destilliertes Wasser

Bei Korn- und Halmbasenproben aus dem FAEN-Feldversuch wurden zusätzlich $100 \mathrm{mg} / \mathrm{ml}$ Streptomycin auf $500 \mathrm{ml}$ PDA zugesetzt.

Kartoffel Glukose Broth (PDB)

26,5 g/l Potato-Dextrose-Broth

ad. $1000 \mathrm{ml}$ destilliertes Wasser 
Spezieller Nährstoffarmer Agar (SNA)

$\begin{array}{ll}1 \mathrm{~g} & \mathrm{KH}_{2} \mathrm{PO}_{4} \\ 1 \mathrm{~g} & \mathrm{KNO}_{3} \\ 0,5 \mathrm{~g} & \mathrm{MgSO}_{4} \times 7 \mathrm{H}_{2} \mathrm{O} \\ 0,5 \mathrm{~g} & \mathrm{KCl} \\ 0,2 \mathrm{~g} & \text { Glukose } \\ 0,2 \mathrm{~g} & \text { Saccharose } \\ 15 \mathrm{~g} & \text { Agar-Agar } \\ \text { ad. } 1000 \mathrm{ml} & \text { destilliertes Wasser }\end{array}$

Mungobohnen-Medium

$40 \mathrm{~g} \quad$ Mungobohnen

$1000 \mathrm{ml}$ destilliertes Wasser

Strohextrakt-Medium (2\%)

$6 \mathrm{~g} \quad$ gehäckseltes, unbehandeltes Weizenstroh (4 mm)

$300 \mathrm{ml} \quad$ destilliertes Wasser

Alle Medien wurden vor Verwendung für 20 min bei $121^{\circ} \mathrm{C}$ autoklaviert.

\subsection{Biologisches Material}

Aufgelistet ist jegliches pflanzliches und pilzliches Material, welches für Feld-, Gewächshaus-, Klimakammer- und In vitro-Versuche verwendet wurde.

\subsubsection{Pilzliches Material}

Tab. 5: Für Feld-, Gewächshaus-, Klimakammer- und In vitro-Versuche verwendete Fusarium-Isolate.

\begin{tabular}{lllll}
\hline Art & Bezeichnung & Herkunft & Isoliert aus & Pflanzenteil \\
\hline F. avenaceum & Fav1 & FAEN-Feldversuch & Winterweizen & Halmbasis \\
F. avenaceum & Fav2 & FAEN-Feldversuch & Winterweizen & Halmbasis \\
F. avenaceum & Fav3 & FAEN-Feldversuch & Winterweizen & Halmbasis \\
F. culmorum & Fcul1 & FAEN-Feldversuch & Winterweizen & Halmbasis \\
\hline
\end{tabular}




\begin{tabular}{|c|c|c|c|c|}
\hline F. culmorum & Fcul2 & FAEN-Feldversuch & Winterweizen & Halmbasis \\
\hline F. culmorum & Fcul3 & FAEN-Feldversuch & Winterweizen & Halmbasis \\
\hline F. equiseti & Fequ1 & FAEN-Feldversuch & Winterweizen & Halmbasis \\
\hline F. equiseti & Fequ2 & FAEN-Feldversuch & Winterweizen & Halmbasis \\
\hline F. equiseti & Fequ3 & FAEN-Feldversuch & Winterweizen & Halmbasis \\
\hline F. equiseti & O19 & $\begin{array}{c}\text { Institut für } \\
\text { Zuckerrübenforschung }\end{array}$ & Zuckerrübe & Rübe \\
\hline F. graminearum & Fgr1 & FAEN-Feldversuch & Winterweizen & Ähre \\
\hline F. graminearum & Fgr2 & FAEN-Feldversuch & Winterweizen & Ähre \\
\hline F. graminearum & Fgr4 & FAEN-Feldversuch & Winterweizen & Ähre \\
\hline F. graminearum & Fgr5 & FAEN-Feldversuch & Winterweizen & Halmbasis \\
\hline F. graminearum & Fgr6 & FAEN-Feldversuch & Winterweizen & Halmbasis \\
\hline F. graminearum & Fgr7 & FAEN-Feldversuch & Winterweizen & Halmbasis \\
\hline F. graminearum & FG142 & IPP-Stammsammlung & k. A. & k. A. \\
\hline F. poae & Fpo1 & FAEN-Feldversuch & Winterweizen & Ähre \\
\hline F. poae & Fpo2 & FAEN-Feldversuch & Winterweizen & Ähre \\
\hline F. poae & Fpo3 & FAEN-Feldversuch & Winterweizen & Ähre \\
\hline F. poae & Fpo5 & FAEN-Feldversuch & Winterweizen & Halmbasis \\
\hline F. poae & Fpo6 & FAEN-Feldversuch & Winterweizen & Halmbasis \\
\hline F. poae & Fpo7 & FAEN-Feldversuch & Winterweizen & Halmbasis \\
\hline F. tricinctum & Ftri1 & FAEN-Feldversuch & Winterweizen & Halmbasis \\
\hline F. tricinctum & Ftri2 & FAEN-Feldversuch & Winterweizen & Halmbasis \\
\hline F. tricinctum & Ftri3 & FAEN-Feldversuch & Winterweizen & Halmbasis \\
\hline F. tricinctum & Ftri5 & FAEN-Feldversuch & Winterweizen & Ähre \\
\hline F. tricinctum & Ftri6 & FAEN-Feldversuch & Winterweizen & Ähre \\
\hline F. tricinctum & Ftri7 & FAEN-Feldversuch & Winterweizen & Ähre \\
\hline F. tricinctum & 063 & $\begin{array}{c}\text { Institut für } \\
\text { Zuckerrübenforschung }\end{array}$ & Zuckerrübe & Rübe \\
\hline
\end{tabular}




\subsubsection{Pflanzliches Material}

Tab. 6: Für Feld-, Gewächshaus-, Klimakammer- und In vitro-Versuche verwendete Sommerund Winterweizensorten. Die Anfälligkeiten gegenüber Ährenfusarium sind den Beschreibenden Sortenlisten 2006 und 2011 des Bundessortenamtes entnommen (Anonymus, 2006 und 2011).

\begin{tabular}{cccc}
\hline Sortenbezeichnung & Typ & $\begin{array}{c}\text { Anfälligkeit für } \\
\text { Ährenfusarium }\end{array}$ & Züchter \\
\hline Centrum & Winterweizen & 2 & Diekmann Seed GmbH \\
JB Asano & Winterweizen & 5 & $\begin{array}{c}\text { Saatzucht Breun } \\
\text { GmbH }\end{array}$ \\
Ritmo & Winterweizen & 7 & LG Nederland B.V \\
Tybalt & Sommerweizen & 6 & Saatenunion GmbH \\
\hline
\end{tabular}

\subsection{Saat-, Erntegut- und Halmsegmentsterilisation}

\subsubsection{Saatgutsterilisation}

Das für die im Rahmen dieser Arbeit durchgeführten Versuche verwendete Saatgut wurde für 10 min in einer 0,1\%igen $\mathrm{AgNO}_{3}$-Lösung geschwenkt. Anschließend wurde es dreimal für jeweils $1 \mathrm{~min}$ in autoklaviertem, destilliertem Wasser gewaschen und danach rückgetrocknet.

\subsubsection{Erntegutsterilisation}

Erntegut aus dem FAEN-Fruchtfolgeversuch, welches auf Besatz mit Fusarium-Arten untersucht werden sollte, wurde vor der weiteren Verwendung für $1 \mathrm{~min}$ in einer zweiprozentigen $\mathrm{NaOCl}$-Lösung geschwenkt. Im Anschluss daran wurden sie zweimal für jeweils 1 min mit sterilem Leitungswasser gewaschen und zum Trocknen in der sterilen Werkbank ausgelegt.

\subsubsection{Halmsegmentsterilisation}

Die Sterilisation der Halmsegmente erfolgte mit einer zweiprozentigen $\mathrm{NaOCl-Lösung,} \mathrm{in}$ die die Halmsegmente für 3 min eingetaucht wurden. Daraufhin wurden die Segmente 
zweimal für jeweils $1 \mathrm{~min}$ in sterilem Leitungswasser gewaschen und kurz zum Trocknen in der sterilen Werkbank belassen.

\subsection{Pflanzenanzucht}

Für alle Versuche unter kontrollierten Bedingungen wurde die Sommerweizensorte „Tybalt" verwendet.

\subsubsection{Versuche unter kontrollierten Bedingungen im Gewächshaus}

Zur Pflanzenanzucht innerhalb der Versuche unter kontrollierten Bedingungen im Gewächshaus wurde eine Bodenmischung bestehend aus Blumenerde $(50 \% \mathrm{v} / \mathrm{w})$, Komposterde (ungedämpft, $20 \% \mathrm{v} / \mathrm{w}$ ) und Sand (30\% v/w) verwendet, in $9 \times 9 \times 9,5 \mathrm{~cm}$ Töpfe gegeben und angedrückt. Jeweils zwei ungebeizte Körner wurden pro Topf ca. $2 \mathrm{~cm}$ tief eingesät. Die erste Düngung erfolgte drei Wochen nach Aussaat und wurde anschließend einmal pro Woche bis zum Erreichen der Frühen Blüte zu BBCH 61 durchgeführt. Als Dünger diente der Multinährstoffdünger Hakaphos® $\left(15 \% \mathrm{~N}, 15 \% \mathrm{~K}_{2} \mathrm{O}\right.$, $11 \% \mathrm{P}_{2} \mathrm{O}, 1 \% \mathrm{MgO}$ ) mit einer Konzentration von $4 \mathrm{~g} / \mathrm{l}$.

\subsubsection{Versuche unter kontrollierten Bedingungen in der Klimakammer}

Für die Versuche unter kontrollierten Bedingungen im Klimakammerversuch wurden ebenfalls ungebeizte, jedoch oberflächensterilisierte Körner verwendet. Die Körner wurden zunächst in angefeuchtetem, doppelt autoklaviertem Quarzsand ausgesät und in der Klimakammer bei einer Temperatur von $22^{\circ} \mathrm{C}$, einer Licht/Dunkel-Photoperiode von $16 / 8 \mathrm{~h}$ und $430 \mu \mathrm{mol} \mathrm{s}{ }^{-1} \mathrm{~m}^{-2}$ sowie $70 \%$ relativer Luftfeuchte zum Keimen gebracht. Fünf Tage nach Aussaat konnten die Pflanzen aus dem Sand gezogen und für die Versuche verwendet werden.

\subsubsection{Versuche unter kontrollierten Bedingungen im Klimaschrank}

Weizenkeimlinge wurden durch Auslegen von zuvor oberflächensterilisierten Körnern auf angefeuchtetem, sterilem Filterpapier gewonnen. Die Körner wurden dazu für $24 \mathrm{~h}$ in einem biologischen Klimaschrank (Mytron, Heilbad Heiligenstadt) bei einer Temperatur von $22^{\circ} \mathrm{C}$, einer Licht/Dunkel-Photoperiode von $16 / 8 \mathrm{~h}$ und $\mu \mathrm{mol} \mathrm{s}^{-1} \mathrm{~m}^{-2}$ vorgekeimt. 


\subsection{Herstellung von Einzelsporenisolaten}

Die Einzelsporenisolate wurden für alle Inokulationsversuche im Feld, im Gewächshaus und in der Klimakammer hergestellt, um das Vorliegen eines einzigen Genotyps pro Isolat zu gewährleisten. Aus dem FAEN-Fruchtfolgeversuch stammende Fusarium-Isolate, die zur Inokulation sowohl der Halmbasis als auch der Ähre von Weizen dienen sollten, wurden auf PDA bei Raumtemperatur für sieben Tage angezogen. Zur Konidienproduktion wurde Mungobohnenextrakt-Medium verwendet. Hundert ml Medium wurden in $250 \mathrm{ml}$ Erlenmeyerkolben gegeben und bei $121^{\circ} \mathrm{C}$ autoklaviert. Anschließend wurden die Kolben mit einem 0,5 $\mathrm{cm}^{2}$ großen Myzelstück angeimpft. Nach drei Tagen bei $100 \mathrm{rpm}$ auf dem Horizontalschüttler wurden die Sporen mittels Filtration gewonnen, in sterile Falcons überführt, bei $4000 \mathrm{rpm}(2000 \mathrm{xg})$ für $10 \mathrm{~min}$ zentrifugiert, in $10 \mathrm{ml}$ sterilem Leitungswasser aufgenommen und geschüttelt. Anschließend wurden sie in einer 1:10 Verdünnungsreihe auf PDA ausplattiert. Die angeimpften PDA-Platten wurden bei $22^{\circ} \mathrm{C}$ im Dunkeln inkubiert. Nach zwei Tagen zeigten sich aus einzelnen Sporen hervorgegangene Myzelkolonien, welche schließlich auf neue PDA-Platten transferiert wurden. Zur Aufbewahrung der Isolate wurden diese auf SNA überimpft.

\subsection{Herstellung von Fusarium-Inokulum}

Für alle Versuche in denen mit Konidien von Fusarium-Arten Inokulationen durchgeführt wurden, wurde dieselbe Methode zur Herstellung des Inokulums verwendet. Von zuvor für sieben Tage bei $22^{\circ} \mathrm{C}$ auf PDA angezogenen Fusarium-Isolaten wurden jeweils fünf $0,5 \mathrm{~cm}^{2}$ große PDA-Stücke in einen mit $300 \mathrm{ml}$ eines zweiprozentigen Strohextraktmediums befülten, 1 I Erlenmeyerkolben gegeben. Das Stroh wurde dabei im Medium belassen. Es wurden immer drei verschiedene Isolate jeder Fusarium-Art zum Animpfen der Kolben verwendet, sodass jeder Kolben insgesamt mit 15 Myzelstücken angeimpft wurde. Die Inokulumkolben wurden für einen Monat bei $22^{\circ} \mathrm{C}$ und $120 \mathrm{rpm}$ auf einem Horizontalschüttler (Clim-O-Shake, Adolf Kühner AG, Basel) belassen. Anschließend wurden die Konidien mittels Filtration des Strohs und weiterer Schwebstoffe gewonnen und mit Hilfe einer Fuchs-Rosenthal-Zählkammer auf die gewünschte Sporenkonzentration eingestellt. Während der Auszählung der Konidien wurde darauf geachtet, dass verschiedene Fusarium-Arten unterschiedliche Konidienformen ausbilden. Als Beispiele hierfür seien F. culmorum und F. tricinctum genannt. Während F. culmorum lediglich Makrokonidien ausbildet, kann F. tricinctum neben Makrokonidien auch napi-, pyri-, citriforme sowie ovale Mikrokonidien produzieren (Leslie und Summerell, 2006) (Abb. 6a und 6b). 


\subsection{Anzucht von Fusarium-Arten in Flüssigkultur}

Zur Gewinnung von DNA mittels DNA-Extraktion wurde Myzel verschiedener FusariumArten in Flüssigkultur angezogen. In $300 \mathrm{ml}$ Erlenmeyerkolben wurden $70 \mathrm{ml}$ PDB gegeben und diese autoklaviert. Auf mindestens 10 Tage alte, komplett mit Myzel bewachsene PDA-Platten, wurden jeweils $4 \mathrm{ml}$ steriles Leitungswasser pipettiert. Mit Hilfe eines Drigalski-Spatels wurde vorsichtig über das Myzel gekratzt und somit eine Sporen/Myzelsuspension hergestellt, welche in ein $15 \mathrm{ml}$ Falcon-Gefäß überführt wurde. Es wurden in jeden Erlenmeyerkolben $50 \mu$ S Suspension pipettiert. Die Kolben wurden für sieben Tage bei Raumtemperatur inkubiert, bis dichtes Myzelwachstum zu erkennen war. Daraufhin wurden die Myzelkulturen mittels Wasserstrahlpumpe und Büchner-Trichters abgenutscht und für 72 h lyophyllisiert (ALPHA 1050, Christ, Osterode). Das getrocknete Myzel wurde anschließend mit Hilfe einer Kugelmühle (MM 200, Retsch, Haan) unter Verwendung von Wolframcarbidkugeln zu einem feinen Pulver vermahlen (20 Bewegungen/s, $15 \mathrm{~s}$ ).

\subsection{DNA-Extraktion}

Zur Gewinnung von DNA wurde die CTAB-Methode (Brandfaß und Karlovsky, 2008) verwendet. Hierfür wurden bei aus reinem Myzel bestehenden Proben $25 \mathrm{mg}$ lyophyllisierte und gemahlene Trockenmasse verwendet, bei zu extrahierendem Weizenmehl wurden $100 \mathrm{mg}$ eingesetzt. Das jeweilige Material wurde nach Einwaage in $2 \mathrm{ml}$ Eppendorfgefäße überführt.

Zunächst wurden $1 \mathrm{ml}$ CTAB-Puffer, $2 \mu \mathrm{l}$ Mercaptoethanol und $1 \mu \mathrm{l}$ Proteinase $\mathrm{K}$ (20 mg/ml) zum Ansatz hinzugegeben und dieser geschüttelt. Anschließend wurde der Ansatz für $10 \mathrm{~min}$ bei $42^{\circ} \mathrm{C}$ und danach weitere $10 \mathrm{~min}$ bei $65^{\circ} \mathrm{C}$ im Wasserbad inkubiert. Während der Inkubation erfolgte ein dreimaliges Schütteln des Ansatzes. Hiernach wurden $\quad 0,8 \mathrm{ml}$ eines 24:1 Chloroform-Isoamylalkohol-Gemisches zum Ansatz hinzugegeben, dieser kräftig geschüttelt und danach auf Eis inkubiert. Die Phasentrennung wurde durch 10-minütige Zentrifugation bei $8.000 \mathrm{rpm}(3.800 \mathrm{xg})$ herbeigeführt (Biofuge, Heraeus, Hanau). Der oberen, wässrigen Phase wurden daraufhin $600 \mu \mathrm{l}$ entnommen und diese in ein neues, 1,5 ml Eppendorfgefäß überführt. Zur Fällung der DNA wurden $500 \mu \mathrm{l}$ Isopropanol zum Ansatz hinzugegeben, dieser wiederum kräftig geschüttelt und bei Raumtemperatur für 20 min inkubiert. Im Anschluss daran erfolgte die Pelletierung der DNA mittels 15-minütiger Zentrifugation bei $13.000 \mathrm{rpm}$ (9.500 xg). Zur Reinigung der DNA wurden $500 \mu \mathrm{l}$ 70\%igen Ethanols vorsichtig zum Ansatz hinzugegeben und anschließend verworfen. Die Trocknung der DNA wurde unter 
Verwendung einer Vakuumzentrifuge (Concentrator 5301, Eppendorf, Hamburg) erreicht, in welcher die DNA bei $30^{\circ} \mathrm{C}$ für 15 min getrocknet wurde. Die DNA wurde daraufhin in $100 \mu$ TE-Puffer aufgenommen und $24 \mathrm{~h}$ bei $4^{\circ} \mathrm{C}$ resuspendiert.

\subsection{Inokulationsmethoden}

Für die Ähreninokulationen in den Versuchen zur Pathogenität sowohl unter kontrollierten Bedingungen als auch im Feldversuch (s. 2.16.1-2.16.3) wurden Konidienkonzentrationen von $2 \times 10^{5}$ bzw. $1 \times 10^{5}$ Konidien $/ \mathrm{ml}$, für die Halmbasisinokulationen in der Klimakammer (s. 2.16.4) eine Konzentration von $8 \times 10^{5}$ Konidien/ml verwendet. Zudem wurde sowohl für die Gewächshausversuche, als auch für den Feldversuch das Konidieninokulum mit 0,1\% des Superbenetzers Silwet ${ }^{\circledR}$ Gold (Spiess Urania, Hamburg) zugesetzt, um eine gleichmäßige Benetzung der Weizenähren zu gewährleisten. Der Superbenetzer hatte keinen Einfluss auf die Keimfähigkeit der Konidien (Gödecke, 2010). In den Versuchen zur Pathogenität von Fusarium-Arten an der Halmbasis unter kontrollierten Bedingungen wurde dem Konidieninokulum keinerlei Benetzungsmittel zugesetzt. Die Inokulationen der Ähre erfolgten sowohl unter kontrollierten Bedingungen im Gewächshaus, als auch im Feldversuch zu BBCH 61-65 (Lancashire et al., 1991), wenn ca. 50\% der Antheren sichtbar waren. Die Halmbasisinokulationen unter kontrollierten Bedingungen erfolgten dagegen direkt nach fünftägiger Anzucht der Pflanzen.

\subsubsection{Inokulationsmethode für Feldversuche}

Die Inokulation der Weizenähren innerhalb des Feldversuchs erfolgte mit Hilfe eines manuell zu bedienenden Spritzbalkens, der mit einer Rückenspritze verbunden war. Der Spritzbalken wurde mit ca. $30 \mathrm{~cm}$ Abstand zu den Ähren zweimal über jede Kleinparzelle bewegt. Dabei wurden mit einem Druck von fünf Bar ca. $100 \mathrm{ml}$ Konidiensuspension gleichmäßig über die Parzelle verteilt (verändert nach Bockmann, 1962). Das Ausbringen der Konidiensuspensionen erfolgte in den Abendstunden, um eine möglichst gute Infektion durch Ausnutzung der geringen Sonneneinstrahlung und der Taubildung zu erreichen.

\subsubsection{Inokulationsmethode für Gewächshausversuche}

Die auf Konzentrationen von $2 \times 10^{5}$ bzw. $1 \times 10^{5}$ Konidien/ml eingestellten Konidiensuspensionen wurden in zuvor ausgeliterte Handsprühflaschen gegeben. Die Ähren wurden mit zwei Sprühstößen pro Spindelachse besprüht, um eine gleichmäßige 
Benetzung herbeizuführen, wobei ein Sprühstoß $1 \mathrm{ml}$ Konidiensuspension entprach. Für eine spätere Bonitur wurde jede Ähre mit einem Fähnchen versehen, auf dem das Datum der Inokulation notiert war. Anschließend wurde den inokulierten Ähren ein verschließbarer Polyethylenbeutel $(60 \times 130 \times 0,5 \mathrm{~mm})$ übergezogen (verändert nach Stein et al., 2009). Innerhalb des Beutels herrschte eine Luftfeuchtigkeit von ca. $100 \%$. Dies sollte die intitiale Infektion der Ähren durch den Pilz fördern. Die Pflanzen wurden anschließend für $48 \mathrm{~h}$ bei konstanten Umweltbedingungen $\left(\operatorname{Tag} 22^{\circ} \mathrm{C}\right.$, Nacht $16^{\circ} \mathrm{C}, 16 / 8 \mathrm{~h}$ Tag-Nacht Rhythmus) inkubiert.

\subsubsection{Inokulationsmethode für Kilmakammerversuche}

Die Inokulation der Pflanzen für die Klimakammerversuche erfolgte in Form einer Tauchinokulation. Hierzu wurden fünf Tage alte Weizenpflanzen der Sorte „Tybalt“ für 30 min bis oberhalb des Hypokotyls in Konidiensuspensionen verschiedener FusariumArten getaucht und anschließend in zuvor vorbereitete, mit doppelt autoklavierter Erde befüllte Töpfe eingepflanzt (M. Winter, mündliche Mitteilung).

\subsection{Visuelle Erfassung der Befallsparameter}

\subsubsection{Bonitur im Feldversuch}

Die visuelle Ermittlung des Auftretens von FHB erfolgte während der späten Milchreife zu $\mathrm{BBCH}$ 75-77. Die Versuchsparzellen wurden auf Ähren mit typischer Symptomausprägung untersucht. Hierbei wurde die Befallshäufigkeit, bzw. die Anzahl befallener Ähren pro $\mathrm{m}^{2}$ ermittelt sowie in Abhängigkeit von der Bestandesdichte der prozentuale Anteil befallener Ähren. Zusätzlich wurde über das Auszählen, symptomatischer Einzelährchen an 20 verschiedenen, zufällig gewählten Weizenpflanzen (verändert nach Culler et al., 2007) über die gesamte Parzelle verteilt die Befallsstärke ermittelt. Pro Einzelähre wurde der prozentuale Anteil befallener Einzelährchen in 5\%-Schritten bestimmt (verändert nach Stack et al., 1998). In beiden dieser Arbeit zu Grunde liegenden Versuchsjahren (2010 und 2011) waren auf Grund sehr geringer natürlicher Infektion durch Fusarium die Befallshäufigkeiten und Befallsstärken äußert niedrig und führten somit nicht zu aussagekräftigen Befallsdaten. Sie sind in dieser Arbeit daher nicht aufgeführt. 


\subsubsection{Bonitur Pathogenitätsversuche an der Ähre unter kontrollierten Bedingungen}

Die visuelle Ermittlung des Ährenbefalls durch Fusarium erfolgte für die Pathogenitätsversuche unter Verwendung der bereits im Feldversuch angewandten Methodik zur Evaluierung der Befallshäufigkeit, bzw. der Befallsstärke. Es wurde jedoch zusätzlich der Fusarium Head Blight-Index (FHB-Index) als Produkt von Befallshäufigkeit und Befallsstärke ermittelt, welcher durch Produktbildung der beiden Befallsparameter eine genauere Beziehung zur tatsächlichen Infektion herstellt, als diese es einzeln vermögen (Wilcoxson et al., 1992). Auf Grund des Auftretens von Symptomen, die nicht den typischen FHB-Symptomen entsprachen, wie Verbräunungen der Deck- und Hüllspelzen sowie des Black-Point-Symptoms (Christ et al., 2011b), wurde im Rahmen dieser Versuche der Begriff „FHB-Index“ durch „Disease-Index“ ersetzt. Auch wenn die in den Versuchen untersuchten Fusarium-Arten in der Literatur zum FHB-Komplex gezählt werden (Bottalico und Perrone, 2002), wird die unterschiedliche Symptomausprägung durch einen allgemeineren Terminus treffender dargestellt. Die Berechnung des DiseaseIndex' (in \%) beruhte auf der Befallshäufigkeit für jede Versuchsvariante und deren Multiplikation mit dem arithmetischen Mittel der Befallsstärken für jede Einzelpflanze derselben Variante.

$$
\text { Disease }- \text { Index }(\%)=\frac{\text { Befallshäufigkeit (Variante) }}{100} \times \frac{\text { Befallsstärke (Mittelwert Var.) }}{100} \times 100
$$

Um den Infektionsverlauf möglichst in seiner Gesamtheit zu erfassen, wurden Bonituren zu den Zeitpunkten 7, 14 und 21 dpi durchgeführt.

\subsubsection{Bonitur Pathogenitätsversuch an der Halmbasis unter kontrollierten Bedingungen}

Die visuelle Befallsermittlung des Halmbasisbefalls wurde zunächst zum Zeitpunkt der späten Milchreife zu BBCH 77 durchgeführt, eine weitere Bonitur erfolgte zur Totreife zu $\mathrm{BBCH}$ 92. Die typischen, durch Fusarium hervorgerufenen Symptomausprägungen an der Halmbasis, welche sich bei geringerem Befall als senkrechte, streifige, bei Starkbefall bis zur Vermorschung fortgeschrittene Verbräunungen der Halmbasis darstellten, wurden im Einklang mit den EPPO-Richtlinien mit Befallsstufen von 0-3 bewertet (Broschewitz et al., 1999). 
Tab. 7: Befallsstufen zur Erfassung der Symptomausprägungen an der Halmbasis nach Broschewitz et al. (1999).

\begin{tabular}{cc}
\hline Befallsstufe & Symptomausprägung \\
\hline 0 & keine sichtbaren Symptome \\
1 & $<50 \%$ des Stängelumfangs verbräunt \\
2 & $>50 \%$ des Stängelumfangs verbräunt \\
3 & Vermorschung \\
\hline
\end{tabular}

\subsubsection{Visuelle Erfassung von Trockenstresssymptomen}

Die Pflanzen des Pathogenitätsversuchs an der Halmbasis unter kontrollierten Bedingungen (s. 2.16.4) wurden im Abstand von 1 Woche zweimal für 2 Tage nicht gegossen. Dies führte beide Male zur vollständigen Austrocknung des Bodens, wodurch die Pflanzen unter erheblichen Trockenstress gesetzt wurden. Die Pflanzen wiesen zur späten Milchreife (BBCH 77) starke Trockenstresssymptome auf, welche sich in trockenen Blattspitzen, besonders des Fahnenblattes, vorzeitiger Abreife und Stauchung bis hin zum Absterben der gesamten Pflanzen äußerten. Daher wurde eine Bonitur der Trockenstresssymptome durchgeführt. Hierzu wurde der prozentuale Anteil der vertrockneten Blattfläche des Fahnen- und des zweiten Blattes ermittelt.

\subsubsection{Bonitur des In vitro-Pathogenitätstests unter kontrollierten Bedingungen}

Die visuelle Bonitur des In vitro-Pathogenitätstests erfolgte wie unter 2.11.3 beschrieben.

\subsection{Tausendkorngewicht (TKG) und Ertragserfassung}

\subsubsection{Erfassung des Tausendkorngewichts von Erntegut aus dem FAEN- Feldversuch}

Aus dem Erntegut jeder Versuchsparzelle wurden 400 Körner ausgezählt und gewogen. Das TKG wurde bestimmt, indem das Gewicht der Körner mit 2,5 multipliziert und auf einen Kornfeuchtegehalt von $14 \%$ bezogen wurde. 


\subsubsection{Erfassung des Tausendkorngewichts von Erntegut aus Pathogenitäts- versuchen}

In den Pathogenitätsversuchen (Feld und unter kontrollierten Bedingungen im Gewächshaus) wurde zur Bestimmung des TKG zunächst aus der Kontrollvariante eine Kornprobe entnommen und die Kornfeuchte gemessen (HOH-Express HE 50, Pfeuffer, Kitzingen). Danach wurde die Anzahl der Körner in jeder Wiederholung jeder Versuchsvariante manuell ausgezählt, gewogen, das Gewicht auf 1000 Körner hochgerechnet und auf die zuvor gemessene Kornfeuchte bezogen.

\subsubsection{Erfassung des Kornertrags}

Eine Ertragserfassung erfolgte nur im Zuge des FAEN-Fruchtfolgeversuchs. Hier wurde die Ernte der Versuchsparzellen mit Hilfe eines Mähdreschers (Farmliner, Deutz-Fahr, Köln) durchgeführt. Das Erntegut jeder Parzelle wurde in $40 \times 50 \mathrm{~cm}$ große Leinensäcke abgefüllt und diese gewogen, um den Parzellenertrag zu ermitteln und das Gewicht des Ernteguts auf einen handelsüblichen Restfeuchtegehalt von 14\% bezogen.

\subsection{Isolation und Identifikation des Fusarium-Spektrums an Halmbasis und Körnern von Weizen innerhalb des FAEN-Fruchtfolgeversuchs}

\subsubsection{Probenahme}

\section{Halmbasis}

Die Probenahme zur Bestimmung des Fusarium-Artenspektrums an der Halmbasis erfolgte am Standort Torland. Die Auswahl der zu entnehmenden Weizenpflanzen wurde zufällig vorgenommen. Dabei wurde pro Pflanze jeweils der Haupthalm ausgewählt und gezogen. Anschließend wurden die Pflanzen von Erdresten befreit und ca. $10 \mathrm{~cm}$ lange Halmbasen durch Abtrennen der Wurzel direkt oberhalb der Krone sowie Entfernen des oberen Halmabschnitts und der Ähre gewonnen. Daraufhin wurden die Halmbasen mit Hilfe eines Schüttelturms (Retsch, Haan) für eine Stunde unter fließendem Leitungswasser gewaschen. 


\section{Versuchsjahr 2010}

Im Versuchsjahr 2010 wurden an drei verschiedenen Probenahmeterminen, welche an die Wachstumsstadien BBCH 37-39, BBCH 61-65 und $\mathrm{BBCH}$ 71-75 des Weizens angelehnt waren, insgesamt 720 Pflanzen aus der Versuchsvariante 4 „Ritmo, unbehandelt“ zur Analyse herangezogen. Dies entsprach 240 Pflanzen in sechs Wiederholungen pro Termin. Es wurden 60 Pflanzen aus jeder der vier Vorfruchtparzellen, bzw. 10 Pflanzen pro Wiederholung innerhalb jeder Vorfruchtparzelle entnommen (s. 2.15.4).

\section{Versuchsjahr 2011}

Im Versuchsjahr 2011 wurden zu den Wachstumsstadien BBCH 37-39, BBCH 69 und BBCH 77 insgesamt 2400 Pflanzen gezogen und zwar 480 Pflanzen zum ersten Probenahmezeitpunkt und jeweils 960 Pflanzen zu den beiden folgenden Zeitpunkten. Der Unterschied zwischen dem ersten und den beiden letzten Probenahmezeitpunkten bezüglich der Probenzahl ist dadurch begründet, dass zum ersten Zeitpunkt lediglich Versuchsvariante 1 "Centrum, behandelt“ und Versuchsvariante 2 „Ritmo, behandelt“ beprobt wurden, wogegen $\mathrm{zu}$ den beiden späteren Zeitpunkten ebenfalls aus Versuchsvariante 3 „Centrum, unbehandelt“ und Versuchsvariante 4 „Ritmo, unbehandelt“ Proben entnommen wurden. Die Probenahme wurde in dieser Form durchgeführt, da im Vergleich zu den beiden späteren Probenahmezeitpunkten die Kolonisierungsraten zum ersten Zeitpunkt erfahrungsgemäß insgesamt niedrig waren und noch keine signifikanten Ausprägungen in Bezug auf Kolonisierungsraten und Artenspektren zu beobachten waren, sodass auf eine vollständige Probenahme zu Zeitpunkt 1 verzichtet wurde. Wie bereits 2010 wurden innerhalb jeder Versuchsvariante bestehend aus 6 Wiederholungen insgesamt 60 Pflanzen pro Vorfruchtparzelle gezogen, entsprechend 10 Pflanzen pro Wiederholung.

\section{Körner}

Für die Isolation der Fusarium-Arten an den Körnern wurden diese aus den Rückhalteproben des Ernteguts entnommen (s. 2.14.1). Insgesamt wurden 3200 Körner für die Fusarium-Isolation herangezogen. Die Kornprobenahme variierte zwischen den Versuchsjahren 2010 und 2011 nicht. 


\subsubsection{Isolation von Fusarium-Arten und Bestimmung der Kolonisierungsrate}

\section{Isolation von Fusarium-Arten aus der Halmbasis von Weizen}

Die gewaschenen Halmbasen (s. 2.13.1) wurden für $24 \mathrm{~h}$ luftgetrocknet. Es wurden anschließend unter sterilen Bedingungen von der unteren Seite der Halmbasis fünf ca. $5 \mathrm{~mm}$ lange Halmstücke pro Pflanze geschnitten, auf PDA (mit $100 \mathrm{mg} / \mathrm{ml}$ Streptomycin) ausgelegt und täglich auf Myzelwachstum kontrolliert.

\section{Bestimmung der Kolonisierungsrate an der Halmbasis}

Der Parameter "Gesamtkolonisierungsrate“ beschreibt den prozentualen Anteil der Pflanzen, welche an der Halmbasis durch Fusarium kolonisiert wurden, an der Gesamtanzahl aller untersuchten Weizenpflanzen. Beispielsweise wurde im Versuchsjahr 2010 für die Bestimmung der Gesamtkolonisierungsrate nach Winterweizen zu BBCH 3739 die Anzahl durch Fusarium kolonisierter Pflanzen durch die Gesamtanzahl von 60 untersuchten Pfllanzen pro Winterweizen-Vorfruchtparzelle dividiert (s. 2.13.1). Dabei wurde ausschließlich qualitativ zwischen „durch Fusarium kolonisierte Pflanze“ und "nicht durch Fusarium kolonisierte Pflanze" unterschieden. Eine Quantifizierung der Kolonisierung pro Pflanze wurde nicht vorgenommen.

Der Parameter „Kolonisierungsrate“ beschreibt den prozentualen Anteil der Pflanzen, die durch eine bestimmte Fusarium-Art kolonisiert wurden, an der Gesamtzahl aller untersuchten Pflanzen. Die Bestimmung der artspezifischen Kolonisierungsraten erfolgte daher ähnlich wie für die Gesamtkolonisierungsraten, wurde aber für jede Art einzeln durchgeführt. Auch diese Bestimmung war rein qualitativ. 


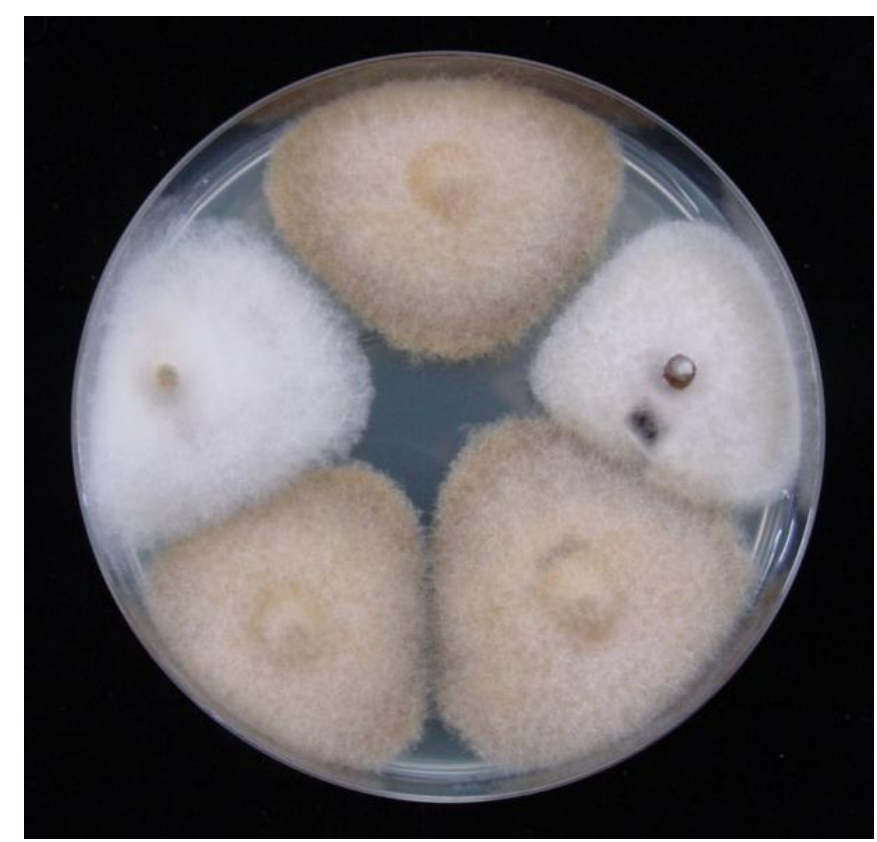

Abb. 4: Auf PDA ausgelegte Halmbasenstücke. Die Kultur ist ca. sieben Tage alt. Die Halmbasen wurden senkrecht auf dem Agar platziert, sodass die Schnittflächen in direktem Kontakt mit dem Agar standen.

Das Pilzwachstum trat, je nach Infektionsgrad der Probe, nach einem bzw. spätestens zwei Tagen ein. Nach ca. drei Tagen konnten die auswachsenden Fusarium-Myzelien visuell identifiziert und auf PDA isoliert werden. Dabei wurden alle Isolate zunächst grob anhand ihrer Myzelmorphologie, die sie auf PDA entwickelten, Gruppen zugeteilt. 

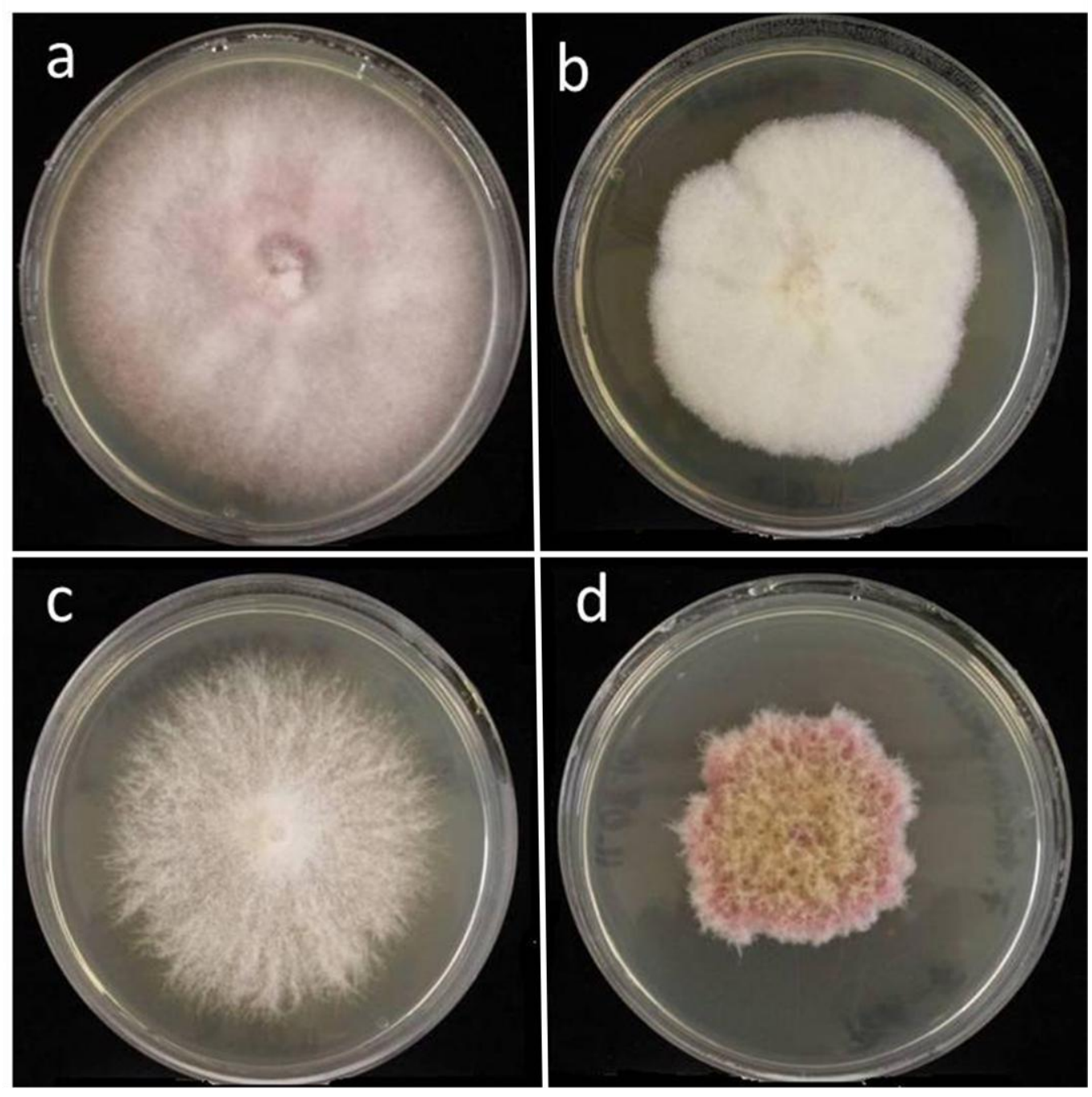

Abb. 5: Myzelmorphotypen verschiedener Fusarium-Arten auf PDA. a) F. avenaceum, b) F. equiseti, c) F. redolens, d) F. tricinctum.

Nach sieben Tagen wurden die Fusarium-Isolate auf SNA transferiert und für 10 Tage bei Dauer-NUV-Licht (NUV $=$ near UV mit $\lambda=400-440 \mathrm{~nm}$ ) und $22^{\circ} \mathrm{C}$ inkubiert. Der Spezielle Nährstoffarme Agar, zusammen mit der Bestrahlung durch Dauer-NUV-Licht sorgte für ausreichend günstige Bedingungen für die Bildung von Konidien, um die für eine mikroskopische Identifikation notwendigen und für die einzelnen Fusarium-Arten in ihrer Morphologie charakteristischen, asexuellen Vermehrungsstrukturen der Pilze in ausreichender Form zu erhalten. 


\section{Isolation von Fusarium-Arten aus Weizenkörnern}

Bei der Isolierung der Fusarium-Flora aus Weizenkörnern wurde genauso vorgegangen, wie für die Isolierung aus der Halmbasis beschrieben. Die Körner wurden jedoch zuvor oberflächensterilisiert (s. 2.4.2). Zudem wurden fünf Körner pro PDA-Platte ausgelegt, die nicht zur gleichen Pflanze gehörten, sondern lediglich einen Teil einer Kornprobe darstellten und zufällig ausgewählt worden waren.

\section{Bestimmung der Kolonisierungsrate an Körnern}

Die Bestimmung der Kolonisierungsraten an den Körnern wurde wie bereits für die Halmbasis beschrieben durchgeführt (s. 2.13.2, Bestimmung der Kolonisierungsrate an der Halmbasis).

\subsubsection{Morphologische Identifikation}

Zur morphologischen Identifikation der aus Halmbasis und Körnern von Weizen isolierten Fusarium-Arten wurden Quetschpräparate aller auf SNA inkubierten Fusarium-Isolate hergestellt. Hierzu wurde unter sterilen Bedingungen mit Hilfe einer Impfnadel ein ca. $5 \mathrm{~mm}^{2}$ großes, mit Myzel bewachsenes Agarstückchen auf einen Objektträger übertragen und dann vorsichtig mit einem Deckgläschen angedrückt. Das Quetschpräparat ermöglichte es, eine genaue morphologische Identifikation der einzelnen Fusarium-Arten vorzunehmen, da hierzu notwendige, empfindliche Vermehrungsstrukturen nicht zerstört wurden. Die morphologische Charakterisierung erfolgte auf Basis des „The Fusarium Laboratory Manual“ (Leslie und Summerell, 2006). 

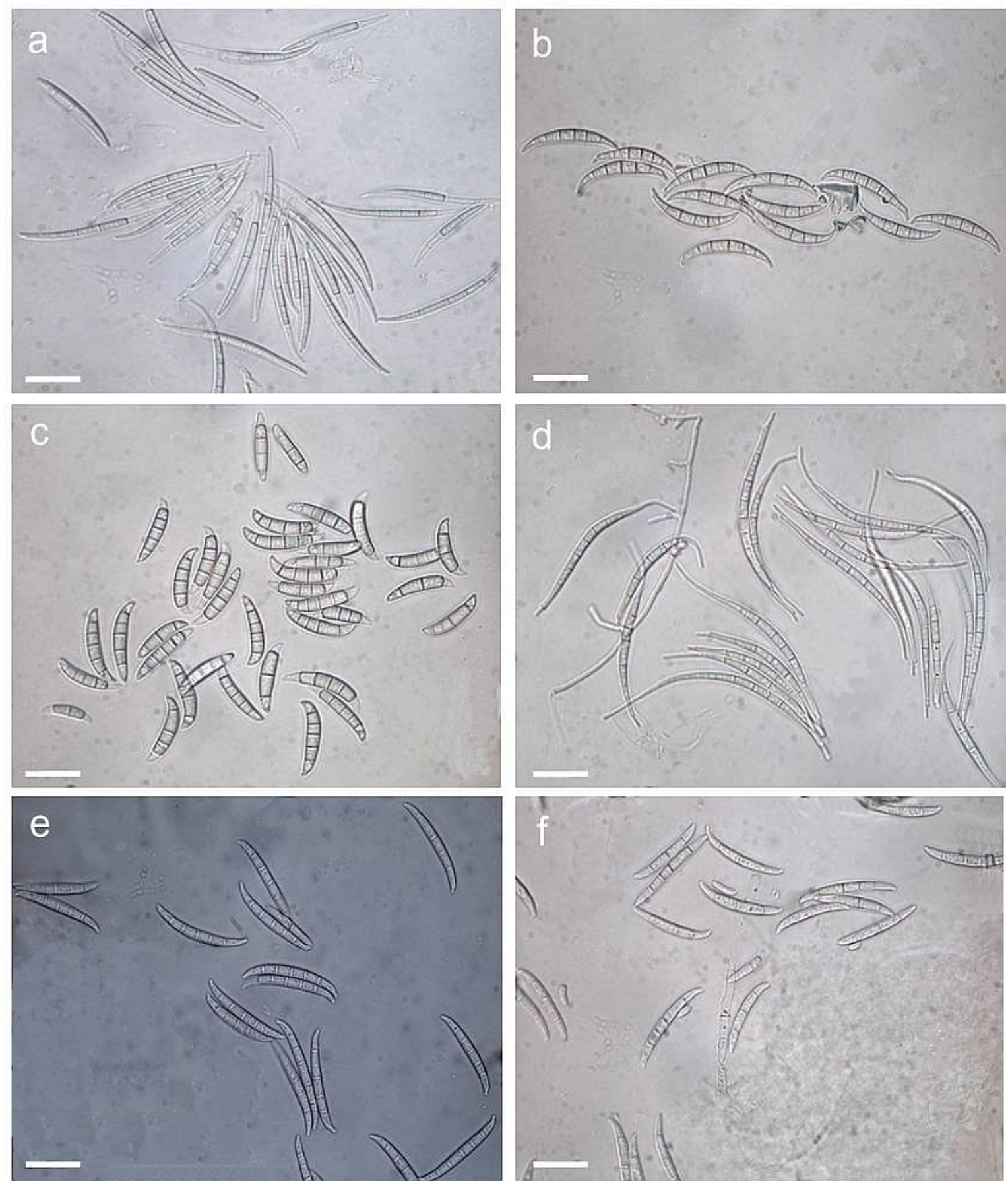

Abb. 6 a: Aufnahmen von Konidien verschiedener Fusarium-Arten bei 100-facher Vergrößerung mit dem Lichtmikroskop (Mikroskop: Leica, Leitz DM RB; Kamera: Leica DFC 420, Leica GmbH). a) Makrokonidien von F. avenaceum, b) Makrokonidien von F. cerealis, c) Makrokonidien von F. culmorum, d) Makrokonidien von F. equiseti, e) Makrokonidien von F. graminearum, f) Makro- und Mikrokonidien von F. oxysporum. (weißer Balken $=25 \mu \mathrm{m}$ ). 

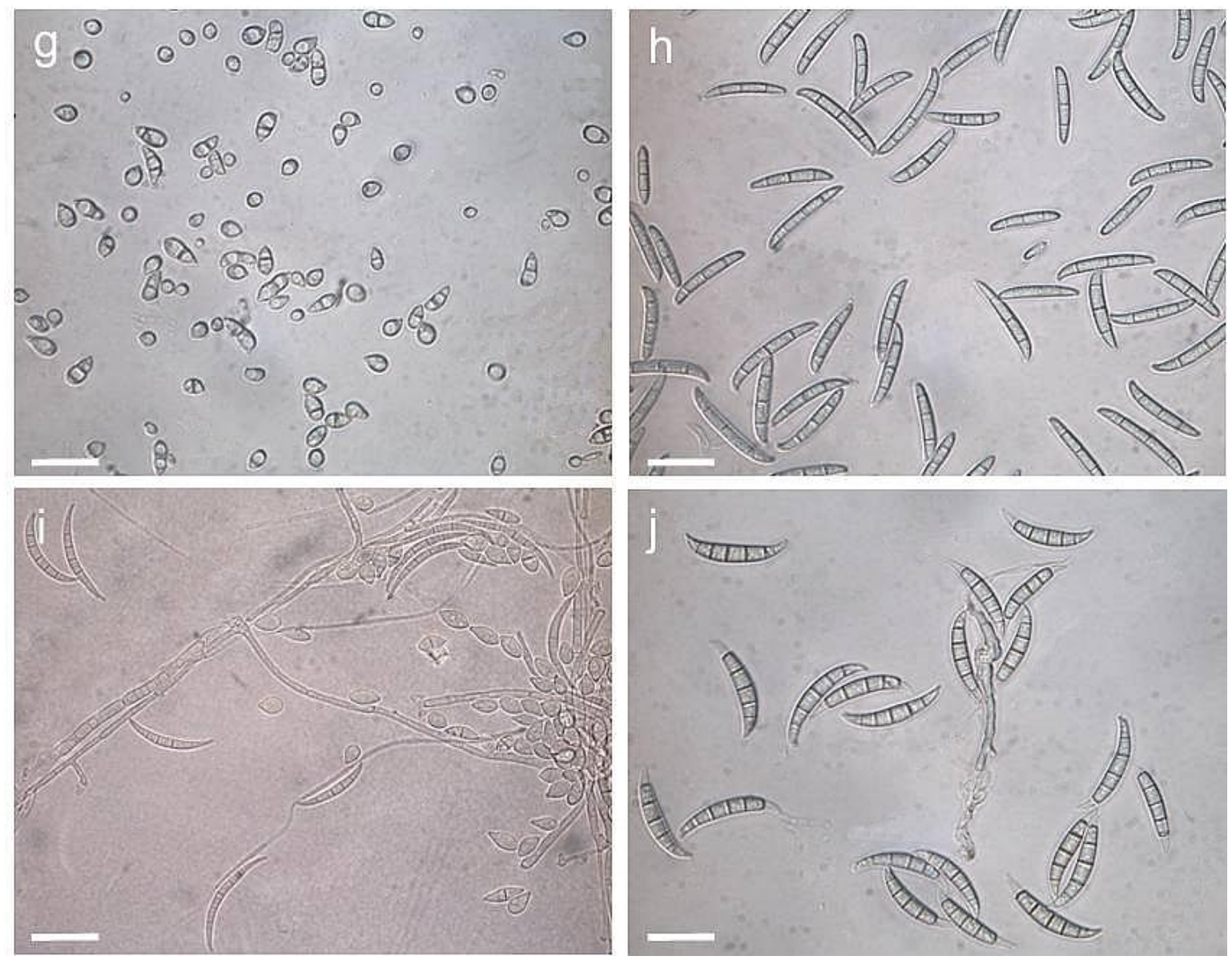

Abb. 6 b: Aufnahmen von Konidien verschiedener Fusarium-Arten bei 100-facher Vergrößerung mit dem Lichtmikroskop (Mikroskop: Leica, Leitz DM RB; Kamera: Leica DFC 420, Leica GmbH). g) Mikrokonidien von F. poae, h) Makro- und Mikrokonidien von F. redolens, i) Makro- und Mikrokonidien von F.tricinctum, j) Makrokonidien von F. venenatum. (weißer Balken $=25 \mu \mathrm{m}$ ).

\subsubsection{Identifikation mittels speziesspezifischer PCR}

Die Methode der speziesspezifischen PCR wurde eingesetzt, wenn bei einzelnen Isolaten keine eindeutige morphologische Identifikation vorgenommen werden konnte. Zudem wurden alle Fusarium-Isolate, welche für weitergehende Versuche verwendet wurden (s. 2.3.1), nach morphologischer Identifikation nochmals mittels speziesspezifischer PCR überprüft. Hierzu wurde die DNA wie unter 2.9 beschrieben extrahiert und zunächst eine „Internal Transcribed Spacer“ (ITS)-PCR durchgeführt (Tab. 8 und 9). Die „Internal Transcribed Spacer" (ITS)-Regionen pilzlicher ribosomaler DNA (rDNA) sind hoch konservierte, variable Sequenzen und von großer Bedeutung für die Unterscheidung von Pilzen auf Artebene mittels PCR. Die Multicopy-Eigenschaften der rDNA-Repeats gestatten zudem eine erfolgreiche Amplifikation aus kleinen Probenmengen sowie verdünnten oder teilweise degradierten DNA-Proben (Gardes et al., 1993). Auf Basis 
dieser Eigenschaften wurde die ITS-PCR als Methode ausgewählt, um nachzuweisen, dass die zur Identifikation verschiedener Fusarium-Arten extrahierte DNA grundsätzlich amplifizierbar war, sodass vor Durchführung speziesspezifischer PCRs ausgeschlossen werden konnte, dass negative Resultate der speziesspezifischen PCRs auf nicht amplifizierbare DNA zurückzuführen waren. Für die ITS-PCR wurde folgendes Primerpaar verwendet:

Internal Transcribed Spacer-Primerpaar (White et al., 1990):

ITS4: 5'-TCCTCCGCTTATTGATATGC-3'

ITS5: 5'-GGAAGTAAAAGTCGTAACAAGG-3،

Tab. 8: Für die Überprüfung der extrahierten DNA verwendetes ITS-PCR-Programm.

\begin{tabular}{|c|c|c|c|}
\hline Programm & Schritt & Temperatur & Dauer \\
\hline 1 & Denaturierung & $95^{\circ} \mathrm{C}$ & $5 \mathrm{~min}$ \\
\hline 2 & Annealing & $57^{\circ} \mathrm{C}$ & $1 \mathrm{~min}$ \\
\hline 3 & Synthese & $72^{\circ} \mathrm{C}$ & $1 \mathrm{~min}$ \\
\hline 4 & Denaturierung & $94^{\circ} \mathrm{C}$ & $5 \mathrm{~min}$ \\
\hline 5 & Annealing & $57^{\circ} \mathrm{C}$ & $1 \mathrm{~min}$ \\
\hline 6 & $\begin{array}{l}\text { Synthese (Wiederholung } \\
\text { Schritt 4-6, } 4 \text { Zyklen) }\end{array}$ & $72^{\circ} \mathrm{C}$ & $1 \mathrm{~min}$ \\
\hline 7 & Denaturierung & $94^{\circ} \mathrm{C}$ & $5 \mathrm{~min}$ \\
\hline 8 & Annealing & $57^{\circ} \mathrm{C}$ & $1 \mathrm{~min}$ \\
\hline 9 & $\begin{array}{l}\text { Synthese (Wiederholung } \\
\text { Schritt 7-9, } 30 \text { Zyklen) }\end{array}$ & $72^{\circ} \mathrm{C}$ & $1 \mathrm{~min}$ \\
\hline 10 & Ende & & \\
\hline
\end{tabular}


Tab. 9: Mastermix für 1 Reaktion der ITS-PCR, $25 \mu \mathrm{l}$ Gesamtvolumen pro Reaktion.

\begin{tabular}{ccc}
\hline Chemikalie & Konzentration & $\mu \mathrm{l} /$ Reaktion \\
\hline $\mathrm{H}_{2} \mathrm{O}$ bidest & - & 14,3 \\
10x Puffer (Fermentas) & $10 \mathrm{x}$ & 2,5 \\
$\mathrm{MgCl}_{2}$ (Fermentas) & $25 \mathrm{mM}$ & 1,5 \\
Primer ITS4 (Invitrogen) & $10 \mathrm{pmol} / \mu \mathrm{l}$ & 2,5 \\
Primer ITS5 (Invitrogen) & $10 \mathrm{pmol} / \mu \mathrm{l}$ & 2,5 \\
dNTP (Fermentas) & $25 \mathrm{mM}$ & 0,5 \\
DreamTaq-Polymerase (Fermentas) & $5 \mathrm{U} / \mu \mathrm{l}$ & 0,2 \\
\hline
\end{tabular}

Nach Überprüfung der zur Identifikation herangezogenen DNA-Proben mittels ITS-PCR erfolgte die speziesspezifische PCR (Tab. 10 und 11). 
Tab. 10: Speziesspezifische Primer zur Identifikation verschiedener Fusarium-Arten.

\begin{tabular}{|c|c|c|c|}
\hline Fusarium-Art & Primer & Sequenz & Quelle \\
\hline F. avenaceum & JIAF/JIAR & $\begin{array}{l}\text { 5'-GCTAATTCTTAACTTACTAGGGGCC-3' } \\
\text { 5'-CTGTAATAGGTTATTTACATGGGCG-3' }\end{array}$ & $\begin{array}{l}\text { Turner et } \\
\text { al., } 1998\end{array}$ \\
\hline F. culmorum & C51F/C51R & $\begin{array}{l}\text { 5'-ATGGTGAACTCGTCGTGGC-3' } \\
\text { 5'-CCCTTCTTACGCCAATCTCG-3' }\end{array}$ & $\begin{array}{l}\text { Nicholson } \\
\text { et al., } 1998\end{array}$ \\
\hline F. equiseti & 198F2/198R1 & $\begin{array}{l}\text { 5'-GACAGCAAGATTGACCTTTTGG-3' } \\
\text { 5'-GACATACTCTACAAGTGCCAA-3' }\end{array}$ & $\begin{array}{l}\text { Wilson et } \\
\text { al., } 2004\end{array}$ \\
\hline F. graminearum & Fg16NF/Fg16NR & $\begin{array}{l}\text { 5'-ACAGATGACAAGATTCAGGCACA-3' } \\
\text { 5'-TTCTTTGACATCTGTTCAACCCA-3' }\end{array}$ & $\begin{array}{l}\text { Nicholson } \\
\text { et al., } 1998\end{array}$ \\
\hline F. poae & Fp82F/Fp82R & $\begin{array}{l}\text { 5'-CAAGCAAACAGGCTCTTCACC-3' } \\
\text { 5'-TGTTCCACCTCAGTGACAGGTT-3' }\end{array}$ & $\begin{array}{c}\text { Parry und } \\
\text { Nicholson, } \\
1996\end{array}$ \\
\hline F. tricinctum & F-tri1/F-tri2 & $\begin{array}{l}\text { 5'-CGTGTCCCTCTGTACAGCTTTGA-3' } \\
\text { 5'-GTGGTTACCTCCCGATACTCTA-3' }\end{array}$ & Kulik, 2008 \\
\hline F. venenatum & VEN-BF/VEN-BR & $\begin{array}{l}\text { 5'-GGCGGATAAGGATAGTGGTAGAAG-3' } \\
\text { 5'-GGCGGATAAGCAAATAAGATGCTT-3' }\end{array}$ & $\begin{array}{l}\text { Yoder und } \\
\text { Christian- } \\
\text { son, } 1998\end{array}$ \\
\hline
\end{tabular}


Tab. 11: PCR-Programm der speziesspezifischen PCRs zur Identifikation verschiedener Fusarium-Arten.

\begin{tabular}{|c|c|c|c|}
\hline Programm & Schritt & Temperatur & Dauer \\
\hline 1 & Denaturierung & $95^{\circ} \mathrm{C}$ & $30 \mathrm{~s}$ \\
\hline 2 & Annealing & $66^{\circ} \mathrm{C}$ & $20 \mathrm{~s}$ \\
\hline 3 & $\begin{array}{l}\text { Synthese (Wiederholung Schritt } \\
1 \text { 1-3, } 5 \text { Zyklen) }\end{array}$ & $72^{\circ} \mathrm{C}$ & $45 \mathrm{~s}$ \\
\hline 4 & Denaturierung & $95^{\circ} \mathrm{C}$ & $30 \mathrm{~s}$ \\
\hline 5 & Annealing & $64^{\circ} \mathrm{C}$ & $20 \mathrm{~s}$ \\
\hline 6 & $\begin{array}{l}\text { Synthese (Wiederholung Schritt } \\
\qquad 4-6,5 \text { Zyklen) }\end{array}$ & $72^{\circ} \mathrm{C}$ & $45 \mathrm{~s}$ \\
\hline 7 & Denaturierung & $95^{\circ} \mathrm{C}$ & $30 \mathrm{~s}$ \\
\hline 8 & Annealing & $62^{\circ} \mathrm{C}$ & $20 \mathrm{~s}$ \\
\hline 9 & $\begin{array}{l}\text { Synthese (Wiederholung } \\
\text { Schritt 7-9, } 24 \text { Zyklen) }\end{array}$ & $72^{\circ} \mathrm{C}$ & $45 \mathrm{~s}$ \\
\hline 10 & Finale Synthese & $72^{\circ} \mathrm{C}$ & $5 \mathrm{~min}$ \\
\hline 11 & Ende & & \\
\hline
\end{tabular}

\subsubsection{Identifikation mittels Restriktionsfragmentlängenpolymorphismus (RFLP)}

Die Identifikation jener Fusarium-Isolate aus dem FAEN-Fruchtfolgeversuch, welche morphologisch nicht identifiziert werden konnten, erfolgte mit Hilfe von PCR-RFLP-

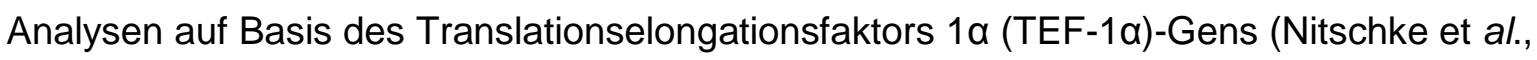
2009). Hierzu wurden die in Frage kommenden Isolate für sieben Tage in PDBFlüssigkulturen kultiviert, lyophyllisiert und anschließend eine DNA-Extraktion durchgeführt (s. 2.9). 


\section{TEF-1 $\alpha-P C R$}

Die DNA-Extrakte wurden für eine TEF-1a-PCR herangezogen (Tab. 12 und 13). Das amplifizierte Genfragment besaß eine Größe von 690-730bp, je nach Fusarium-Art.

Zur Durchführung der PCR wurde das Primerpaar EF1T/EF2T (O'Donnell et al., 1998; Nitschke et al., 2009) genutzt.

TEF-1 $\alpha$ - Primerpaar:

EF1T 5'-ATGGGTAAGGAGGACAAGAC-3'

EF2T 5'-GGAAGTACCAGTGATCATGTT-3'

Tab. 12: Programm der TEF-1 $\alpha-P C R$.

\begin{tabular}{|c|c|c|c|}
\hline Programm & Schritt & Temperatur & Dauer \\
\hline 1. & Initiale Denaturierung & $94^{\circ} \mathrm{C}$ & $5 \min$ \\
\hline 2. & Denaturierung & $94^{\circ} \mathrm{C}$ & $45 \mathrm{~s}$ \\
\hline 3. & Annealing & $57^{\circ} \mathrm{C}$ & $45 \mathrm{~s}$ \\
\hline 4. & $\begin{array}{l}\text { Synthese (Wiederholung } \\
\text { Schritt 2-4, } 36 \text { Zyklen) }\end{array}$ & $72^{\circ} \mathrm{C}$ & $1 \mathrm{~min}$ \\
\hline 5. & Finale Synthese & $72^{\circ} \mathrm{C}$ & $10 \mathrm{~min}$ \\
\hline 6. & Ende & & \\
\hline
\end{tabular}


Tab. 13: Reaktionsansatz der TEF-1 $\alpha-P C R, 50 \mu l$ Gesamtvolumen je Reaktionsansatz.

\begin{tabular}{ccc}
\hline Chemikalie & Konzentration & $\begin{array}{c}\mu \mathrm{l} / \\
\text { Reaktion }\end{array}$ \\
\hline $\mathrm{H}_{2} \mathrm{O}$ bidest & - & 33,3 \\
10x Puffer (Fermentas) inkl. $\mathrm{MgCl}_{2}$ (Fermentas) & $10 \mathrm{x}, 25 \mathrm{mM}$ & 5 \\
$\mathrm{MgCl}_{2}$ (Fermentas) & $25 \mathrm{mM}$ & 2 \\
Primer EF1T (Invitrogen) & $10 \mathrm{pmol} / \mu \mathrm{l}$ & 3 \\
Primer EF2T (Invitrogen) & $10 \mathrm{pmol} / \mu \mathrm{l}$ & 3 \\
dNTP (Fermentas) & $25 \mathrm{mM}$ & 0,5 \\
DreamTaq-Polymerase (Fermentas) & $5 \mathrm{U} / \mu \mathrm{l}$ & 0,2 \\
\hline
\end{tabular}

\section{Restriktionsverdau}

Das erhaltene PCR-Produkt wurde anschließend mittels Restriktionsverdau unter Verwendung des FastDigest ${ }^{\circledR}$-Restrikitonsenzyms Bsh1236I gespalten. Die DNA wurde somit an spezifischen Schnittstellen gespalten, wodurch DNA-Fragmente in verschiedenen Größen und Anzahlen entstanden. Es wurden für jeden Reaktionsansatz $20 \mu \mathrm{l}$ DNA eingesetzt. Für die Spaltung wurde zunächst ein Mastermix hergestellt (Tab. 14).

Tab. 14: Mastermix für 1 Reaktionsansatz des Restriktionsverdaus mit Bsh1236I, $10 \mu \mathrm{l}$ Gesamtvolumen je Reaktion.

Chemikalie

$\mathrm{H}_{2} \mathrm{O}$ bidest

Puffer

Bsh1236I $\mu \mathrm{l} /$ Reaktion 
Durch Zugabe von $5 \mu \mathrm{l}$ des Mastermixes pro Reaktion in den Deckel des Eppedorfgefäßes und anschließendem, kurzen Abzentrifugieren (Tischzentrifuge Sprout, Heathrow Scientific, Illinois, USA), wurde der Verdau gestartet. Die Inkubation erfolgte für 20 min bei $37^{\circ} \mathrm{C}$ im Wasserbad. Nach Ablauf der Inkubationszeit wurde der Verdau durch Zugabe von $5 \mu$ l Ladungspuffer („Blue Juice“) gestoppt. Im Anschluss daran konnten die Restriktionsansätze direkt auf ein Agarosegel aufgetragen werden, um eine elektrophoretische Auftrennung der einzelnen durch die Restriktion der DNA entstandenen Fragmente zu erreichen. Für das Auftragen der verdauten DNA wurden $3 \%$ ige Agarosegele mit TBE-Puffer verwendet, denen bereits vor dem Gießen $3 \mu$ einer $1 \%$ igen Ethidiumbromidlösung pro $100 \mathrm{ml}$ Gel hinzugefügt worden waren. Die Aufwandmenge pro Reaktion betrug $20 \mu \mathrm{l}$, zu denen $5 \mu \mathrm{l}$ Ladungspuffer addiert wurden. Zudem wurden in die erste, mittlere und letzte Tasche des Gels $5 \mu$ leines 50 bp-Markers (Fermentas) gegeben. Die Gelelektrophoresen wurden bei $4 \mathrm{~V} / \mathrm{cm}$ Gel in 0,5\%igem TBEPuffer für $90 \mathrm{~min}$ durchgeführt. Die anschließende Dokumentation der Gele mittels Erfassen der Fluoreszenz erfolgte mit dem Programm Quantity One (Version 4.5.0; Fa. Bio-Rad, Hagen). Das Auftrennen der DNA-Banden durch Gelelektrophorese erlaubte die Generierung spezifischer Bandenmuster, anhand derer unter Abgleich mit dem DNAMarker bestimmte Fusarium-Arten wie z.B. F. graminearum und F. poae direkt identifiziert werden konnten. Für andere Arten, wie beispielsweise F. culmorum oder F. tricinctum, erfolgte durch die Restriktion zunächst eine Zusammenfassung in Gruppen von FusariumArten mit demselben Bandenmuster. Unter Zuhilfenahme sowohl der vorhergegangenen morphologischen Untersuchung, als auch speziesspezifischer PCR (s. 2.13.4) war es möglich, alle Fusarium-Isolate eindeutig zu identifizieren.

\subsection{Analyse der Proben aus Freiland- und Gewächshausversuchen}

\subsubsection{Probenahme und Probenaufbereitung für Mykotoxinanalysen}

\section{FAEN-Feldversuch}

Es wurde ca. $1 \mathrm{~kg}$ Erntegut jeder Parzelle als Rückstellprobe für weitere Analysen aufbewahrt. Das Getreide wurde zunächst auf einen Restfeuchtegehalt von 14\% getrocknet, anschließend wurde es mit einem Probenreiniger (MLN Rationel, Pfeuffer, Kitzingen) von Staub und Spelzen befreit und im Anschluss daran mittels Zentrifugalmühle (ZM 200, Retsch, Haan) mit einer Sieblochgröße von $1 \mathrm{~mm}$ zu einem Vollkornmehl vermahlen und bei $4^{\circ} \mathrm{C}$ eingelagert. 


\section{Pathogenitätsversuch an der Ähre im Feld und unter kontrollierten Bedingungen}

Die Beprobung des Pathogenitätsversuchs am Standort Gladebeck erfolgte zu BBCH 92. Aus jeder Kleinparzelle wurden 50 befallene Ähren entnommen. Das Erntegut wurde manuell gewonnen, indem die zum Teil sehr stark befallenen Körner einzeln aus den Ährchen gezogen und somit von Spelzen und Spindel getrennt wurden. Im Anschluss daran wurden die Körner mit Hilfe einer Kugelmühle (MM 200, Retsch, Haan) bei 20 Bewegungen/s für $1 \mathrm{~min}$ zu einem feinen Vollkornmehl vermahlen. Mehl, Spelzen und Spindeln wurden jeweils separat bei $-20^{\circ} \mathrm{C}$ eingelagert.

In den Versuchen unter kontrollierten Bedingungen zur Pathogenität von Fusarium-Arten an der Ähre erfolgten Probenahme und -aufbereitung auf die gleiche Weise wie im Feld.

\subsubsection{Mykotoxinanalyse mittels HPLC-MS/MS}

Die gesamten während des Projektes erfolgten Mykotoxinanalysen wurden in der Abteilung Molekulare Phytopathologie und Mykotoxinforschung von Prof. Dr. Karlovsky im Rahmen des FAEN-Teilprojekts 4 nach Protokollen von Becker et al. (2010) (verändert nach Klötzel et al., 2006) mittels HPLC-MS/MS durchgeführt.

\section{FAEN-Feldversuch}

Die Untersuchung der Mykotoxinbelastungen des Ernteguts aus dem FAEN-Feldversuch am Standort Torland beschränkte sich auf das Vorkommen des B-Trichothecens Deoxynivalenol (DON).

\section{Pathogenitätsversuche an der Ähre}

Die innerhalb der verschiedenen Pathogenitätsversuche an der Ähre (s. 2.16.1 und 2.16.2) durch Inokulation hervorgerufenen Mykotoxinbelastungen im Erntegut wurden detailliert untersucht, in dem die spezifischen Mykotoxinspektren der einzelnen, in den Versuchen verwendeten, toxigenen Fusarium-Arten analysiert wurden. Dabei wurden sowohl das Vorkommen als auch die Gehalte der Mykotoxine Deoxynivalenol (DON), 3Acetyldeoxynivalenol (3-ADON), 15-Acetyldeoxynivalenol (15-ADON), Deoxynivalenol-3glucosid (DON-3-G), Nivalenol (NIV), Zearalenon (ZEA), Beauvericin (BEAU) und Enniatin (ENNI A, A1, B, B) bestimmt. Enniatingehalte wurden für die Auswertung zusammengefasst (Tab. 24, 28 und 32). 


\subsection{FAEN-Fruchtfolgeversuch}

\subsubsection{Standort}

Der Standort Torland liegt am nördlichen Ortsausgang der Gemeinde Bovenden $\left(51^{\circ} 36^{\prime} \mathrm{N}, 9^{\circ} 55^{\prime} \mathrm{O}\right)$, in einem lössreichen Becken zwischen dem Leinetal und dem Mittelgebirgszug Göttinger Wald, mit einem Kalkstein-Braunlehm über Muschelkalk als standortspezifische Bodenart. Die Fläche des Standortes gehört zu den Versuchswirtschaften der Georg-August-Universität Göttingen.

\subsubsection{Meteorologische Daten}

Daten der für die Fragestellungen des Versuches bedeutenden Witterungsparameter Niederschlag, relative Luftfeuchte und Tagesdurchschnittstemperaturen wurden bis Ende Juni 2010 mit freundlicher Genehmigung des Betreibers von der Wetterstation Göttingen (www.wetterstation-goettingen.de) bezogen. Ab Ende Juni 2010 wurden alle Witterungsparameter direkt am Standort Torland ganzjährig mit einer Davis Vantage Pro2 ${ }^{\mathrm{TM}}$-Wetterstation (Davis Instruments, Hayward, USA) aufgezeichnet. Die unter 3.1.1 und 3.3.1 dargestellten Temperatur- und Niederschlagsabweichungen beziehen sich auf langjährige Durchschnittswerte des Referenzzeitraums 1960-1990, welche von der Wetterwarte des Deutschen Wetterdienstes in Göttingen zur Verfügung gestellt wurden.

\subsubsection{Fragestellung des Versuchs}

Der Hauptfokus dieser Arbeit lag auf der Charakterisierung von Fusarium-Artenspektren sowie deren Kolonisierungsraten an der Halmbasis und an Körnern von Weizen nach den vier in den Versuch integrierten Fruchtfolgegliedern (s. 2.15.4). Der Begriff „Kolonisierungsrate“ wurde als neutraler Begriff zur Benennung der Besiedlung des Weizens durch Fusarium eingeführt, um wertende Begriffe wie beispielsweise „Befall“ zu vermeiden, da nicht für alle Fusarium-Arten von Beginn an ein pathogener Befall der Weizenpflanze angenommen werden konnte. Im Rahmen der Charakterisierung der Fusarium-Artenspektren war zunächst die Untersuchung des Effektes der Versuchsparameter „Probenahmezeitpunkt“, „Vorfrucht“, „Sorte“ und „Blattfungizidapplikation“ auf die Gesamtkolonisierungsraten der Fusarium-Arten an den beiden unterschiedlichen Pflanzenteilen von Bedeutung. Jahresbedingte Effekte wurden im Zuge der o.g. Versuchsfaktoren miterfasst. Die Gesamtkolonisierungsraten wurden anschließend für jeden Versuchsparameter auf Artebene detailliert betrachtet, wodurch Aufschluss sowohl über das genaue Artenspektrum, als auch über das Vorkommen und 
die Bedeutung der verschiedenen Fusarium-Arten anhand ihrer individuellen Kolonisierungsraten für jeden Versuchsparameter gegeben werden konnte.

\subsubsection{Versuchsaufbau}

Der am Standort Torland innerhalb des Forschungsverbundes Agrar- und Ernährungswissenschaften Niedersachsen (FAEN) bestehende Fruchtfolgeversuch wurde 2006 bei nichtwendender Bodenbearbeitung mit den drei Vorfruchtvarianten Winterweizen, Mais und Zuckerrübe vor Winterweizen angelegt. Ab 2008 wurde zudem die Vorfrucht Ölrettich (als Rapsäquivalent) in den Versuch integriert und dieser bis 2011 in der Form fortgeführt. Die Vorfruchtvarianten waren in Reihen von jeweils drei $900 \mathrm{~m}^{2}$ großen Blöcken (Großparzellen) in jährlicher Rotation angeordnet (Abb. 7). Die Großparzelle der zu untersuchenden Nachfrucht Winterweizen war in 24 Versuchsparzellen mit einer Größe von jeweils $25 \mathrm{~m}^{2}$ aufgeteilt (Abb. 8). 


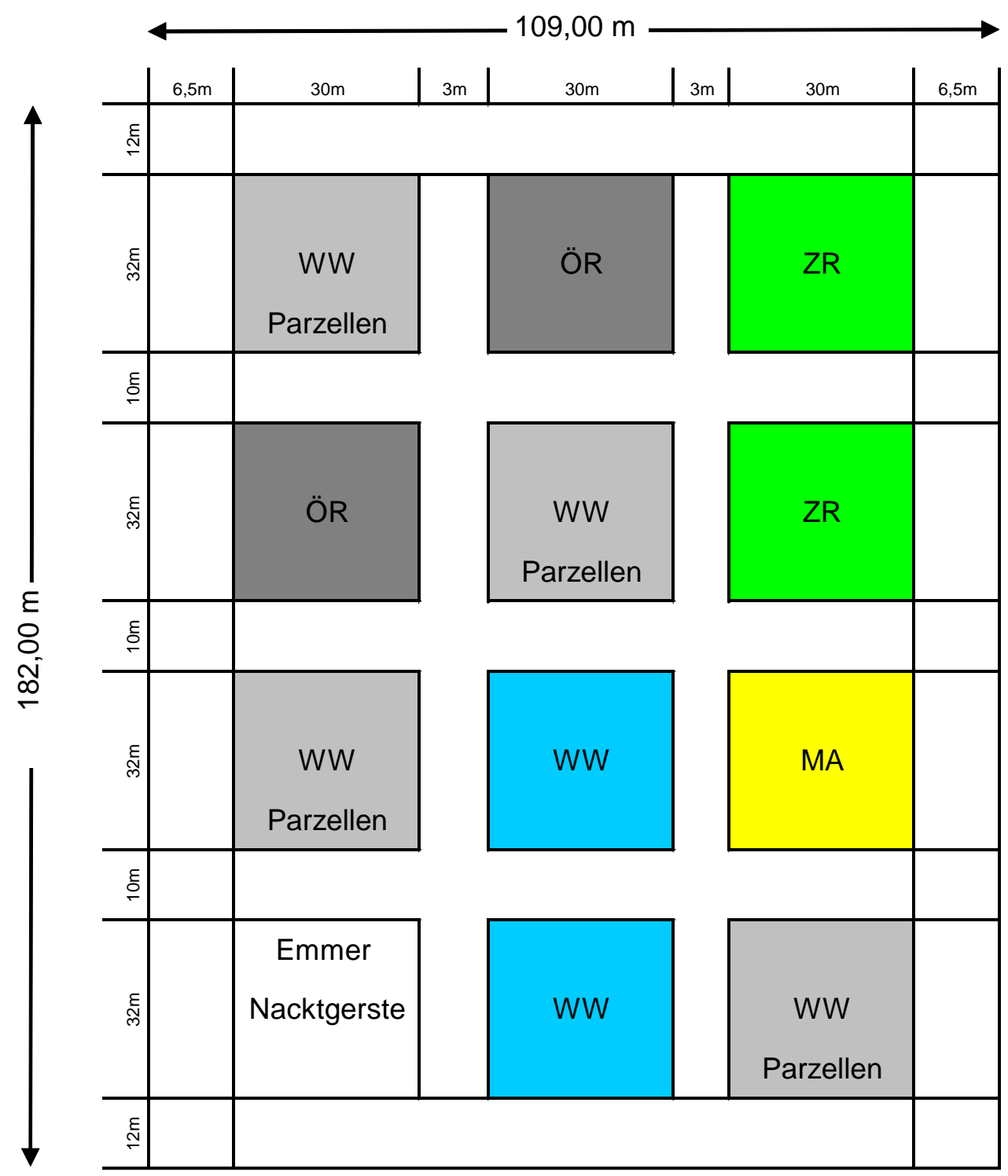

Abb. 7: Versuchsaufbau des FAEN-Fruchtfolgeversuchs am Standort Torland. Der Versuch beinhaltete die vier Vorfruchtvarianten Winterweizen, Mais, Zuckerrübe und Ölrettich, welche in Großparzellen bei nichtwendender Bodenbearbeitung für Winterweizen als Nachfrucht in Spalten angelegt wurden. Jede Vorfruchtvariante bestand aus je drei Großparzellen à $900 \mathrm{~m}^{2}$, von denen jeweils eine dieser Großparzellen mit Winterweizen als Nachfrucht in 24 Kleinparzellen à $25 \mathrm{~m}^{2}$ eingeteilt wurde, welche als Versuchsparzellen herangezogen wurden.

Für die Anlage der 24 Versuchsparzellen innerhalb einer Großparzelle wurde eine SplitSplit-Split-Plot Anlage gewählt, wobei die beiden Versuchssorten „Ritmo“ und „Centrum“ als fest definierte Spalten in die jeweiligen Großparzellen integriert wurden (Gödecke, 2010) (Abb. 8). Die Vorfruchtvarianten wechselten von einem Versuchsjahr zum darauffolgenden auf zuvor definierte Flächen, sodass sie lediglich als teilrandomisiert betrachtet werden können. 
Die vier Vorfrüchte ergaben zusammen mit der Applikation von $0,8 \mathrm{I} /$ ha Aufwandmenge Prothioconazol zu BBCH 31-33 (Behandlungstermin 2010: 05.05.2010; Behandlungstermin 2011: 04.05.2011) und BBCH 37-39 (Behandlungstermin 2010: 03.06.2010; Behandlungstermin 2011: 19.05.2011) die folgenden vier Versuchsvarianten, von denen zwei Varianten behandelt wurden, die anderen beiden unbehandelt blieben:

Variante 1: Centrum (resistent), behandelt

Variante 2: Ritmo (anfällig), behandelt

Variante 3: Centrum, unbehandelt

Variante 4: Ritmo, unbehandelt

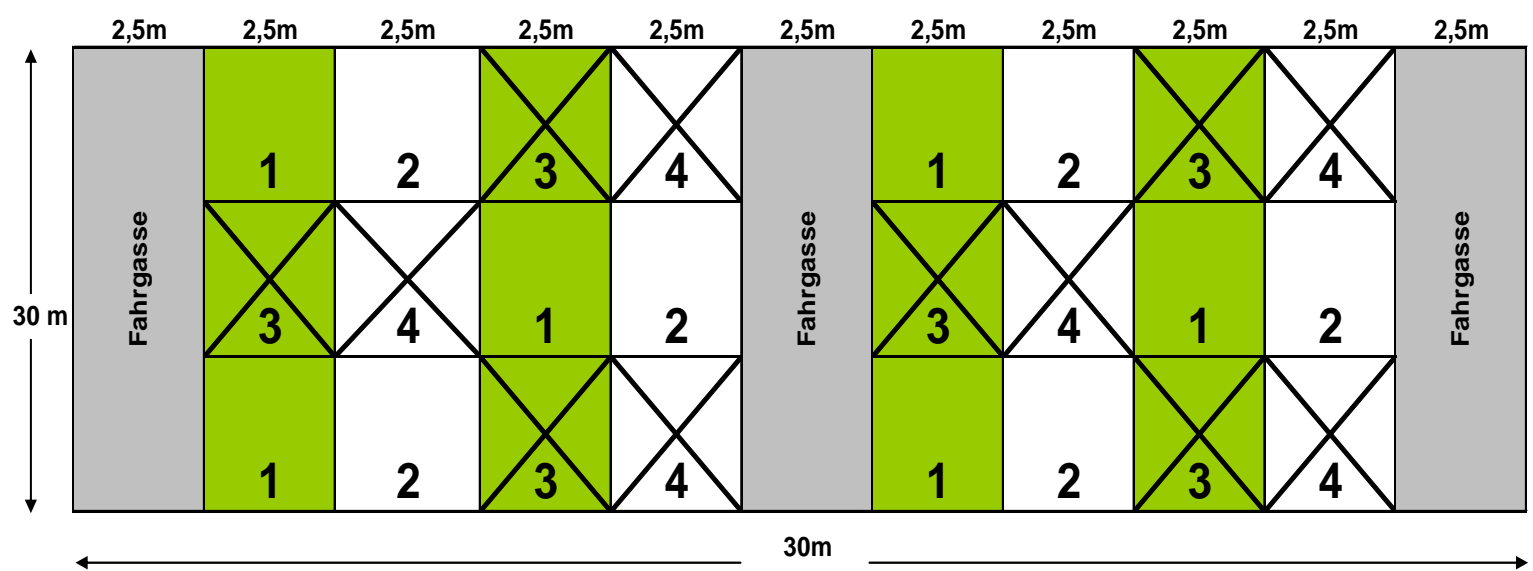

Abb. 8: Detailansicht der Winterweizen-Nachfruchtparzellen des FAEN-Fruchtfolgeversuchs. Die Aufteilung in $\mathbf{2 4}$ Kleinparzellen wurde durch die Integration der vier Versuchsvarianten „Centrum (resistent), behandelt mit Prothioconazol“ (Variante 1), „Ritmo (anfällig), behandelt mit Prothioconazol“ (Variante 2), "Centrum, unbehandelt" (Variante 3) und „Ritmo, unbehandelt“ (Variante 4) erzielt.

Durch die Fungizidbehandlung in Form zweier Blattbehandlungen während des Schossens kam es nicht zu einer direkten Wirkung des Fungizids auf einen potenziellen Befall der Ähre seitens Fusarium. Düngung, Schädlings- und Unkrautbekämpfung wurden nach guter fachlicher Praxis durchgeführt.

\subsection{Pathogenitätsversuche mit Fusarium-Arten an Halmbasis und Ähre von Weizen}

Zur Untersuchung der Pathogenität der innerhalb des FAEN-Feldversuchs häufig isolierten Fusarium-Arten wurden Pathogenitätstests an Halmbasis und Ähre von Weizen durchgeführt. 


\subsubsection{Pathogenitätsversuch an der Ähre im Feld}

Dieser Versuch sollte sowohl die Pathogenität einzelner, aus Winterweizen isolierter Fusarium-Arten als auch ihre Konkurrenzfähigkeit im Hinblick auf eine Etablierung an der Ähre bei Anwesenheit weiterer Fusarium-Arten im Feld näher untersuchen.

\section{Standort}

Der Versuch wurde 2011 am Standort Gladebeck (513' N, 952' O), am Rande des Leinetals ca. $20 \mathrm{~km}$ von Göttingen entfernt, angelegt. Die spezifische Bodenart des Standorts ist eine Parabraunerde. Zur Durchführung des Versuchs wurde eine $30 \times 30 \mathrm{~m}$ große Füllparzelle des von den FAEN-Teilprojekten 2 und 5 an diesem Standort bearbeiteten Fruchtfolgeversuches herangezogen. Als Weizensorte diente die als mittelanfällig gegenüber Ährenfusarium eingestufte Winterweizensorte „Asano“ (s. 2.3.2).

\section{Versuchsaufbau}

Auf der $900 \mathrm{~m}^{2}$ großen Fläche wurde eine vollrandomisierte Spaltanlage (v. Lochow und Schuster, 1961) in vierfacher Wiederholung angelegt, die 32 Kleinparzellen mit einer Fläche von $2,5 \mathrm{~m}^{2}$ beinhaltete.

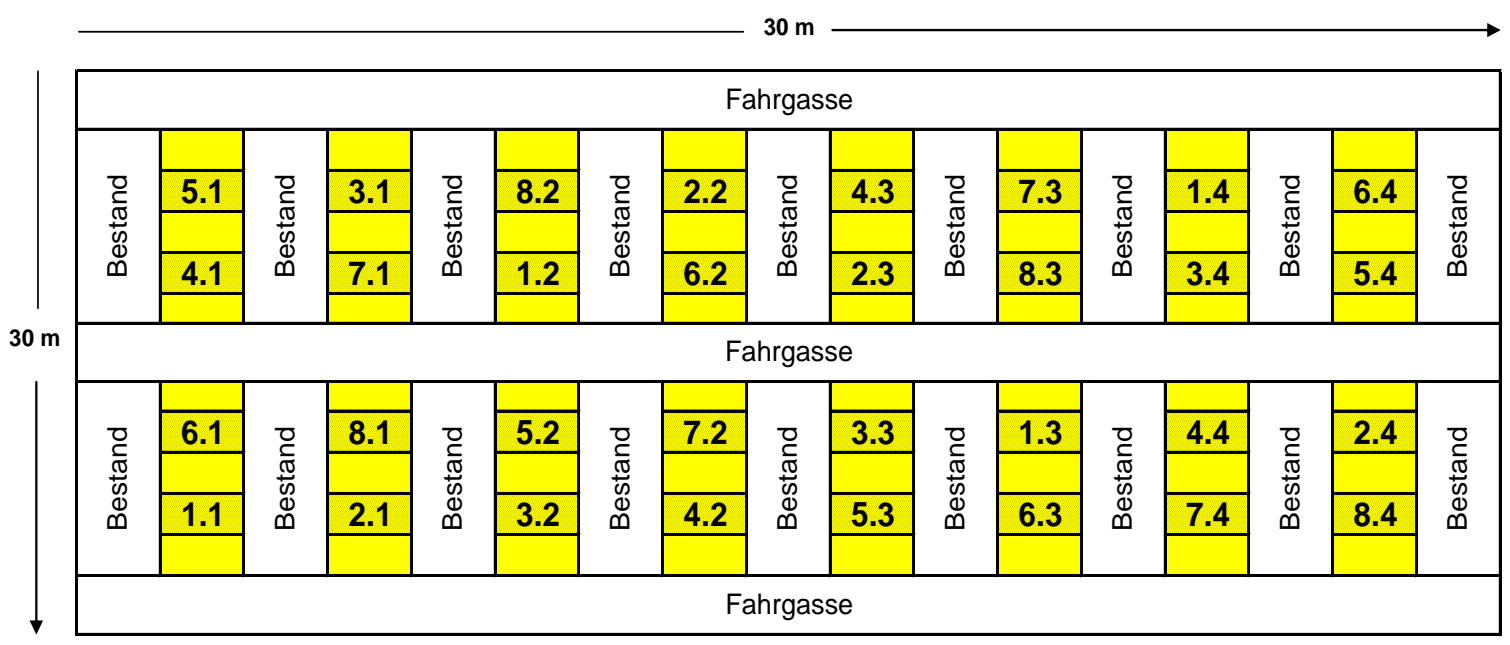

Abb. 9: Versuchsaufbau des Freiland-Inokulationsversuches am Standort Gladebeck 2011. Der Versuch wurde als vollrandomisierte Spaltanlage mit Kleinparzellen von $2,5 \mathrm{~m}^{2}$ in einer Füllparzelle der Winterweizensorte „Asano“ angelegt. Diese Füllparzelle war Teil des Fruchtfolgeversuches der FAEN-Teilprojekte 2 und 5 an diesem Standort. Gepunktete Flächen stellen Versuchsparzellen dar. Die Nummerierung innerhalb dieser Parzellen bezieht sich auf die Versuchsvarianten (Zahl vor dem Punkt) und deren Wiederholungen (Zahl nach dem Punkt). 
Die Abstände jeder Kleinparzelle zur nächsten betrugen in alle vier Richtungen 2,5 m, um einer Kreuzkontamination durch etwaige Inokulumverwehungen bei der Sprühinokulation der Weizenpflanzen vorzubeugen. Es wurden sieben Versuchsvarianten, das heißt, drei Einzelvarianten mit lediglich einer Art sowie Mischvarianten mit zwei, bzw. drei FusariumArten sowie zwei Kontrollvarianten (Wasser- und Randkontrolle) in den Versuch integriert. Variante 1 fungierte als Positivkontrolle, wird hier jedoch als Versuchsvariante behandelt. Der Fokus der Mischvarianten lag besonders auf der Untersuchung der Etablierung der im FAEN-Fruchtfolgeversuch in den Versuchsjahren 2010 und 2011 häufig isolierten Arten F. poae und F.tricinctum an der Ähre (s.3.2.2 und 3.2.5) in Anwesenheit von F. graminearum sowie dem Besiedlungsverhalten und Durchsetzungsvermögen beider Arten bei gleichzeitiger Applikation in einer Versuchsvariante. Die Mischungsverhältnisse der Konidiensuspensionen der Mischvarianten mit zwei Fusarium-Arten betrug 1:1. Bei drei Fusarium-Arten pro Gemisch betrug das Mischungsverhältnis demnach 1:1:1. Diese Mischungsverhältnisse wurden für alle Pathogenitätsversuche an der Ähre beibehalten. 
Tab. 15: Versuchsvarianten des Pathogenitätsversuchs im Feld.

\begin{tabular}{|c|c|c|c|}
\hline Bezeichnung & Eigenschaft & Isolate & Fusarium-Arten \\
\hline Variante 1 & Versuchsvariante & Fgr1, Fgr2, Fgr4 & F. graminearum \\
\hline Variante 2 & Versuchsvariante & Fequ1, Fequ2, Fequ3 & F. equiseti \\
\hline Variante 3 & Versuchsvariante & $\begin{array}{l}\text { Fpo1, Fpo2, Fpo3, } \\
\text { Ftri5, Ftri6, Ftri7 }\end{array}$ & F. poae, F. tricinctum \\
\hline Variante 4 & Versuchsvariante & Ftri5, Ftri6, Ftri7 & F. tricinctum \\
\hline Variante 5 & $\begin{array}{l}\text { Kontrollvariante } \\
\text { (Wasserkontrolle) }\end{array}$ & keine & keine \\
\hline Variante 6 & Versuchsvariante & $\begin{array}{c}\text { Fgr1, Fgr2, Fgr4, } \\
\text { Fpo1, Fpo2, Fpo3, } \\
\text { Ftri5, Ftri6, Ftri7 }\end{array}$ & $\begin{array}{c}\text { F. graminearum, F. poae } \\
\text { F. tricinctum }\end{array}$ \\
\hline Variante 7 & Versuchsvariante & $\begin{array}{l}\text { Fgr1, Fgr2, Fgr4, } \\
\text { Ftri5, Ftri6, Ftri7 }\end{array}$ & $\begin{array}{l}\text { F. graminearum, } \\
\text { F. tricinctum }\end{array}$ \\
\hline Variante 8 & Versuchsvariante & Fpo1, Fpo2, Fpo3 & F. poae \\
\hline Variante 9 & $\begin{array}{l}\text { Kontrollvariante } \\
\text { (Randkontrolle) }\end{array}$ & keine & keine \\
\hline
\end{tabular}

Die Sprühinokulation erfolgte zu BBCH 61-65 nach 20 Uhr, um ein zu schnelles Abtrocknen der Ähren zu verhindern. Nach 10 und 24 dpi wurde mittels visueller Bonitur (s. 2.11.1) die Befallsstärke in den einzelnen Kleinparzellen ermittelt. Probenahme, Probenaufbereitung und Analyse erfolgten wie unter 2.14 beschrieben.

\subsubsection{Pathogenitätsversuche unter kontrollierten Bedingungen an der Ähre}

\section{Pathogenitätsversuch mit Einzelvarianten}

Zur Überprüfung und Validierung der Ergebnisse aus dem Freiland-Pathogenitätsversuch am Standort Gladebeck wurde im Gewächshaus unter kontrollierten Bedingungen zunächst die Pathogenität der Einzelvarianten aus dem Feldversuch getestet. Der 
Versuch bestand aus vier Versuchsvarianten und einer Kontrollvariante (Wasserkontrolle), die in einer randomisierten Blockanlage angeordnet waren.

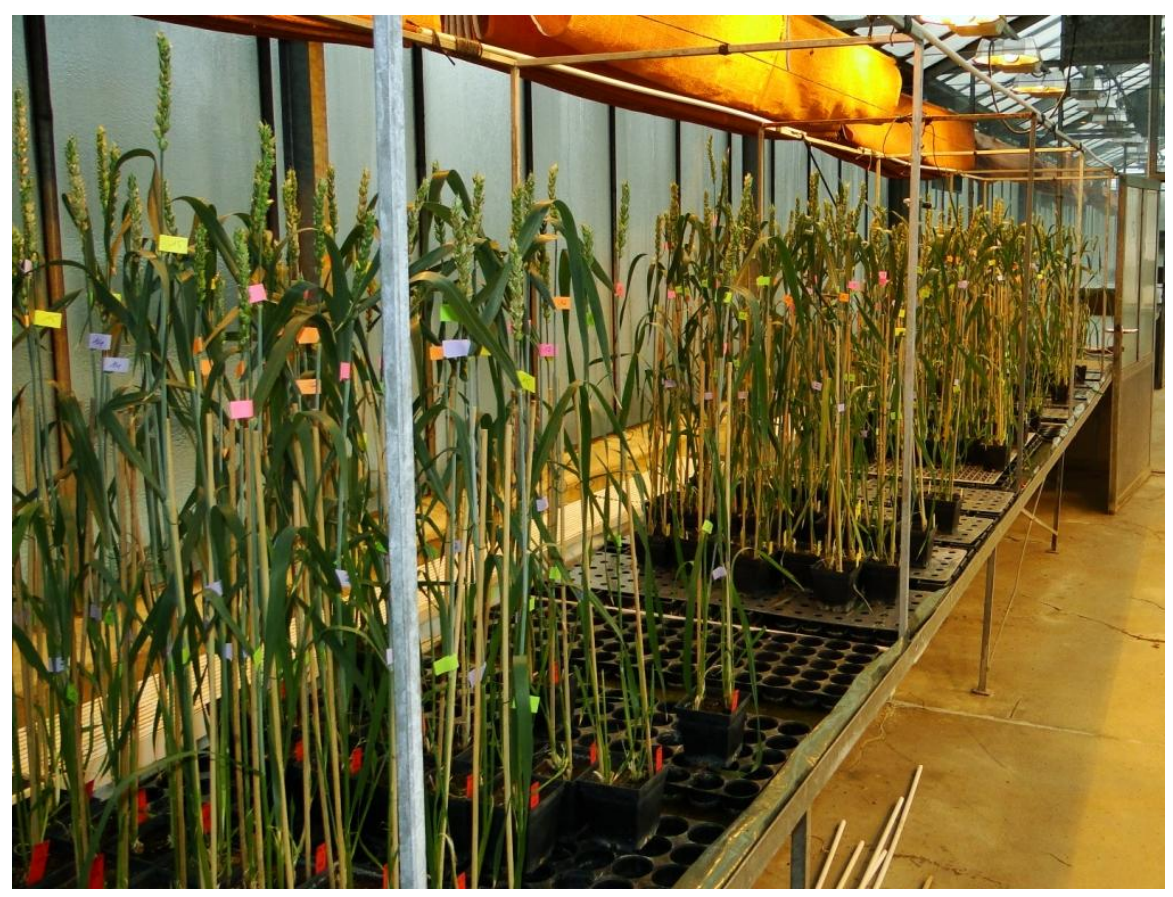

Abb. 10: Weizenpflanzen des Pathogenitätsversuchs mit Einzelvarianten unter kontrollierten Bedingungen im Gewächshaus nach der Sprühinokulation.

Jede Versuchsvariante bestand aus 10 Wiederholungen, wobei jede Wiederholung vier Töpfe, mit jeweils zwei ährentragenden Halmen enthielt. Die Versuche wurden bei einer durchschnittlichen relativen Luftfeuchte von $50 \%$ durchgeführt.

Tab. 16: Versuchsvarianten des Pathogenitätstests mit Einzelvarianten im Gewächshaus.

\begin{tabular}{|c|c|c|c|}
\hline Bezeichnung & Eigenschaft & Isolate & Fusarium-Arten \\
\hline Variante 1 & Versuchsvariante & Fgr1, Fgr2, Fgr4 & F. graminearum \\
\hline Variante 2 & Versuchsvariante & Fequ1, Fequ2, Fequ3 & F. equiseti \\
\hline Variante 3 & Versuchsvariante & Fpo1, Fpo2, Fpo3 & F. poae \\
\hline Variante 4 & Versuchsvariante & Ftri5, Ftri6, Ftri7 & F. tricinctum \\
\hline Variante 5 & $\begin{array}{l}\text { Kontrollvariante } \\
\text { (Wasserkontrolle) }\end{array}$ & keine & keine \\
\hline
\end{tabular}


Zu BBCH 61-65 erfolgte eine Sprühinokulation mittels Handsprüher. Nach 7, 14 und $21 \mathrm{dpi}$ wurden die inokulierten Pflanzen bonitiert (s. 2.11.2). Nach Erreichen des Entwicklungsstadiums BBCH 92 wurden die Proben gewonnen (s.2.14.1), eine Bestimmung des TKG durchgeführt (s. 2.12.2) und anschließend in Abhängigkeit der verschiedenen Varianten auf Black-Point-Besatz und Vorkommen von „Fusarium-HeadBlight"-Körnern untersucht sowie Häufigkeitsverteilungen für die entsprechenden Kornfraktionen erstellt (Christ et al., 2011b). Zusätzlich wurden zur Bestätigung der Koch'schen Postulate aus den Varianten 2, 3, 4 und 5 symptomlose und aus den Varianten 2, 3, und 4 Black-Point-Körner entnommen und auf PDA ausgelegt. Auf Basis einer visuellen Beurteilung der Myzelmorphologie konnten die zuvor applizierten Fusarium-Arten reisoliert und identifiziert werden. Anschließend erfolgte die Aufbereitung und Bestimmung der Mykotoxinprofile (s. 2.14.2). Die in den Varianten 2, 3 und 4 auftretenden Black-Point-Körner wurden dabei von den symptomlosen Körnern getrennt analysiert.

\section{Pathogenitätsversuch mit Einzel- und Mischvarianten}

Analog zum Pathogenitätsversuch mit Einzelvarianten wurden Versuche mit Einzel- und Mischvarianten durchgeführt. Hierbei sollten in den Mischvarianten, wie unter 2.16.1 beschrieben, die Konkurrenzfähigkeit der Arten F. poae und F. tricinctum untereinander und in Anwesenheit von F. graminearum unter kontrollierten Bedingungen untersucht werden. 
Tab. 17: Versuchsvarianten des Pathogenitätstests mit Einzel- und Mischvarianten im Gewächshaus.

\begin{tabular}{|c|c|c|c|}
\hline Bezeichnung & Eigenschaft & Isolate & Fusarium-Arten \\
\hline Variante 1 & Versuchsvariante & Fgr1, Fgr2, Fgr4 & F. graminearum \\
\hline Variante 2 & Versuchsvariante & $\begin{array}{c}\text { Fgr1, Fgr2, Fgr4, } \\
\text { Fpo1, Fpo2, Fpo3, } \\
\text { Ftri5, Ftri6, Ftri7 }\end{array}$ & $\begin{array}{c}\text { F. graminearum, } \\
\text { F. poae, F. tricinctum }\end{array}$ \\
\hline Variante 3 & Versuchsvariante & $\begin{array}{l}\text { Fgr1, Fgr2, Fgr4, } \\
\text { Ftri5, Ftri6, Ftri7 }\end{array}$ & $\begin{array}{l}\text { F. graminearum, } \\
\text { F. tricinctum }\end{array}$ \\
\hline Variante 4 & Versuchsvariante & $\begin{array}{l}\text { Fpo1, Fpo2, Fpo3, } \\
\text { Ftri5, Ftri6, Ftri7 }\end{array}$ & F. poae, F. tricinctum \\
\hline Variante 5 & Versuchsvariante & Ftri5, Ftri6, Ftri7 & F. tricinctum \\
\hline Variante 6 & Versuchsvariante & Fpo1, Fpo2, Fpo3 & F. poae \\
\hline Variante 7 & $\begin{array}{c}\text { Kontrollvariante } \\
\text { (Wasserkontrolle) }\end{array}$ & keine & keine \\
\hline
\end{tabular}

Die Versuchsvarianten 5 und 6 dienten als Referenzvarianten für Versuchsvarianten 3 und 4. Die Versuchsdurchführung entsprach der des Pathogenitätsversuchs mit Einzelvarianten. Eine Bestätigung der Koch'schen Postulate erfolgte lediglich in den Versuchsvarianten 5 und 6.

\subsubsection{Pathogenitätsversuch unter kontrollierten Bedingungen an der Halmbasis}

Im Rahmen der Untersuchungen zu Pathogenität verschiedener Fusarium-Arten an der Halmbasis unter kontrollierten Bedingungen in der Klimakammer, wurden Pflanzen der Sommerweizensorte "Tybalt" mittels Tauchinokulation (s. 2.10.3) mit Konidiensuspensionen benetzt. Als Versuchsaufbau wurde eine randomisierte Blockanlage mit fünf Versuchsvarianten à 10 Wiederholungen gewählt, wobei jede Wiederholung vier Töpfen mit jeweils zwei ährentragenden Halmen entsprach. Der Versuch wurde bei einer Licht/Dunkel-Photoperiode von 16/8 h $\left(430 \mu \mathrm{mol} \mathrm{s}{ }^{-1} \mathrm{~m}^{-2}\right)$ und einer Temperatur von $22^{\circ} \mathrm{C}$ (Tag) und $16^{\circ} \mathrm{C}$ (Nacht) sowie einer relativen Luftfeuchte von ca. $40 \%$ durchgeführt. Der Versuch beinhaltete vier Versuchsvarianten und eine Kontrollvariante. 
Tab. 18: Versuchsvarianten des Pathogenitätsversuchs unter kontrollierten Bedingungen an der Halmbasis.

\begin{tabular}{cccc}
\hline Bezeichnung & Eigenschaft & Isolate & Fusarium-Art \\
\hline Variante 1 & Versuchsvariante & Fcul1, Fcul2, Fcul3 & F. culmorum \\
Variante 2 & Versuchsvariante & Fequ1, Fequ2, Fequ3 & F. equiseti \\
Variante 3 & Versuchsvariante & Fpo1, Fpo2, Fpo3 & F. poae \\
Variante 4 & Versuchsvariante & Ftri1, Ftri2, Ftri3 & F. tricinctum \\
Variante 5 & $\begin{array}{c}\text { Kontrollvariante } \\
\text { (Wasserkontrolle) }\end{array}$ & keine & keine \\
\hline
\end{tabular}

Zum Zeitpunkt der späten Milchreife $(\mathrm{BBCH} 77)$ erfolgte eine visuelle Bonitur nach Broschewitz et al. (1999) (Tab. 7) der Halmbasis aller Pflanzen, um die Symptomausprägungen in den Versuchsvarianten zu ermitteln. Im Anschluss daran wurde die Ausbreitung der verschiedenen Fusarium-Arten im Halm der Weizenpflanzen untersucht. Hierzu wurde die Hälfte der Pflanzen jeder Variante entnommen. Die Pflanzen wurden direkt oberhalb der Wurzeln abgeschnitten. Die Blätter, Blattscheiden und Ähren wurden manuell entfernt und Segmente des Halms im Bereich der Halmbasis (Fuß), des ersten Nodiums, des zweiten Nodiums und des Pedunkels entnommen. Die Halmsegmente wurde daraufhin oberflächensterilisiert (s. 2.4.3) und auf PDA mit $100 \mathrm{mg} / \mathrm{ml}$ Streptomycin ausgelegt. Die ausgelegten Halmbasen wurden für sieben Tage bei $22^{\circ} \mathrm{C}$ im Klimaschrank (Mytron, Heilbad Heiligenstadt) inkubiert. Anschließend wurde visuell die Auswuchsrate der Fusarium-Arten an den verschiedenen Halmsegmenten dokumentiert. Hierzu wurde, ähnlich wie für die Bestimmung der Kolonisierungsraten im FAEN-Fruchtfolgeversuch beschrieben (s. 2.13.1), für jeden Halmbasisabschnitt einzeln der prozentuale Anteil der kolonisierten Halmsegmente an der Gesamtanzahl der Pflanzen jeder Variante bestimmt. Eine weitere Bonitur der Halmbasis wurde zum Zeitpunkt der Totreife (BBCH 92) durchgeführt.

\subsection{In vitro-Pathogenitätstests mit Fusarium-Arten an Weizen}

Der In vitro-Pathogenitätstest sollte die Aggressivität verschiedener Fusarium-Arten auf nährstoffarmem Agar untersuchen, wenn als Nährstoffquelle lediglich Wirtspflanzenkeimlinge zugegen sind. 
Für $24 \mathrm{~h}$ vorgekeimte Weizenkeimlinge wurden dafür auf SNA im Quadrat angeordnet. Anschließend wurde von sieben Tage alten Fusarium-Isolaten aus der Kolonieperipherie ein $5 \mathrm{~mm}^{2}$ großes Myzelstück gestanzt und in der Mitte des zuvor mit den Weizenkeimlingen bestückten SNA platziert. Pro Fusarium-Art wurden drei Einzelsporisolate herangezogen. Der Versuch wurde in einem biologischen Klimaschrank (Mytron, Heilbad Heiligenstadt) bei einer Temperatur von $22^{\circ} \mathrm{C}$, eine Licht/DunkelPhotoperiode von $16 / 8 \mathrm{~h}$ und $65 \mu \mathrm{mol} \mathrm{s} \mathrm{s}^{-1} \mathrm{~m}^{-2}$ durchgeführt. Dabei erfolgte die Platzierung der Platten innerhalb des Klimaschrankes zufällig. Eine visuelle Bonitur der Symptome erfolgte nach 12 Tagen. Die Versuchsansätze für jede Fusarium-Art beinhalteten neun Wiederholungen.

\subsection{Statistische Auswertung}

\subsubsection{FAEN-Feldversuch}

\section{Charakterisierung der Fusarium-Artenspektren}

\section{Versuchsjahr 2010}

Die im Versuchsjahr 2010 erhobenen Daten über Kolonisierungsraten verschiedener Fusarium-Arten an Halmbasis und Körnern von Weizen wurden mittels Prozentsatzdifferenz unter Annahme der Normalverteilung der Residuen berechnet (Kühnel und Krebs, 2012). Diese Methode wurde gewählt, da die Kolonisierungsraten der einzelnen Fusarium-Arten teilweise sehr gering waren, sodass eine faktorielle Berechnung auf Grund zu geringer Fallzahlen nicht ausgeführt werden konnte. Die statistische Berechnung erfolgte nach folgender Formel:

Prozentsatzdifferenz $(\mathrm{P})$ :

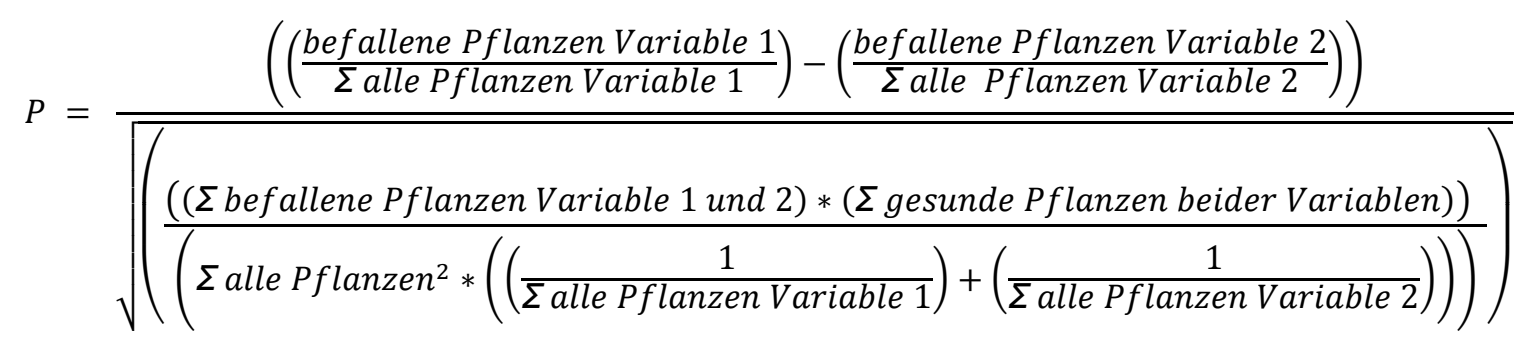


Die Berechnung wurde in dieser Form ebenso für die Fusarium-Artenspektren an den Körnern durchgeführt.

Unterschiedliche Buchstaben kennzeichnen signifikante Unterschiede bei einer Irrtumswahrscheinlichkeit von $5 \%(p<0,05)$, die Symbole ${ }^{\circ},{ }^{*},{ }^{* *}$ und ${ }^{* * *}$ stehen für Irrtumswahrscheinlichkeiten von 10\% $(p<0,1), 5 \%(p<0,05), 1 \%(p<0,01)$ und $0,1 \%$ $(p<0,001)$.

\section{Versuchsjahr 2011}

Im Versuchsjahr 2011 waren die Fallzahlen auf Grund höherer Kolonisierungsraten besonders an der Halmbasis ausreichend für eine statistische Analyse der Daten mittels tTests nach Tamhane-2 bzw. einfaktorieller ANOVA. Die Auswertung erfolgte daher mit dem Statistikprogramm SPSS (IBM, Armonk, New York) unter Annahme der Normalverteilung der Residuen in Form einer einfaktoriellen ANOVA für Gesamtkolonisierungsraten sowie eines t-Tests für die statistische Berechnung der Häufigkeitsverteilungen der Fusarium-Artenspektren. Unterschiedliche Buchstaben kennzeichnen signifikante Unterschiede bei einer Irrtumswahrscheinlichkeit von 5\% $(p<0,05)$, die Symbole ${ }^{\circ},{ }^{*},{ }^{* *}$ und ${ }^{* * *}$ stehen für Irrtumswahrscheinlichkeiten von $10 \%$ $(p<0,1), 5 \%(p<0,05), 1 \%(p<0,01)$ und $0,1 \%(p<0,001)$.

\section{Gesamtvarianzanalyse}

Der Effekt der Versuchsfaktoren sowie alle Interaktionen auf die Gesamtkolonisierungsraten wurden für jedes Jahr einzeln mittels mehrfaktorieller ANOVA bei einer Irrtumswahrscheinlichkeit von 5\% $(p<0,05)$ unter Annahme der Unabhängigkeit aller Proben varianzanalytisch erfasst. Hierzu wurde das Statistikprogramm SAS (Cary/NC, USA) in Kooperation mit Herrn Dr. Kluth (Applied Biostatistics and Consulting) verwendet.

\section{Halmbasisbonitur des FAEN-Feldversuchs 2011}

Die statistische Auswertung der Halmbasisbonitur 2011 erfolgte mit Hilfe des Statistikprogramms SAS (Cary/NC, USA) in Zusammenarbeit mit Herrn Dr. Kluth (Applied Biostatistics and Consulting). Für die Varianzanalyse und adäquate Darstellung der erhobenen Daten wurde zunächst eine nichtparametrische Rangtransformation der erhobenen Boniturdaten durchgeführt (Kluth et al., 2010, Brunner und Munzel, 2002). Hierbei wurde den Boniturwerten der primären Untersuchungseinheit, in diesem Fall jeder Parzelle des Versuchs, ein mittlerer Rang zugeordnet. Mittlere Ränge stellen die relativen 
Effekte der zu untersuchenden abhängigen Variablen auf den Befall innerhalb eines Versuchs untereinander dar. Dabei entsprachen auf einer Skala von 0-1 hohe relative Effekte hohen Boniturnoten, niedrige relative Effekte dementsprechend niedrigen Boniturnoten. Im Anschluss an die 1. Rangtransformation erfolgte eine weitere, wodurch jedem mittleren Rang jeder primären Versuchseinheit (Parzelle) ein erneuter mittlerer Rang vergeben wurde. Mit Hilfe der 2. Rangtransformation konnten die Versuchsfaktoren Vorfrucht, Sorte und Fungizid auf die primäre Versuchseinheit angewendet und mit Hilfe einer einfaktoriellen ANOVA (Irrtumswahrscheinlichkeit 5\% $(p<0,05)$; unterschiedliche Buchstaben desselben Typs kennzeichnen signifikante Unterschiede) die relativen Effekte der Versuchsfaktoren untereinander auf den Befall mit Fusarium an der Halmbasis varianzanalytisch erfasst werden.

\section{DON-Gehalte FAEN-Feldversuch}

Die DON-Gehalte des Ernteguts wurden mit Hilfe des Statistikprogramms SPSS (IBM®) unter Annahme der Normalverteilung der Residuen einem multiplen Mittelwertvergleich nach Tukey unterzogen. Unterschiedliche Buchstaben kennzeichnen signifikante Unterschiede bei einer Irrtumswahrscheinlichkeit von $5 \%(p<0,05)$.

\section{Einfluss der Versuchsfaktoren auf den Ertrag im FAEN-Fruchtfolgeversuch}

Die Varianzanalysen erfolgten wie unter 2.18.1 (Gesamtvarianzanalyse) beschrieben.

\subsubsection{Pathogenitätsversuche an der Ähre in Freiland und Gewächshaus}

Die statistischen Auswertungen erfolgten wie unter 2.18.1 (Versuchsjahr 2011) beschrieben.

\subsubsection{Pathogenitätsversuch an der Halmbasis unter kontrollierten Bedingungen}

Die statistische Auswertung sowohl der Halmbasis- als auch der Trockenstressbonitur erfolgte wie unter 2.18.1 (Halmbasisbonitur des FAEN-Feldversuchs 2011) beschrieben mit Hilfe des Statistikprogramms SAS (Cary/NC, USA) und in Kooperation mit Herrn Dr. Kluth (Applied Biostatistics and Consulting) nichtparametrisch mit Hilfe einer einfaktoriellen ANOVA bei einer Irrtumswahrscheinlichkeit von 5\% $(p<0,05)$. Unterschiedliche Buchstaben kennzeichnen signifikante Unterschiede. 


\section{Reisolation von Fusarium-Arten aus Halmsegmenten}

Die Ergebnisse der Isolation von Fusarium-Arten aus Halmsegmenten im Zuge der Pathogenitätsversuche an der Halmbasis unter kontrollierten Bedingungen wurden mittels multiplen Mittelwertvergleichs nach Tamhane-2 bei einer Irrtumswahrscheinlichkeit von $5 \%(p<0,05)$ und unter vorheriger Testung der Varianzhomogenität statistisch überprüft. Das dafür verwendete Programm war SPSS (IBM®). Unterschiedliche Buchstaben kennzeichnen signifikante Unterschiede.

\subsubsection{In vitro-Pathogenitätstest mit Fusarium-Arten an Weizen}

Die statistische Analyse erfolgte wie unter 2.18.1 (Halmbasisbonitur des FAENFeldversuchs 2011) beschrieben. 


\section{$3 \quad$ Ergebnisse}

\subsection{FAEN-Fruchtfolgeversuch}

\subsubsection{Meteorologische Daten}

\section{Witterung während der Vegetationsperioden 2009/10 und 2010/11 am Standort Torland}

Die Vegetationsperiode von Oktober 2009 bis August 2010 unterlag beträchtlichen Witterungsschwankungen (Abb. 11). Im Jahr 2009 folgte auf einen recht kühlen $\left(-1,3^{\circ} \mathrm{C}\right)^{1}$ und feuchten (+30,5 mm) Oktober ein ebenso niederschlagsreicher $(+34,6 \mathrm{~mm})$, aber sehr warmer November $\left(+3,3^{\circ} \mathrm{C}\right)$. Zum Jahresende fielen die Temperaturen deutlich auf zunächst durchschnittliche $0,5^{\circ} \mathrm{C}$ im Dezember ab, worauf Anfang 2010 ein sehr kalter $\left(-3,5^{\circ} \mathrm{C}\right)$ und vergleichsweise trockener $(-18,1 \mathrm{~mm})$ Januar folgte. Auch im Februar lag die Durchschnittstemperatur mit $-0,6^{\circ} \mathrm{C}$ unter dem Gefrierpunkt. Das Frühjahr war im April zunächst von recht ausgeglichenen Temperaturen geprägt, stellte sich jedoch mit Niederschlagsmengen von $-35,9 \mathrm{~mm}$ als überaus trocken dar. Im Mai wurden dagegen unterdurchschnittliche Temperaturen gemessen $\left(-2,4^{\circ} \mathrm{C}\right)$ und der Vegetationsbeginn verzögerte sich. Im Gegensatz dazu waren die Sommermonate Juni und Juli von Trockenheit $\left(-52,6 \mathrm{~mm}\right.$ im Juni) und extremer Hitze $\left(+3^{\circ} \mathrm{C}\right.$ im Juli) gekennzeichnet, was besonders zum Zeitpunkt der Weizenblüte zu beobachten war. Der August brachte dagegen eine dem langjährigen Mittel entsprechende mittlere Temperatur von $17,0^{\circ} \mathrm{C}$, bei einer sehr hohen Niederschlagsrate von $+73,4 \mathrm{~mm}$. Die relative Luftfeuchte entsprach während der gesamten Vegetationsperiode dem langjährigen Mittel.

\footnotetext{
${ }^{1}$ Temperaturangaben und Niederschlagsdifferenzen beziehen sich auf das langjährige Mittel 19601990 (s. 2.15.2).
} 


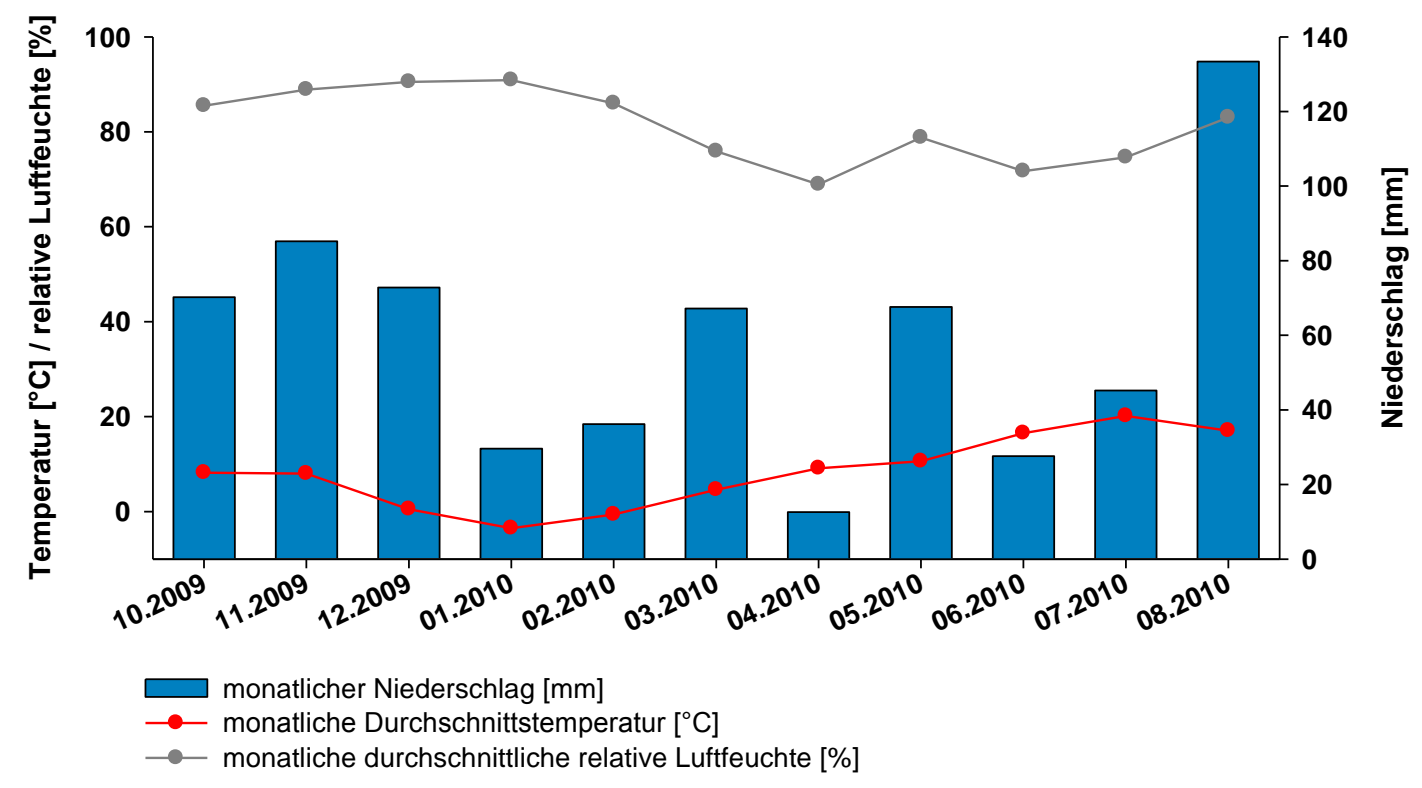

Abb. 11: Durchschnittliche monatliche Temperatur $\left[{ }^{\circ} \mathrm{C}\right]$, durchschnittliche monatliche relative Luftfeuchte [\%] und monatlicher Niederschlag $[\Sigma \mathrm{mm}]$ für die Vegetationsperiode von Oktober 2009 bis August 2010 am Standort Torland.

Die Vegetationsperiode 2010/11 begann mit Temperaturen, die dem langjährigen Mittel entsprachen (Abb. 12). Die Niederschlagsereignisse unterlagen jedoch starken Schwankungen. Nach einem relativ trockenen Oktober des Jahres 2010 (-18,7 mm), folgte ein sehr nasser November $(+74,0 \mathrm{~mm})$. Im Dezember waren deutlich niedrigere Temperaturen $\left(-2,1^{\circ} \mathrm{C}\right) \mathrm{zu}$ verzeichnen und die Niederschlagsmenge verringerte sich gegenüber November um $116 \mathrm{~mm}$. Die Monate Januar bis April waren dagegen im Schnitt $2^{\circ} \mathrm{C} \mathrm{zu}$ warm. Im Frühjahr zwischen März und Mai gingen die Niederschlagssummen zudem um rund $100 \mathrm{~mm}$ zurück, sodass diese Monate von Trockenheit geprägt waren. Besonders der Monat April wies äußerst geringe 5,4 mm Niederschlag auf. Die Temperaturen der Sommermonate Juni und Juli lagen insgesamt im Bereich des langjährigen Mittels. Der Juni war mit leicht erhöhtem Niederschlag $(+10,9 \mathrm{~mm})$ etwas feuchter, der Juli dagegen war mit -25,1 mm deutlich zu trocken. 


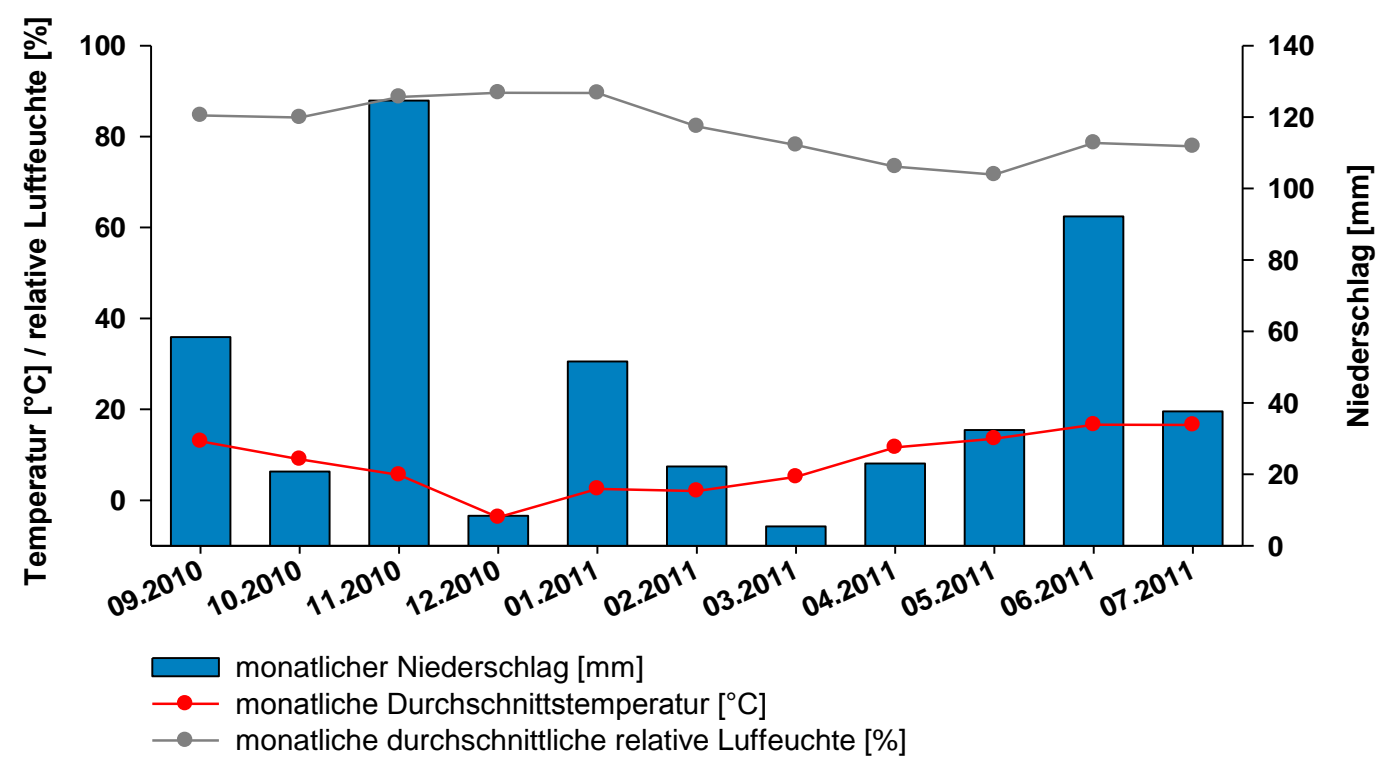

Abb. 12: Durchschnittliche monatliche Temperatur $\left[{ }^{\circ} \mathrm{C}\right]$, durchschnittliche monatliche relative Luftfeuchte [\%] und monatlicher Niederschlag [ $\Sigma \mathrm{mm}]$ für die Vegetationsperiode von September 2010 bis Juli 2011 am Standort Torland.

\subsubsection{Befallshäufigkeit und Befallsstärke der Partiellen Weißährigkeit 2010 und 2011 Torland}

Wie im vorhergehenden Kapitel beschrieben, waren am Standort Torland sowohl das Versuchsjahr 2010, als auch das Versuchsjahr 2011 durch geringe Niederschläge und damit verbundener Trockenheit zum Zeitpunkt der Blüte geprägt. Auf Grund dieser Witterungsverhältnisse waren die Voraussetzungen für eine Infektion der Weizenähren durch Fusarium ungünstig, woraus ein in beiden Jahren sehr niedriger natürlicher Ährenbefall durch die „Partielle Weißährigkeit“, bzw. „Fusarium Head Blight“ (FHB) resultierte. Die Befallsbonituren wurden in beiden Jahren etwa drei Wochen nach der Milchreife durchgeführt. Die geringen Befallshäufigkeiten und die damit einhergehenden niedrigen Befallsstärken reichten sowohl 2010 als auch 2011 nicht aus, um etwaige Einflüsse von Vorfrucht, Sorte oder Blattfungizidapplikation zu quantifizieren bzw. statistisch zu verrechnen und werden somit hier nicht dargestellt.

\subsubsection{Deoxynivalenolgehalte des FAEN-Fruchtfolgeversuchs am Standort Torland 2010 und 2011}

Aus dem niedrigen Befall mit FHB in den Jahren 2010 und 2011 am Standort Torland resultierte eine ebenso niedrige Belastung des Ernteguts mit Deoxynivalenol (DON). Lediglich nach Vorfrucht Mais konnten sowohl 2010 als auch 2011 DON-Kontaminationen gemessen werden (Abb. 13). Dabei zeigte sich für das Jahr 2010 in jeder der vier 
Varianten „Centrum (resistent gegenüber Ährenfusarium), behandelt“, „Ritmo (anfällig gegenüber Ährenfusarium), behandelt“, „Centrum, unbehandelt“ und „Ritmo, unbehandelt“ eine Belastung mit DON. Zwischen den Varianten schwankten die DON-Gehalte jedoch stark, was auf den Einfluss der Sorte sowie des Fungizids bzw. deren Kombination in den verschiedenen Varianten zurückzuführen war. Die Variante „Ritmo, unbehandelt“ wies mit durchschnittlich $1.177 \mu \mathrm{g} / \mathrm{kg}$ Mehl den signifikant höchsten Gehalt an DON auf. Dieser war im Schnitt mehr als doppelt so hoch wie die Gehalte der Varianten „Ritmo, behandelt“ mit $538 \mu \mathrm{g} / \mathrm{kg}$ und „Centrum, unbehandelt" mit $492 \mu \mathrm{g} / \mathrm{kg}$ sowie 7,5-fach höher als der DON-Gehalt von $154 \mu \mathrm{g} / \mathrm{kg}$ Mehl in der Variante "Centrum, behandelt“. Einzelne Proben der Variante „Ritmo, unbehandelt“ überschritten die zulässige Höchstmenge von DON im Erntegut von $1.250 \mu \mathrm{g} / \mathrm{kg}$ (nach EU-Verordnung (EG) Nr. 856/2005). Im Versuchsjahr 2011 enthielten nur das Erntegut der Varianten mit der anfälligen Sorte „Ritmo“ nachweisbare DON-Gehalte, die mit 132 („Ritmo, behandelt“) und $133 \mu \mathrm{g} / \mathrm{kg}$ DON („Ritmo, unbehandelt“) signifikant geringer waren, als die DON-Gehalte der entsprechenden Varianten im Versuchsjahr 2010.

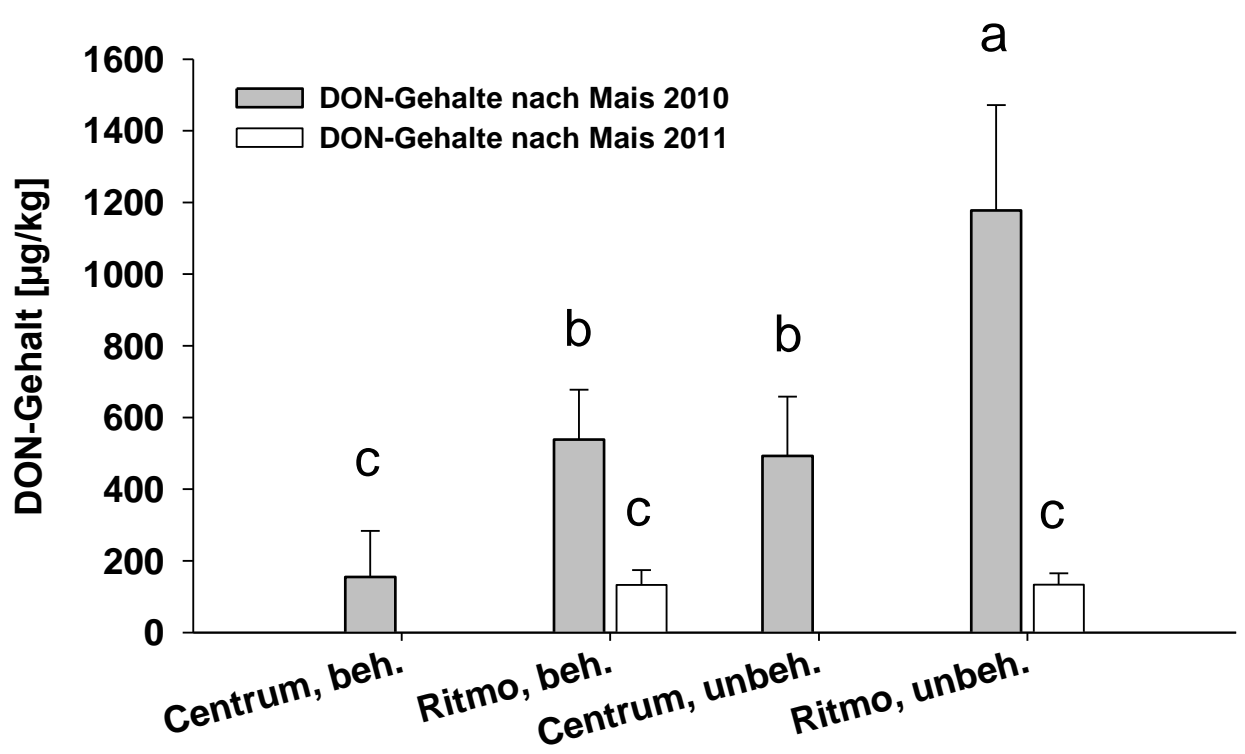

Abb. 13: Analyse der DON-Gehalte $[\mu \mathrm{g} / \mathrm{kg}]$ in Vollkornmehl der vier Versuchsvarianten „Centrum, behandelt", „Ritmo, behandelt“, „Centrum, unbehandelt" sowie „Ritmo, unbehandelt" nach Vorfrucht Mais der Versuchsjahre 2010 und 2011 am Standort Torland. Unterschiedliche Buchstaben kennzeichnen signifikante Unterschiede zwischen den DONGehalten der Varianten eines Versuchsjahres sowie zwischen den Versuchsjahren $(n=4$, multipler Mittelwertvergleich nach Tukey mit $p<0,05$ ). 


\subsubsection{Einfluss der Versuchsfaktoren auf den Ertrag des FAEN-Fruchtfolge- versuchs am Standort Torland 2010 und 2011}

Tabelle 19 stellt die varianzanalytische Berechnung des Einflusses der Effekte der drei Versuchsfaktoren Vorfrucht, Sorte und Fungizid sowie die daraus resultierenden Interaktionskomponenten dar. Die Berechnung wurde zunächst getrennt nach Jahren durchgeführt. In Tabelle 20 sind diese Effekte zusätzlich über beide Jahre aufgeführt. Tabelle 19 stellt den in beiden Jahren auftretenden Vorfruchteffekt auf den Ertrag deutlich heraus. Dieser war 2010 und 2011 signifikant. Darüber hinaus hatte im Versuchsjahr 2010 die Fungizidbehandlung einen signifikanten Einfluss auf den Ertrag, wogegen alle anderen Effekte sowohl 2010 als auch 2011 nicht signifikant waren.

Tab. 19: Varianzanalyse der Erträge im FAEN-Fruchtfolgeversuch der Jahre 2010 und 2011 am Standort Torland. Dargestellt sind die Effekte der drei Versuchsfaktoren Vorfrucht, Sorte und Fungizid sowie die daraus resultierenden Interaktionskomponenten getrennt nach Jahren (statistische Berechnung mittels mehrfaktorieller ANOVA, Signifikanz der Effekte bei $p<0,05)$.

\begin{tabular}{lccccc}
\hline Jahr & Effekt & $\begin{array}{c}\text { Freiheitsgrade } \\
\text { (Zähler) }\end{array}$ & $\begin{array}{c}\text { Freiheitsgrade } \\
\text { (Nenner) }\end{array}$ & F-Wert & p-Wert \\
\hline 2010 & Vorfrucht & 3 & 80 & 142,34 & $<0,0001$ \\
2011 & Vorfrucht & 3 & 48 & 59,86 & $<0,0001$ \\
2010 & Sorte & 1 & 80 & 1,22 & 0,2721 \\
2011 & Sorte & 1 & 48 & 3,17 & 0,0812 \\
2010 & Fungizid & 1 & 80 & 28,08 & $<0,0001$ \\
2011 & Fungizid & 1 & 48 & 0,10 & 0,7526 \\
2010 & Vorfrucht ${ }^{*}$ Sorte & 3 & 80 & 0,32 & 0,8077 \\
2011 & Vorfrucht ${ }^{*}$ Sorte & 3 & 48 & 0,46 & 0,7142 \\
2010 & Vorfrucht ${ }^{\star}$ Fungizid & 3 & 80 & 0,75 & 0,5238 \\
2011 & Vorfrucht*Fungizid & 3 & 48 & 0,50 & 0,6812 \\
2010 & Vorfrucht ${ }^{\star}$ Sorte*Fungizid & 3 & 80 & 0,38 & 0,7708 \\
2011 & Vorfrucht ${ }^{*}$ Sorte*Fungizid & 3 & 48 & 0,77 & 0,5185 \\
2010 & Sorte*Fungizid & 1 & 80 & 3,16 & 0,0795 \\
2011 & Sorte*Fungizid & 1 & 48 & 0,07 & 0,7925 \\
\hline
\end{tabular}


Wie in Tabelle 20 zu erkennen, war der Jahreseffekt auf den Ertrag im Mittel über alle anderen Effekte signifikant. Auch die Vorfrucht hatte im Mittel über beide Jahre, beide Sorten und beide Fungizidstufen einen signifikanten Einfluss auf den Ertrag. Der Sortenund der Fungizideffekt waren ebenfalls im Mittel über beide Jahre und über alle Vorfrüchte signifikant, wobei beide Effekte jahresabhängig waren. Alle anderen Faktoren sowie Interaktionen zwischen diesen waren nicht signifikant.

Tab. 20: Varianzanalyse der Erträge im FAEN-Fruchtfolgeversuch der Jahre 2010 und 2011 am Standort Torland. Dargestellt sind die Effekte der vier Versuchsfaktoren Jahr, Vorfrucht, Sorte und Fungizid sowie die daraus resultierenden Interaktionskomponenten über beide Jahre (statistische Berechnung mittels mehrfaktorieller ANOVA, Signifikanz der Effekte bei $p<0,05)$.

\begin{tabular}{|c|c|c|c|c|}
\hline Effekt & $\begin{array}{c}\text { Freiheitsgrade } \\
\text { (Zähler) }\end{array}$ & $\begin{array}{c}\text { Freiheitsgrade } \\
\text { (Nenner) }\end{array}$ & F-Wert & $p-$ Wert \\
\hline Jahr & 1 & 128 & 43,30 & $<0,0001$ \\
\hline Vorfrucht & 3 & 128 & 124,69 & $<0,0001$ \\
\hline Sorte & 1 & 128 & 4,80 & 0,0304 \\
\hline Fungizid & 1 & 128 & 11,38 & 0,0010 \\
\hline Jahr*Vorfrucht & 3 & 128 & 61,96 & $<0,0001$ \\
\hline Jahr Sorte & 1 & 128 & 0,79 & 0,3752 \\
\hline Jahr*Fungizid & 1 & 128 & 7,99 & 0,0054 \\
\hline Vorfrucht*Sorte & 3 & 128 & 0,10 & 0,9596 \\
\hline Vorfrucht ${ }^{\star}$ Fungizid & 3 & 128 & 0,88 & 0,4509 \\
\hline Sorte*Fungizid & 1 & 128 & 1,62 & 0,2049 \\
\hline Jahr*Vorfrucht ${ }^{\star}$ Sorte & 3 & 128 & 0,81 & 0,4912 \\
\hline Jahr*Vorfrucht*Fungizid & 3 & 128 & 0,38 & 0,7649 \\
\hline Jahr ${ }^{\star}$ Vorfrucht*Sorte*Fungizid & 3 & 128 & 0,40 & 0,7798 \\
\hline Jahr ${ }^{\star}$ Sorte*Fungizid & 1 & 128 & 0,65 & 0,4208 \\
\hline Vorfrucht*Sorte*Fungizid & 3 & 128 & 1,00 & 0,3969 \\
\hline
\end{tabular}

Signifikante Effekte der einzelnen Versuchsfaktoren auf den Ertrag wurden nachfolgend grafisch dargestellt.

2010 konnte gegenüber 2011 im Mittel über alle anderen Effekte ein signifikanter Mehrertrag von 6,1 dt/ha verzeichnet werden (Abb. 14). 


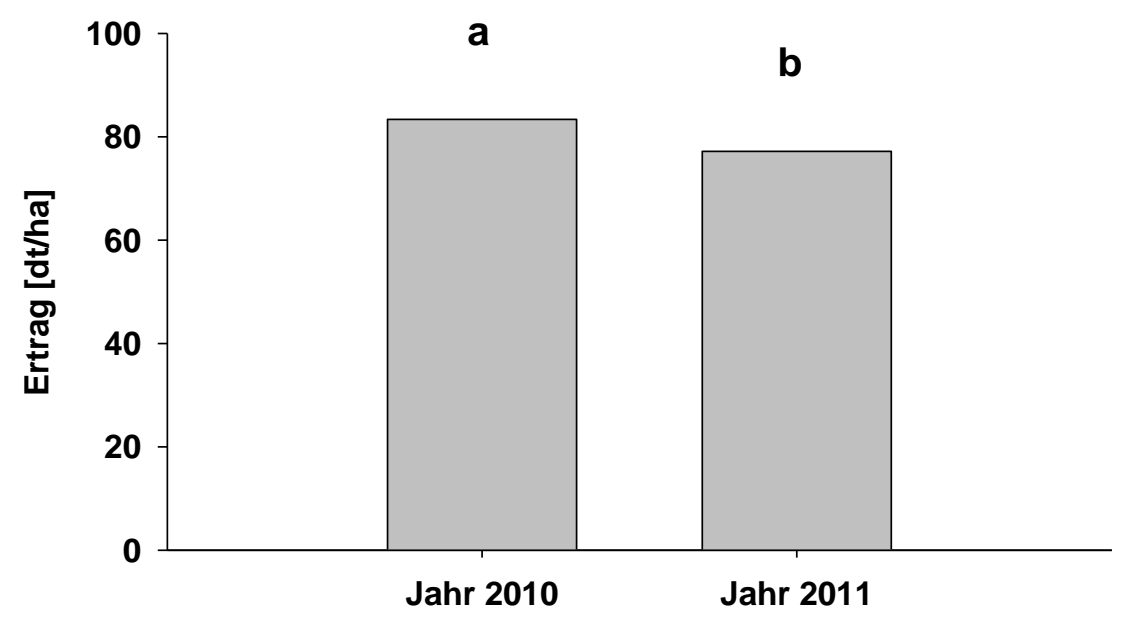

Abb. 14: Jahresbedingter Effekt auf die Erträge im FAEN-Fruchtfolgeversuch der Jahre 2010 und 2011 am Standort Torland. Vorfrüchte: Winterweizen, Mais, Zuckerrübe und Ölrettich. Fungizidstufen: „behandelt mit Prothioconazol“ und „unbehandelt“. Sorten: „Ritmo“" und "Centrum“. Unterschiedliche Buchstaben kennzeichnen signifikante Ertragsunterschiede ( $n=192$ für 2010, $n=128$ für 2011, statistische Berechnung mittels ANOVA, Signifikanz der Effekte bei $p<0,05)$.

Signifikante Mehrerträge ergaben sich ebenfalls über beide Jahre in der resistenten Sorte „Centrum“ (Abb. 15)

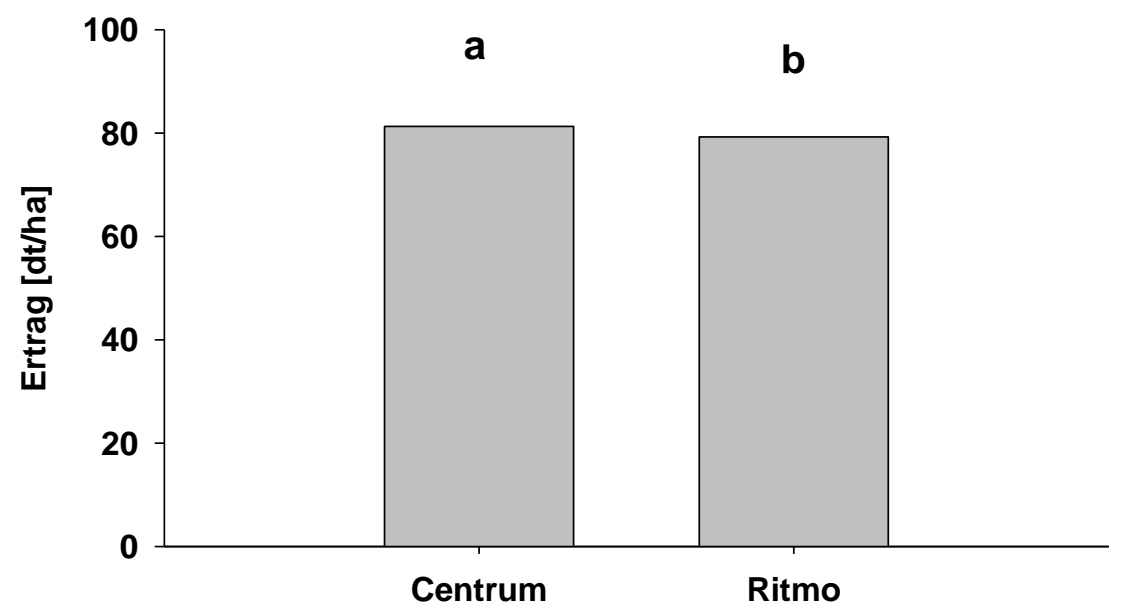

Abb. 15: Sorteneffekt über beide Jahre auf die Erträge im FAEN-Fruchtfolgeversuch der Jahre 2010 und 2011 am Standort Torland. Vorfrüchte: Winterweizen, Mais, Zuckerrübe und Ölrettich. Fungizidstufen: „behandelt mit Prothioconazol“ und „unbehandelt“. Unterschiedliche Buchstaben kennzeichnen signifikante Ertragsunterschiede zwischen den Sorten ( $n=160$, statistische Berechnung mittels ANOVA, Signifikanz der Effekte bei $\mathrm{p}<0,05)$.

Abbildung 16 und Abbildung 17 machen die Jahresabhängigkeit des Vorfrucht- sowie des Fungizideffektes deutlich. Während nach Winterweizen, Zuckerrübe und Ölrettich keine 
signifikanten Ertragsunterschiede zwischen 2010 und 2011 zu beobachten waren, erbrachte der Weizen nach Vorfrucht Mais einen signifikant höheren Ertrag im Jahr 2010, als im Jahr 2011. Die vorfruchtabhängigen Ertragsunterschiede sind auf einen signifikant höheren Mehrertrag von 28 dt/ha nach Mais im Jahr 2010 zurückzuführen. Ein signifikant höherer Ertrag in den behandelten Varianten war im Jahr 2010 zu erkennen. Dieser war im Jahr 2011 ebenfalls vorhanden, jedoch sehr schwach ausgeprägt und somit nicht signifikant.

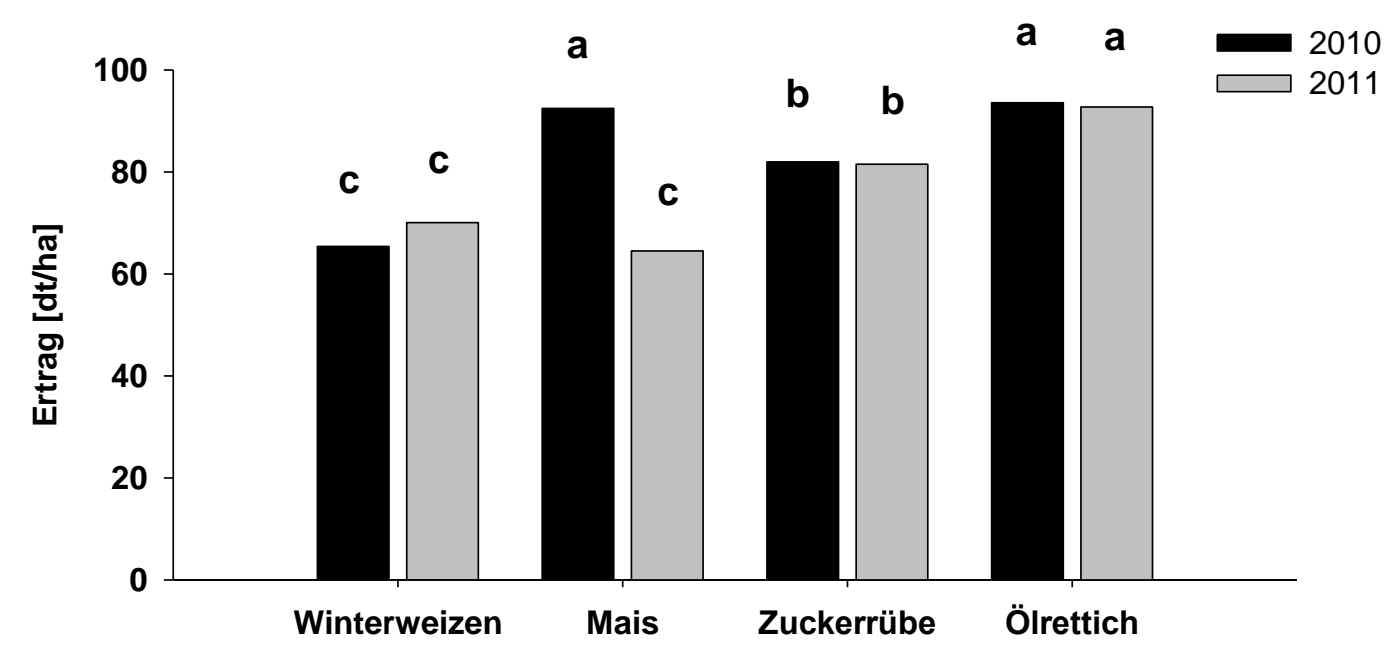

Abb. 16: Vorfruchteffekte auf die Erträge im FAEN-Fruchtfolgeversuch in Abhängigkeit des Versuchsjahres am Standort Torland. Sorten: „Centrum" und „Ritmo“, Fungizidstufen: „behandelt mit Prothioconazol“ und „unbehandelt". Unterschiedliche Buchstaben kennzeichnen signifikante Ertragsunterschiede zwischen den Jahren $(n=24$ für 2010, $n=16$ für 2011, statistische Berechnung mittels ANOVA, Signifikanz der Effekte bei $p<0,05$ ). 


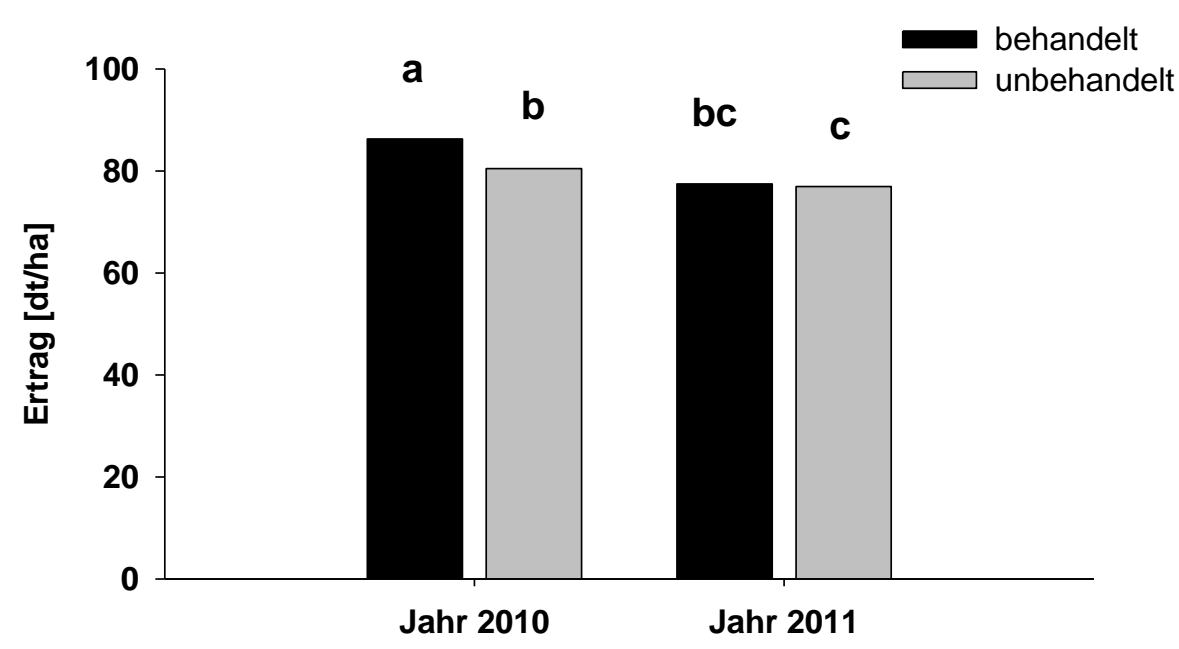

Abb. 17: Fungizideffekte auf die Erträge im FAEN-Fruchtfolgeversuch in Abhängigkeit des Versuchsjahres am Standort Torland. Vorfrüchte: Winterweizen, Mais, Zuckerrübe und Ölrettich. Sorten: „Centrum“ und „Ritmo“. Unterschiedliche Buchstaben kennzeichnen signifikante Ertragsunterschiede zwischen den Fungizidstufen über beide Jahre ( $n=96$ für 2010, $n=64$ für 2011, statistische Berechnung mittels ANOVA, Signifikanz der Effekte bei $p<0,05)$.

Korrelationen der Kolonisierungsraten von Halmbasis und Körnern der beiden Versuchsjahre mit den Erträgen in Abhängigkeit von den einzelnen Versuchsfaktoren konnten nicht festgestellt werden.

\subsubsection{Halmbasisbonitur zu BBCH 75-77 am Standort Torland 2011}

Die für die Charakterisierung der Fusarium-Artenspektren an der Halmbasis am Standort Torland gezogenen Weizenpflanzen (s. 2.13.1) wurden unmittelbar nach der Probenahme einer visuellen Bonitur auf „Fusarium Foot Rot“-Symptome unterzogen. Zur grafischen Darstellung der statistischen Auswertung des Einflusses der Sorte und der Fungizidbehandlung in Abhängigkeit der vier Vorfüchte auf den symptomatischen Befall durch Fusarium-Arten an der Halmbasis, wurden die rangtransformierten Boniturergebnisse in Abbildung 18 als Box-Plots in Form von relativen Effekten der Versuchsparameter auf den Befall aufgeführt.

Es konnte gezeigt werden, dass nach Winterweizen (A), Mais (B), und Ölrettich (D), die anfällige Sorte „Ritmo" einen signifikant höheren Befall aufwies, als die resistente Sorte "Centrum“, wobei nach allen drei Vorfrüchten kein Einfluss der Blattfungizidbehandlung beobachtet werden konnte. Zuckerrübe (C) zeigte jedoch ein gegenteiliges Bild. Hier konnte kein Sorteneffekt, jedoch zumindest bei „Ritmo“ ein signifikanter Effekt der Blattfungizidbehandlung ermittelt werden. Der Effekt der Vorfrucht wurde der Übersicht halber nicht dargestellt, jedoch wies der Weizen nach Ölrettich insgesamt die stärksten 
Symptome auf gefolgt von den Vorfrüchten Weizen und Mais. Der niedrigste Befall konnte nach Zuckerrübe festgestellt werden.
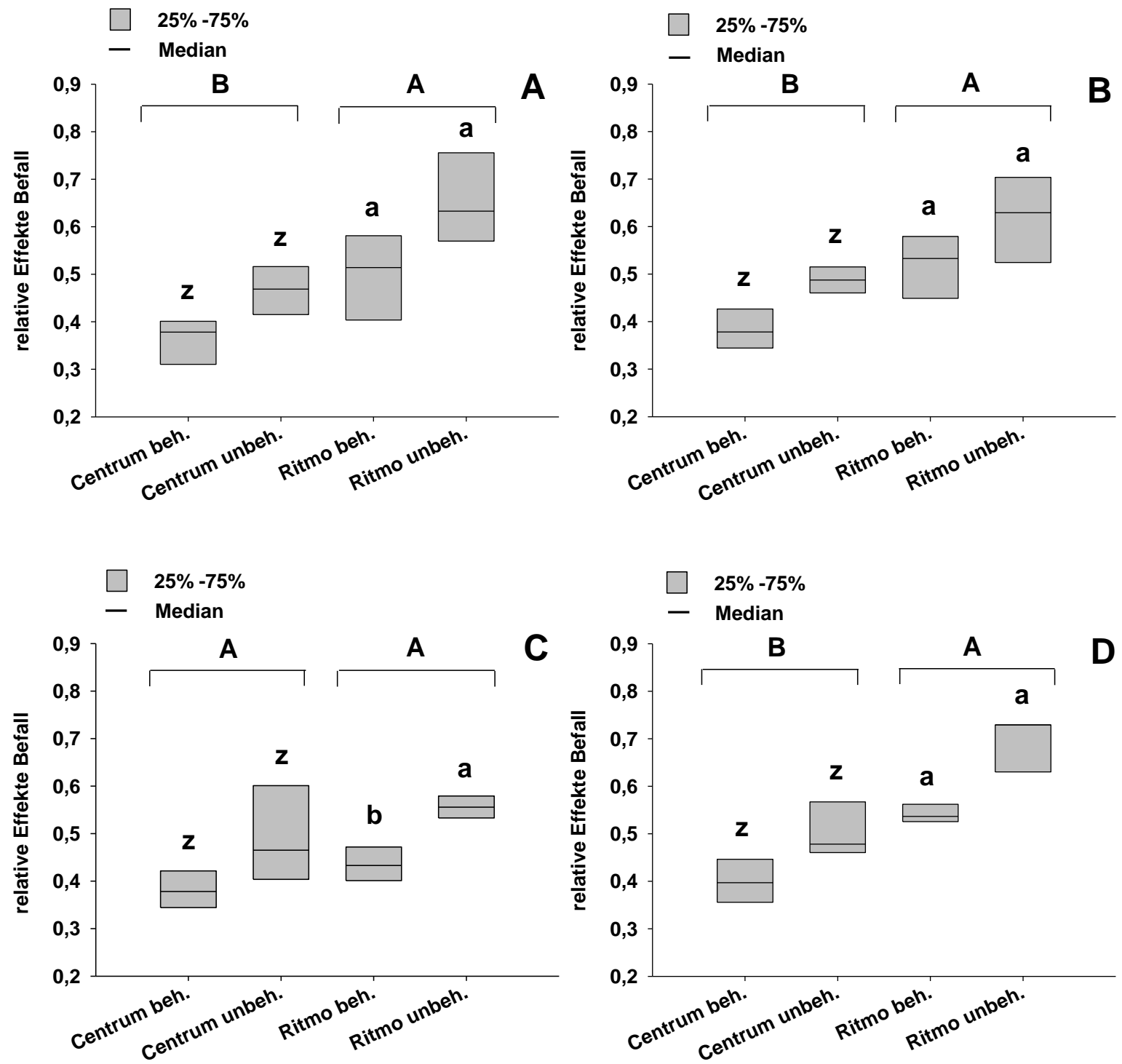

Abb. 18: Darstellung des Befalls der Halmbasis mit Fusarium am Standort Torland 2011 zu BBCH 75-77 in den Varianten „Centrum behandelt“, „Ritmo behandelt“, „Centrum unbehandelt" und „Ritmo unbehandelt" nach den Vorfrüchten A) Winterweizen, B) Mais, C) Zuckerrübe und D) Ölrettich. Buchstaben über den Klammern beziehen sich auf den Effekt der Sorte, Buchstaben über den Box-Plots auf den Effekt der Blattfungizidbehandlung. Unterschiedliche Buchstaben desselben Typs kennzeichnen signifikante Unterschiede zwischen den relativen Effekten $(n=60$, statistische Berechnung nichtparametrisch mittels mehrfaktorieller ANOVA mit $p<0,05)$. 


\subsection{Fusarium-Artenspektren an Halmbasis und Körnern von Weizen}

\subsubsection{Einfluss der Versuchsparameter auf das Fusarium-Artenspektrum an der Halmbasis 2010}

Im Versuchsjahr 2010 zeigten sich moderate sowie vereinzelt hohe Kolonisierungsraten von Fusarium an der Halmbasis von Weizen, hervorgerufen durch die Arten F. culmorum, F. equiseti, F. graminearum, F. oxysporum und F. tricinctum. Deren Bedeutung für die Kolonisierung der Halmbasis in Abhängigkeit von den unter 3.2 genannten Versuchsparametern „Probenahmezeitpunkt" und "Vorfrucht" wurde in diesem Kapitel für das Jahr 2010 herausgestellt.

\section{Einfluss des Probenahmezeitpunktes}

Die Probenahme an der Halmbasis erfolgte im Versuchsjahr 2010 in der Versuchsvariante „Ritmo unbehandelt" zu den Zeitpunkten BBCH 37-39, BBCH 61-65 und BBCH 71-75. Da im Verlauf dieses Kapitels die Effekte des Versuchsparameters „Vorfrucht“ für 2010 bzw. „Vorfrucht", „Sorte“ und „Blattfungizidbehandlung“ für 2011 auf einzelne Fusarium-Arten sowie deren Kolonisierungsraten an der Halmbasis zu jedem Probenahmezeitpunkt gesondert betrachtet wurden, werden hier lediglich die Gesamtkolonisierungsraten, d.h., der prozentuale Anteil durch Fusarium kolonisierter Pflanzen nach den Vorfü̈chten Winterweizen, Mais, Zuckerrübe und Ölrettich zu den drei Probenahmezeitpunkten exemplarisch behandelt, um insbesondere den Kolonisierungsverlauf in Abhängigkeit von der Zeit darzustellen.

Aus Abbildung 19 wird deutlich, dass zum Teil beträchtliche Schwankungen hinsichtlich der Kolonisierungsraten zu den verschiedenen Probenahmezeitpunkten besonders nach den Vorfü̈chten Winterweizen und Mais zu verzeichnen waren. Nach den beiden genannten Vorfü̈chten war die Gesamtkolonisierungsrate zu BBCH 37-39 signifikant höher als zu BBCH 61-65. Zumindest nach Winterweizen glich sie sich zu BBCH 71-75 wieder an den Wert des ersten Probenahmezeitpunktes an, nach Mais war lediglich ein nicht signifikanter Anstieg zu BBCH 71-75 zu verzeichnen. Nach Ölrettich war dagegen sogar ein kontinuierlicher Rückgang der Kolonisierungsraten über die drei Zeitpunkte zu verzeichnen, welcher in signifikant niedrigeren Kolonisierungsraten zu BBCH 71-75 im Vergleich zu BBCH 37-39 resultierte. Auffällig war besonders der starke Anstieg der Kolonisierungsrate nach Zuckerrübe zu BBCH $71-75$ auf $66,7 \%$. 


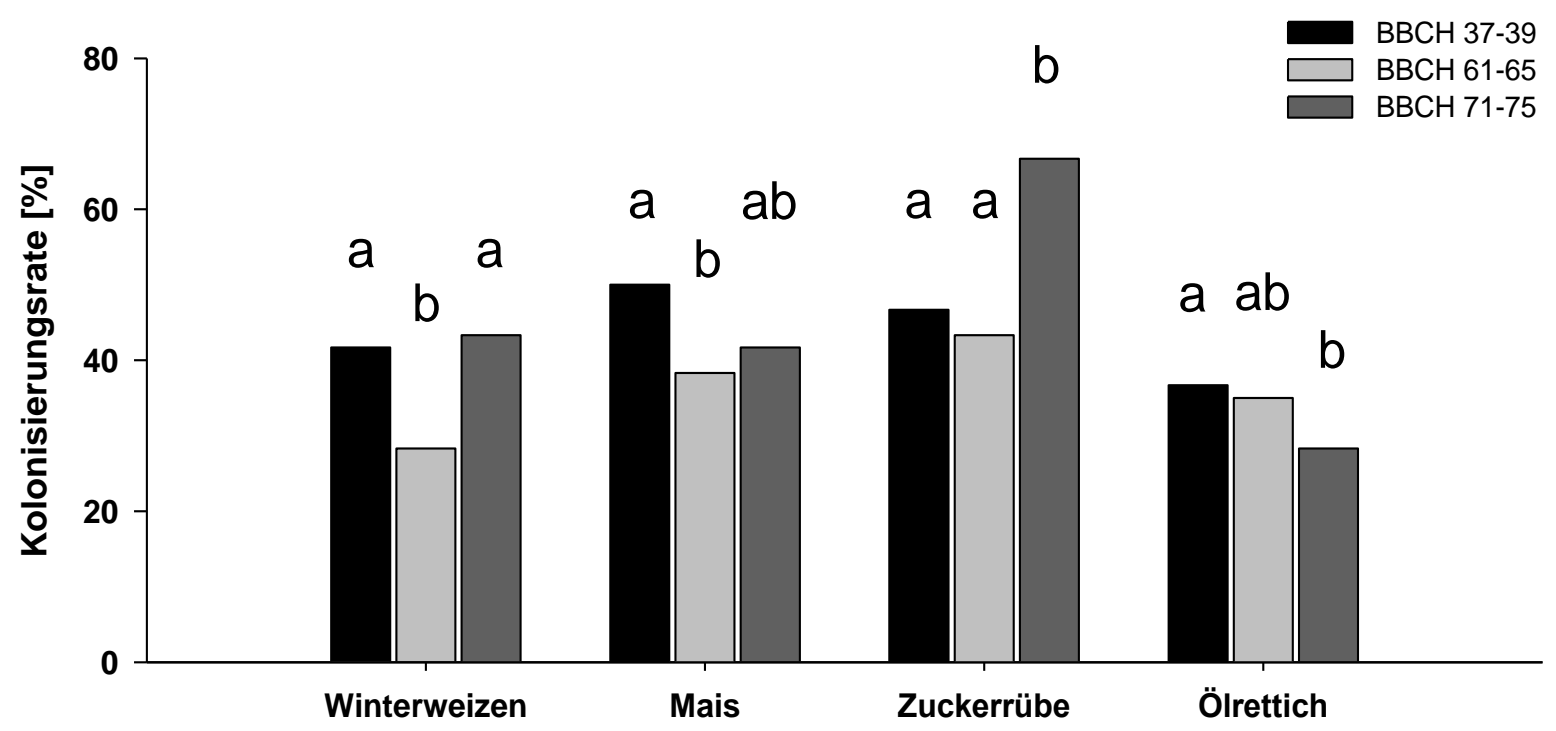

Abb. 19: Einfluss des Probenahmezeitpunktes auf die Gesamtkolonisierungsraten von Fusarium [\%] an der Halmbasis von Winterweizen nach den vier Vorfrüchten Winterweizen, Mais, Zuckerrübe und Ölrettich zu BBCH 37-39, BBCH 61-65 und BBCH 71-75 des Versuchsjahres 2010 am Standort Torland. Sorten: „Centrum“ und „Ritmo“, Fungizidstufen: „behandelt mit Prothioconazol“ und „unbehandelt“. Es wurden die Gesamtkolonisierungsraten der verschiedenen Probenahmezeitpunkte innerhalb jeder Vorfruchtvariante untereinander statistisch überprüft. Unterschiedliche Buchstaben kennzeichnen signifikante Unterschiede zwischen den Gesamtkolonisierungsraten innerhalb der Vorfruchtvarianten $(n=60$, statistische Berechnung mittels Prozentsatzdifferenz mit $p<0,05$ ).

\section{Einfluss der Vorfrucht}

Zu BBCH 37-39 stellten sich die Gesamtkolonisierungsraten nach den vier Vorfrüchten Winterweizen, Mais, Zuckerrübe und Ölrettich als relativ ähnlich dar. Dennoch konnte nach Mais mit $51,6 \%$ die höchste Kolonisierungsrate ermittelt werden, welche sich signifikant von der nach Ölrettich mit 36,7\% unterschied (Abb. 20). 


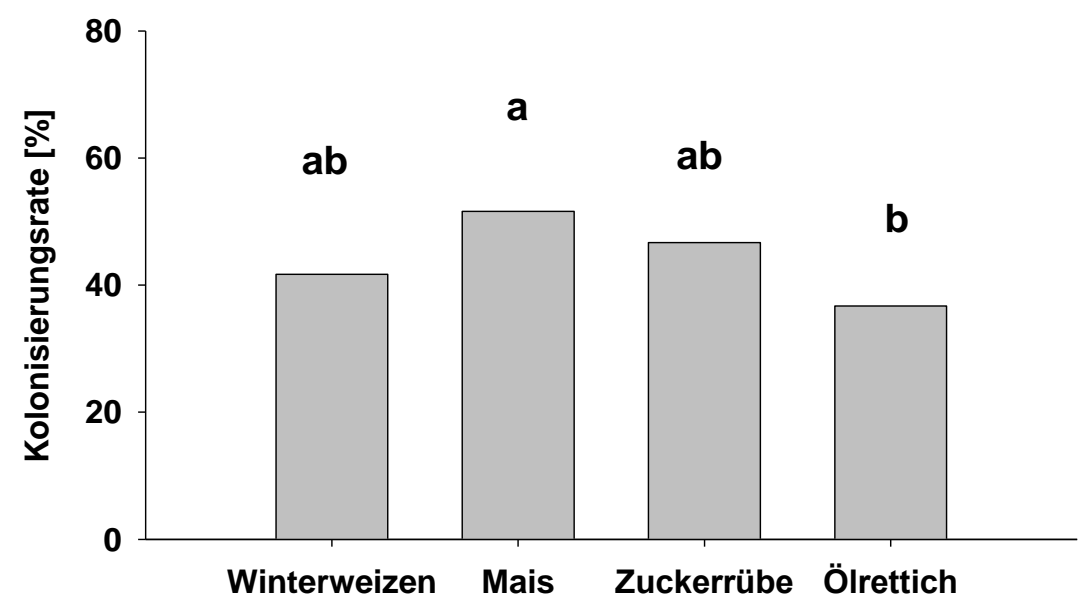

Abb. 20: Einfluss der Vorfrucht auf die Gesamtkolonisierungsraten von Fusarium [\%] an der Halmbasis von Winterweizen nach den vier Vorfrüchten Winterweizen, Mais, Zuckerrübe und Ölrettich zu BBCH 37-39 des Versuchsjahres 2010 am Standort Torland. Sorte: „Ritmo“, Fungizidstufe: „unbehandelt“. Unterschiedliche Buchstaben kennzeichnen signifikante Unterschiede zwischen den Gesamtkolonisierungsraten $(n=60$, statistische Berechnung mittels Prozent-satzdifferenz mit $p<0,05$ ).

Abbildung 21 gibt Aufschluss über das Artenspektrum und die Kolonisierungsraten der verschiedenen Fusarium-Arten nach jeder Vorfrucht. So waren nach Winterweizen $(A)$ hauptsächlich die mit signifikant erhöhten Kolonisierungsraten von 23,3\% einhergehenden Arten $F$. culmorum und $F$. tricinctum für die Kolonisierung der Halmbasis verantwortlich, während die Arten F. avenaceum, F. equiseti und F.graminearum nur eine untergeordnete Rolle spielten. F. oxysporum trat nicht auf. Nach Mais (B) zeigten sich die Kolonisierungsraten etwas ausgeglichener. Hier wiesen die Arten F.avenaceum, F. culmorum, F. equiseti und F. tricinctum signifikant erhöhte Kolonisierungsraten zwischen $8,3 \%$ und $15,0 \%$ auf. Nach Zuckerrübe (C) waren die Arten F. equiseti und F. tricinctum mit den signifikant höchsten Kolonisierungsraten von $16,7 \%$ und $23,3 \%$ von Bedeutung. Neben diesen beiden Arten wiesen allerdings auch F. avenaceum und F. culmorum erhöhte Raten auf. Nach Ölrettich (D) waren die Kolonisierungsraten auf dem insgesamt niedrigsten Niveau. Signifikant erhöhte Kolonisierungsraten wiesen die Arten F. equiseti (13,3\%), F. tricinctum (10,0\%), F. graminearum $(8,3 \%)$ und $F$. culmorum $(6,7 \%)$ auf. 

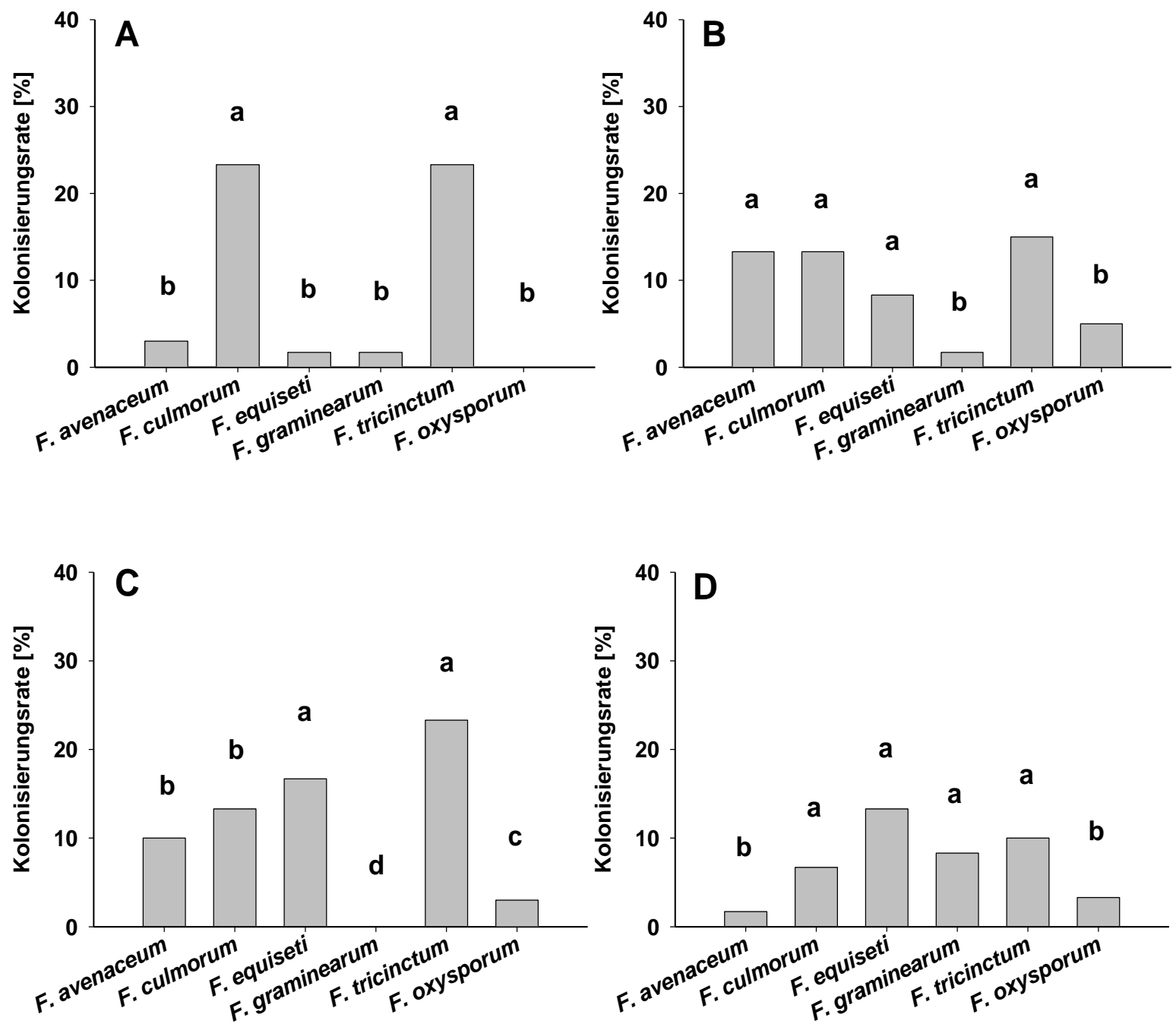

Abb. 21: Einfluss der Vorfrucht auf Fusarium-Artenspektrum und Kolonisierungsraten der einzelnen Arten [\%] an der Halmbasis von Winterweizen nach den vier Vorfrüchten A) Winterweizen, B) Mais, C) Zuckerrübe und D) Ölrettich zu BBCH 37-39 des Versuchsjahres 2010 am Standort Torland. Sorte: „Ritmo“, Fungizidstufe: „unbehandelt“. Unterschiedliche Buchstaben kennzeichnen signifikante Unterschiede zwischen den Kolonisierungsraten $(n=60$, statistische Berechnung mittels Prozentsatzdifferenz mit $p<0,05)$.

Die Gesamtkolonisierungsraten zu BBCH 61-65 (Abb. 22) unterschieden sich in ihrer Höhe teilweise signifikant gegenüber $\mathrm{BBCH}$ 37-39. Zwar unterschieden sich die Kolonisierungsraten nach Mais, Zuckerrübe und Ölrettich signifikant von denen nach Weizen, jedoch nicht signifikant voneinander. Dennoch wiesen die untersuchten Halmbasen nach Zuckerrübe mit $43,3 \%$ die höchste Kolonisierungsrate auf. 


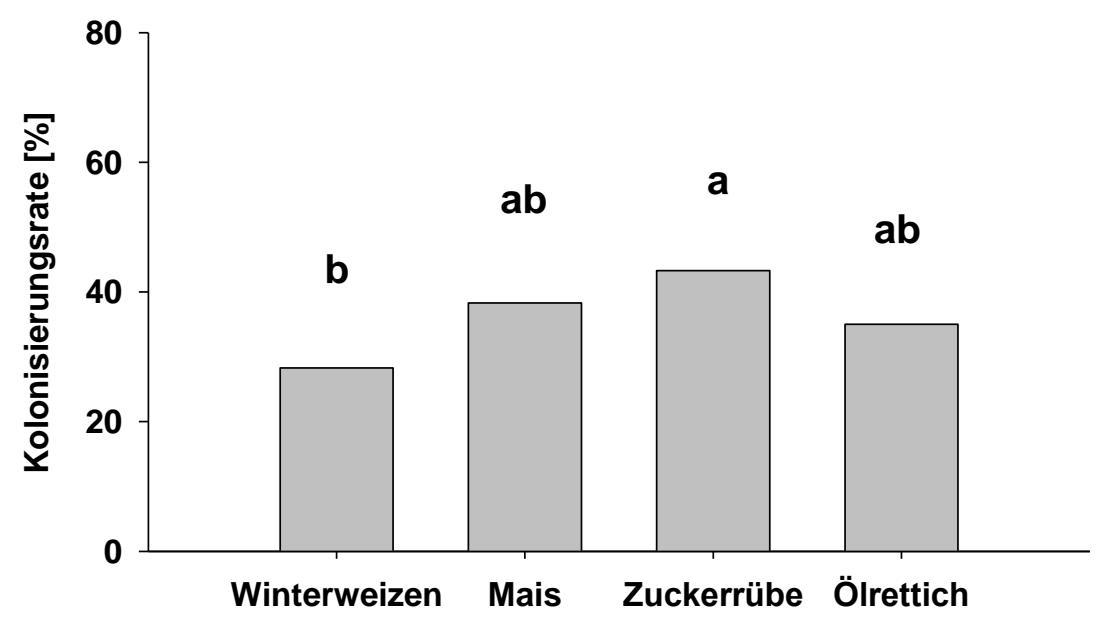

Abb. 22: Einfluss der Vorfrucht auf die Gesamtkolonisierungsraten von Fusarium [\%] an der Halmbasis von Winterweizen nach den vier Vorfrüchten Winterweizen, Mais, Zuckerrübe und Ölrettich zu BBCH 61-65 des Versuchsjahres 2010 am Standort Torland. Sorte: „Ritmo“, Fungizidstufe: „unbehandelt“. Unterschiedliche Buchstaben kennzeichnen signifikante Unterschiede zwischen den Gesamtkolonisierungsraten $(n=60$, statistische Berechnung mittels Prozentsatzdifferenz mit $p<0,05$ ).

Auch zu BBCH 61-65 waren in Bezug auf die Artenspektren und ihre Kolonisierungsraten nach den vier Vorfrüchten mit Raten zwischen $10,0 \%$ und $30,0 \%$ besonders die Arten F. tricinctum, F. culmorum und F. equiseti von Bedeutung, während alle anderen Arten relativ selten isoliert wurden (Abb. 23). 

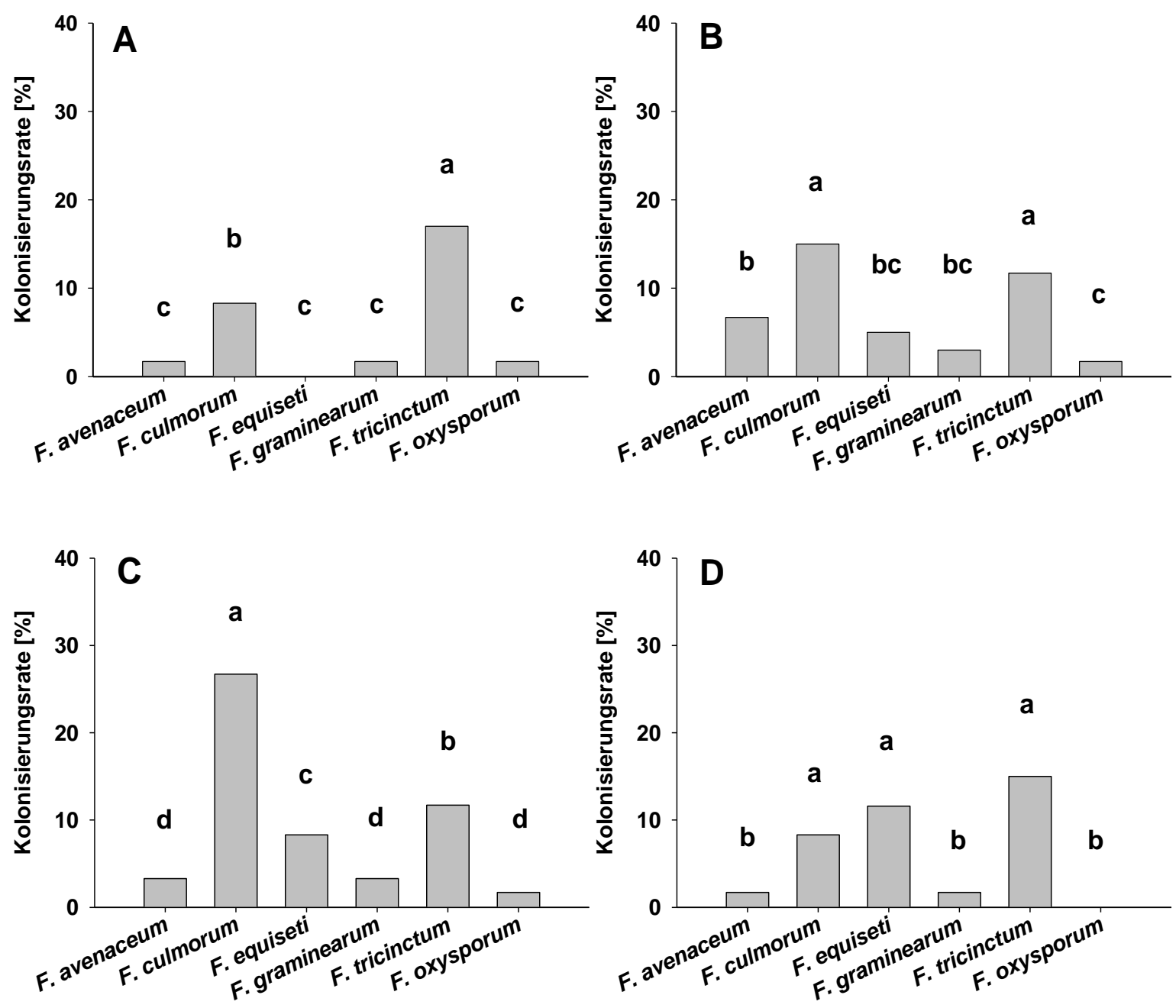

Abb. 23: Einfluss der Vorfrucht auf Fusarium-Artenspektrum und Kolonisierungsraten der einzelnen Arten [\%] an der Halmbasis von Winterweizen nach den vier Vorfrüchten A) Winterweizen, B) Mais, C) Zuckerrübe und D) Ölrettich zu BBCH 61-65 des Versuchsjahres 2010 am Standort Torland. Sorte: „Ritmo“, Fungizidstufe: „unbehandelt“. Unterschiedliche Buchstaben kennzeichnen signifikante Unterschiede zwischen den Kolonisierungsraten $(n=60$, statistische Berechnung mittels Prozentsatzdifferenz mit $\mathrm{p}<0,05)$.

Ein deutlicher Anstieg der Gesamtkolonisierungsrate konnte zu BBCH 71-75 nach Vorfrucht Zuckerrübe verzeichnet werden (Abb. 24). Die Kolonisierungsrate betrug 66,7\% und war somit signifikant von denen nach Winterweizen (43,3\%), Mais $(41,7 \%)$ und Ölrettich (28,3\%) verschieden, wobei sich die Kolonisierungsrate nach Ölrettich ebenfalls signifikant von Winterweizen und Mais unterschied. 


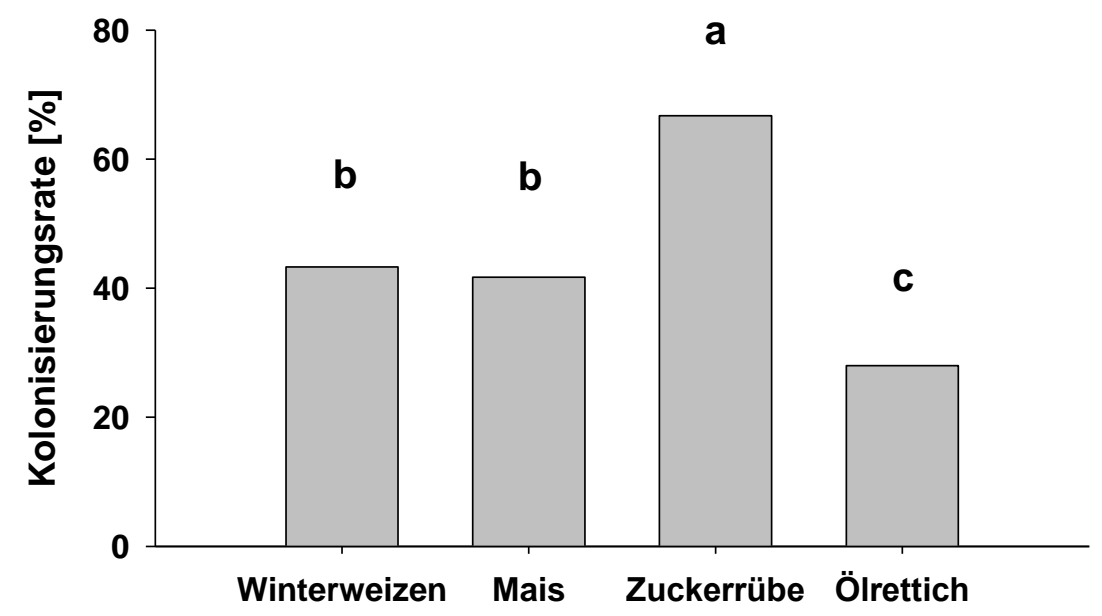

Abb. 24: Einfluss der Vorfrucht auf die Gesamtkolonisierungsraten von Fusarium [\%] an der Halmbasis von Winterweizen nach den vier Vorfrüchten Winterweizen, Mais, Zuckerrübe und Ölrettich zu BBCH 71-75 des Versuchsjahres 2010 am Standort Torland. Sorte: „Ritmo“, Fungizidstufe: „unbehandelt“. Unterschiedliche Buchstaben kennzeichnen signifikante Unterschiede zwischen den Gesamtkolonisierungsraten $(n=60$, statistische Berechnung mittels Prozentsatzdifferenz mit $p<0,05$ ).

Ebenso wie zu BBCH 69 waren zu BBCH 71-75 die Arten F. culmorum, F. equiseti und F. tricinctum nach allen vier Vorfrüchten die Hauptkolonisierer der Halmbasis (Abb. 25). Dennoch ergaben sich Unterschiede in der Höhe der Kolonisierungsraten dieser Arten und daher auch für ihre Bedeutung nach den Vorfrüchten. Nach Winterweizen $(A)$ traten F. culmorum und F. tricinctum mit Kolonisierungsraten von $23,3 \%$ und $18,3 \%$ am signifikant häufigsten auf, gefolgt von F. equiseti mit einer erheblich geringeren Kolonisierungsrate von 5,0\%. Alle anderen Arten traten nicht auf. Nach Mais (B) zeigte sich ein im Hinblick auf $F$. culmorum und $F$. equiseti umgekehrtes Bild, sodass $F$. equiseti zusammen mit $F$. tricinctum mit Kolonisierungsraten von $21,7 \%$ und 18,3\% am häufigsten isoliert werden konnte. Nach Zuckerrübe traten zu diesem Probenahmezeitpunkt verursacht durch die Arten F. culmorum, F. equiseti und F. tricinctum die mit Abstand höchsten Raten zwischen 28,3\% für $F$. equiseti und 35,0\% für $F$. culmorum auf. Dies stellte im Vergleich zu allen anderen Vorfrüchten an allen drei Probenahmezeitpunkten die höchste Besiedlung der Halmbasis mit Fusarium dar. Auch nach Ölrettich (D) waren F. culmorum, F. equiseti und F. tricinctum am signifikant häufigsten vertreten 

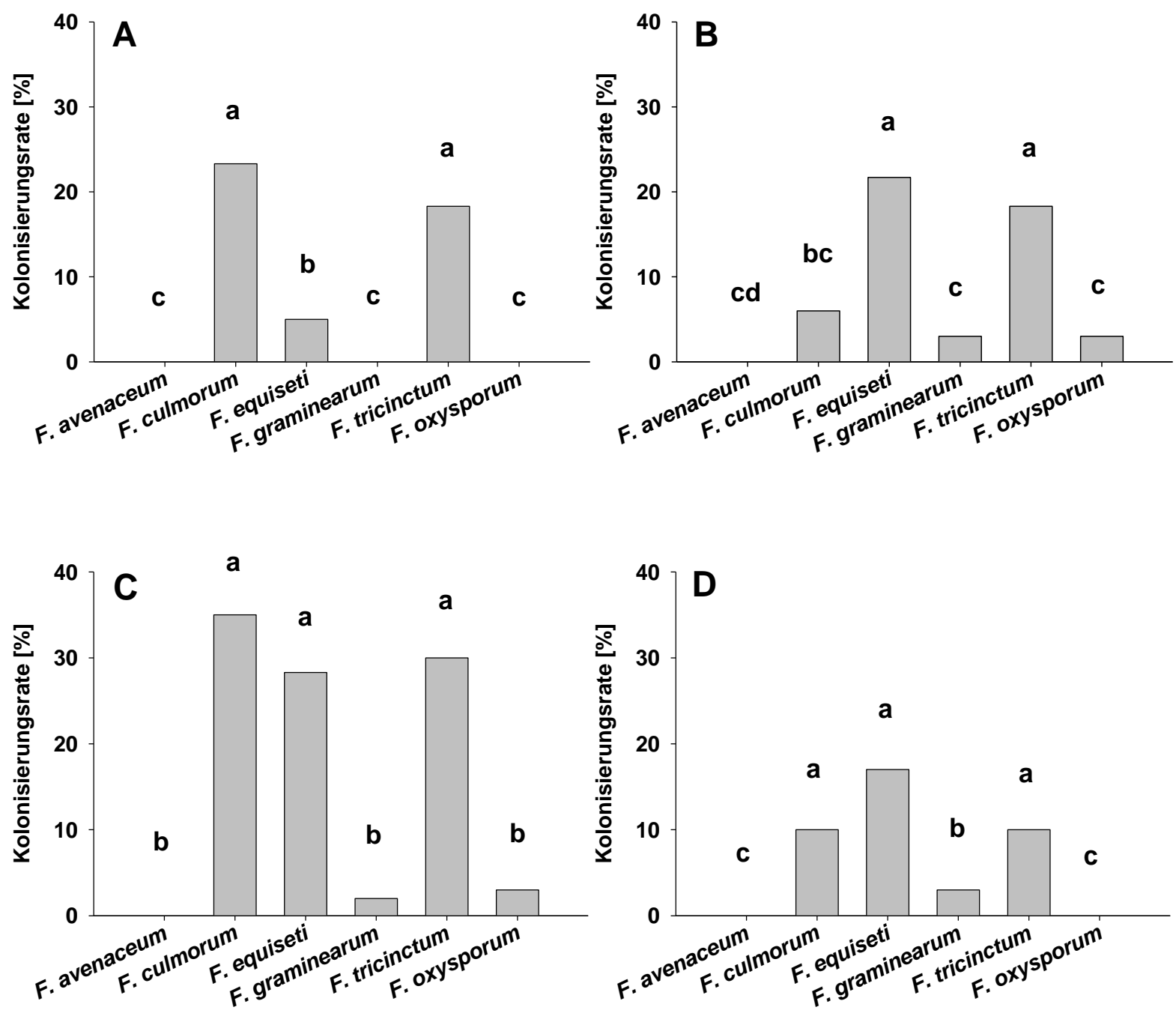

Abb. 25: Einfluss der Vorfrucht auf Fusarium-Artenspektrum und Kolonisierungsraten der einzelnen Arten [\%] an der Halmbasis von Winterweizen nach den vier Vorfrüchten A) Winterweizen, B) Mais, C) Zuckerrübe und D) Ölrettich zu BBCH 71-75 des Versuchsjahres 2010 am Standort Torland. Sorte: „Ritmo“, Fungizidstufe: „unbehandelt“. Unterschiedliche Buchstaben kennzeichnen signifikante Unterschiede zwischen den Kolonisierungsraten $(n=60$, statistische Berechnung mittels Prozentsatzdifferenz mit $p<0,05)$.

In Bezug auf die Kolonisierungsraten an der Halmbasis von Weizen zu BBCH 37-39, $\mathrm{BBCH}$ 61-65 und $\mathrm{BBCH} 71-75$ in Abhängigkeit von der Vorfrucht waren große Unterschiede zu erkennen, die sich besonders deutlich in der signifikanten Zunahme der Gesamtkolonisierungsrate nach Zuckerrübe zu BBCH 71-75 manifestierten. Insgesamt konnten die Arten $F$. culmorum, $F$. equiseti und $F$. tricinctum als wichtigste und am häufigsten auftretende Halmbasiskolonisierer identifiziert werden. 


\subsubsection{Einfluss der Versuchsparameter auf das Fusarium-Artenspektrum an Körnern 2010}

\section{Einfluss der Vorfrucht}

Das Vorkommen von Fusarium an Körnern des Ernteguts zu BBCH 92 im Versuchsjahr 2010 war im Vergleich zur Kolonisierung der Halmbasen weitaus geringer (Abb. 26). Eine maximale Gesamtkolonisierungsrate von 26,4\% konnte nach Mais festgestellt werden. Signifikant niedrigere Raten wurden nach Zuckerrübe mit 20,1\% und Ölrettich mit 20,9\% ermittelt. Nach Winterweizen konnten nur 24 Isolate von den Körnern gewonnen werden, sodass die Gesamtkolonisierungsrate hier bei 3,0\% lag.

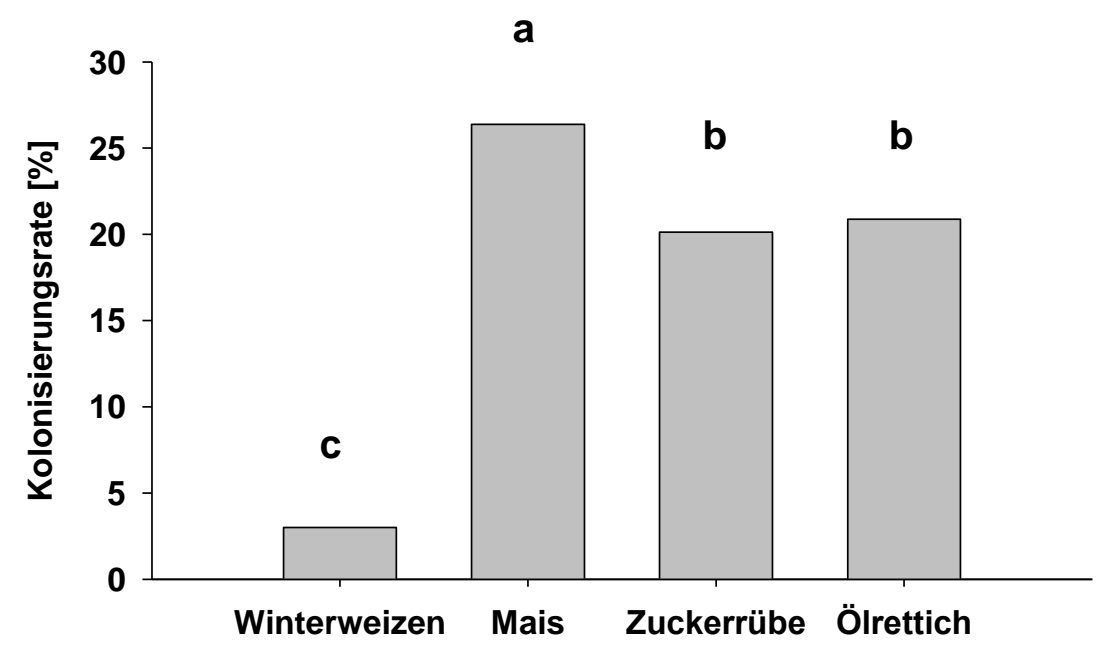

Abb. 26: Einfluss der Vorfrucht auf Gesamtkolonisierungsraten [\%] an Körnern von Winterweizen nach den vier Vorfrüchten Winterweizen, Mais, Zuckerrübe und Ölrettich zu BBCH 92 des Versuchsjahres 2010 am Standort Torland. Sorten: „Centrum“ und „Ritmo“, Fungizidstufen: „behandelt mit Prothioconazol“ und „unbehandelt“. Unterschiedliche Buchstaben kennzeichnen signifikante Unterschiede zwischen den Gesamtkolonisierungsraten nach den vier Vorfrüchten $(n=800$, statistische Berechnung mittels Prozentsatzdifferenz mit $p<0,05$ ).

Dies spiegelte sich auch in den in Abbildung 27 angegebenen Artenspektren nach den vier Vorfüchten wider. Nach Winterweizen (A) kamen ausschließlich die Arten F. culmorum, F. equiseti, F. poae und F. tricinctum vor, jedoch nur in unbedeutendem Ausmaß, da die signifikant höchste Kolonisierungsrate $F$. tricinctum mit lediglich 1,9\% erreichte. Dagegen konnten nach Mais (B) viele verschiedene Arten isoliert werden. Besonders häufig traten F.graminearum mit $10,3 \%$ und F.poae mit $9,5 \%$ Kolonisierungsrate auf. Mit einer signifikant niedrigeren Kolonisierungsrate von 4,5\% konnte F. tricinctum als dritthäufigste Art identifiziert werden. 
Nach Zuckerrübe (C) und Ölrettich (D) waren nur die Arten F. tricinctum mit Kolonisierungsraten von $9,6 \%$ und $12,9 \%$ sowie $F$. poae mit einer Kolonisierung von 9,6\% (nach Zuckerrübe) und 5,0\% (nach Ölrettich) von Bedeutung.
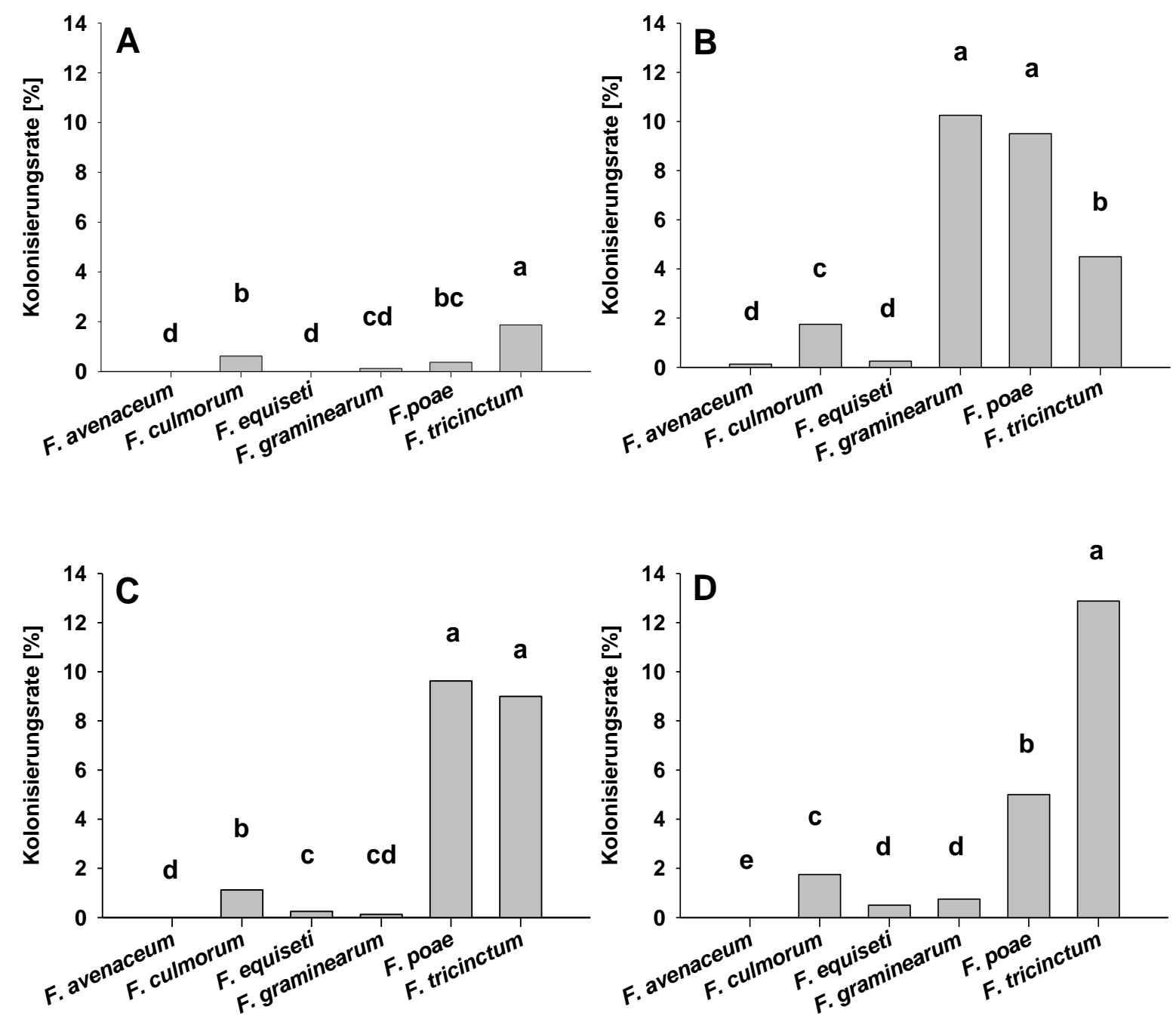

Abb. 27: Einfluss der Vorfrucht auf Fusarium-Artenspektrum und Kolonisierungsraten der einzelnen Arten [\%] an Körnern von Winterweizen nach den vier Vorfrüchten A) Winterweizen, B) Mais, C) Zuckerrübe und D) Ölrettich zu BBCH 92 des Versuchsjahres 2010 am Standort Torland. Sorten: „Centrum“ und „Ritmo“, Fungizidstufen: „behandelt mit Prothioconazol“ und „unbehandelt". Unterschiedliche Buchstaben kennzeichnen signifikante Unterschiede zwischen den Gesamtkolonisierungsraten nach den vier Vorfrüchten ( $n=800$, statistische Berechnung mittels Prozentsatzdifferenz mit $p<0,05)$.

\section{Einfluss der Sorte}

Auf die Gesamtkolonisierungsrate der Körner besaß die hochanfällige Sorte „Ritmo“ erheblichen Einfluss. So waren Körner der Sorte „Ritmo“ mit 26,1\% fast dreimal häufiger mit Fusarium kolonisiert, als Körner der Sorte „Centrum“ mit 9,3\%. Dieser signifikante Unterschied ist in Abbildung 28 aufgeführt. 


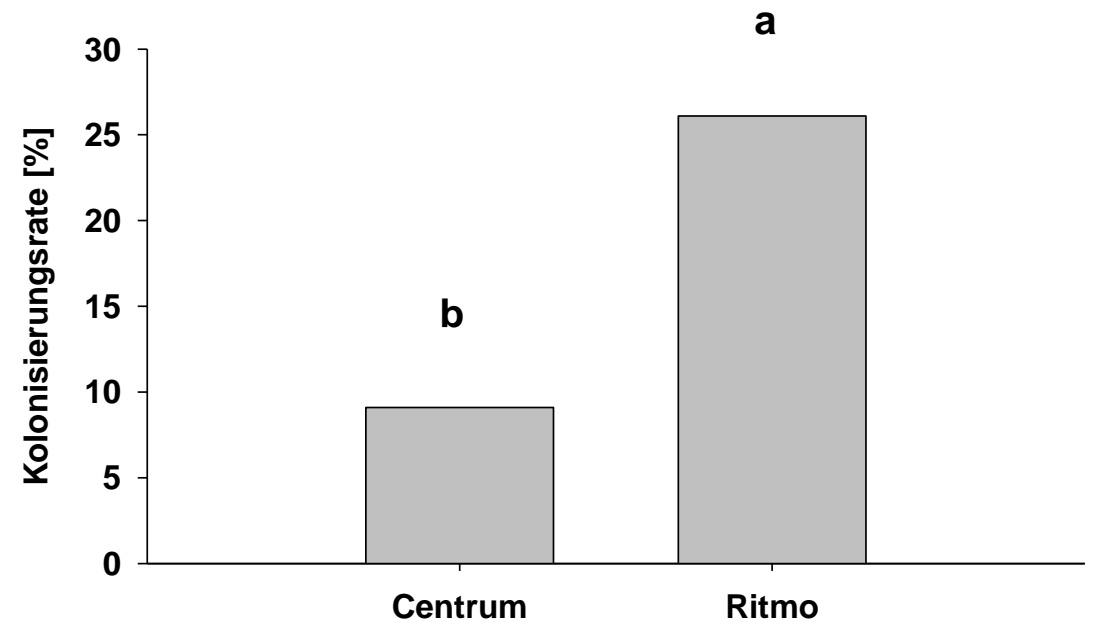

Abb. 28: Einfluss der Sorte auf Gesamtkolonisierungsraten [\%] an Körnern von Winterweizen der Sorten „Centrum“ und „Ritmo“ zu BBCH 92 des Versuchsjahres 2010 am Standort Torland. Vorfrüchte: Winterweizen, Mais, Zuckerrübe und Ölrettich. Fungizidstufen: „behandelt mit Prothioconazol“ und „unbehandelt“. Unterschiedliche Buchstaben kennzeichnen signifikante Unterschiede zwischen den Gesamtkolonisierungsraten in den beiden Sorten $(n=1600$, statistische Berechnung mittels Prozentsatzdifferenz mit $p<0,05$ ).

Die signifikante Erhöhung der Kolonisierung war vor allem auf die Arten F.poae und F. tricinctum zurückzuführen, die in der Sorte „Ritmo“ mit $11,6 \%$ und $9,2 \%$ einen signifikant höheren Prozentsatz an Körnern kolonisiert hatten, als dies in der Sorte „Centrum“ der Fall war (Abb. 29). Hier wurden Kolonisierungsraten von 2,6\% für F. poae und $3,1 \%$ für $F$. tricinctum erreicht. Im Vergleich zu diesen beiden Arten spielten die übrigen Arten in beiden Sorten keine Rolle an den Körnern. 

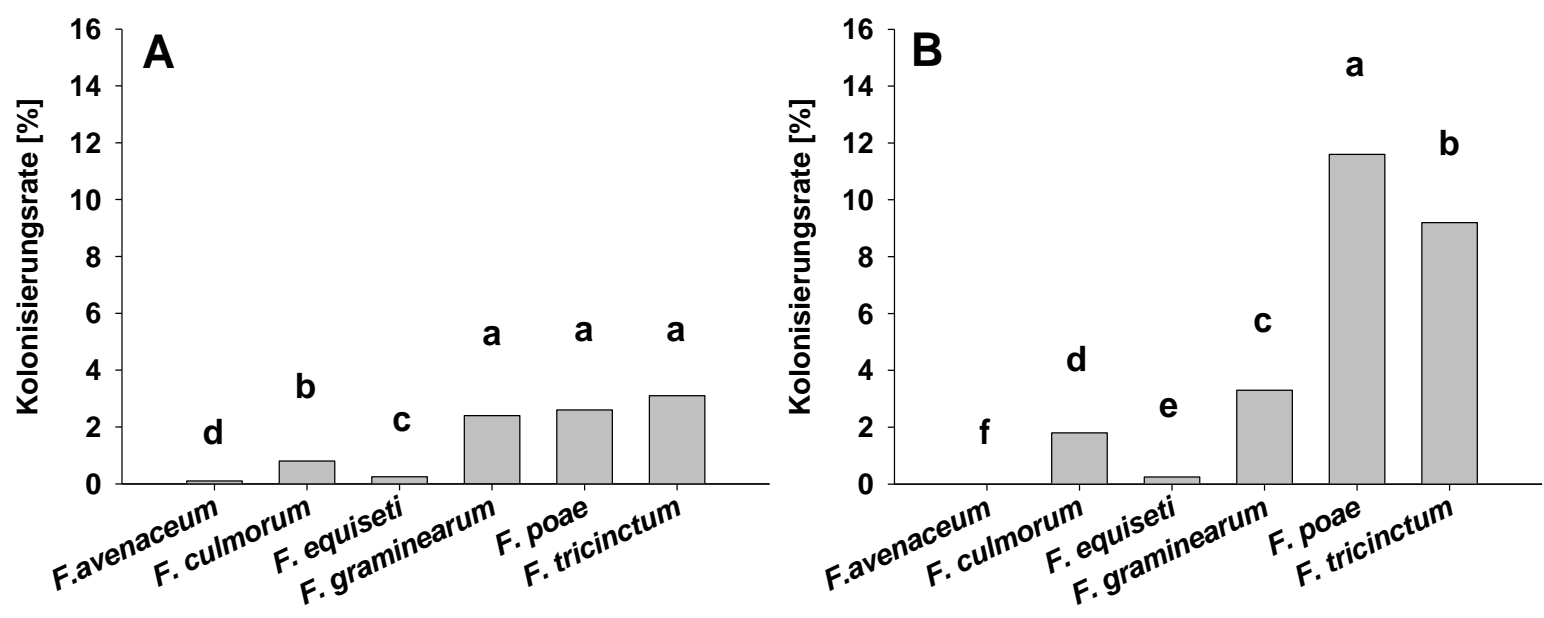

Abb. 29: Einfluss der Sorte auf Fusarium-Artenspektrum und Kolonisierungsraten der einzelnen Arten [\%] an Körnern von Winterweizen der Sorten A) „Centrum“ und B) „Ritmo“ zu BBCH 92 des Versuchsjahres 2010 am Standort Torland. Vorfrüchte: Winterweizen, Mais, Zuckerrübe und Ölrettich. Fungizidstufen: „behandelt mit Prothioconazol“ und „unbehandelt". Unterschiedliche Buchstaben kennzeichnen signifikante Unterschiede zwischen den Kolonisierungsraten einzelner Arten in den beiden Sorten $(n=1600$, statistische Berechnung mittels Prozentsatzdifferenz mit $p<0,05$ ).

\section{Einfluss der Blattfungizidbehandlung}

Im Gegensatz zum deutlichen Sorteneffekt an den Körnern (s.3.2.2) konnte kein signifikanter Effekt der Blattfungizidbehandlung auf die Gesamtkolonisierungsraten der beiden Fungizidstufen „behandelt“ und „unbehandelt“ gezeigt werden (Abb. 30). 


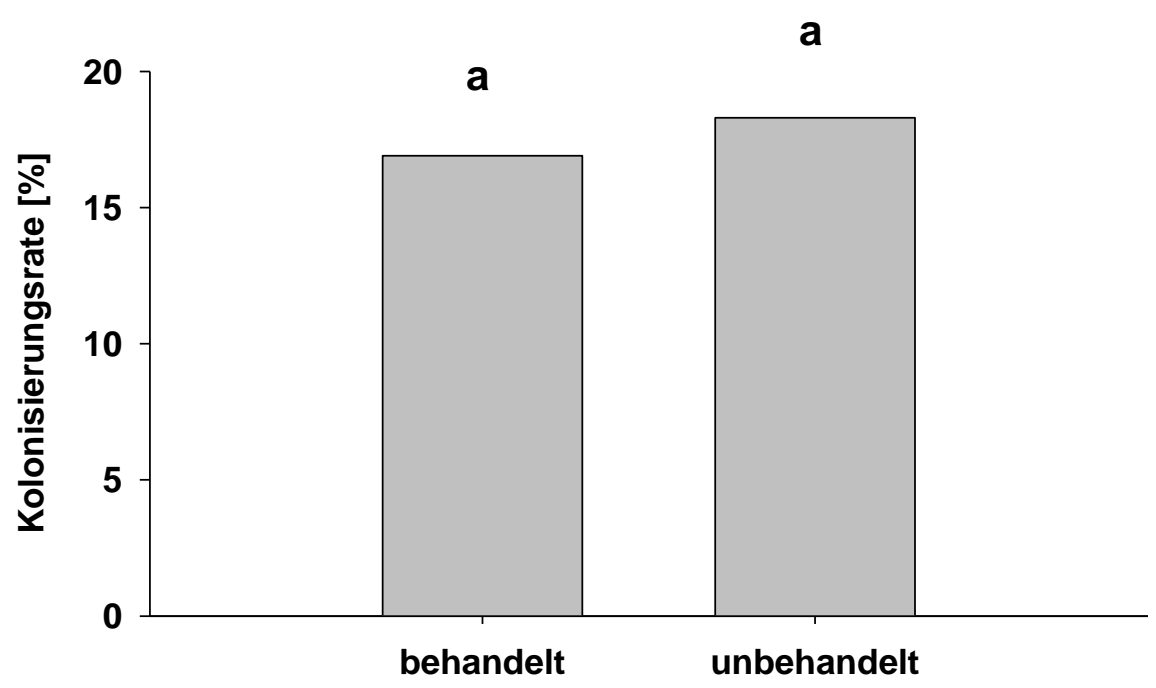

Abb. 30: Einfluss der Blattfungizidbehandlung mit Prothioconazol auf Gesamtkolonisierungsraten [\%] an Körnern von Winterweizen der Fungizidstufen „,behandelt“ und "unbehandelt" zu BBCH 92 des Versuchsjahres 2010 am Standort Torland. Vorfrüchte: Winterweizen, Mais, Zuckerrübe und Ölrettich. Sorten: „Centrum“ und „Ritmo“. Unterschiedliche Buchstaben kennzeichnen signifikante Unterschiede zwischen den Gesamtkolonisierungsraten in den beiden Fungizidstufen $(n=1600$, statistische Berechnung mittels Prozentsatzdifferenz mit $p<0,05$ ).

In beiden Fungizidstufen waren besonders die Arten F. poae mit Kolonisierungsraten von $6,8 \%$ in der behandelten und $7,4 \%$ in der unbehandelten Fungizidstufe sowie $F$. tricinctum mit 7,0\% bzw. 5,3\% anzutreffen (Abb. 31). Die Artenspektren variierten jedoch zwischen den beiden Fungizidstufen. Während an den behandelten Körnern mit 1,7\% nur wenig F. graminearum zu finden war, war der Prozentsatz kolonisierter Körner in der unbehandelten Variante mit $3,8 \%$ nahezu doppelt so hoch, wobei sich wie oben beschrieben der Prozentsatz für $F$. tricinctum verringerte. 

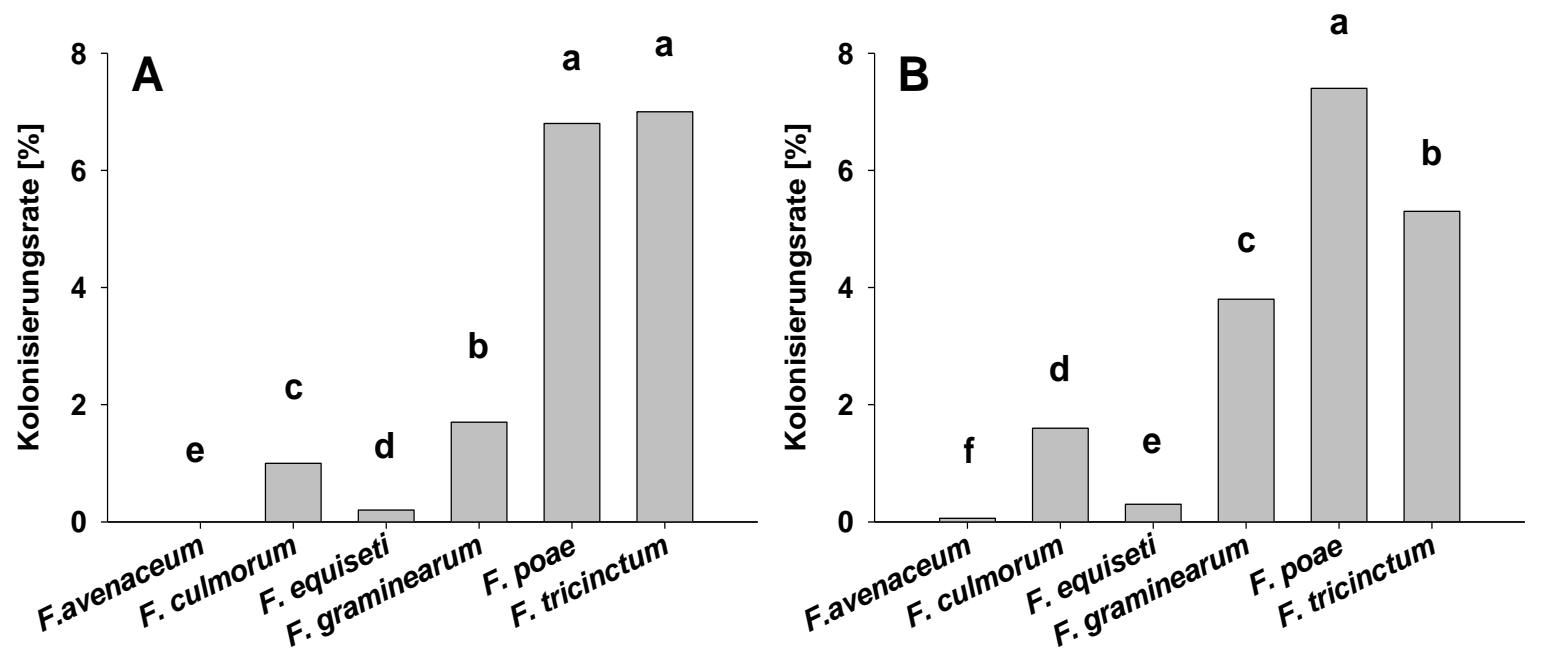

Abb. 31: Einfluss der Blattfungizidbehandlung mit Prothioconazol auf FusariumArtenspektrum und Kolonisierungsraten der einzelnen Arten [\%] an Körnern von Winterweizen der Fungizidstufen A) „behandelt" und B) „unbehandelt“ zu BBCH 92 des Versuchsjahres 2010 am Standort Torland. Vorfrüchte: Winterweizen, Mais, Zuckerrübe und ÖIrettich. Sorten: „Centrum“ und „Ritmo“. Unterschiedliche Buchstaben kennzeichnen signifikante Unterschiede zwischen den Kolonisierungsraten einzelner Arten in den beiden Fungizidstufen ( $n=1600$, statistische Berechnung manuell mittels Prozentsatzdifferenz mit $p<0,05)$.

\subsubsection{Vergleich der Fusarium-Artenspektren an Halmbasis und Körnern 2010}

Im Versuchsjahr 2010 wurde, wie bereits unter 3.2.1 beschrieben, die Beprobung der Halmbasis zu allen drei Probenahmezeitpunkten ausschließlich in der Variante „Ritmo, unbehandelt“ durchgeführt. Um einen Vergleich des Fusarium-Artenspektrums der Halmbasis mit dem der Körner zu ermöglichen, wurde daher für die Gegenüberstellung der Spektren für beide Pflanzenteile die Variante „Ritmo, unbehandelt“ betrachtet. Zudem wurde für die Halmbasis nur der Zeitpunkt der Milchreife herangezogen, da dieser dem Zeitpunkt der Ernte zu BBCH 92 der Körner zeitlich am nächsten lag.

Abbildung 32 fasst den Vergleich der Fusarium-Artenspektren an Halmbasis und Körnern zusammen und gibt auf Grund der Darstellung der Kolonisierungsraten der einzelnen Arten für jedes der beiden Spektren Aufschluss über die Bedeutung bestimmter Arten an den beiden Pflanzenteilen. Es konnten deutliche Unterschiede bezüglich des Vorkommens und der damit verbundenen Relevanz der verschiedenen Fusarium-Arten herausgestellt werden. Grundsätzlich lagen die Kolonisierungsraten an den Körnern deutlich niedriger, als an der Halmbasis. Während das Artenspektrum an der Halmbasis eindeutig von den Arten F. culmorum, F. equiseti und F. tricinctum dominiert wurde, spielten an den Körnern besonders die Arten F. poae und F. tricinctum und nach Mais vor allem F. graminearum eine Rolle. 


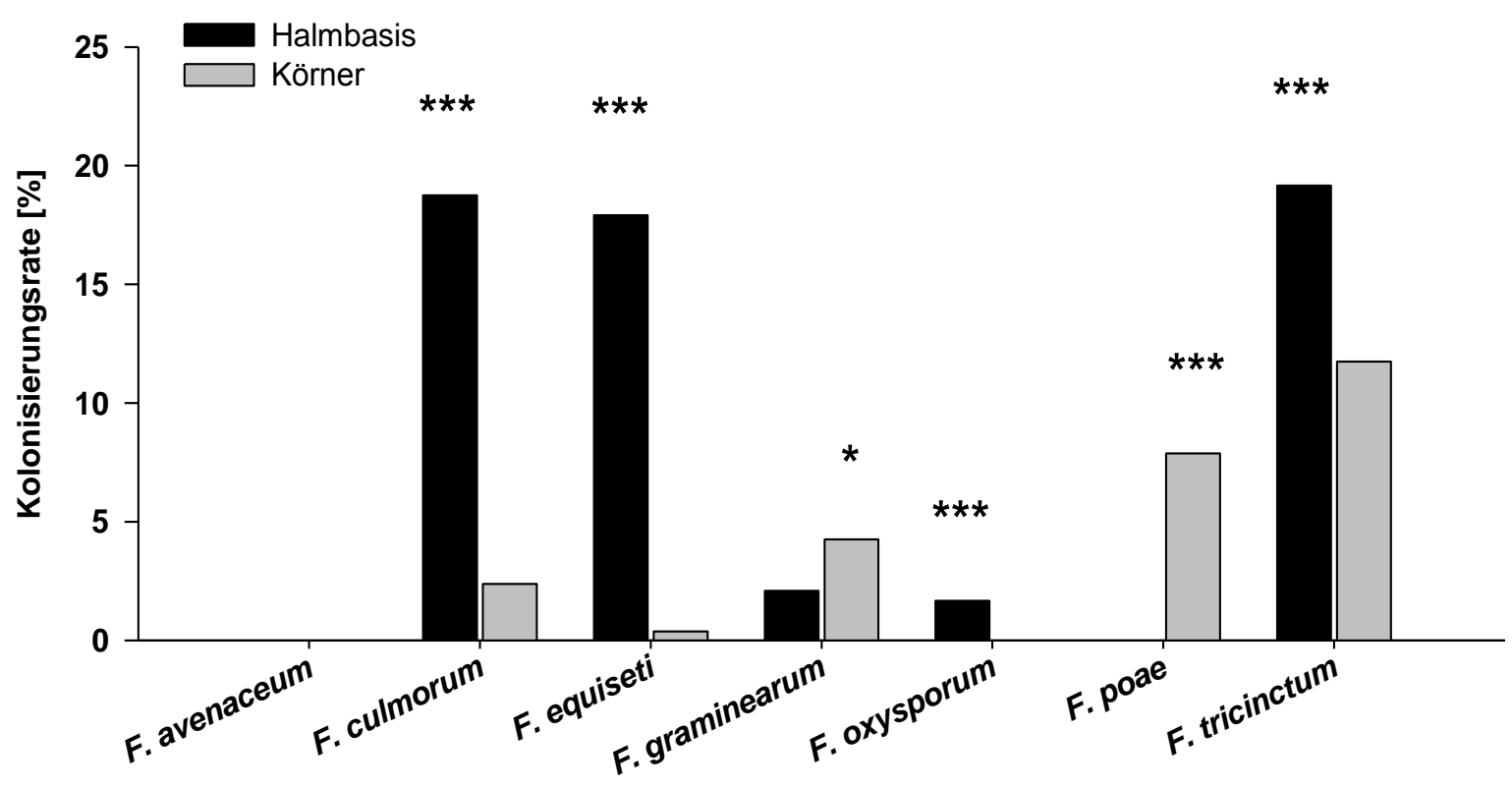

Abb. 32: Vergleich von Fusarium-Artenspektren und Kolonisierungsraten an Halmbasis und Körnern von Winterweizen der Versuchsvariante „Ritmo, unbehandelt“ zu BBCH 71-75 (Halmbasis) und BBCH 92 (Körner) des Versuchsjahres 2010 am Standort Torland. Vorfrüchte: Winterweizen, Mais, Zuckerrübe und Ölrettich. Die Symbole * und *** kennzeichnen signifikante Unterschiede zwischen den Kolonisierungsraten der einzelnen Arten an den verschiedenen Pflanzenteilen. Arten, die nicht vorkamen, wurden für die statistische Auswertung nicht berücksichtigt (Halm: $n=240$, Körner: $n=3200$ statistische Berechnung mittels Prozentsatzdifferenz mit Irrtumswahrscheinlichkeiten von * $=5 \%$ $(p<0,05),{ }^{* *}=1 \%(p<0,01)$ und $^{* * *}=0,1 \%(p<0,001)$.

Zur statistischen Absicherung der Ergebnisse wurde die Kolonisierungsrate jeder Art an der Halmbasis mit der Kolonisierungsrate derselben Art an den Körnern verglichen. Abbildung 32 verdeutlicht die Unterschiede der Kolonisierungsraten jeder Art an den verschiedenen Pflanzenteilen. Somit zeigten sich an der Halmbasis für die Arten F. culmorum, F. equiseti, F.tricinctum sowie F.oxysporum mit Irrtumswahrscheinlichkeiten von $p<0,1$ hoch signifikante Unterschiede der Kolonisierungsraten, verglichen mit dem Vorkommen dieser Arten an den Körnern. Dagegen erwies sich die Kolonisierungsrate von F. graminearum an den Körnern als signifikant höher, als an der Halmbasis. Der Unterschied des Auftretens von F. poae an den Körnern im Vergleich zur Halmbasis war hoch signifikant. 


\subsubsection{Einfluss der Versuchsparameter auf das Fusarium-Artenspektrum an der Halmbasis 2011}

Im Versuchsjahr 2011 wurde im Unterschied zu 2010 nicht ausschließlich die Variante „Ritmo unbehandelt“ beprobt, sondern die Varianten „Centrum, behandelt“ und „Ritmo, behandelt“ zu BBCH 37-39 sowie alle vier Varianten („Centrum, behandelt“, „Ritmo, behandelt“, „Centrum, unbehandelt" und „Ritmo, unbehandelt“) zu den Zeitpunkten $\mathrm{BBCH} 69$ und $\mathrm{BBCH}$ 75-77. Auf Grund der Witterungsbedingungen bewegte sich der Weizen im Vergleich zum Vorjahr sehr schnell durch seine Entwicklungsstadien, sodass die Probenahme zum Zeitpunkt 2 zu BBCH 69 erfolgte und somit zur Einhaltung der zeitlichen Distanz zwischen den Beprobungen Probenahmezeitpunkt 3 angepasst werden musste. 2011 zeigte sich ein breiteres Spektrum von insgesamt 10 Fusarium-Arten an der Halmbasis. Insgesamt konnten die Arten F. avenaceum, F. cerealis, F. culmorum, F. equiseti, F. graminearum, F. oxysporum, F. poae, F. redolens, F. tricinctum und F. venenatum identifiziert werden. F. sporotrichioides wurde nur vereinzelt an der Ähre gefunden, wurde aber der Vollständigkeit halber in die Darstellungen der Ergebnisse für die Halmbasis zum späteren Vergleich der Artenspektren beider Pflanzenteile integriert.

\section{Einfluss des Probenahmezeitpunktes}

2011 ergaben sich zu den drei verschiedenen Probenahmezeitpunkten teilweise große Unterschiede bezüglich der Gesamtkolonisierungsraten nach den vier Vorfrüchten (Abb. 33). Die mit 30,0\% im Vergleich zu den übrigen Vorfrüchten geringe Gesamtkolonisierungsrate nach Winterweizen zu BBCH 37-39 sank auf signifikant niedrigere 18,3\% zu BBCH 69 und 17,9\% zu BBCH 75-77 ab. Hier fand also eine Abnahme der Halmbasiskolonisierung im Verlauf des Probenahmezeitraumes statt. Dieses Phänomen zeigte sich auch nach Mais. Hier erfolgte zunächst eine Verdopplung der Gesamtkolonisierungsrate von 46,7\% zu BBCH 37-39 auf 82,5\% zu BBCH 69. Zu $\mathrm{BBCH} 75-77$ konnte jedoch eine zwanzigprozentige Reduktion der Kolonisierung gegenüber dem vorherigen Probenahmezeitpunkt auf 62,5\% gezeigt werden. Sowohl nach Zuckerrübe als auch nach Ölrettich trat eine sukzessive Zunahme der Gesamtkolonisierungsrate über den Probenahmezeitraum auf. Ähnlich wie nach Mais, stieg zwischen $\mathrm{BBCH} 37-39$ und $\mathrm{BBCH} 69$ die Rate von 41,7\% auf signifikant höhere $72,1 \%$ an. Zu BBCH 75-77 hatte sich die Kolonisierungsrate nochmals signifikant auf 82,9\% erhöht, sodass nach Zuckerrübe zu diesem Probenahmezeitpunkt die höchste Kolonisierungsrate im Vergleich zu den übrigen Vorfrüchten beobachtet werden konnte. Nach Ölrettich waren geringere Gesamtkolonisierungsraten zu verzeichnen, als nach Mais und Zuckerrübe. So stieg die Gesamtkolonisierungsrate von zunächst $27,5 \%$ zu 
BBCH 37-39 auf 41,7\% zu BBCH 69 und um weitere 10,2\% auf 50,9\% zu BBCH 75-77 an. Auch wenn nach Ölrettich im Vergleich zu Mais und Zuckerrübe niedrigere Gesamtkolonisierungsraten ermittelt wurden, war zu BBCH 75-77 dennoch die Hälfte aller Pflanzen durch Fusarium kolonisiert.

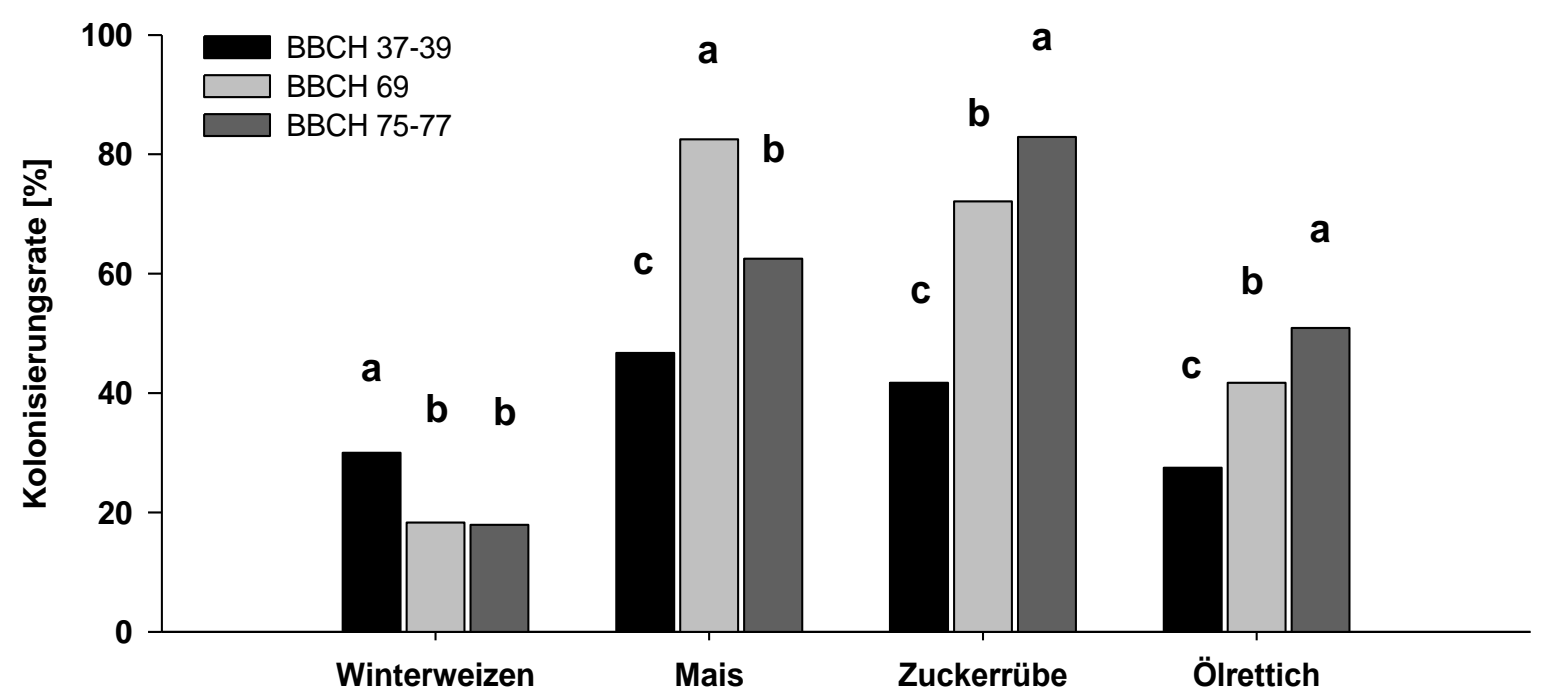

Abb. 33: Einfluss des Probenahmezeitpunktes auf die Gesamtkolonisierungsraten [\%] an der Halmbasis von Winterweizen nach den vier Vorfrüchten Winterweizen, Mais, Zuckerrübe und Ölrettich zu BBCH 37-39, BBCH 69 und BBCH 75-77 des Versuchsjahres 2011 am Standort Torland. Sorten: „Centrum“ und „Ritmo“, Fungizidstufen: „behandelt mit Prothioconazol“ und „unbehandelt“. Es wurden die Gesamtkolonisierungsraten der verschiedenen Probenahmezeitpunkte innerhalb jeder Vorfruchtvariante untereinander statistisch überprüft. Unterschiedliche Buchstaben kennzeichnen signifikante Unterschiede zwischen den Gesamtkolonisierungsraten innerhalb der Vorfruchtvarianten ( $n=120$ für $\mathrm{BBCH} 37-39, \mathrm{n}=240$ für $\mathrm{BBCH} 69$ und $\mathrm{BBCH} 75-77$, statistische Berechnung mittels Prozentsatzdifferenz mit $p<0,05$ ).

\section{Einfluss der Vorfrucht}

Der Einfluss der Vorfrucht auf Fusarium-Artenspektren und Kolonisierungsraten an der Halmbasis 2011 verhielt sich im Wesentlichen wie bereits für 2010 beobachtet. 2011 betrug die Gesamtkolonisierungsrate nach Mais zu BBCH 37-39 46,7\% und zeigte damit zusammen mit Zuckerrübe $(41,7 \%)$ einen signifikanten Vorfruchteffekt im Vergleich zu Winterweizen und Ölrettich mit Raten von 30,0\% bzw. 27,5\% (Abb. 34). 


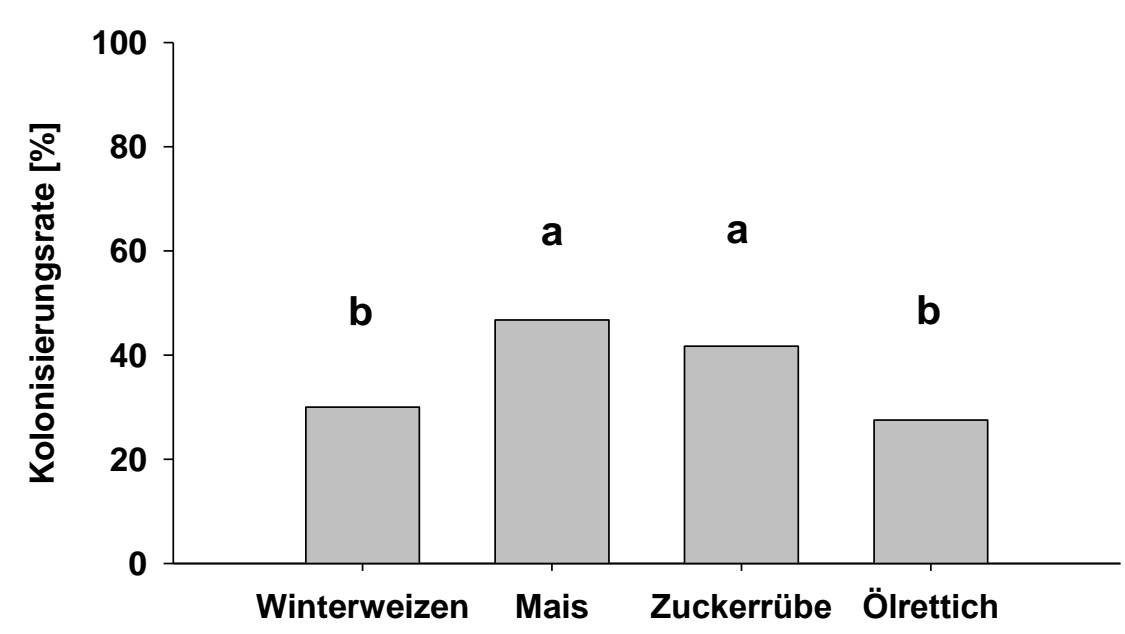

Abb. 34: Einfluss der Vorfrucht auf die Gesamtkolonisierungsraten von Fusarium [\%] an der Halmbasis von Winterweizen nach den vier Vorfrüchten Winterweizen, Mais, Zuckerrübe und Ölrettich zu BBCH 37-39 des Versuchsjahres 2011 am Standort Torland. Sorten: „Centrum" und „Ritmo“, Fungizidstufen: „behandelt mit Prothioconazol“ und „unbehandelt". Unterschiedliche Buchstaben kennzeichnen signifikante Unterschiede zwischen den Gesamtkolonisierungsraten $(n=120$, statistische Berechnung mittels einfaktorieller ANOVA mit $p<0,05$ ).

Die Artenspektren und artspezifischen Kolonisierungsraten nach den vier Vorfrüchten sind in Abbildung 35 dargestellt. Nach den Vorfrüchten Mais, Zuckerrübe und Ölrettich dominierten die Arten F. culmorum mit Kolonisierungsraten von 10,8\% bis $15,8 \%$, F. tricinctum mit Raten zwischen $9,2 \%$ und $18,3 \%$ und $F$. equiseti mit Raten von $7,5 \%$ und $11,7 \%$ (nach Ölrettich und Mais) das Artenspektrum an der Halmbasis. Nach Winterweizen waren die Arten F. culmorum, F. equiseti, F. graminearum, F. oxysporum, $F$. redolens und $F$. tricinctum die am häufigsten vorkommenden Arten, welche insgesamt ähnliche Kolonisierungsraten aufwiesen. 

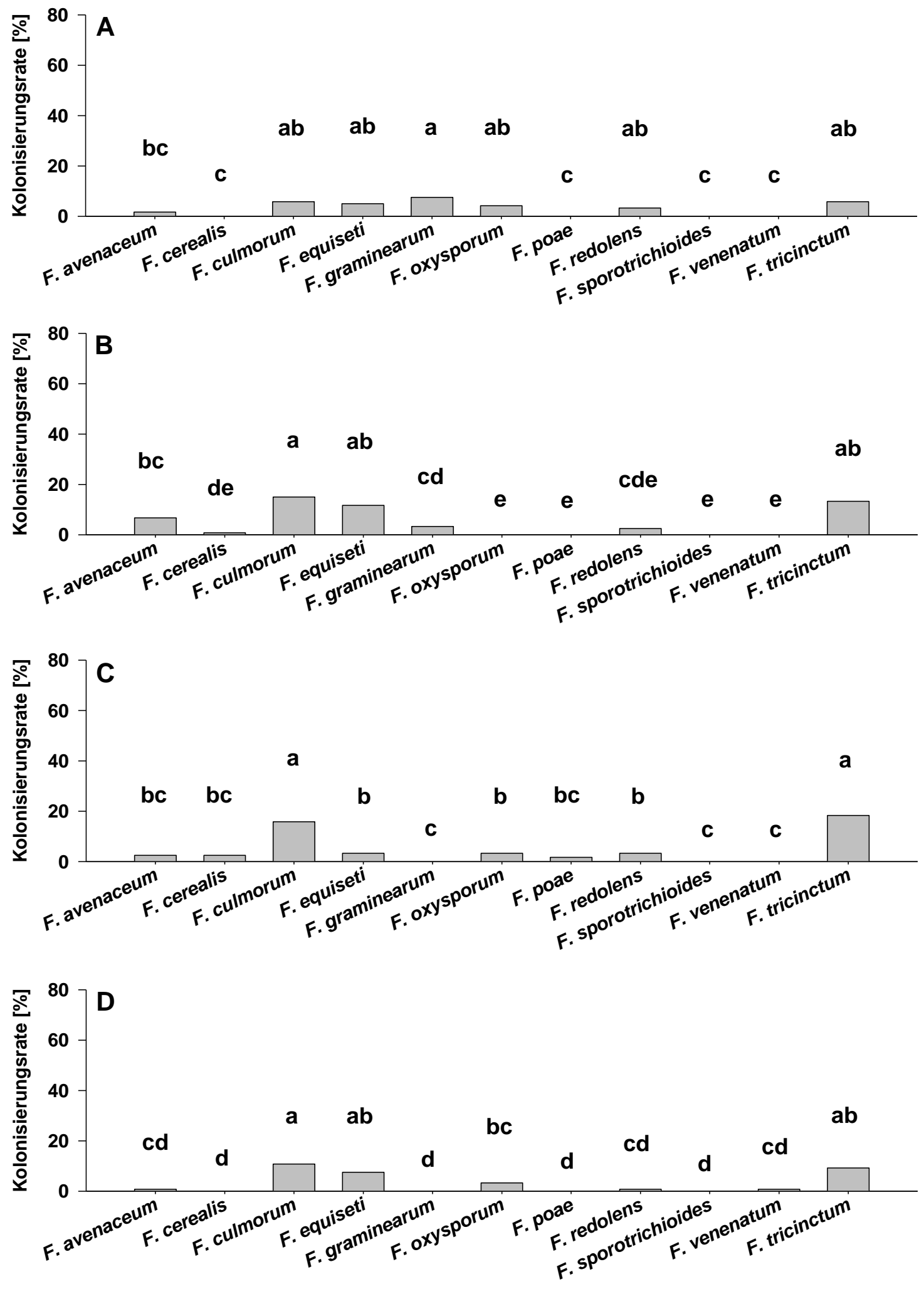

Abb. 35: Einfluss der Vorfrucht auf Fusarium-Artenspektrum und Kolonisierungsraten der einzelnen Arten [\%] an der Halmbasis von Winterweizen nach den vier Vorfrüchten A) Winterweizen, B) Mais, C) Zuckerrübe und D) Ölrettich zu BBCH 37-39 des Versuchsjahres 2011 am Standort Torland. Sorten: „Centrum" und „Ritmo“, Fungizidstufen: „behandelt mit Prothioconazol“ und „unbehandelt". Unterschiedliche Buchstaben kennzeichnen signifikante Unterschiede zwischen den Kolonisierungsraten $(n=120$, statistische Berechnung mittels t-Test mit $p<0,05$ ). 
Zum Zeitpunkt der späten Blüte (BBCH 69) erwiesen sich die Gesamtkolonisierungsraten nach den Vorfrüchten Mais und Zuckerrübe mit $82,5 \%$ bzw. $72,7 \%$ als stark erhöht gegenüber BBCH 37-39 (Abb. 36). Auch Ölrettich wies eine erhöhte Gesamtkolonisierungsrate gegenüber dem ersten Probenahmezeitpunkt auf. Die Rate nach Winterweizen hatte sich zu $\mathrm{BBCH} 69$ jedoch um ca. $10 \%$ gegenüber $\mathrm{BBCH} 37-39$ reduziert und wies die signifikant niedrigste Gesamtkolonisierungsrate auf. Insgesamt konnte sowohl nach Mais, als auch nach Zuckerrübe ein deutlicher Einfluss auf die Kolonisierung mit Fusarium-Arten ermittelt werden.

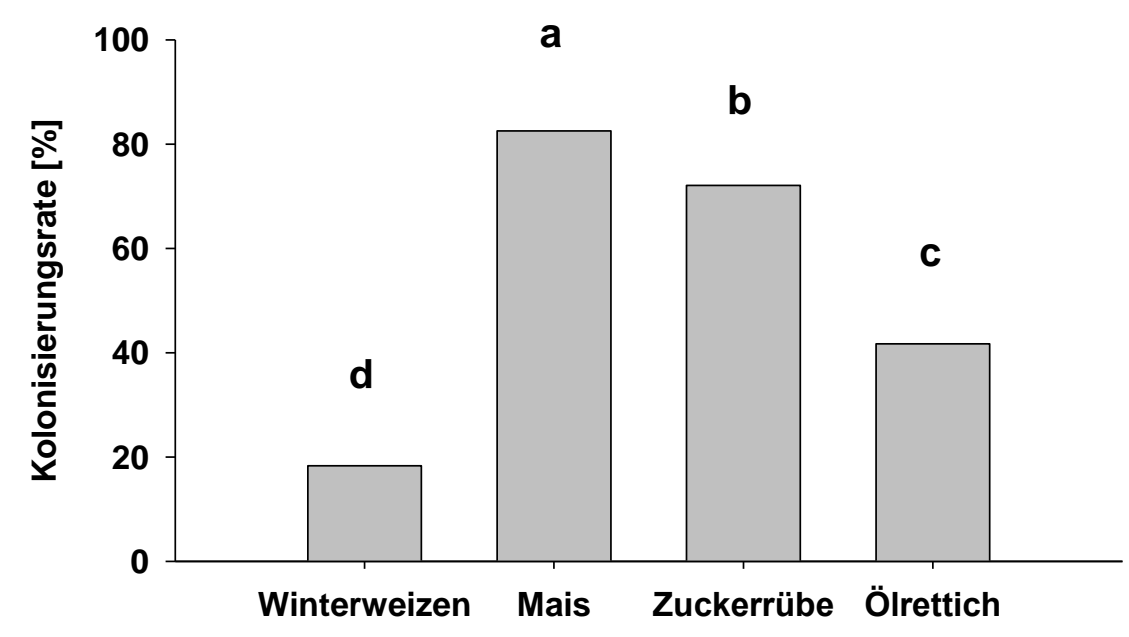

Abb. 36: Einfluss der Vorfrucht auf die Gesamtkolonisierungsraten von Fusarium [\%] an der Halmbasis von Winterweizen nach den vier Vorfrüchten Winterweizen, Mais, Zuckerrübe und Ölrettich zu BBCH 69 des Versuchsjahres 2011 am Standort Torland. Sorten: „Centrum“ und „Ritmo“, Fungizidstufen: „,behandelt mit Prothioconazol“ und "unbehandelt". Unterschiedliche Buchstaben kennzeichnen signifikante Unterschiede zwischen den Gesamtkolonisierungsraten $(n=240$, statistische Berechnung mittels einfaktorieller ANOVA mit $p<0,05)$.

Die hohen Gesamtkolonisierungsraten nach Mais, Zuckerrübe und Ölrettich waren durch ein starkes Auftreten von F. culmorum mit Kolonisierungsraten von 28,8\% nach Ölrettich (D), 55,8\% nach Zuckerrübe (C) und 67,5\% nach Mais (B) geprägt (Abb. 37). Weitere Arten, die nach diesen drei Vorfüchten durch höhere Kolonisierungsraten von Bedeutung waren, waren vor allem F. tricinctum mit Raten von 10,0-25,0\% und F. equiseti, besonders nach Zuckerrübe mit 10,4\% und Mais mit 13,3\% Kolonisierungsrate. Im Vergleich dazu konnten sich nach Winterweizen (A) die Arten F.culmorum und F. tricinctum nur leicht von den übrigen Arten abheben. 

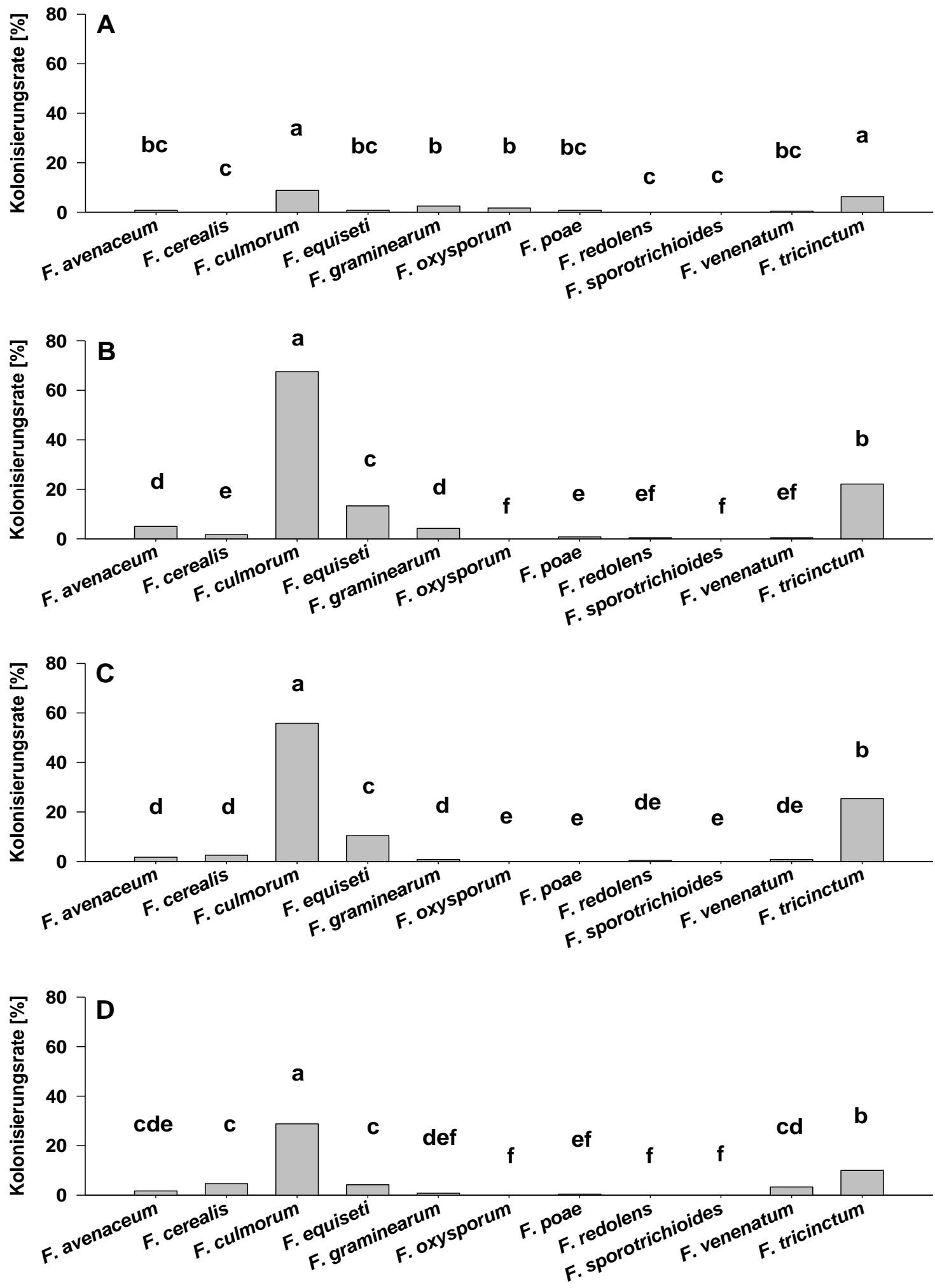

Abb. 37: Einfluss der Vorfrucht auf Fusarium-Artenspektrum und Kolonisierungsraten der einzelnen Arten [\%] an der Halmbasis von Winterweizen nach den vier Vorfrüchten A) Winterweizen, B) Mais, C) Zuckerrübe und D) Ölrettich zu BBCH 69 des Versuchsjahres 2011 am Standort Torland. Sorten: „Centrum“ und „Ritmo“, Fungizidstufen: „behandelt mit Prothioconazol" und "unbehandelt". Unterschiedliche Buchstaben kennzeichnen signifikante Unterschiede zwischen den Kolonisierungsraten $(n=240$, statistische Berechnung mittels t-Test mit $p<0,05$ ). 
Zum dritten Probenahmezeitpunkt zu BBCH 75-77 war eine weitere Steigerung der Gesamtkolonisierungsrate nach Zuckerrübe um ca. 10\% auf den signifikant höchsten Wert von 82,9\% im Vergleich zu BBCH 69 zu beobachten, bei einem gleichzeitigen Rückgang der Gesamtkolonisierungsraten um rund 20\% nach Mais (Abb. 38). Zuckerrübe als Vorfrucht löste Mais damit wie schon 2010 zum Zeitpunkt der Milchreife als größte Risikovorfrucht bezüglich des Einflusses auf die Kolonisierung durch Halmbasisfusarium ab. Die Gesamtkolonisierungsrate nach Winterweizen blieb gegenüber BBCH 69 auf konstant niedrigem Niveau, nach Ölrettich war ein Ansteigen um ca. 10\% zu verzeichnen.

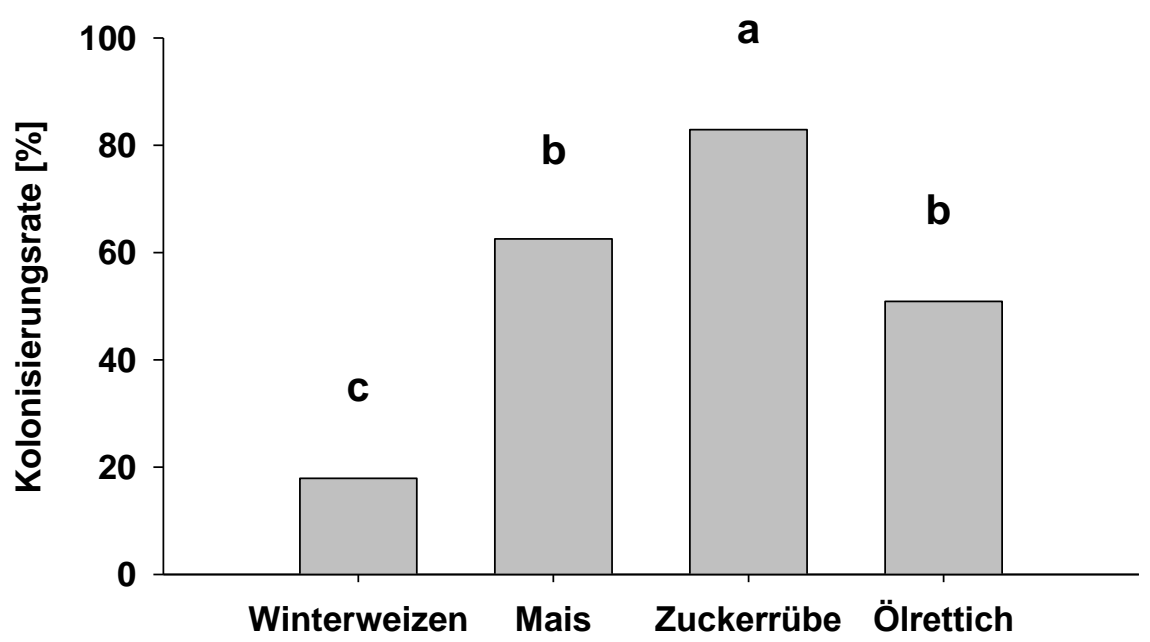

Abb. 38: Einfluss der Vorfrucht auf die Gesamtkolonisierungsraten von Fusarium [\%] an der Halmbasis von Winterweizen nach den vier Vorfrüchten Winterweizen, Mais, Zuckerrübe und Ölrettich zu BBCH 75-77. des Versuchsjahres 2011 am Standort Torland. Sorten: „Centrum“ und „Ritmo“", Fungizidstufen: „behandelt mit Prothioconazol“ und „unbehandelt". Unterschiedliche Buchstaben kennzeichnen signifikante Unterschiede zwischen den Gesamtkolonisierungsraten $(n=240$, statistische Berechnung mittels einfaktorieller ANOVA mit $p<0,05$ ).

Auch zum dritten Probenahmezeitpunkt erwiesen sich nach Mais (B), Zuckerrübe (C) und Ölrettich (D) wiederum die Arten F. culmorum mit signifikant hohen Kolonisierungsraten zwischen $37,9 \%$ nach Ölrettich und 58,3\% nach Zuckerrübe, F. tricinctum mit Raten zwischen $15,5 \%$ und $38,8 \%$ sowie $F$. equiseti mit Raten von $5,0-12,5 \%$ als die wichtigsten Arten zur Milchreife (Abb. 39). Nach Zuckerrübe war zudem F. avenaceum mit einer Kolonisierungsrate von $19,2 \%$ bedeutsam. Die übrigen Arten waren kaum oder nicht vertreten. 

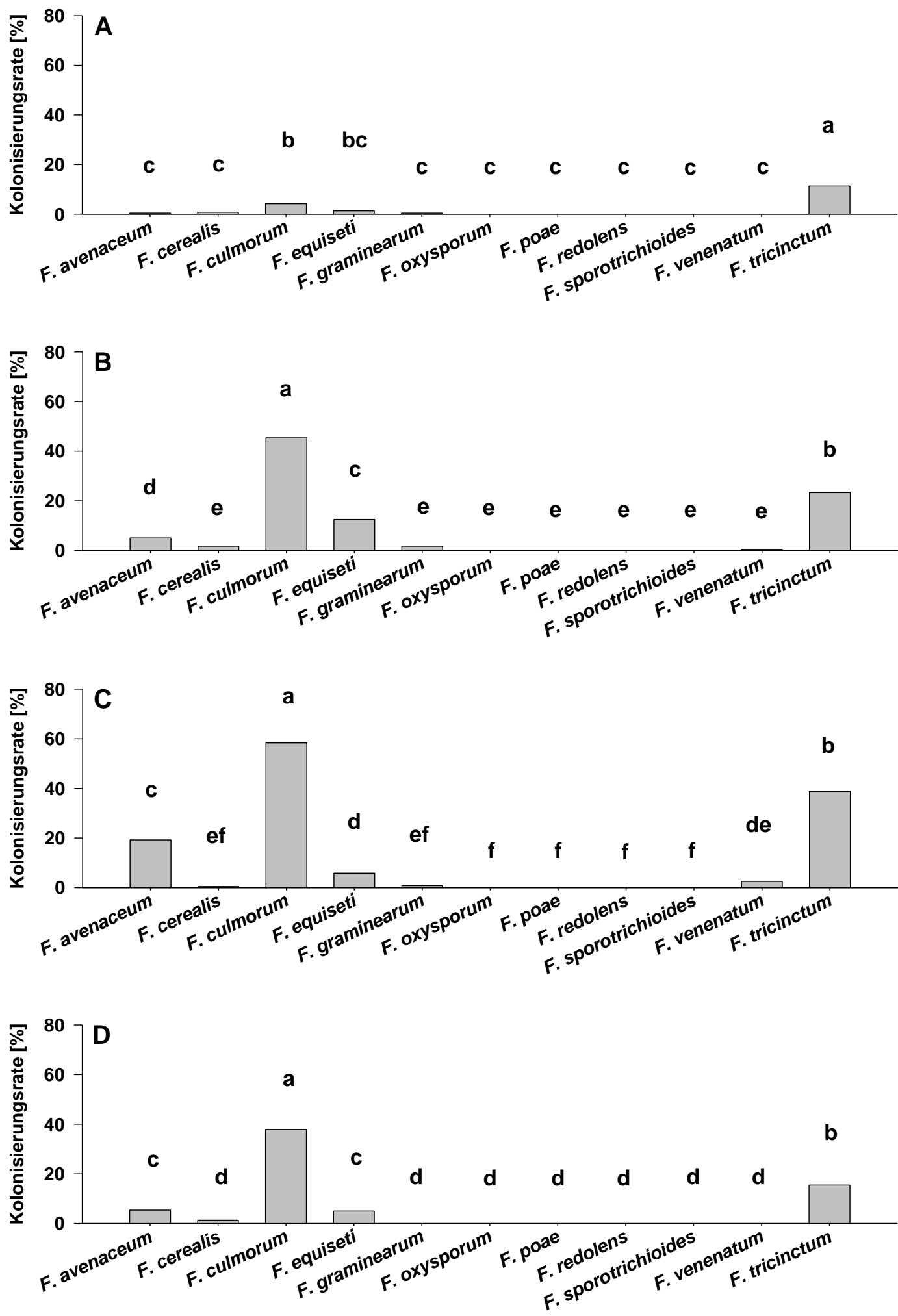

Abb. 39: Einfluss der Vorfrucht auf Fusarium-Artenspektrum und Kolonisierungsraten der einzelnen Arten [\%] an der Halmbasis von Winterweizen nach den vier Vorfrüchten A) Winterweizen, B) Mais, C) Zuckerrübe und D) Ölrettich zu BBCH 75-77 des Versuchsjahres 2011 am Standort Torland. Sorten: "Centrum“ und „Ritmo“, Fungizidstufen: „behandelt mit Prothioconazol“ und „unbehandelt". Unterschiedliche Buchstaben kennzeichnen signifikante Unterschiede zwischen den Kolonisierungsraten $(n=240$, statistische Berechnung mittels t-Test mit $p<0,05$ ). 
Im Hinblick auf die Gesamtkolonisierungsraten konnte somit eine Verschiebung von Mais zu Zuckerrübe innerhalb des Untersuchungszeitraums am Standort Torland beobachtet werden, bei gleichzeitig starkem Abnehmen der Gesamtkolonisierungsrate nach Winterweizen. Zu allen drei Probenahmezeitpunkten waren die Arten F.culmorum, $F$. equiseti und $F$. tricinctum wie auch 2010 insgesamt die am häufigsten anzutreffenden Arten, mit Ausnahme von F. avenaceum zum dritten Probenahmezeitpunkt besonders nach Zuckerrübe.

\section{Einfluss der Sorte}

Im Hinblick auf den Einfluss der Sorte auf die Gesamtkolonisierungsraten zu BBCH 37-39 konnte kein signifikanter Unterschied zwischen der resistenten Sorte "Centrum" und der anfälligen Sorte „Ritmo“ ermittelt werden (Abb. 40). Die Kolonisierungsraten beider Sorten lagen bei $33,0 \%$ und somit um durchschnittlich 25\% niedriger, als zu BBCH 69 und 75-77. Allerdings muss darauf hingewiesen werden, dass die Ergebnisse zu BBCH 37-39 auf Daten der Varianten "Centrum behandelt" und "Ritmo behandelt" beruhen, wogegen zu den beiden späteren Zeitpunkten alle vier Varianten mit einbezogen wurden (s. 2.13.1).

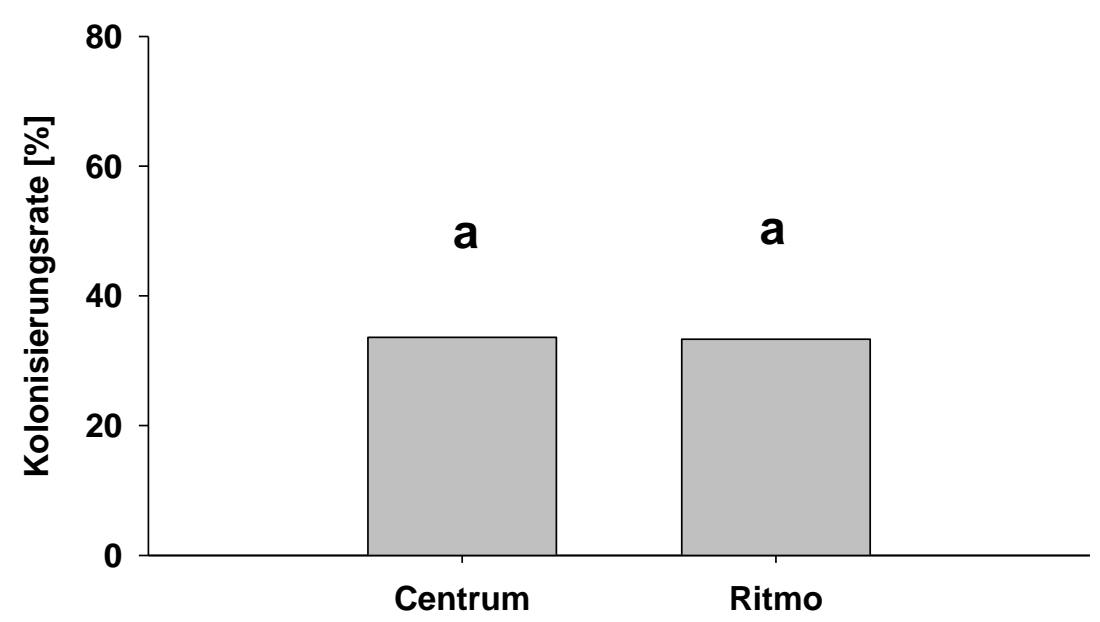

Abb. 40: Einfluss der Sorte auf die Gesamtkolonisierungsraten von Fusarium [\%] an der Halmbasis von Winterweizen in den beiden Winterweizensorten "Centrum" (resistent) und „Ritmo“ (anfällig) zu BBCH 37-39 des Versuchsjahres 2011 am Standort Torland. Vorfrüchte: Winterweizen, Mais, Zuckerrübe und Ölrettich. Fungizidstufen: „behandelt mit Prothioconazol“ und "unbehandelt". Unterschiedliche Buchstaben kennzeichnen signifikante Unterschiede zwischen den Gesamtkolonisierungsraten $(n=240$, statistische Berechnung mittels t-Test mit $p<0,05$ ).

Sowohl "Centrum" (Abb. 41, A), als auch "Ritmo“ (B) wiesen mit 10,4-13,3\% zwar insgesamt im Vergleich zu den späteren Probenahmezeitpunkten niedrige, jedoch gegenüber allen anderen Arten signifikant erhöhte Kolonisierungsraten der Arten 
F. culmorum und F. tricinctum auf. Dabei erwiesen sich die Raten für die beiden Arten in der anfälligen Variante sogar als marginal niedriger als in der resistenten Sorte. Die Art mit der dritthöchsten Kolonisierungsrate war in beiden Sorten F. equiseti mit $7,5 \%$ für „Centrum“ bzw. 6,3\% für „Ritmo“.
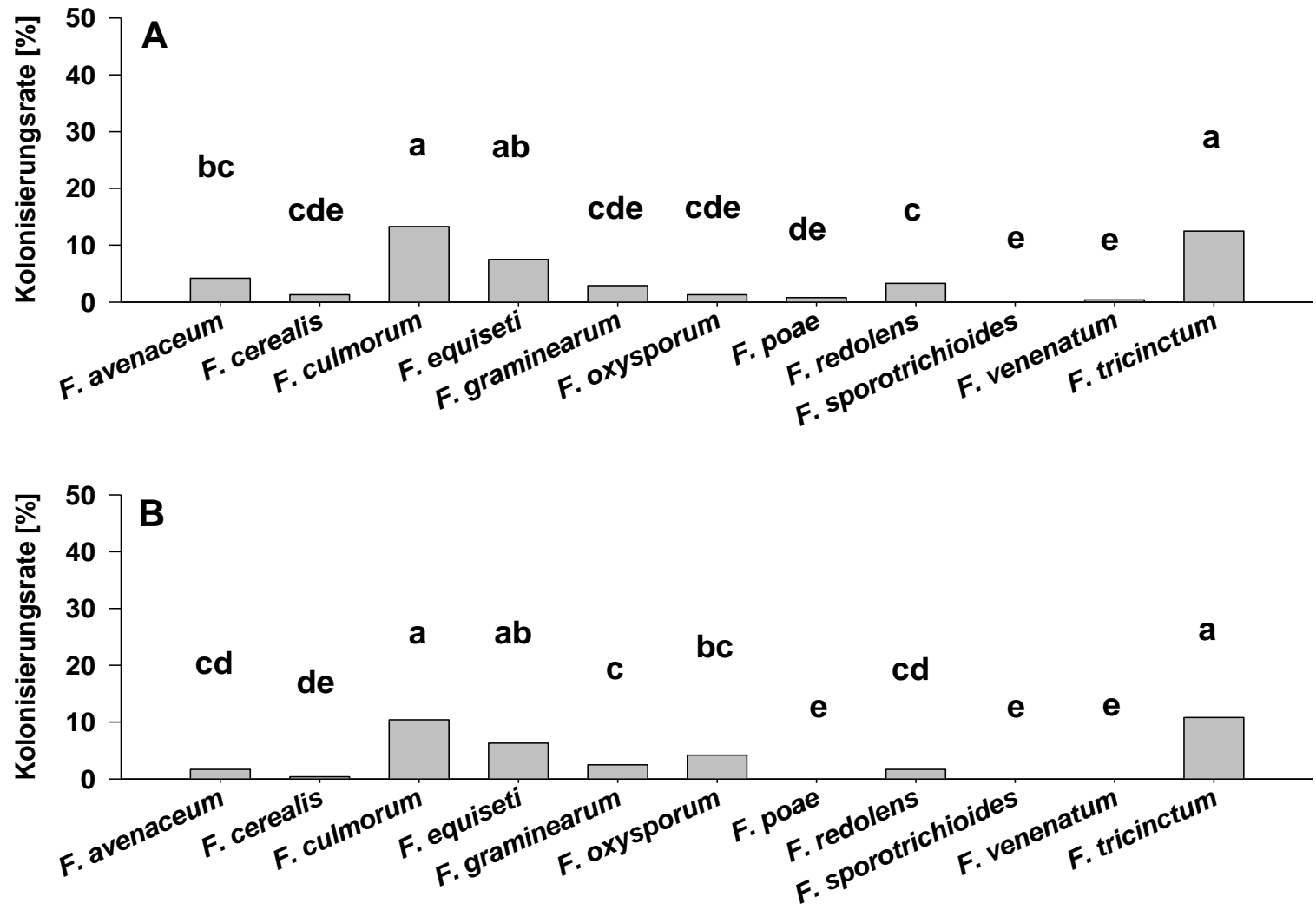

Abb. 41: Einfluss der Sorte auf Fusarium-Artenspektrum und Kolonisierungsraten der einzelnen Arten [\%] an der Halmbasis von Winterweizen in den beiden Winterweizensorten A) „Centrum“ (resistent) und B) „Ritmo“ (anfällig) zu BBCH 37-39 des Versuchsjahres 2011 am Standort Torland. Vorfrüchte: Winterweizen, Mais, Zuckerrübe und Ölrettich. Fungizidstufen: „behandelt mit Prothioconazol“ und „unbehandelt". Unterschiedliche Buchstaben kennzeichnen signifikante Unterschiede zwischen den Kolonisierungsraten ( $n=240$, statistische Berechnung mittels $t-T e s t$ mit $p<0,05$ ).

Zu BBCH 69 war die Gesamtkolonisierungsrate der Sorte „Ritmo“ mit 57,1\% gegenüber „Centrum“ mit 50,2\% signifikant höher, sodass ein klarer Sortenunterschied in Bezug auf die Kolonisierung durch Fusarium an der Halmbasis bestätigt werden konnte (Abb. 42). 


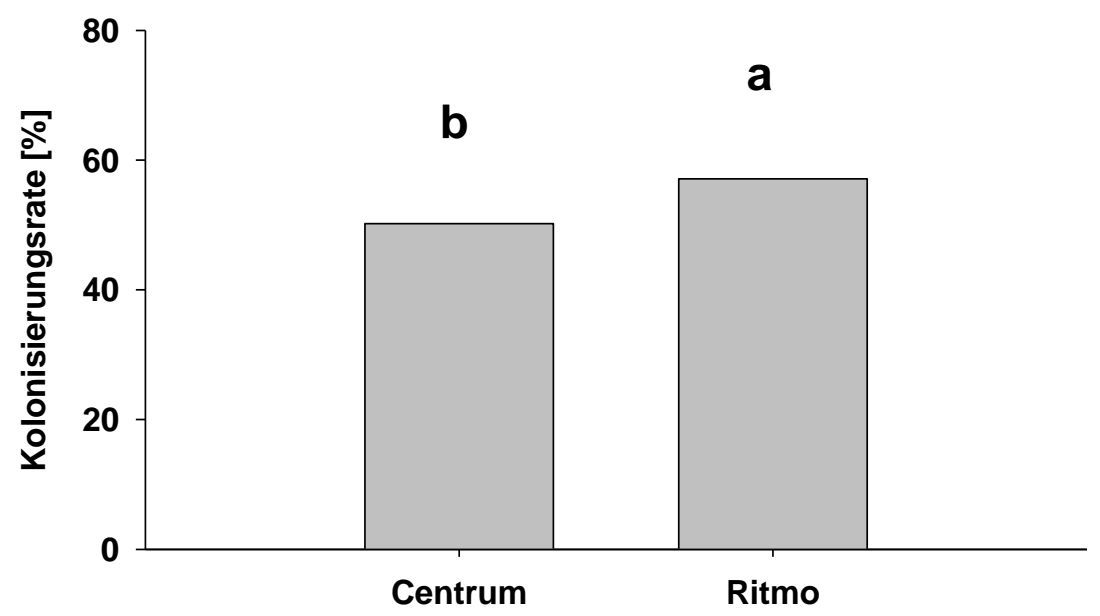

Abb. 42: Einfluss der Sorte auf die Gesamtkolonisierungsraten von Fusarium [\%] an der Halmbasis von Winterweizen in den beiden Winterweizensorten "Centrum" (resistent) und „Ritmo“ (anfällig) zu BBCH 69 des Versuchsjahres 2011 am Standort Torland. Vorfrüchte: Winterweizen, Mais, Zuckerrübe und Ölrettich. Fungizidstufen: „behandelt mit Prothioconazol“ und „unbehandelt“. Unterschiedliche Buchstaben kennzeichnen signifikante Unterschiede zwischen den Gesamtkolonisierungsraten ( $n=480$, statistische Berechnung mittels t-Test mit $p<0,05$ ).

Zum zweiten Probenahmezeitpunkt erwiesen sich die Arten F. culmorum, F. tricinctum und $F$. equiseti wiederum als wichtigste Halmbasiskolonisierer (Abb. 43). Allerdings zeigte F. culmorum mit 35,8\% Kolonisierungsrate für "Centrum“ (A) und 44,6\% für „Ritmo“ (B) signifikant höhere Raten, als F. tricinctum mit Raten von 13,1\% („Centrum“) sowie 18,8\% („Ritmo“) und F. equiseti mit 7,9\% für "Centrum“ und 6,5\% für „Ritmo“. Die Kolonisierungsraten von $F$. equiseti waren im Vergleich zu F.tricinctum wiederum signifikant niedriger. Alle anderen Arten lagen jedoch im Hinblick auf ihre Kolonisierungsraten teilweise noch weit unter denen von $F$. equiseti, bzw. kamen nicht vor und waren somit zu diesem Probenahmezeitpunkt an der Halmbasis nicht relevant. Die in Abbildung 42 dargestellte, signifikant niedrigere Kolonisierungsrate der Sorte „Centrum“ war daher auf niedrigere Raten der Arten F. culmorum und F. tricinctum zurückzuführen. 


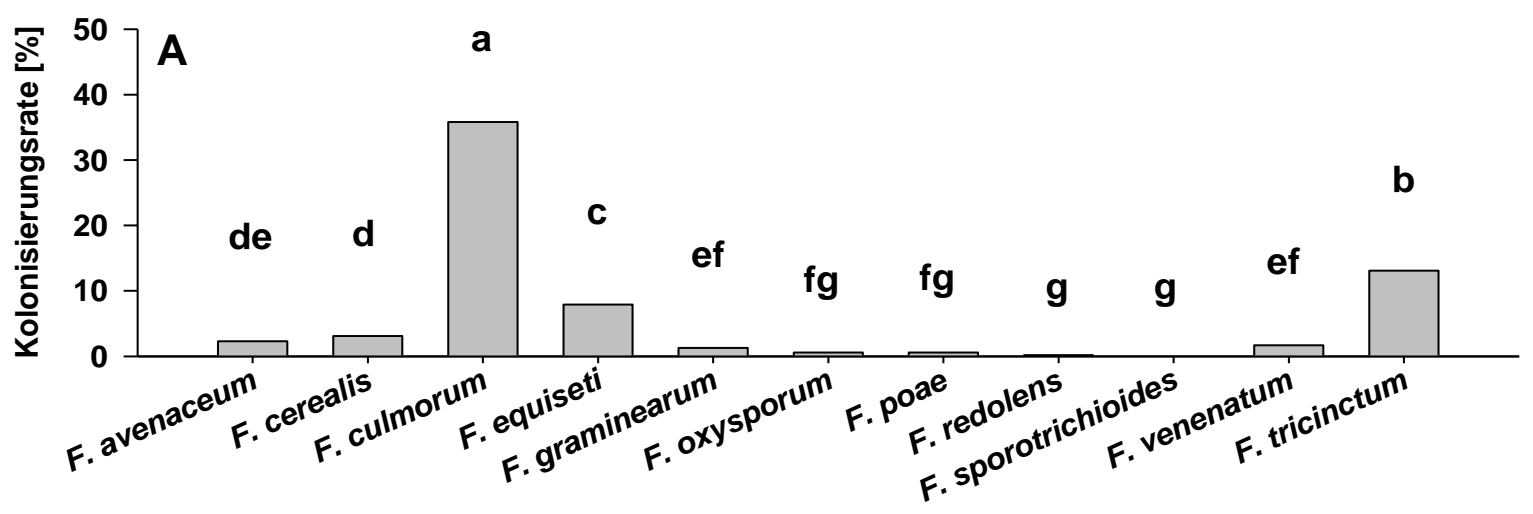

a

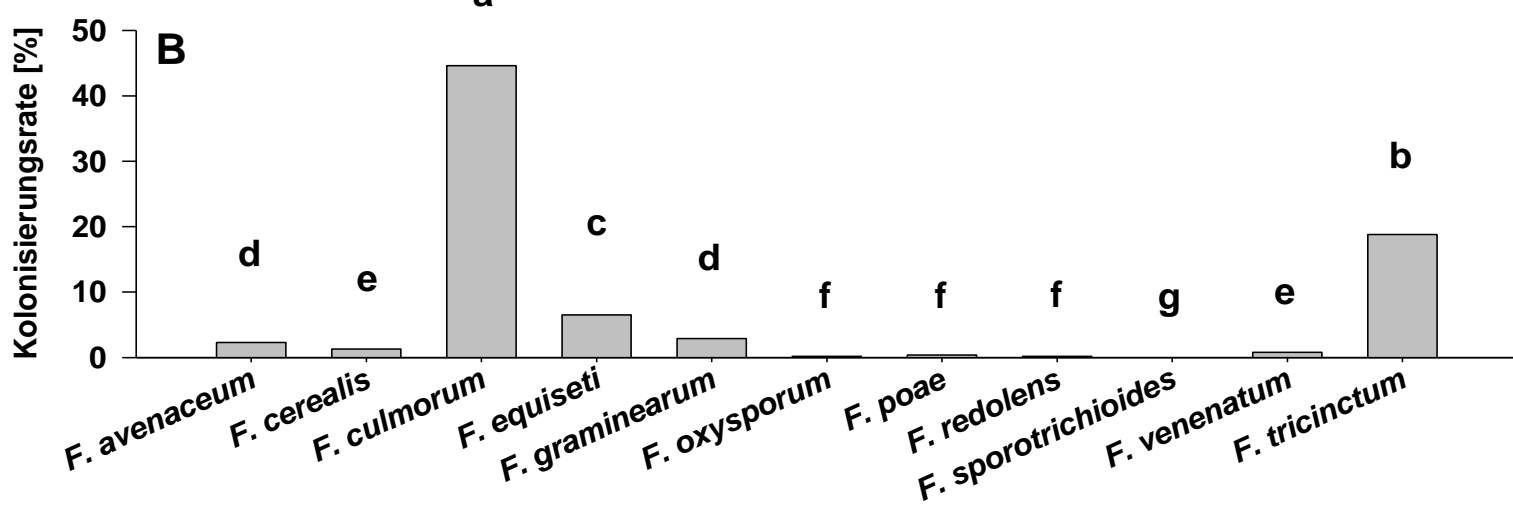

Abb. 43: Einfluss der Sorte auf Fusarium-Artenspektrum und Kolonisierungsraten der einzelnen Arten [\%] an der Halmbasis von Winterweizen in den beiden Winterweizensorten A) „Centrum“ (resistent) und „Ritmo“ (anfällig) zu BBCH 69 des Versuchsjahres 2011 am Standort Torland. Vorfrüchte: Winterweizen, Mais, Zuckerrübe und Ölrettich. Fungizidstufen: „behandelt mit Prothioconazol“ und „unbehandelt“. Unterschiedliche Buchstaben desselben Typs kennzeichnen signifikante Unterschiede zwischen den Kolonisierungsraten ( $n=480$, statistische Berechnung mittels t-Test mit $p<0,05$ ).

Der zu BBCH 69 beobachtete Sortenunterschied konnte auch für BBCH 75-77 bestätigt werden (Abb. 44). Hier lag die Gesamtkolonisierungsrate für "Centrum“ bei $48,8 \%$ und für „Ritmo“ bei signifikant höheren 58,3\%. 


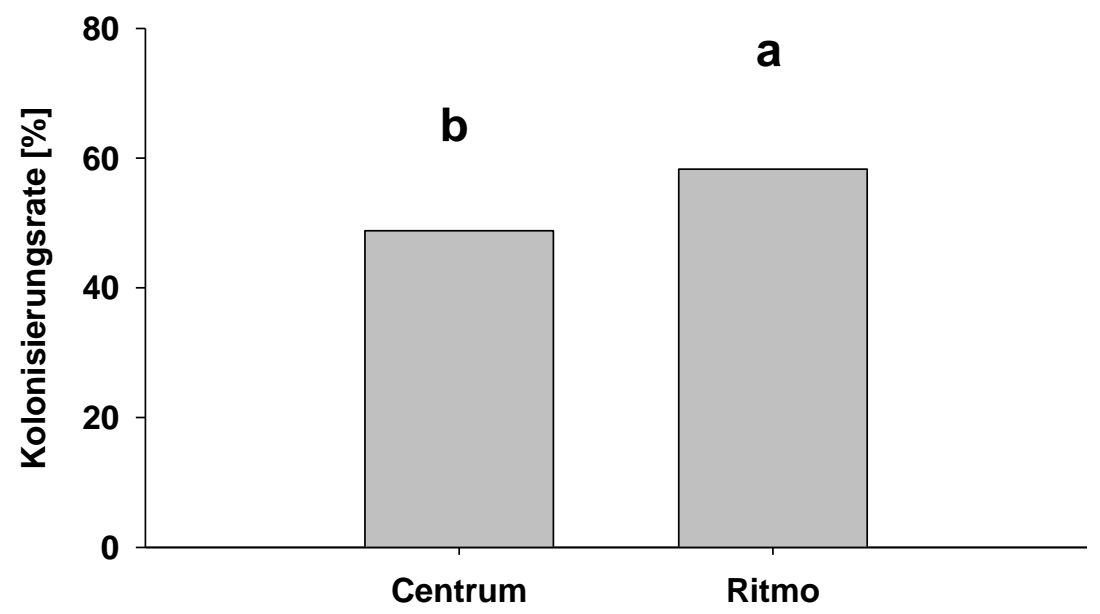

Abb. 44: Einfluss der Sorte auf die Gesamtkolonisierungsraten von Fusarium [\%] an der Halmbasis von Winterweizen in den beiden Winterweizensorten "Centrum" (resistent) und „Ritmo“ (anfällig) zu BBCH 75-77 des Versuchsjahres 2011 am Standort Torland. Vorfrüchte: Winterweizen, Mais, Zuckerrübe und Ölrettich. Fungizidstufen: „behandelt mit Prothioconazol“ und „unbehandelt“. Unterschiedliche Buchstaben kennzeichnen signifikante Unterschiede zwischen den Gesamtkolonisierungsraten $(n=480$, statistische Berechnung mittels t-Test mit $p<0,05)$.

Wie bereits zu den zwei Probenahmezeitpunkten zuvor, waren sowohl in der Sorte "Centrum“ als auch in "Ritmo“ die am häufigsten anzutreffenden Arten F. culmorum, $F$. tricinctum und $F$. equiseti, wobei jedoch zu BBCH 75-77 mit $F$. avenaceum noch eine weitere Art häufiger auftrat (Abb. 45). Alle anderen Arten traten mit Kolonisierungsraten noch deutlich unter denen von $F$. equiseti und $F$. avenaceum nur vereinzelt auf oder waren nicht auffindbar. Auch zu Probenahmezeitpunkt 3 erwiesen sich die Artenspektren in den beiden Sorten als sehr ähnlich. Der ca. zehnprozentige Unterschied in den in Abbildung 44 dargestellten Gesamtkolonisierungsraten der beiden Sorten kam hauptsächlich durch einen additiven Effekt der für jede der häufig vorkommenden Arten im Schnitt 2\% höheren Kolonisierungsraten in der Sorte „Ritmo“ zustande (B).

Für den Einfluss der Sorte konnte somit herausgestellt werden, dass ein eindeutiger Sortenunterschied im Hinblick auf die Gesamtkolonisierungsraten erst ab BBCH 69 bestätigt werden konnte und dieser sich nicht in signifikant unterschiedlichen Artenspektren, sondern in niedrigeren Kolonisierungsraten der Sorte "Centrum" für die in beiden Sorten am häufigsten vorkommenden Arten F.culmorum, F. equiseti und F. tricinctum (zu BBCH 75-77 ebenfalls $F$. avenaceum) manifestierte. 

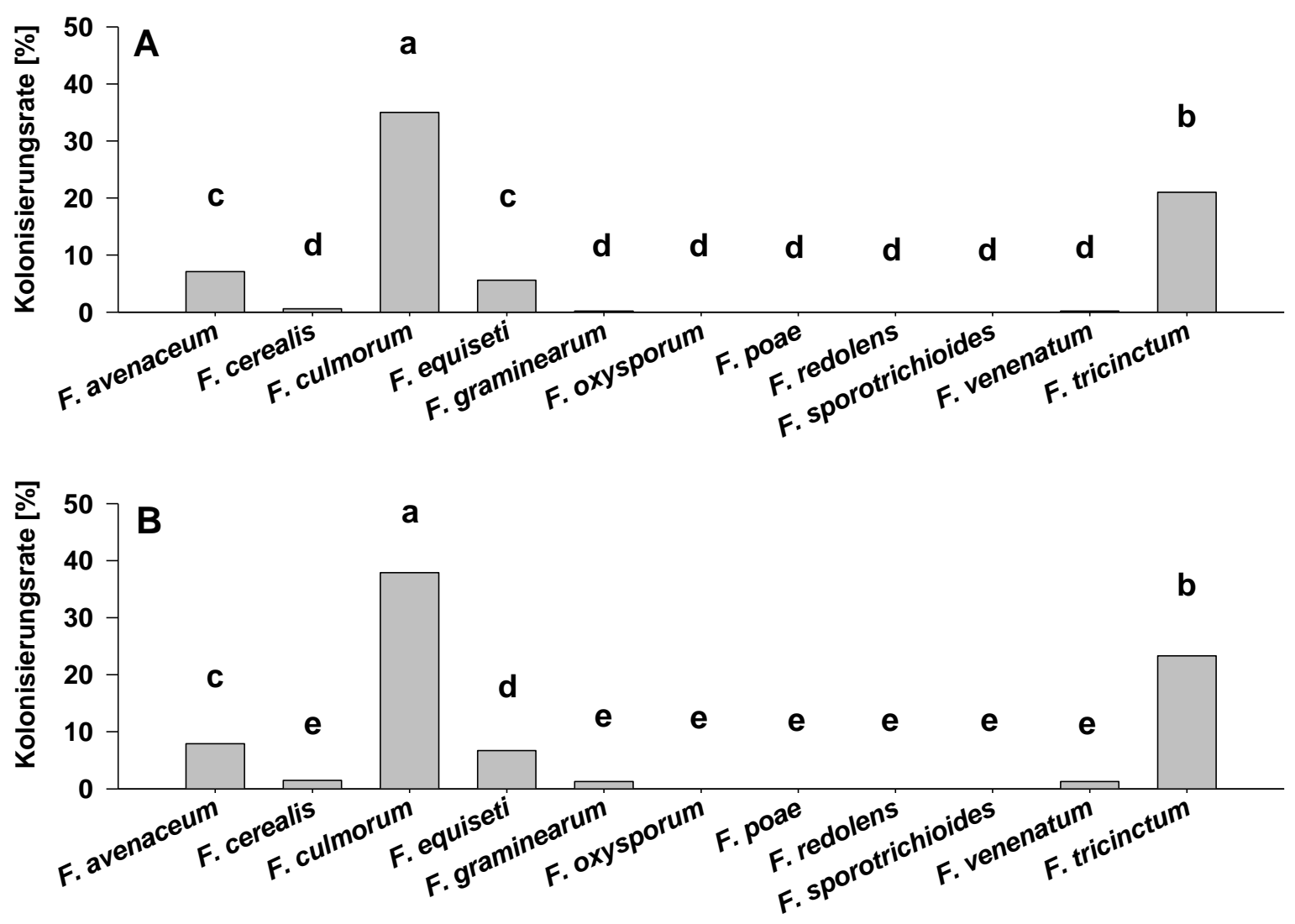

Abb. 45: Einfluss der Sorte auf Fusarium-Artenspektrum und Kolonisierungsraten der einzelnen Arten [\%] an der Halmbasis von Winterweizen in den beiden Winterweizensorten A) "Centrum" und B) „Ritmo“ zu BBCH 75-77 des Versuchsjahres 2011 am Standort Torland. Vorfrüchte: Winterweizen, Mais, Zuckerrübe und Ölrettich. Fungizidstufen: „behandelt mit Prothioconazol“ und „unbehandelt". Unterschiedliche Buchstaben kennzeichnen signifikante Unterschiede zwischen den Kolonisierungsraten $(n=480$, statistische Berechnung mittels t-Test mit $p<0,05$ ).

\section{Einfluss der Blattfungizidbehandlung}

Der Vergleich der Gesamtkolonisierungsraten der Fungizidstufen „behandelt“ und „unbehandelt“ konnte für den Probenahmezeitpunkt zu BBCH 37-39 nicht dargestellt werden, da für diesen Zeitpunkt nur die behandelten Varianten „Centrum, behandelt" und „Ritmo, behandelt“ untersucht worden waren. Dennoch sind in Abbildung 46 das detaillierte Artenspektrum sowie die Kolonisierungsraten der Fungizidstufe „behandelt“ für jede Art dargestellt, um einen Vergleich mit den beiden späteren Probenahmezeitpunkten zu ermöglichen. Die Abbildung macht deutlich, dass zu BBCH 37-39 in den behandelten Varianten die Kolonisierungsraten der einzelnen Arten in ihrer Gesamtheit recht niedrig waren. Die Arten mit den höchsten Kolonisierungsraten waren F. culmorum mit 11,9\% und F. tricinctum mit 11,7\%. Die Kolonisierungsraten beider Arten unterschieden sich nicht signifikant voneinander, jedoch zu allen anderen Arten signifikant. F. equiseti wies 
mit 6,9\% die nächsthöhere Kolonisierungsrate auf. Alle weiteren Arten brachten mit 0,2\% ( $F$. venenatum) $-2,9 \%$ ( $F$. avenaceum) noch geringere Raten hervor.

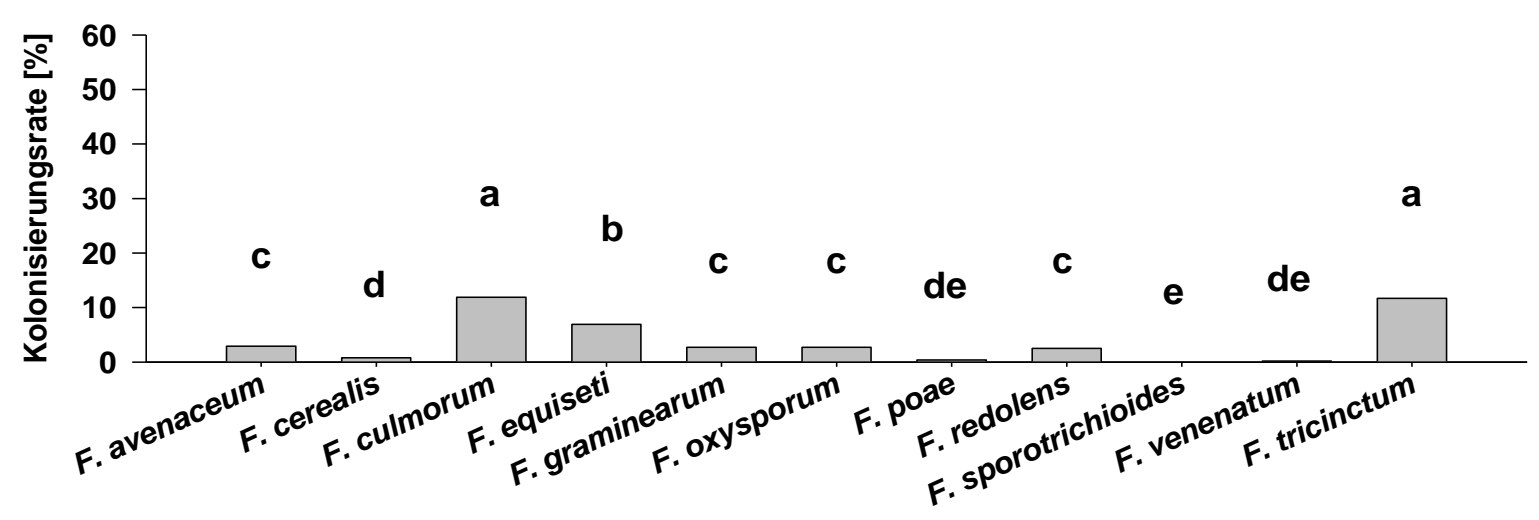

Abb. 46: Artspektrum und artspezifische Kolonisierungsraten [\%] an der Halmbasis von Winterweizen für die Fungizidstufe „behandelt“ (Prothioconazol) zu BBCH 37-39 des Versuchsjahres 2011 am Standort Torland. Vorfrüchte: Winterweizen, Mais, Zuckerrübe und Ölrettich. Sorten: „Centrum“ und „Ritmo“. Unterschiedliche Buchstaben kennzeichnen signifikante Unterschiede zwischen den Kolonisierungsraten $(n=240$, Berechnung mittels $t-$ Test mit $\mathrm{p}<0,05$ ).

$\mathrm{Zu}$ BBCH 69 ergaben die Untersuchungen der Halmbasis einen signifikanten Einfluss der Fungizidbehandlung auf die Gesamtkolonisierungsraten in den Fungizidstufen des Versuchs (Abb. 47). So konnte für die unbehandelten Varianten mit $62,8 \%$ gegenüber $44,8 \%$ in den behandelten Varianten eine fast zwanzigprozentige und damit signifikant höhere Gesamtkolonisierungsrate beobachtet werden. 


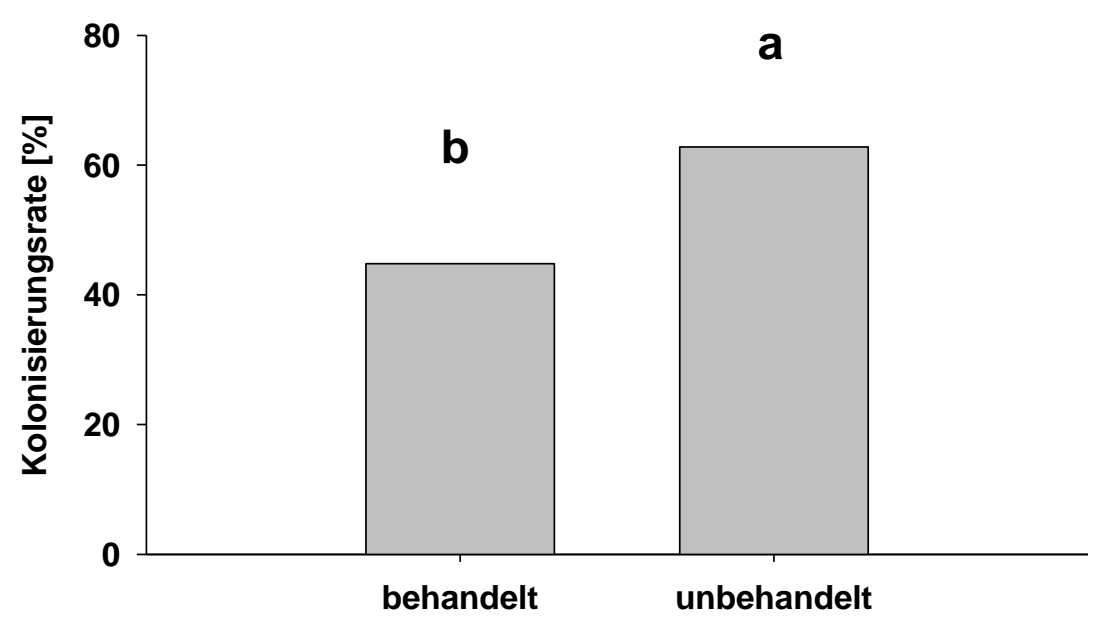

Abb. 47: Einfluss der Blattfungizidbehandlung mit Prothioconazol auf die Gesamtkolonisierungsraten von Fusarium [\%] an der Halmbasis von Winterweizen für die Fungizidstufen „,behandelt“ und „unbehandelt“ zu BBCH 69 des Versuchsjahres 2011 am Standort Torland. Vorfrüchte: Winterweizen, Mais, Zuckerrübe und Ölrettich. Sorten: "Centrum“ und „Ritmo“. Unterschiedliche Buchstaben kennzeichnen signifikante Unterschiede zwischen den Gesamtkolonisierungsraten $(n=480$, Berechnung mittels $t$-Test mit $p<0,05)$.

Die für die Gesamtkolonisierungsraten beider Fungizidstufen verantwortlichen FusariumArten waren F. culmorum mit 34,6\% Kolonisierungsrate in den behandelten (Abb. 48, A) und $45,8 \%$ in den unbehandelten Varianten (B), F. tricinctum mit 8,5\% (A) bzw. 23,3\% (B) sowie $F$. equiseti mit $5,8 \%(A)$ und $8,5 \%(B)$ Kolonisierungsrate.

Der in Abbildung 47 aufgeführte Unterschied der Gesamtkolonisierungsraten der verschiedenen Fungizidstufen war also, wie bereits für den Einfluss der Sorte beschrieben, abhängig von höheren Kolonisierungsraten der am häufigsten vorkommenden Arten, wobei die Artenspektren der beiden Fungizidstufen insgesamt gleich blieben. Ein leichter Anstieg der Kolonisierungsraten der Arten F. avenaceum, $F$. cerealis und F. graminearum von durchschnittlich $1-2 \%$ konnte in den unbehandelten Varianten jedoch festgestellt werden, was ebenso einen geringen Beitrag zur erhöhten Gesamtkolonisierungsrate in den unbehandelten Varianten geleistet hat. 

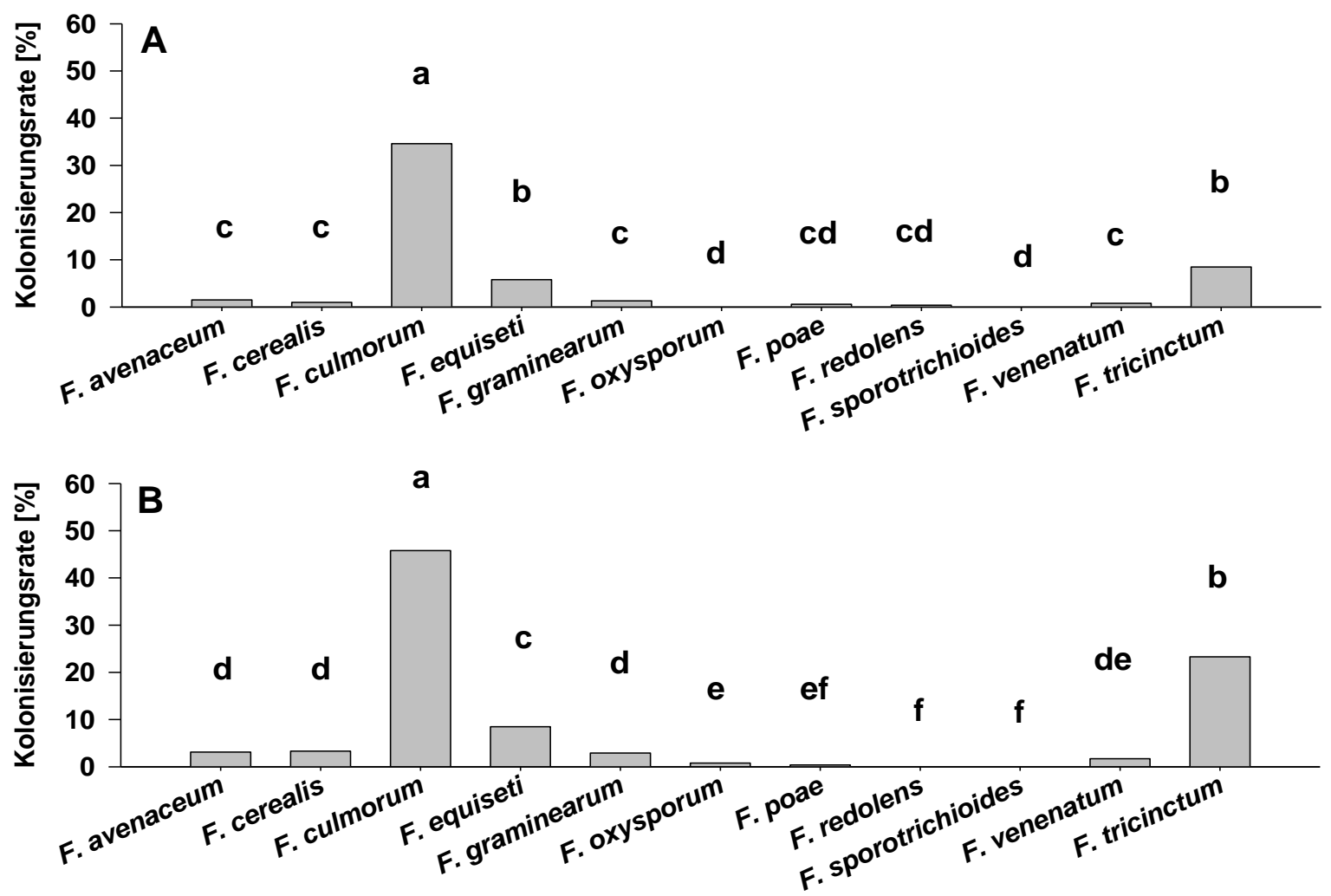

Abb. 48: Einfluss der Blattfungizidbehandlung mit Prothioconazol auf FusariumArtenspektrum und Kolonisierungsraten der einzelnen Arten [\%] an der Halmbasis von Winterweizen für die Fungizidstufen „,behandelt“ (A) und „unbehandelt“ (B) zu BBCH 69 des Versuchsjahres 2011 am Standort Torland. Vorfrüchte: Winterweizen, Mais, Zuckerrübe und ÖIrettich. Sorten: „Centrum" und „Ritmo“. Unterschiedliche Buchstaben kennzeichnen signifikante Unterschiede zwischen den Kolonisierungsraten $(n=480$, Berechnung mittels tTest mit $\mathrm{p}<0,05)$.

Ein noch deutlicherer Einfluss des Blattfungizids konnte zu $\mathrm{BBCH} 75-77$ beobachtet werden (Abb. 49). Während in den behandelten Varianten $35,8 \%$ aller Pflanzen mit Fusarium besiedelt waren, belief sich die Gesamtkolonisierungsrate in den unbehandelten Varianten mit knapp 40\% Unterschied auf 71,7\% und war somit signifikant höher, als in den behandelten Varianten. Auffällig war, dass in den behandelten Varianten zu $\mathrm{BBCH}$ 75-77 die Gesamtkolonisierungsrate 9\% unter der zu BBCH 69 lag. 
a

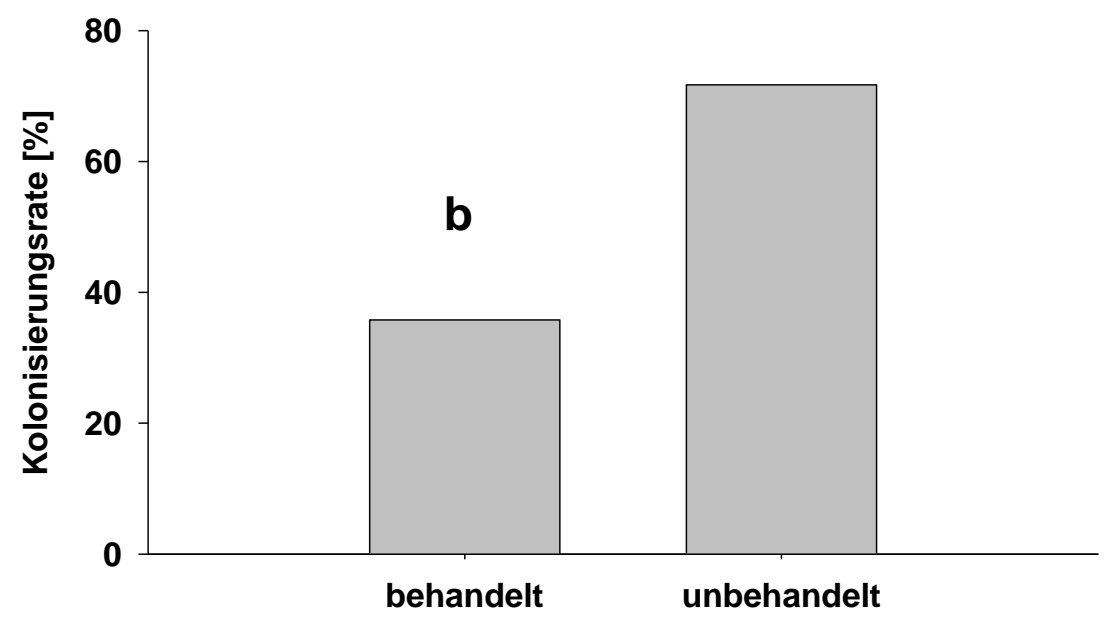

Abb. 49: Einfluss der Blattfungizidbehandlung mit Prothioconazol auf die Gesamtkolonisierungsraten von Fusarium [\%] an der Halmbasis von Winterweizen für die Fungizidstufen „behandelt" (A) und „unbehandelt" (B) zu BBCH 75-77 des Versuchsjahres 2011 am Standort Torland. Vorfrüchte: Winterweizen, Mais, Zuckerrübe und Ölrettich. Sorten: „Centrum" und „Ritmo“. Unterschiedliche Buchstaben kennzeichnen signifikante Unterschiede zwischen den Gesamtkolonisierungsraten $(n=480$, Berechnung mittels $t-T e s t$ mit $p<0,05)$.

Die zu BBCH 69 bezüglich der Artenspektren und Kolonisierungsraten in den verschiedenen Fungizidstufen gemachten Beobachtungen entsprachen in weiten Teilen denen für $\mathrm{BBCH} 75-77$. Wiederum waren die Arten F.culmorum, F. equiseti und F. tricinctum die wichtigsten Halmbasiskolonisierer (Abb. 50), wobei zu diesem Probenahmezeitpunkt auch F. avenaceum in beiden Fungizidstufen von Bedeutung war $(A, B)$ und in den behandelten Varianten sogar signifikant mehr vertreten war, als F. equiseti. Auch zu diesem Zeitpunkt war der Effekt des Fungizids in der behandelten Variante auf durchschnittlich $20 \%$ niedrigere Kolonisierungsraten der Arten F. culmorum, $F$. equiseti und F. tricinctum zurückzuführen (A). Alle übrigen Arten wiesen in beiden Varianten Kolonisierungsraten von 0,4-1,9\% auf oder waren nicht auffindbar und spielten somit keine Rolle. 


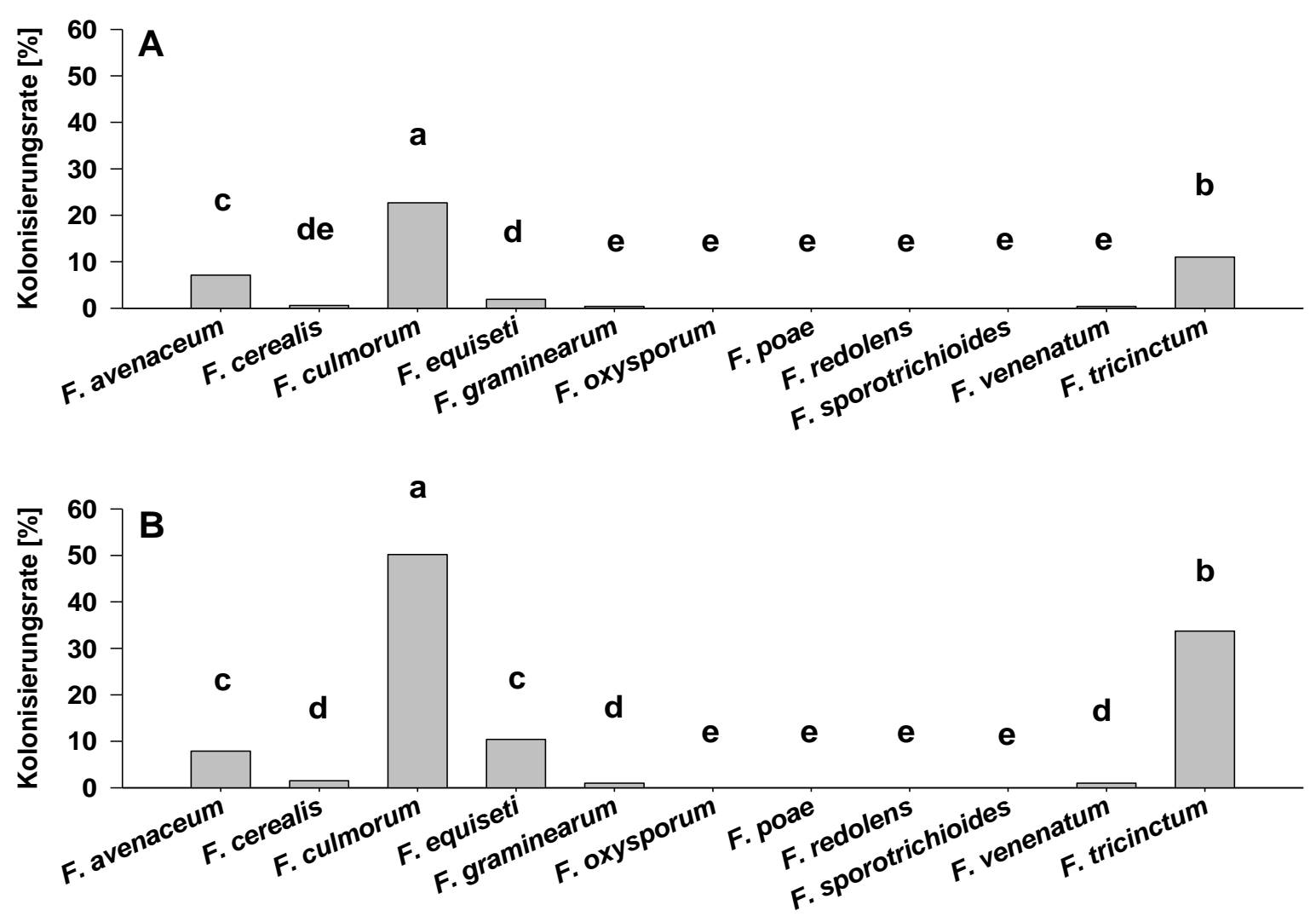

Abb. 50: Einfluss der Blattfungizidbehandlung mit Prothioconazol auf FusariumArtenspektrum und Kolonisierungsraten der einzelnen Arten [\%] an der Halmbasis von Winterweizen für die Fungizidstufen „,behandelt“ (A) und „unbehandelt" (B) zu BBCH 75-77 des Versuchsjahres 2011 am Standort Torland. Vorfrüchte: Winterweizen, Mais, Zuckerrübe und Ölrettich. Sorten: „Centrum“ und „Ritmo“. Unterschiedliche Buchstaben kennzeichnen signifikante Unterschiede zwischen den Kolonisierungsraten $(n=480$, statistische Berechnung mittels t-Test mit $p<0,05)$.

\subsubsection{Einfluss der Versuchsparameter auf das Fusarium-Artenspektrum an Körnern 2011}

Auf Grund für eine Infektion mit Fusarium ungünstiger Witterungsverhältnisse zur Blüte im Versuchsjahr 2011 (s. 3.1.1), stellte sich der Befall der Körner am Standort Torland zu $\mathrm{BBCH} 92$ als äußerst gering dar. Dennoch werden die Ergebnisse dieses Abschnitts wie in den vorherigen Abschnitten behandelt. Im Folgenden sind, wie bereits für das Versuchsjahr 2010 erfolgt (s. 3.2.2), die Effekte der verschiedenen Versuchsparameter auf Gesamtkolonisierungsraten, Artenspektren und deren Kolonisierung der Körner aufgeführt. 


\section{Einfluss der Vorfrucht}

Im Versuchsjahr 2011 war das Gesamtauftreten von Fusarium im Erntegut als sehr niedrig anzusehen. Dennoch konnten eindeutige Effekte herausgestellt werden. In diesem Versuchsjahr zeigten sich signifikante Unterschiede der Kolonisierung des Weizens nach den verschiedenen Vorfrüchten, welche in Abbildung 51 dargestellt sind. Nach Winterweizen trat mit $15,5 \%$ die signifikant höchste Gesamtkolonisierungsrate vor Mais mit 9,1\%, Zuckerrübe mit 7,0\% und Ölrettich mit 5,6\% auf, sodass ein kontinuierliches Abnehmen der Gesamtkolonisierungsraten von Winterweizen hin zu Ölrettich festgestellt werden konnte.

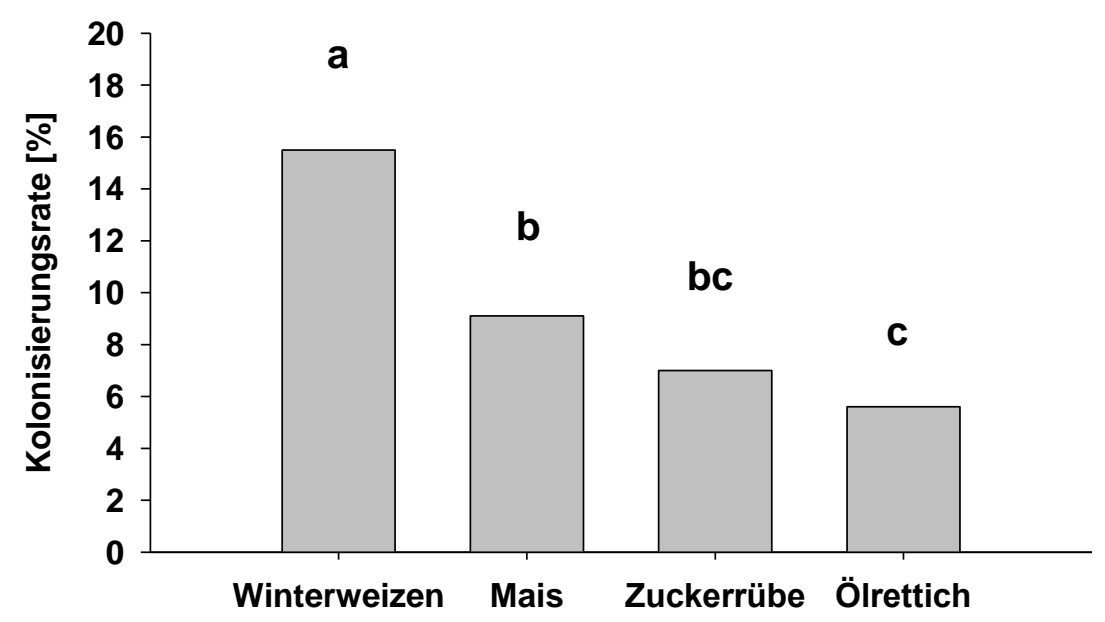

Abb. 51: Einfluss der Vorfrucht auf die Gesamtkolonisierungsraten von Fusarium [\%] an Körnern von Winterweizen nach den vier Vorfrüchten Winterweizen, Mais, Zuckerrübe und Ölrettich zu BBCH 92 des Versuchsjahres 2011 am Standort Torland. Sorten: „Centrum“ und „Ritmo“", Fungizidstufen: „behandelt mit Prothioconazol“ und „unbehandelt". Unterschiedliche Buchstaben kennzeichnen signifikante Unterschiede zwischen den Gesamtkolonisierungsraten $(n=800$, statistische Berechnung mittels einfaktorieller ANOVA mit $p<0,05)$.

Das Artenspektrum nach Winterweizen (Abb. 52, A) wies die signifikant höchsten Kolonisierungsraten für F. culmorum mit $6,5 \%$, F. poae mit 3,6\% und F. tricinctum mit $3,1 \%$ auf, wobei sich F.poae und F. tricinctum mit um die Hälfte niedrigeren Kolonisierungsraten signifikant von F. culmorum unterschieden. Da ohnehin nur sehr geringe Kolonisierungsraten für alle Arten vorlagen, waren die restlichen Arten mit Kolonisierungsraten von 0,1-1\% nicht von Bedeutung. Abbildung 52 (B) zeigt das Artenspektrum nach Vorfrucht Mais. Hier war ein homogeneres Muster an auftretenden Arten zu erkennen, welche mit ihren Kolonisierungsraten die $2 \%$ nicht überschritten. F. tricinctum kam mit einer Kolonisierungsrate von 2,4\% am häufigsten vor. Auch nach Zuckerrübe erreichten lediglich $F$. poae mit 2,1\% und $F$. tricinctum mit 2,6\% gegenüber 
allen anderen Arten signifikant erhöhte Kolonisierungsraten, während F. culmorum mit $0,8 \%$ signifikant weniger anzutreffen war. Nach Ölrettich, der Vorfrucht, welche die niedrigste Gesamtkolonisierungsrate zu verzeichnen hatte, war F.poae mit einer Kolonisierungsrate von $3,4 \%$ die am häufigsten vorkommende Fusarium-Art vor F. tricinctum mit $1,5 \%$. Alle anderen Arten kamen entweder nicht vor oder waren nur durch Einzelisolate vertreten. 

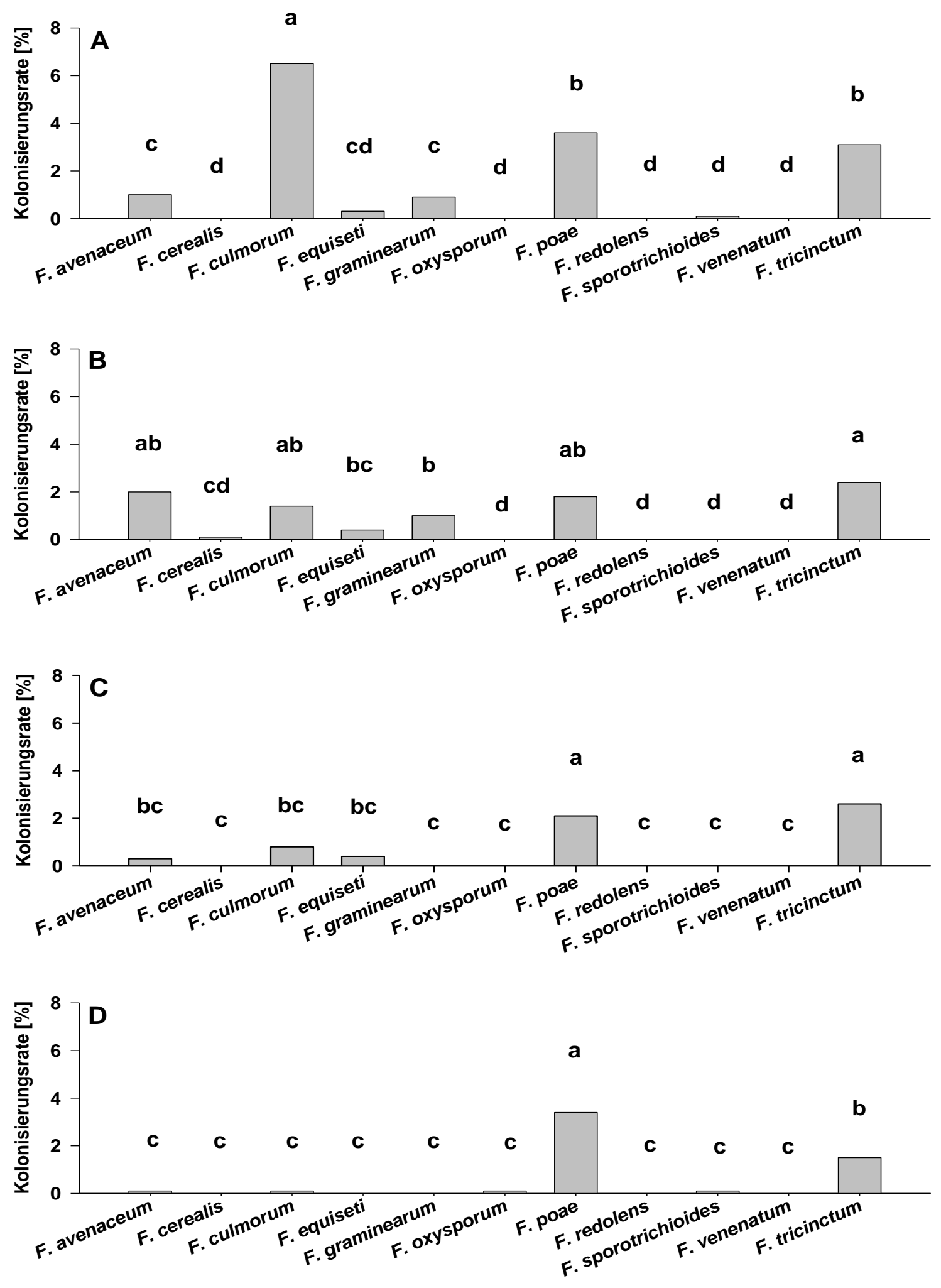

Abb. 52: Einfluss der Vorfrucht auf Fusarium-Artenspektrum und Kolonisierungsraten der einzelnen Arten [\%] an Körnern von Winterweizen nach den vier Vorfrüchten A) Winterweizen, B) Mais, C) Zuckerrübe und D) Ölrettich zu BBCH 92 des Versuchsjahres 2011 am Standort Torland. Sorten: „Centrum“ und „Ritmo“, Fungizidstufen: „,behandelt mit Prothioconazol" und "unbehandelt". Unterschiedliche Buchstaben kennzeichnen signifikante Unterschiede zwischen den Kolonisierungsraten $(n=800$, statistische Berechnung mittels t-Test mit $p<0,05$ ). 


\section{Einfluss der Sorte}

Der Sortenunterschied bezüglich der Gesamtkolonisierungsraten der Körner war 2011, wie bereits für 2010 gezeigt, trotz geringer Kolonisierungsraten recht ausgeprägt (Abb. 53). So verzeichnete die resistente Sorte „Centrum“ mit 4,8\% eine signifikante Verringerung der Gesamtkolonisierungsrate im Vergleich zu „Ritmo“ mit 13,8\%.

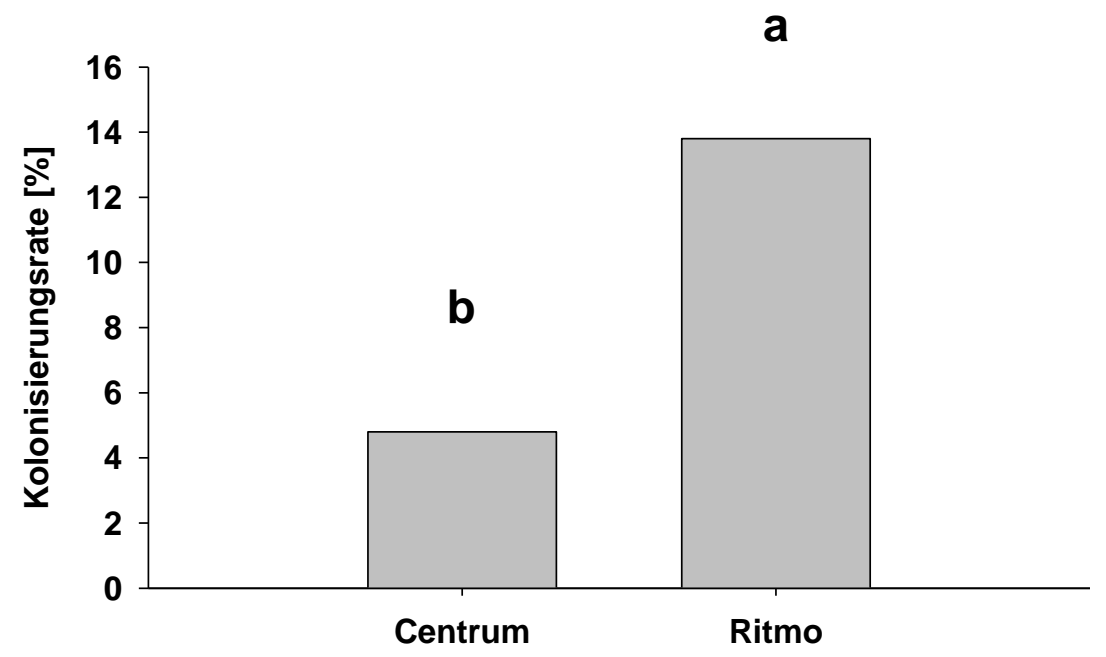

Abb. 53: Einfluss der Sorte auf die Gesamtkolonisierungsraten von Fusarium [\%] an Körnern von Winterweizen in den beiden Winterweizensorten „Centrum" (resistent) und „Ritmo“ (anfällig) zu BBCH 92 des Versuchsjahres 2011 am Standort Torland. Vorfrüchte: Winterweizen, Mais, Zuckerrübe und Ölrettich. Fungizidstufen: „behandelt mit Prothioconazol“ und "unbehandelt". Unterschiedliche Buchstaben kennzeichnen signifikante Unterschiede zwischen den Gesamtkolonisierungsraten $(n=1600$, statistische Berechnung mittels $t$-Test mit $p<0,05$ ).

In der resistenten Sorte "Centrum“ konnten nur äußerst geringe Kolonisierungsraten ermittelt werden (Abb. 54, A). Die Arten mit den höchsten Raten waren F. poae $(1,4 \%)$, F. culmorum (0,9\%), F. avenaceum (0,9\%) und F. tricinctum (0,8\%). Die Arten F. culmorum, F. poae und F. tricinctum verursachten in der anfälligen Sorte „Ritmo“ zu gleichen Teilen erhöhte Kolonisierungsraten von 3,4-4,1\%, welche in der Sorte „Centrum“ erheblich reduziert vorlagen und waren somit für den in Abbildung 53 aufgeführten Sorteneffekt verantwortlich. 

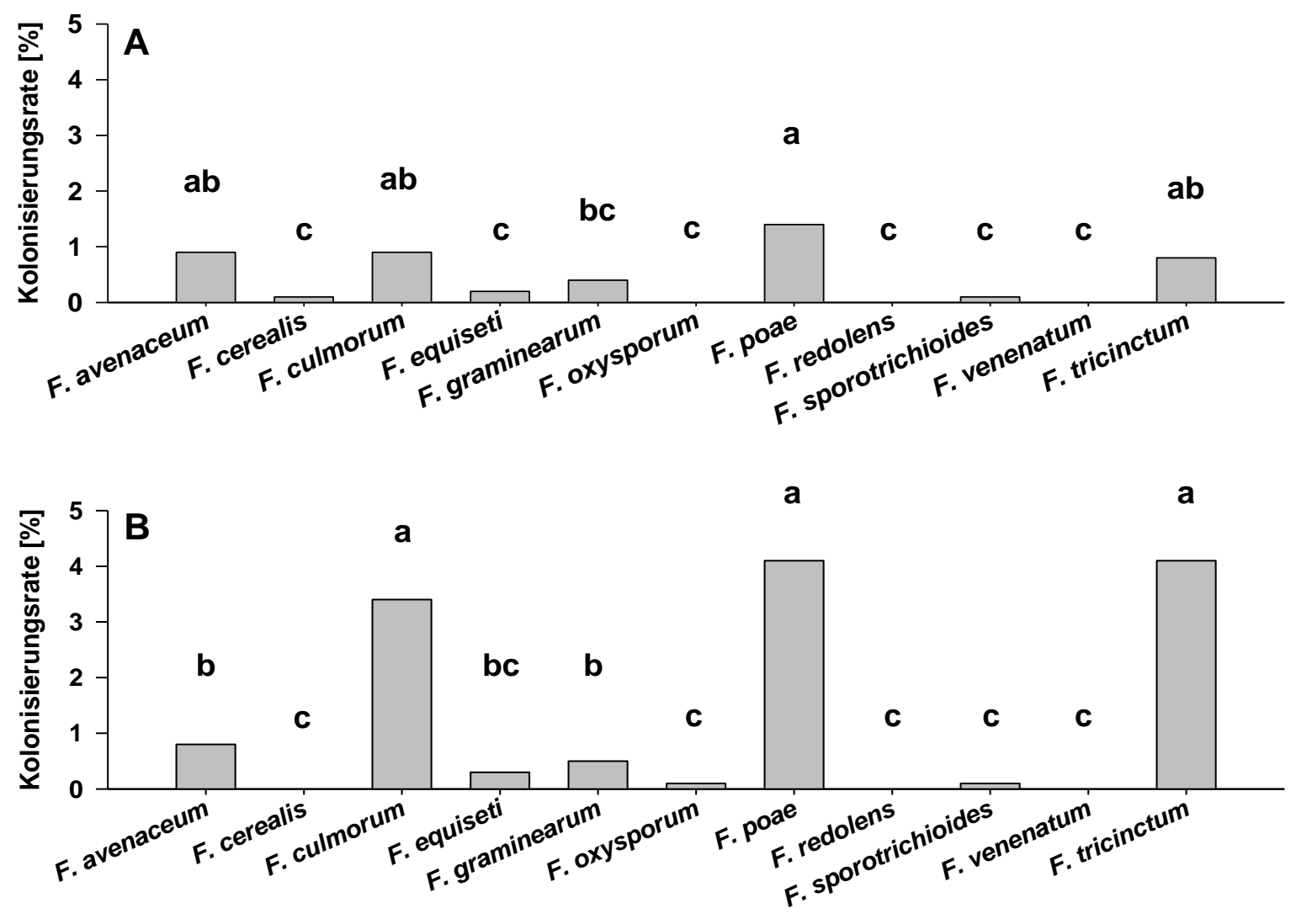

Abb. 54: Einfluss der Sorte auf Fusarium-Artenspektrum und Kolonisierungsraten der einzelnen Arten [\%] an Körnern von Winterweizen in den beiden Winterweizensorten A) „Centrum“ und B) „Ritmo“ zu BBCH 92 des Versuchsjahres 2011 am Standort Torland. Vorfrüchte: Winterweizen, Mais, Zuckerrübe und Ölrettich. Fungizidstufen: „behandelt mit Prothioconazol" und "unbehandelt". Unterschiedliche Buchstaben kennzeichnen signifikante Unterschiede zwischen den Kolonisierungsraten $(n=1600$, statistische Berechnung mittels t-Test mit $p<0,05$ ).

\section{Einfluss des Fungizids}

Die Blattfungizidapplikation hatte mit 4\% Unterschied zwischen den behandelten und den unbehandelten Varianten des Versuchs einen geringen, aber dennoch signifikanten Effekt auf die Gesamtkolonisierungsraten in den behandelten Varianten (Abb. 55). 
a

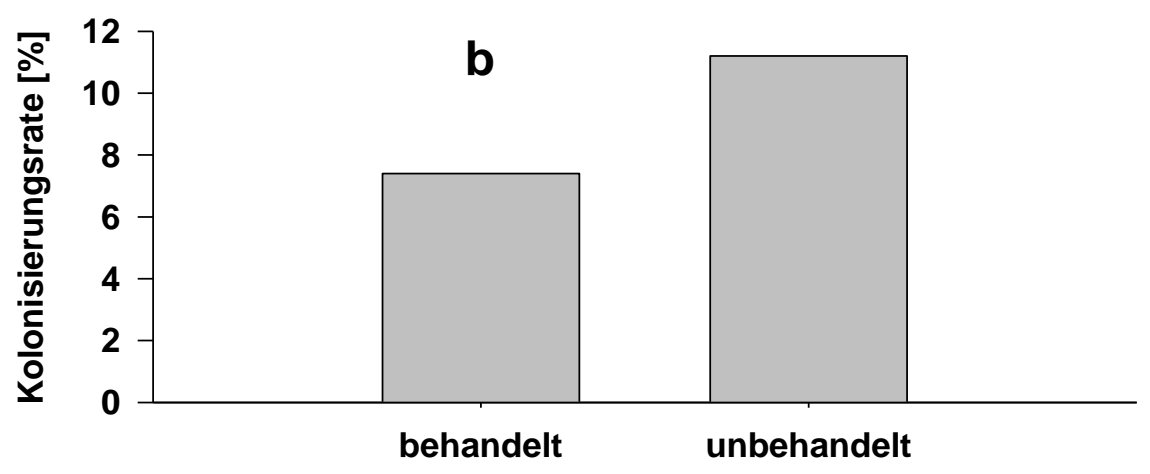

Abb. 55: Einfluss der Blattfungizidbehandlung mit Prothioconazol auf die Gesamtkolonisierungsraten von Fusarium [\%] an Körnern von Winterweizen für die Fungizidstufen „behandelt" und „unbehandelt" zu BBCH 92 des Versuchsjahres 2011 am Standort Torland. Vorfrüchte: Winterweizen, Mais, Zuckerrübe und ÖIrettich. Sorten: „Centrum“ und „Ritmo“. Unterschiedliche Buchstaben kennzeichnen signifikante Unterschiede zwischen den Gesamtkolonisierungsraten ( $n=1600$, Berechnung mittels t-Test mit $p<0,05)$.

Wie in Abbildung 56 A und B zu sehen ist, hatte die Blattfungizidapplikation ausschließlich auf die Kolonisierungsrate von F. culmorum einen limitierenden Effekt, welcher sich in einer 3,2\% niedrigeren Kolonisierungsrate in den behandelten gegenüber den unbehandelten Varianten äußerte. Auf die in beiden Fungizidstufen mit am häufigsten auftretenden Arten F. poae und F. tricinctum blieb die Fungizidanwendung ohne Effekt. 

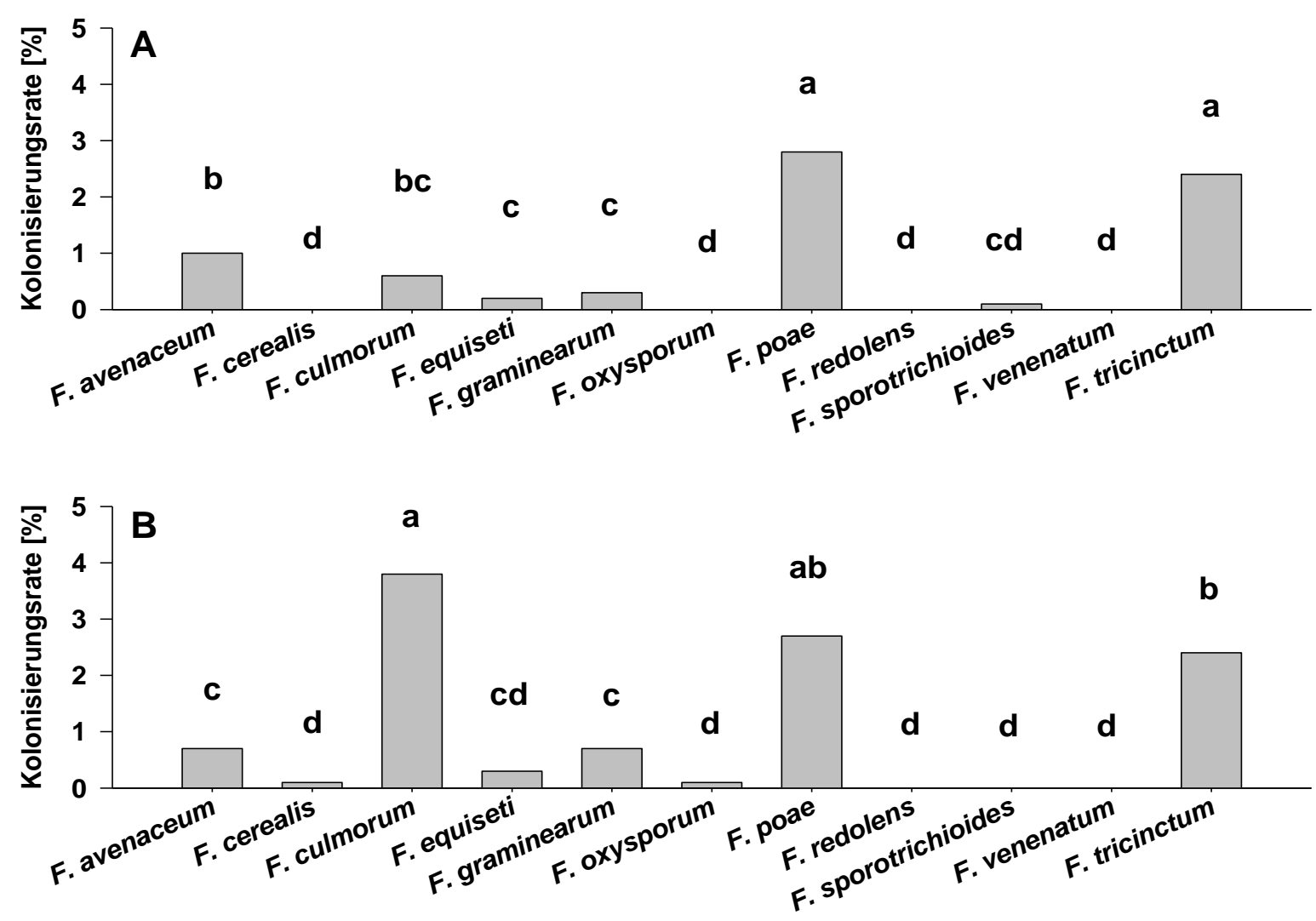

Abb. 56: Einfluss der Blattfungizidbehandlung mit Prothioconazol auf FusariumArtenspektrum und Kolonisierungsraten der einzelnen Arten [\%] an Körnern von Winterweizen für die Fungizidstufen „,behandelt“ (A) und „unbehandelt“ (B) zu BBCH 92 des Versuchsjahres 2011 am Standort Torland. Vorfrüchte: Winterweizen, Mais, Zuckerrübe und ÖIrettich. Sorten: „Centrum“ und „Ritmo“. Unterschiedliche Buchstaben kennzeichnen signifikante Unterschiede zwischen den Kolonisierungsraten $(n=1600$, statistische Berechnung mittels $t$-Test mit $p<0,05$ ).

Ebenso für den Einfluss von Vorfrucht und Sorte, konnte auch für den Einfluss des Fungizids an den Körnern eine dominierende Rolle der Arten F. poae und F. tricinctum sowie zu einem gewissen Grad F. culmorum beobachtet werden.

\subsubsection{Vergleich der Fusarium-Artenspektren an den verschiedenen Pflanzenorganen 2011}

Für den Vergleich der Artenspektren sowie Kolonisierungsraten von Fusarium an Halmbasis und Körnern des Versuchsjahres 2011 wurden für beide Pflanzenteile jeweils die vier Versuchsvarianten „Centrum, behandelt“, „Ritmo, behandelt“, „Centrum, unbehandelt“ und „Ritmo, unbehandelt“ herangezogen. Für die Halmbasis wurde, wie bereits unter 3.2.3 für das Jahr 2010 durchgeführt, nur der Zeitpunkt der Milchreife betrachtet, da dieser dem Zeitpunkt der Ernte zu BBCH 92 der Körner zeitlich am nächsten lag. Bedingt durch den sehr geringen Anteil an durch Fusarium kolonisierten 
Körnern im Erntegut zu BBCH 92, ergaben sich für die meisten Arten, die sowohl an der Halmbasis, als auch an Körnern vorkamen, vergleichsweise deutlich höhere Kolonisierungsraten an der Halmbasis (Abb. 57). F. culmorum beispielsweise erreichte an der Halmbasis eine Kolonisierungsrate von 37,8\% und war damit hoch signifikant häufiger vertreten als an den Körnern (2,2\%). Die an der Halmbasis am zweithäufigsten isolierte Art war F. tricinctum mit einer Kolonisierungsrate von 22,6\%. Auch hier war das Auftreten an der Halmbasis mit einer $20 \%$ höheren Rate gegenüber F. tricinctum an den Körnern hoch signifikant. Dies konnte auch für weitaus weniger häufige Arten wie F. avenaceum, $F$. equiseti, F. cerealis und F. venenatum bestätigt werden. Wie bereits für 2010 gezeigt, war F. poae hoch signifikant häufiger an den Körnern vertreten, als an der Halmbasis. F. graminearum und F. sporotrichioides traten nur sehr vereinzelt sowohl an Halmbasis, als auch an Körnern auf. Bei diesen Arten konnte kein signifikanter Unterschied im Vorkommen zwischen den beiden Pflanzenteilen ermittelt werden. F. oxysporum und F. redolens kamen weder an den Körnern, noch zu dem für den Vergleich herangezogenen Probenahmezeitpunkt zu BBCH 75-77 an der Halmbasis vor.

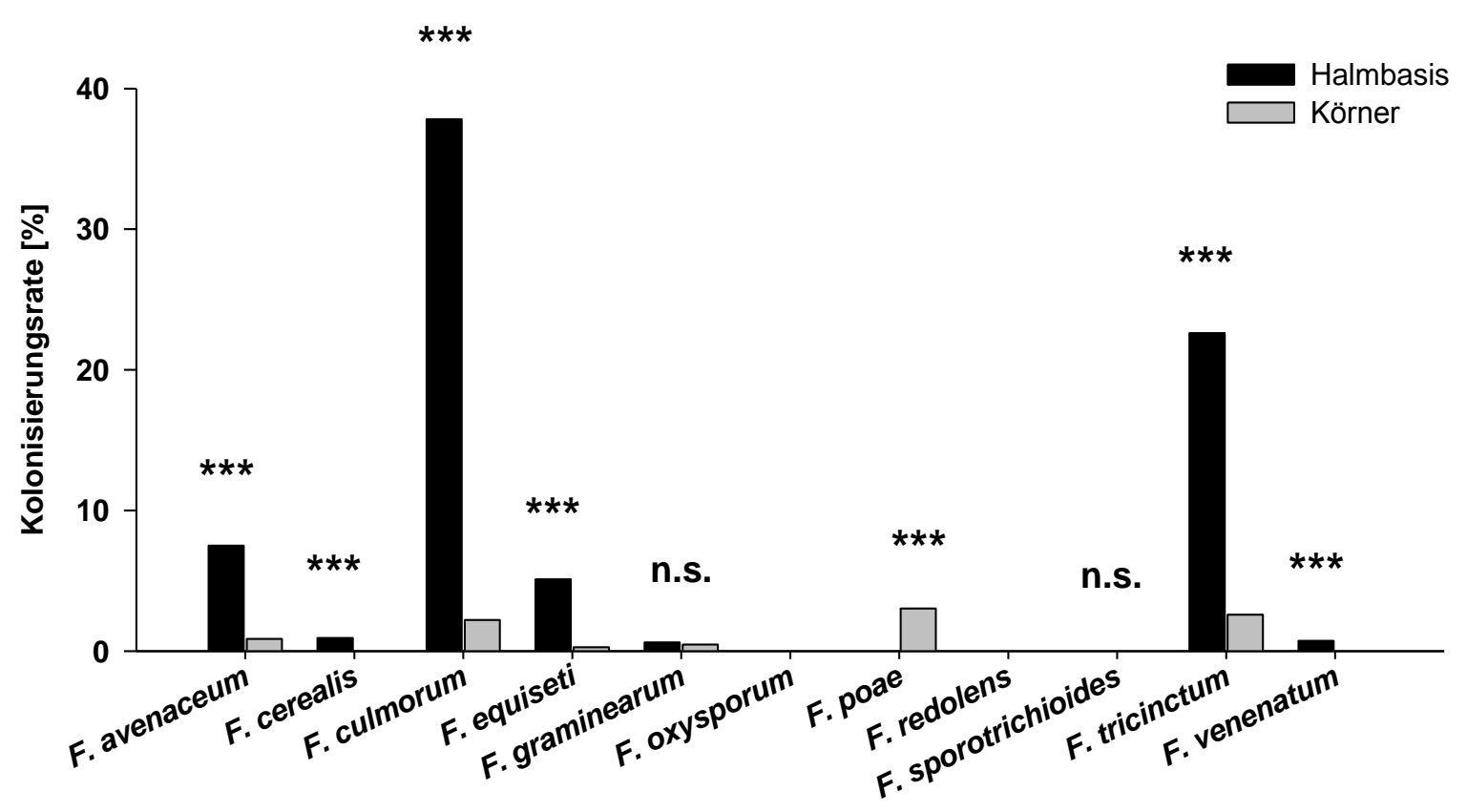

Abb. 57: Vergleich von Fusarium-Artenspektren und Kolonisierungsraten an Halmbasis und Körnern von Winterweizen aller Versuchsvarianten zu BBCH 75-77 (Halmbasis) und BBCH 92 (Körner) des Versuchsjahres 2011 am Standort Torland. Vorfrüchte: Winterweizen, Mais, Zuckerrübe und Ölrettich. Sorten: „Centrum“ und „Ritmo“. Fungizidstufen: „,behandelt mit Prothioconazol“ und "unbehandelt". Das Symbol *** kennzeichnet signifikante Unterschiede zwischen den Kolonisierungsraten der einzelnen Arten an den verschiedenen Pflanzenteilen. Arten die nicht vorkamen, wurden für die statistische Auswertung nicht berücksichtigt (Halm: $n=960$, Körner: $n=3200$ statistische Berechnung mittels Prozentsatzdifferenz mit Irrtumswahrscheinlichkeiten von ${ }^{*}=5 \%(p<0,05),{ }^{* *}=1 \%$ $(p<0,01)$ und $^{* \star \star}=0,1 \%(p<0,001)$, n.s. = nicht signifikant $)$. 
Es konnte somit gezeigt werden, dass an der Halmbasis im Versuchsjahr 2011 F. culmorum und F. tricinctum von großer Bedeutung waren. Auch F. avenaceum und F. equiseti spielten an der Halmbasis eine Rolle, wogegen die übrigen Arten kaum auftraten oder nicht vorkamen. An den Körnern konnte trotz der niedrigen Kolonisierungsraten F.poae, F.tricinctum und F.culmorum (besonders nach Winterweizen), als wichtigste Kolonisierer der Körner identifiziert werden.

\subsubsection{Vergleich der Fusarium-Artenspektren der beiden Versuchsjahre 2010 und 2011}

In den vorangegangenen Abschnitten dieses Kapitels wurden der Einfluss der verschiedenen Versuchsparameter auf Artenspektren und Kolonisierungsraten von Fusarium an Halmbasis und Körnern von Winterweizen für die Versuchsjahre 2010 und 2011 separat dargestellt. Im Folgenden wurden daher die Kolonisierungsraten der verschiedenen Fusarium-Arten der beiden Versuchsjahre einem Vergleich unterzogen. Auf Basis dieses Vergleichs war es möglich, Aussagen darüber zu machen, in wieweit die Ergebnisse des Jahres 2010 im Jahr 2011 bestätigt werden konnten und inwiefern die jahresbedingte Witterung einen Einfluss auf die Artenspektren bzw. Kolonisierungsraten der einzelnen Arten hatte.

\section{Vergleich der Fusarium-Artenspektren der Halmbasis 2010 und 2011}

Für den Vergleich der Artenspektren der Halmbasis wurden unter Berücksichtigung der Vergleichbarkeit für beide Jahre die Ergebnisse der Versuchsvariante 4 „Ritmo unbehandelt" gewählt, da 2010 nur diese Variante untersucht worden war (s. 3.2.1). Um ein vollständiges Bild der Fusarium-Artenspektren zu ermöglichen, sind alle 11 FusariumArten, die in den beiden Versuchsjahren an Halmbasis und Körnern aufgetreten waren, in den Vergleich der Artenspektren mit einbezogen worden.

Im Hinblick auf das Artenspektrum sind in Abbildung 58 große Übereinstimmungen zwischen den Versuchsjahren zu erkennen. Sowohl 2010, als auch 2011 waren F. culmorum, F. tricinctum und F. equiseti die am häufigsten vorkommenden Arten und somit die Haupthalmbasiskolonisierer. Ein großer Unterschied bestand dagegen in den Kolonisierungsraten. 2010 war F. tricinctum mit 30,2 \% die häufigste Art und zeigte hoch signifikant höhere Kolonisierungsraten als 2011. Ähnliches konnte auch in Bezug auf F. culmorum beobachtet werden. Während 2011 F. culmorum mit 51,0\% Kolonisierungsrate die mit Abstand häufigste Art darstellte, war sie 2010 mit insgesamt $16,7 \%$ wesentlich seltener isoliert worden. F. equiseti zeigte 2010 eine signifikant höhere Kolonisierungsrate als 2011, dennoch sind die Raten mit 12,1\% und 9,2\% auf ähnlichem 
Niveau. Für F. avenaceum konnte 2011 eine hoch signifikante Kolonisierungsrate gegenüber 2010 festgestellt werden. Die Arten $F$. cerealis und $F$. venenatum waren nur 2011 vertreten. F. oxysporum wurde im Jahr 2010 häufiger isoliert. Die Kolonisierungsraten für F. graminearum waren nicht signifikant verschieden. F. poae und F. redolens kamen 2010 nicht vor, F. sporotrichioides war in beiden Jahren an der Halmbasis nicht aufzufinden.

Die Ergebnisse der Halmbasis des Versuchsjahres 2010 konnten somit durch 2011 insgesamt bestätigt werden.

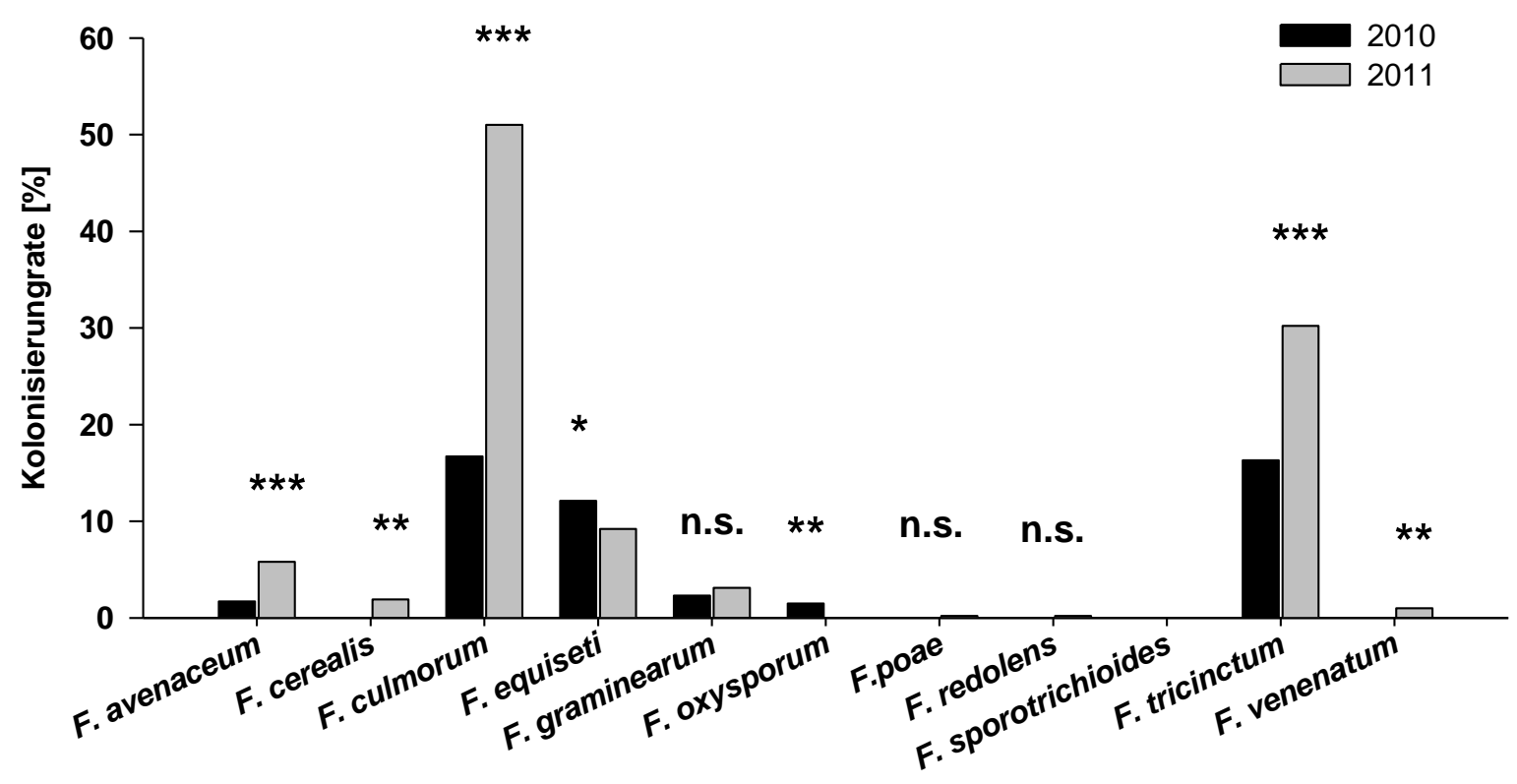

Abb. 58: Vergleich von Fusarium-Artenspektren und Kolonisierungsraten der einzelnen Arten [\%] an der Halmbasis von Winterweizen der Versuchsvariante „Ritmo, unbehandelt“" am Standort Torland. Die Kolonisierungsraten der Probenahmezeitpunkte BBCH 61-65 (BBCH 69 für 2011) und BBCH 71-75 (BBCH 75-77 für 2011) der Versuchsjahre 2010 und 2011 wurden für den Vergleich zusammengefasst. Vorfrüchte: Winterweizen, Mais, Zuckerrübe und ÖIrettich. Die Symbole ${ }^{*}{ }^{* *}$ und ${ }^{* * *}$ kennzeichnen signifikante Unterschiede der Kolonisierungsraten zwischen den beiden Versuchjahren für jede Art. Arten, die nicht vorkamen, wurden für die statistische Auswertung nicht berücksichtigt ( $n=480$ für 2010, $\mathrm{n}=1920$ für 2011, statistische Berechnung mittels Prozentsatzdifferenz mit Irrtumswahrscheinlichkeiten von ${ }^{*}=5 \%(p<0,05),{ }^{* \star}=1 \%(p<0,01)$ und ${ }^{\star \star \star}=0,1 \%(p<$ 0,001, n.s. $=$ nicht signifikant).

\section{Vergleich der Fusarium-Artenspektren an Körnern 2010 und 2011}

Wie bereits unter 3.2.2 und 3.2.5 festgestellt, bewegte sich die Kolonisierung der Körner im Vergleich zur Halmbasis in beiden Jahren auf wesentlich niedrigerem Niveau. In Abbildung 59 sind die Fusarium-Artenspektren sowie Kolonisierungsraten an den Körnern der Versuchsjahre 2010 und 2011 angegeben. Die Artenspektren der beiden Jahre 
wiesen große Ähnlichkeiten auf. Wie zuvor bei der Halmbasis, waren besonders große Unterschiede bezüglich der Kolonisierungsraten zu erkennen. So waren in beiden Jahren die mit Abstand wichtigsten Arten an den Körnern F. tricinctum und F. poae. 2010 waren jedoch die Unterschiede der Kolonisierungsraten mit 7,1\% für F. tricinctum und 6,1\% für F. poae gegenüber Kolonisierungsraten von 2,6\% und 3,0\% im Jahr 2011 hoch signifikant. F. graminearum war 2010 besonders nach Mais häufig zu finden (s. 3.2.2), während die Art 2011 kaum nachgewiesen werden konnte, wodurch sich ein höchst signifikanter Unterschied im Hinblick auf die Kolonisierungsraten ergab. F. culmorum war in beiden Versuchsjahren anzutreffen, die Kolonisierungsrate dieser Art war 2010 jedoch hoch signifikant gegenüber 2011, wo diese Art nur nach Winterweizen häufiger isoliert worden war. Lediglich F. avenaceum konnte 2011 häufiger isoliert werden als 2010, spielte aber in beiden Versuchsjahren insgesamt eine untergeordnete Rolle.

Die Rolle als in Versuchsjahr 2010 wichtigste Kornkolonisierer konnte 2011 für F. poae und F. tricinctum bestätigt werden.

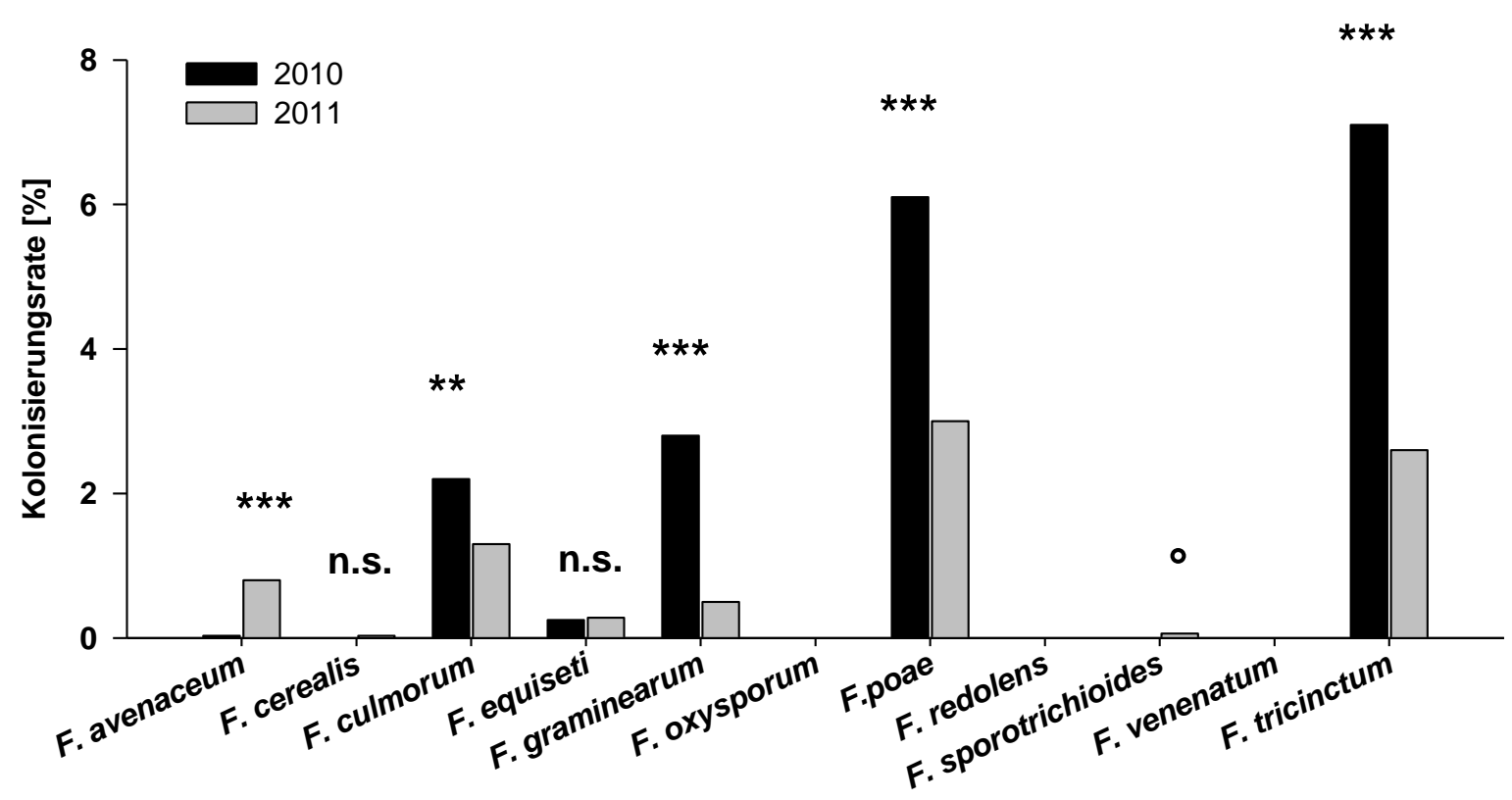

Abb. 59: Vergleich von Fusarium-Artenspektren und Kolonisierungsraten der einzelnen Arten [\%] an Körnern von Winterweizen aller Versuchsvarianten zu BBCH 92 der Versuchsjahre 2010 und 2011 am Standort Torland. Vorfrüchte: Winterweizen, Mais, Zuckerrübe und Ölrettich. Sorten: „Centrum“ und „Ritmo“, Fungizidstufen: „behandelt mit Prothioconazol“ und „unbehandelt". Die Symbole *, ${ }^{\star *}$ und ${ }^{* * *}$ kennzeichnen signifikante Unterschiede der Kolonisierungsraten zwischen den Jahren für jede Art ( $n=3200$ für 2010, $\mathrm{n}=3200$ für 2011, statistische Berechnung mittels Prozentsatzdifferenz mit Irrtumswahrscheinlichkeiten von ${ }^{\circ}=10 \%(p<0,1),{ }^{*}=5 \%(p<0,05),{ }^{* *}=1 \%(p<0,01)$ und ${ }^{\star \star *}=$ $0,1 \%(p<0,001, n . s .=$ nicht signifikant $)$. 


\subsubsection{Varianzanalyse der Gesamtkolonisierungsraten an Halmbasis und Körnern 2010 und 2011}

Die Gesamtkolonisierungsraten an Halmbasis und Körnern wurden zusätzlich zu den unter 3.2.1 und 3.2.4 bzw. 3.2.2 und 3.2.5 durchgeführten Berechnungen einer Gesamtvarianzanalyse unterzogen, um Interaktionen zwischen den Effekten der drei Versuchsfaktoren Vorfrucht, Sorte und Fungizid zu untersuchen. Die Varianzanalyse wurde für beide Jahre getrennt durchgeführt. Hierbei konnte für das Jahr 2010 lediglich der Effekt der Vorfrucht auf die Gesamtkolonisierungsraten an der Halmbasis dargestellt werden (s. 3.2.1). Wie in Tabelle 21 zu erkennen, war der Vorfruchteffekt auf die Gesamtkolonisierungsraten sowohl 2010 als auch 2011 signifikant. Im Versuchsjahr 2011 war zudem ein signifikanter Sorten- sowie Fungizideffekt zu beobachten, sodass die in den vorangegangenen Kapiteln herausgestellten Einzeleffekte der Versuchsfaktoren Vorfrucht, Sorte und Fungizid durch die Varianzanalyse bestätigt werden konnten. Ein signifikanter Effekt ergab sich im Jahr 2011 für die Interaktion VorfruchtFungizid. Alle anderen Interaktionen waren nicht signifikant. 
Tab. 21: Varianzanalyse der Gesamtkolonisierungsraten an der Halmbasis im FAENFruchtfolgeversuch der Jahre 2010 und 2011 am Standort Torland zu BBCH 71-75 (2010) und BBCH 75-77 (2011). Dargestellt sind die Effekte der drei Versuchsfaktoren Vorfrucht, Sorte und Fungizid sowie die daraus resultierenden Interaktionskomponenten getrennt nach Jahren. Für das Jahr 2010 konnte nur der Effekt der Vorfrucht berechnet werden (s. 3.2.1, statistische Berechnung mittels mehrfaktorieller ANOVA, Signifikanz der Effekte bei $p<0,05)$.

\begin{tabular}{|c|c|c|c|c|c|}
\hline Jahr & Effekt & $\begin{array}{c}\text { Freiheitgrade } \\
\text { (Zähler) }\end{array}$ & $\begin{array}{c}\text { Freiheitsgrade } \\
\text { (Nenner) }\end{array}$ & F-Wert & $\mathrm{p}$-Wert \\
\hline 2010 & Vorfrucht & 3 & 20 & 5,86 & 0,0048 \\
\hline 2011 & Vorfrucht & 3 & 80 & 58,94 & $<0,0001$ \\
\hline 2010 & Sorte & - & - & - & - \\
\hline 2011 & Sorte & 1 & 80 & 7,32 & 0,0083 \\
\hline 2010 & Fungizid & - & - & - & - \\
\hline 2011 & Fungizid & 1 & 80 & 104,69 & $<0,0001$ \\
\hline 2010 & Vorfrucht*Sorte & - & - & - & - \\
\hline 2011 & Vorfrucht ${ }^{\star}$ Sorte & 3 & 80 & 1,76 & 0,1622 \\
\hline 2010 & Vorfrucht ${ }^{\star}$ Fungizid & - & - & - & - \\
\hline 2011 & Vorfrucht*Fungizid & 3 & 80 & 7,77 & 0,0001 \\
\hline 2010 & Vorfrucht*Sorte*Fungizid & - & - & - & - \\
\hline 2011 & Vorfrucht ${ }^{\star}$ Sorte ${ }^{\star}$ Fungizid & 3 & 80 & 0,08 & 0,9715 \\
\hline 2010 & Sorte*Fungizid & - & - & - & - \\
\hline 2011 & Sorte*Fungizid & 1 & 80 & 0,01 & 0,9067 \\
\hline
\end{tabular}

Auch die Gesamtvarianzanalyse der Gesamtkolonisierungsraten an den Körnern bestätigte die unter 3.2.2 und 3.2 .5 für beide Versuchsjahre durchgeführten Berechnungen der Einzeleffekte der Versuchsfaktoren Vorfrucht, Sorte und Fungizid. So war sowohl der Effekt der Vorfrucht als auch der Effekt der Sorte in beiden Jahren signifikant (Tab. 22), wogegen nur für 2011 ein signifikanter Effekt des Fungizids auf die Gesamtkolonisierungsraten verzeichnet werden konnte. Ein signifikanter Einfluss auf die Gesamtkolonisierungsraten ging außerdem von der Interaktion Vorfrucht ${ }^{\star}$ Sorte aus. 
Tab. 22: Varianzanalyse der Gesamtkolonisierungsraten im FAEN-Fruchtfolgeversuch an den Körnern der Jahre 2010 und 2011 am Standort Torland. Dargestellt sind die Effekte der drei Versuchsfaktoren Vorfrucht, Sorte und Fungizid sowie die daraus resultierenden Interaktionskomponenten getrennt nach Jahren (statistische Berechnung mittels mehrfaktorieller ANOVA, Signifikanz der Effekte bei $p<0,05$ ).

\begin{tabular}{|c|c|c|c|c|c|}
\hline Jahr & Effekt & $\begin{array}{c}\text { Freiheitgrade } \\
\text { (Zähler) }\end{array}$ & $\begin{array}{c}\text { Freiheitsgrade } \\
\text { (Nenner) }\end{array}$ & F-Wert & p-Wert \\
\hline 2010 & Vorfrucht & 3 & 48 & 43,34497 & $<0,0001$ \\
\hline 2011 & Vorfrucht & 3 & 48 & 3,32993 & 0,0271 \\
\hline 2010 & Sorte & 1 & 48 & 114,8114 & $<0,0001$ \\
\hline 2011 & Sorte & 1 & 48 & 14,31246 & $<0,0001$ \\
\hline 2010 & Fungizid & 1 & 48 & 0,977071 & 0,3279 \\
\hline 2011 & Fungizid & 1 & 48 & 2,369639 & 0,0303 \\
\hline 2010 & Vorfrucht ${ }^{*}$ Sorte & 3 & 48 & 8,810318 & $<0,0001$ \\
\hline 2011 & Vorfrucht* Sorte & 3 & 48 & 1,881325 & 0,1453 \\
\hline 2010 & Vorfrucht ${ }^{\star}$ Fungizid & 3 & 48 & 0,606045 & 0,6143 \\
\hline 2011 & Vorfrucht ${ }^{\star}$ Fungizid & 3 & 48 & 1,574541 & 0,2077 \\
\hline 2010 & Vorfrucht ${ }^{*}$ Sorte ${ }^{\star}$ Fungizid & 3 & 48 & 1,531527 & 0,2184 \\
\hline 2011 & Vorfrucht ${ }^{\star}$ Sorte ${ }^{\star}$ Fungizid & 3 & 48 & 0,960971 & 0,4188 \\
\hline 2010 & Sorte*Fungizid & 1 & 48 & 0,001563 & 0,9686 \\
\hline 2011 & Sorte*Fungizid & 1 & 48 & 1,770592 & 0,1896 \\
\hline
\end{tabular}

\subsection{Pathogenität verschiedener Fusarium-Arten an der Ähre im Feldversuch}

Zur Überprüfung der Pathogenität der im Zuge des FAEN-Fruchtfolgeversuchs am häufigsten an Winterweizen auftretenden Fusarium-Arten wurden diese in einem Inokulationsversuch an der Ähre der Winterweizensorte „Asano“ im Freilandversuch am Standort Gladebeck (s. 2.16.1) getestet.

\subsubsection{Witterung zur Inokulation am 04.06.2011}

Die Inokulation am Standort Gladebeck wurde gegen $20 \mathrm{Uhr}$ abends durchgeführt, um dem raschen Abtrocknen der benetzten Ähren entgegenzuwirken (s. 2.16.1). Trotz späten Einsetzens eines Niederschlagsereignisses am 06.06.2011 mit 5,2 mm Niederschlag und 
eines weiteren am 08.06.2011 (4,2 mm), war die Inokulation des Versuchs erfolgreich. Die ca. $6 \mathrm{~mm}$ über dem langjährigen Mittel liegende Niederschlagssumme von 87,4 mm für den Monat Juni sorgte nachfolgend für ausreichende Feuchtigkeit, um eine starke Besiedlung der Ähren mit den applizierten Fusarium-Arten am Standort Gladebeck zu gewährleisten.

\subsubsection{Visuelle Bonitur}

Im Rahmen des Freiland-Pathogenitätsversuches am Standort Gladebeck erfolgte zu 10 dpi und 24 dpi eine visuelle Bonitur der Befallsstärke. Die Ergebnisse der beiden Boniturtermine sind in Abbildung 60 aufgeführt. Bereits 10 Tage nach der Inokulation waren deutliche Symptome an den Ähren festzustellen. Während die durchschnittlichen Befallsstärken der Versuchsvarianten 1 (F.graminearum), 6 (F.graminearum, F. poae und $F$. tricinctum), und 7 (F. graminearum und F. tricinctum) zwischen 23,2\% (Variante 7 ) und $28 \%$ (Variante 1) lagen, rangierten die Befallsstärken in den Varianten 2 ( $F$. equisetı), 3 (F. poae und F. tricinctum), 4 (F. tricinctum) und 8 (F. poae) zwischen 14,1\% (Variante 2) und 20,9\% (Variante 8). Zwar konnten zwischen den Varianten signifikante Unterschiede im Hinblick auf die Befallsstärke beobachtet werden, dennoch lagen die Befallsstärken zu diesem Zeitpunkt insgesamt noch auf ähnlich hohen Niveaus. Wesentlich stärker ausgeprägte Unterschiede zwischen den Varianten in Bezug auf den Befall konnten zu 24 dpi ermittelt werden. Es war eine durch die statistische Auswertung der Befallsstärken abgesicherte, signifikante Gruppierung der Versuchsvarianten in mit dem FHB-Bildner F.graminearum inokulierten Varianten und Varianten ohne F. graminearum festzustellen. Dies zeigte sich auch im Hinblick auf die Symptomausprägungen im Feld. Während die Versuchsvarianten mit F. graminearum FHB-Symptome ausbildeten, waren diese in den Varianten ohne F. graminearum nicht aufzufinden. Die Varianten 1, 6 und 7, welche als Einzel- oder Mischvarianten mit F. graminearum inokuliert worden waren, wiesen mittlere Befallsstärken von 67,7\% (Variante 7) und 72,4\% (Variante 1) auf, die somit ca. doppelt so hoch waren, wie in den Varianten 2-4 sowie 8. Die Befallsstärken in den letztgenannten Varianten lagen zwischen $33,7 \%$ (Variante 2) und 39,4\% (Variante 8).

Ein bei Freilandversuchen durch natürlich vorkommende, pilzliche Pathogene verursachtes Auftreten von Hintergrundinfektionen zeigte sich sowohl zu $10 \mathrm{dpi}$, als auch zu 24 dpi in der Kontrollvariante. Diese war jedoch insgesamt als äußerst gering anzusehen und unterschied sich in ihrer Befallsstärke zu 10 dpi von sechs der sieben übrigen Versuchsvarianten signifikant, nach $24 \mathrm{dpi}$ war die Befallsstärke der Kontrollvariante von allen anderen Varianten signifikant verschieden. 


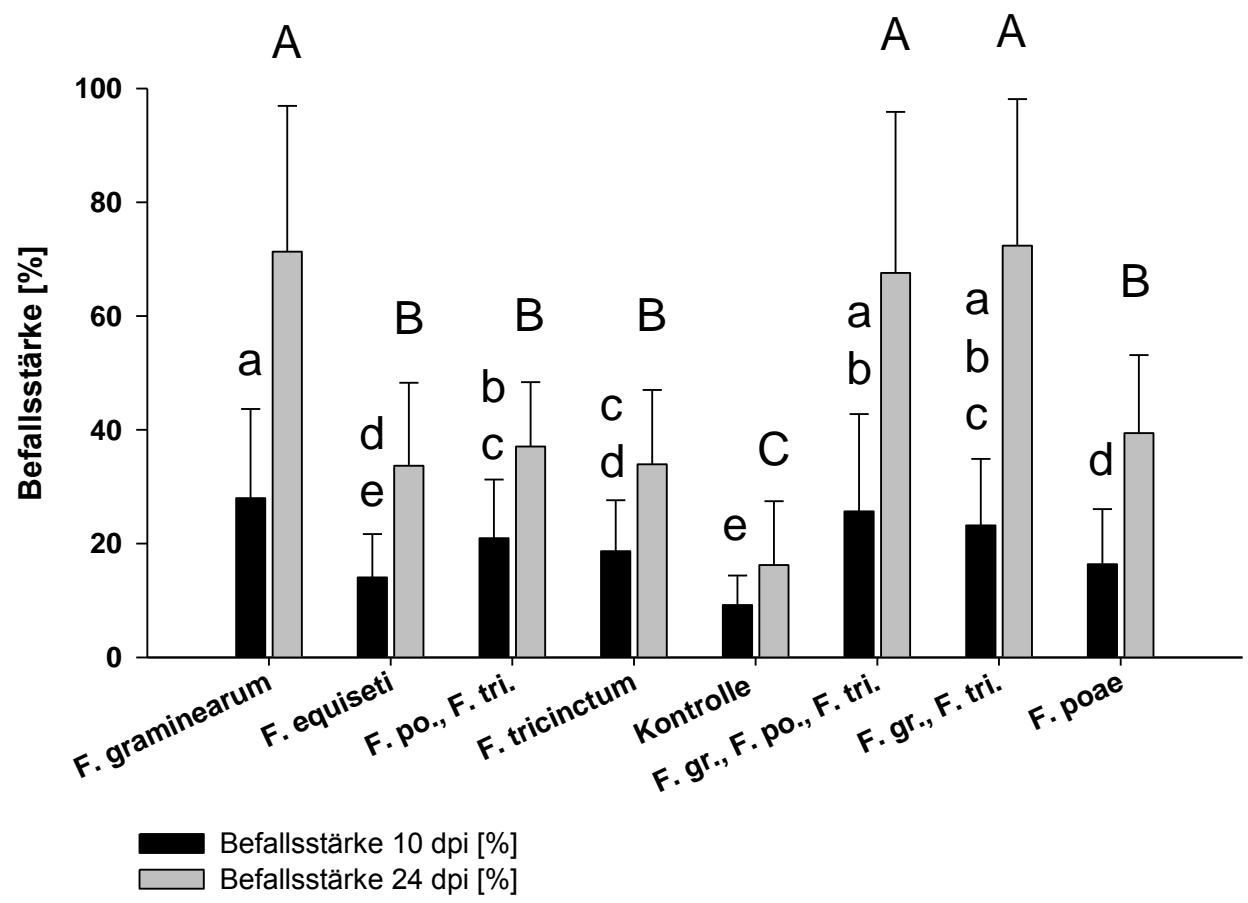

Abb. 60: Befallsstärken (befallene Ährchen [\%] pro 20 befallene Ähren innerhalb einer Wiederholung einer Variante) in den ausgebrachten Einzel- und Mischvarianten nach $10 \mathrm{dpi}$ und $24 \mathrm{dpi}$ im Freiland-Pathogenitätsversuch am Standort Gladebeck. In der für TKG (s. 3.3.3) und Mykotoxinanalyse (s. 3.3.4) berücksichtigten Randkontrolle wurde keine Bonitur durchgeführt. Sorte: „Asano“. Unterschiedliche Buchstaben desselben Typs kennzeichnen signifikante Unterschiede zwischen den Befallsstärken der Versuchsvarianten $\mathrm{zu}$ den verschiedenen Boniturzeitpunkten $(\mathrm{n}=80$, multipler Mittelwertvergleich nach Tukey mit $p<0,05)$. Sorte: „Asano“.

\subsubsection{TKG}

Die Tausendkorngewichte der Versuchsvarianten 1-9 (Tab. 23) wiesen eine eindeutige Gruppierung auf. So waren die TKGs der F. graminearum-Varianten 1, 6 und 7 mit TKGs zwischen 21,5 g und 26,8 g untereinander nicht signifikant verschieden. Die Varianten 2, 3, 4, 5, 8 und 9 unterschieden sich mit weit mehr als doppelt so hohen TKGs zwischen 57,3 g und 59,5 g nicht signifikant voneinander. Ein signifikanter Unterschied war jedoch zwischen diesen beiden Gruppen gegeben. 
Tab. 23: TKGs der Versuchsvarianten 1-9 des Fusarium-Pathogenitätstests an der Ähre im Feldversuch am Standort Gladebeck. Sorte: „Asano“.

\begin{tabular}{ccc}
\hline Variante & Arten & TKG [g] \\
\hline 1 & F. graminearum & $21,5 \pm 5,6 \mathbf{~ b}$ \\
2 & F. equiseti & $59,0 \pm 3,1 \mathbf{a}$ \\
3 & F. poae, F. tricinctum & $57,4 \pm 2,6 \mathbf{a}$ \\
4 & F. tricinctum & $58,1 \pm 1,2 \mathbf{a}$ \\
5 & Kontrolle (Wasser) & $59,5 \pm 2,32 \mathbf{a}$ \\
6 & F. graminearum, F. poae & \\
7 & F. tricinctum & $26,8 \pm 6,8 \mathbf{~ b}$ \\
8 & F. graminearum, F. tricinctum & $22,8 \pm 2,8 \mathbf{~ b}$ \\
9 & F. poae & $58,3 \pm 2,6 \mathbf{~ a ~}$ \\
& Kontrolle (Rand) & $57,3 \pm 0,8 \mathbf{a}$ \\
\hline
\end{tabular}

\subsubsection{Mykotoxingehalte des Ernteguts}

Das Erntegut des Freilandversuches wies deutliche Unterschiede in Mykotoxinprofilen und -gehalten in den verschiedenen Varianten auf. Die Varianten mit F graminearum zeigten im Vergleich mit den Varianten ohne F. graminearum extrem hohe DON-Gehalte, wobei in der F. graminearum-Einzelvariante eine bis zu 1,8 mal höhere DON-Belastung detektiert werden konnte, als in den F. graminearum-Mischvarianten (Tab. 24). Ebenso wurden in diesen Varianten Gehalte von 3-ADON, 15-ADON, gDON sowie hohe Gehalte an ZEA festgestellt. Alle übrigen Varianten wiesen sehr geringe DON-Kontaminationen auf, welche auf Hintergrundkontaminationen oder leichten Sporendrift bei der Inokulation zurückzuführen waren. Besonders hohe Gehalte an Enniatinen konnten in der F. tricinctum-Variante gemessen werden. Diese waren um ein Zehnfaches höher, als in den Mischvarianten mit $F$. graminearum und etwas mehr als doppelt so hoch wie in der F. poae-F. tricinctum-Variante. 3-ADON, 15-ADON, gDON sowie ZEA wurden in den Einzel- und Mischvarianten ohne F. graminearum nicht gefunden. BEAU kam nur in äußerst geringen Mengen in der F. poae-Einzelvariante vor. Nivalenolgehalte wurden sowohl in der F. graminearum-Variante als auch in den F. graminearum-Mischvarianten 
detektiert, jedoch waren die Gehalte in den Mischvarianten ca. 5,5- bzw. 1,5-fach niedriger, als in der Einzelvariante. Weiterhin konnte in der F. equiseti-Variante $772 \mu \mathrm{g} / \mathrm{kg}$ NIV nachgewiesen werden. Die höchsten NIV-Gehalte mit $1.233 \mu \mathrm{g} / \mathrm{kg}$ Mehl wurden in der F. poae-Einzelvariante gemessen. Im Mehl des Ernteguts der F. poae-F. tricinctum Mischvariante war allerdings kein NIV enthalten.

Tab. 24: Mykotoxinprofile und -mengen $[\mu \mathrm{g} / \mathrm{kg}]$ in Weizenmehl des FreilandInokulationsversuchs am Standort Gladebeck. Weizenähren der Winterweizensorte „Asano“ wurden mit Fusarium-Arten in Einzel- und Mischvarianten inokuliert. DON: Deoxynivalenol; 3-ADON: 3-Acetyldeoxynivalenol; 15-ADON: 15-Acetyldeoxynivalenol; gDON: glykosyliertes Deoxynivalenol; NIV: Nivalenol; ZEA: Zearalenon; BEAU: Beauvericin; ENNIs: Enniatine A, A1, B, B1. Mykotoxinmengen unterhalb der Nachweisgrenze (LOD) sind mit ,"” gekennzeichnet, das Symbol "*“ markiert durch natürliche Hintergrundinfektionen bedingte Kontaminationen. Dargestellte Werte sind Mittelwerte, berechnet aus $\mathbf{n}=4$.

\begin{tabular}{|c|c|c|c|c|c|c|c|c|}
\hline \multicolumn{9}{|c|}{ Mykotoxine $[\mu \mathrm{g} / \mathrm{kg}]$} \\
\hline Arten & DON & 3-ADON & 15-ADON & gDON & NIV & ZEA & BEAU & ENNIs \\
\hline F. graminearum & 218.850 & 251 & 1.631 & 584 & 1.102 & 4.679 & - & $93^{*}$ \\
\hline F. equiseti & $257^{*}$ & - & - & - & 772 & - & - & $171^{*}$ \\
\hline F. po., F. tri. & $128^{*}$ & - & - & - & - & - & - & 4.797 \\
\hline F. tricinctum & $155^{*}$ & - & - & - & - & - & - & 11.673 \\
\hline Wasserkontrolle & - & - & - & - & - & $9^{*}$ & - & $286^{*}$ \\
\hline F. gr., F.po., F.tri. & 121.694 & 1.055 & 1.068 & 184 & 204 & 1.902 & - & 1.474 \\
\hline F. gr., F.tri. & 148.873 & 763 & 1.463 & 217 & 771 & 2.440 & - & 1.202 \\
\hline F. poae & $810^{*}$ & - & - & - & 1.233 & - & 70 & $300^{*}$ \\
\hline Randkontrolle & $69^{*}$ & - & - & - & - & - & - & $577^{\star}$ \\
\hline
\end{tabular}




\subsection{Pathogenität verschiedener Fusarium-Arten an der Ähre im Gewächshausversuch}

Der im Freiland erfolgte Pathogenitätsversuch wurde auch unter kontrollierten Bedingungen im Gewächshaus an der Ähre von Sommerweizen (Sorte „Tybalt“) sowohl in Einzel- als auch in Mischvarianten durchgeführt. Die Auswahl der Fusarium-Arten beruhte auf den Ergebnissen des Versuchsjahres 2010 (s. 3.2.1 und 3.2.2) und wurde über alle Versuchsdurchläufe beibehalten. Die im Rahmen dieser Versuche erhaltenen Ergebnisse zur Pathogenität von F. equiseti, F. poae und F. tricinctum, wie Schadbild, Symptomausprägung, FHB- bzw. Black-Point-Besatz und Mykotoxinprofile bzw. -gehalte wurden in Bezug zur Pathogenität von $F$. graminearum als eingehend in der Literatur beschriebener Erreger an Weizen (s. 1.1.2) gesetzt, welcher somit als Referenz zur qualitativen Beurteilung der o.g. Parameter im Hinblick auf die Arten F. equiseti, F. poae und F. tricinctum fungierte.

\subsubsection{Pathogenitätsversuch mit Einzelvarianten}

Der Pathogenitätsversuch mit Einzelvarianten sollte zur Charakterisierung der Pathogenität der beiden im Versuchsjahr 2010 am häufigsten von der Ähre isolierten Fusarium-Arten F. poae und F. tricinctum (s. 3.2.2) beitragen. Hierzu wurden Ährenisolate der beiden Arten verwendet (s. 2.3.1 und 2.16.2). Ferner wurden Halmbasis-Isolate von F. equiseti (s. 2.3.1 und 2.16.2), welcher 2010 häufig von der Halmbasis isoliert werden konnte, jedoch kaum an der Ähre zu finden war, ebenfalls auf ihre Pathogenität an der Ähre getestet. Der Versuch wurde bei einer durchschnittlichen Temperatur von $21,5^{\circ} \mathrm{C}$ sowie einer durchschnittlichen relativen Luftfeuchte von $48 \%$ durchgeführt.

\section{Visuelle Bonitur des Ährenbefalls}

In den Versuchen zur Pathogenität verschiedener Fusarium-Arten an der Ähre von Weizen mit Einzelvarianten, zeigten sich grundsätzlich erhebliche Unterschiede in Schadbild und Symptomausprägung an Ährchen und Körnern zwischen der mit $F$. graminearum sowie den mit F. equiseti, F.poae und F. tricinctum inokulierten Varianten. Während in der mit F.graminearum inokulierten Variante 1 typische FHBSymptome in Form von Kümmerkörnern und teilweisem Ausbleichen der Ähren auftraten, zeigten sich in den Varianten 2 ( $F$. equiseti), 3 ( $F$. poae) und 4 ( $F$. tricinctum) lediglich die für F. equiseti und F. tricinctum bereits durch Christ et al. (2011b) beschriebenen Verbräunungen der Vor-, Deck- und Hüllspelzen. Dass F. poae ebenfalls keine typischen FHB-Symptome verursacht, obwohl diese Art eindeutig dem in der Literatur belegten 
FHB-Komplex angehört (Bottalico und Perrone, 2002), ist jedoch ein im Zuge dieser Arbeit neu beobachtetes Phänomen (Abb. 62). Da sich die Symptome zwischen F. graminearum und den übrigen Fusarium-Arten stark unterscheiden, wurde in diesem und folgenden Versuchen der in der Literatur bisher verwendete Terminus „FHB-Index“ (nach Wilcoxson et al., 1992) durch „Disease-Index“ ersetzt. Dieser wurde dennoch für alle Varianten gleich berechnet.

Bereits nach $7 \mathrm{dpi}$ zeigte die mit $F$. graminearum inokulierte Variante 1 mit einem Disease-Index von 61,1\% einen signifikant höheren Befall als die Varianten 2, 3 und 4, jedoch wies die mit F. poae inokulierte Variante 3 mit 14,9\% einen relativ niedrigen, gegenüber den Varianten 2-4 allerdings signifikant erhöhten Disease-Index auf (Tab. 25). Im Infektionsverlauf nahm der Befall in allen Varianten stark zu. F. graminearum verursachte nach 21 dpi mit einem Disease-Index von 98,1\% ein nahezu vollständiges Absterben der Ähren, wogegen die Indices der mit F. equiseti $(56,2 \%)$, F. poae $(52,5 \%)$ und F. tricinctum (64,2\%) inokulierten Varianten zwar hoch, im Vergleich zu Variante 1 jedoch auf signifikant niedrigerem Niveau verblieben. Die Ähren blichen während des gesamten Beobachtungszeitraumes nicht aus, sondern blieben grün (Abb. 61 und Abb. 62). Innerhalb dieser Varianten erfolgte zwischen 7 dpi und 21 dpi eine Verlagerung von F. poae zu F. tricinctum im Hinblick auf den signifikant höchsten Disease-Index nach Variante 1.

Tab. 25: Disease-Indices [\%] im Pathogenitätsversuch mit Einzelvarianten in der Sommerweizensorte „Tybalt“. Dargestellt ist der Disease-Index zu den drei verschiedenen Boniturterminen 7, 14 und $21 \mathrm{dpi}$, hervorgerufen durch die verschiedenen Fusarium-Arten. Unterschiedliche Buchstaben kennzeichnen signifikante Unterschiede zwischen den Disease-Indices der Versuchsvarianten zu jedem der drei Boniturtermine (multipler Mittelwertvergleich nach Tukey mit $p<0,05$ ).

\begin{tabular}{|c|c|c|c|c|c|}
\hline \multirow[b]{2}{*}{ Variante } & \multirow[b]{2}{*}{ Art } & \multirow[b]{2}{*}{$\mathrm{n}$} & \multicolumn{3}{|c|}{ Disease Index [\%] } \\
\hline & & & $7 \mathrm{dpi}$ & 14 dpi & $21 \mathrm{dpi}$ \\
\hline 1 & F. graminearum & 80 & $61,1 \mathbf{a}$ & $90,0 \mathbf{a}$ & 98,1 a \\
\hline 2 & F. equiseti & 78 & $8,5 \mathrm{c}$ & $39,7 \mathrm{c}$ & $56,2 \mathrm{c}$ \\
\hline 3 & F. poae & 79 & $14,9 \mathbf{b}$ & $41,1 \mathrm{bc}$ & $52,5 \mathrm{c}$ \\
\hline 4 & F. tricinctum & 80 & $8,1 \mathrm{c}$ & $46,9 \mathrm{~b}$ & $64,6 \mathbf{b}$ \\
\hline 5 & Kontrolle & 80 & $0,0 \mathbf{d}$ & $0,0 \mathbf{d}$ & $0,0 \mathbf{d}$ \\
\hline
\end{tabular}



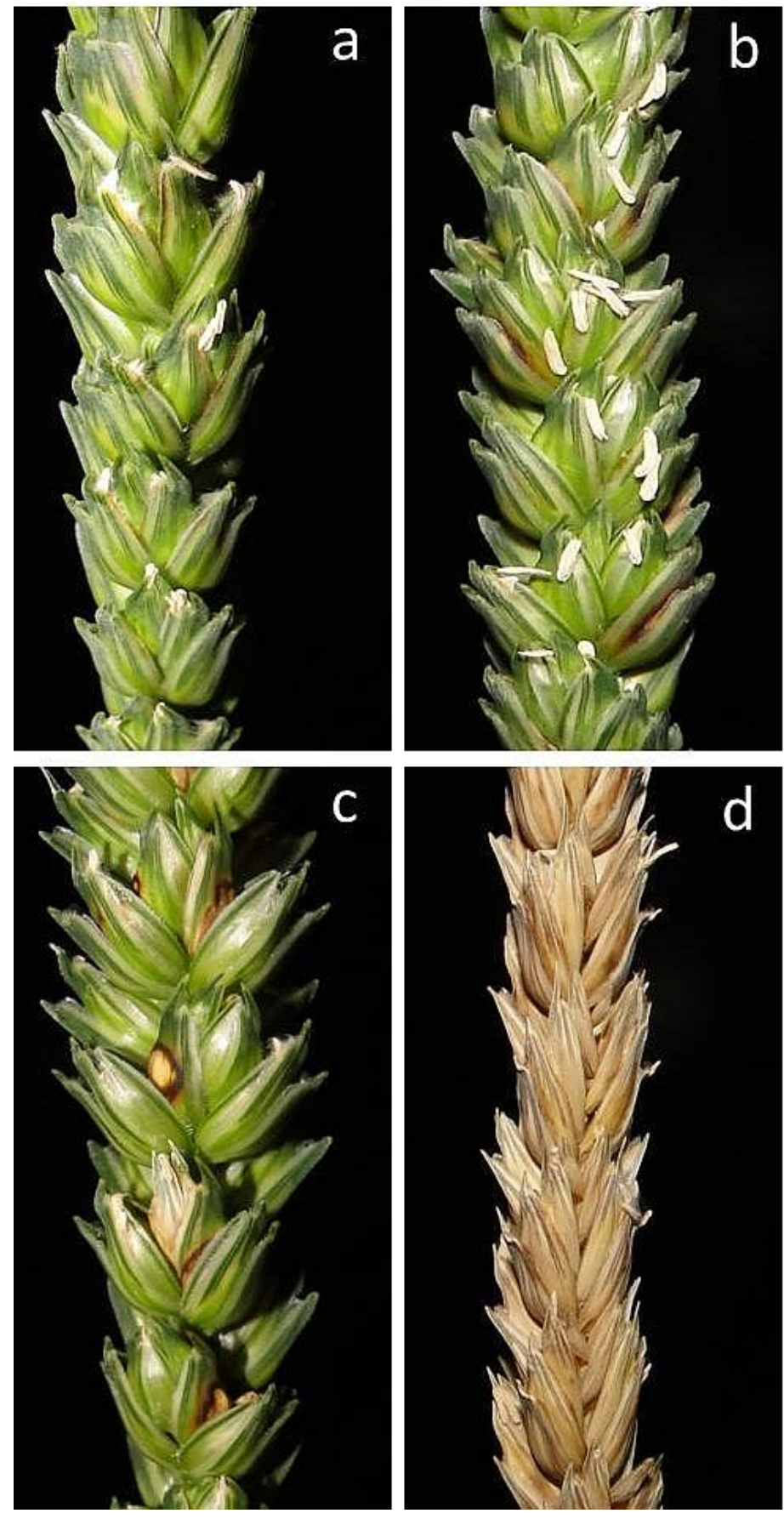

Abb. 61: Symptomausprägungen an der Ähre von Sommerweizen (Sorte „Tybalt“) im Gewächshaus nach Einzelinokulation, hervorgerufen von a) $F$. tricinctum nach $7 \mathrm{dpi}$, b) $F$. tricinctum nach $14 \mathrm{dpi}$, c) $F$. tricinctum nach $21 \mathrm{dpi}$ und d) $F$. graminearum nach $21 \mathrm{dpi}$. Während $F$. graminearum unter Ausprägung zunächst typischer FHB-Symptome im Zuge des Infektionsverlaufs ein komplettes Absterben der Ähre herbeiführt, zeigt F. tricinctum über den gesamten Infektionsverlauf zuerst leichte Verbräunungen der Vor-, Deck- und Hüllspelzen, welche sich später schließlich verstärken und aufhellen. 

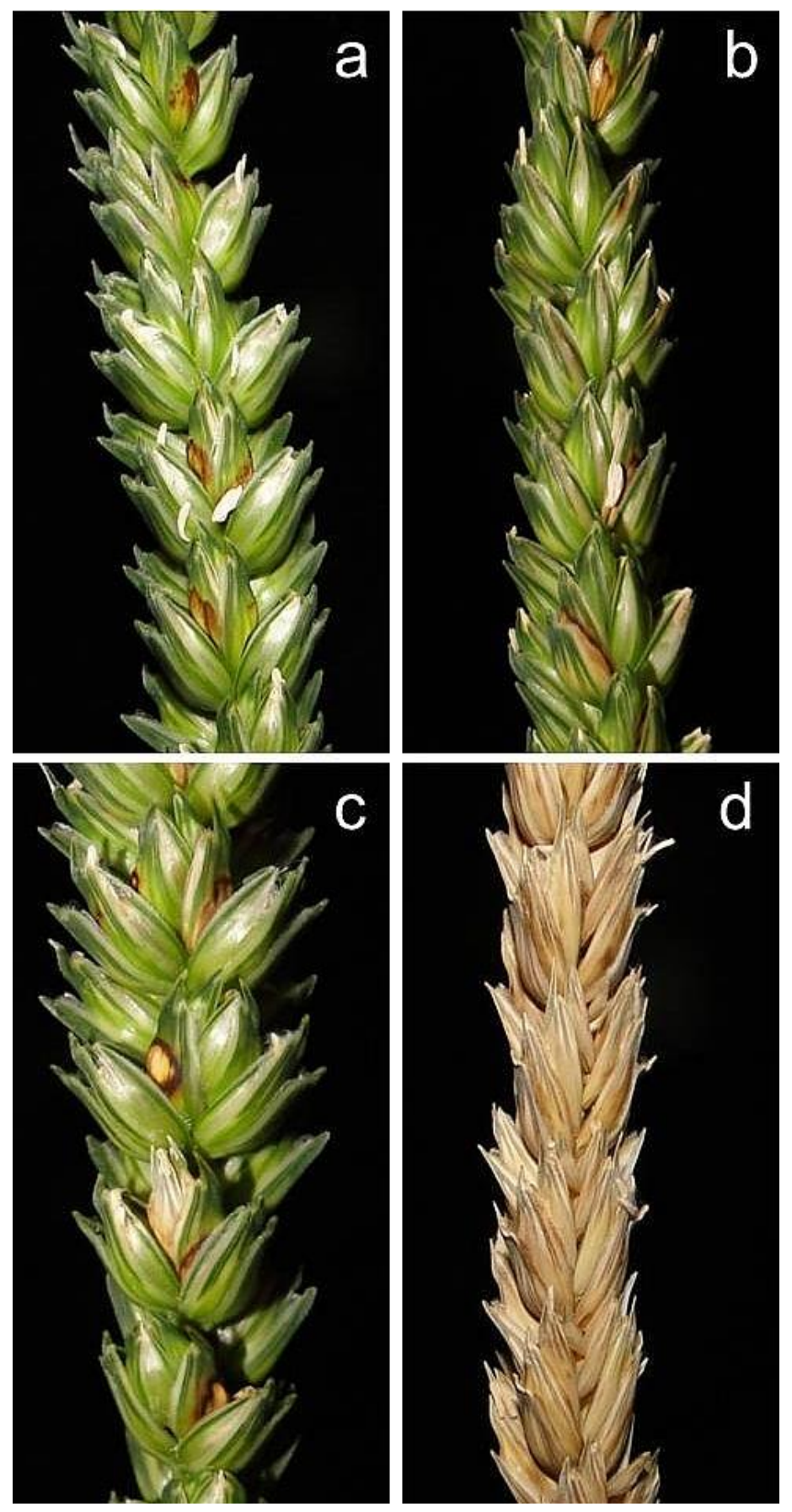

Abb. 62: Symptomausprägungen an der Ähre von Sommerweizen (Sorte „Tybalt“) im Gewächshaus nach Einzelinokulation, hervorgerufen von a) $F$. equiseti nach $21 \mathrm{dpi}$, b) $F$. poae nach $21 \mathrm{dpi}$, c) $F$. tricinctum nach $21 \mathrm{dpi}$ und d) $F$. graminearum nach $21 \mathrm{dpi}$. $F$. poae ruft die gleichen Spelzenverbräunungen hervor, wie $F$. equiseti und $F$. tricinctum.

\section{Auftreten des Black-Point Symptoms}

Im Verlauf des Pathogenitätsversuches wurde deutlich, dass nicht nur F. equiseti und F. tricinctum in der Lage sind, Black-Point-Körner zu produzieren (Christ et al., 2011b), sondern auch F. poae dieses Symptom verursachte. Auch durch F. poae infizierte Ähren wiesen Körner mit der typischen schwärzlichen Verfärbung in der Nähe des Embryos auf, 
die mit den von $F$. equiseti und $F$. tricinctum hervorgerufenen Symptomen identisch war (Abb. 63).

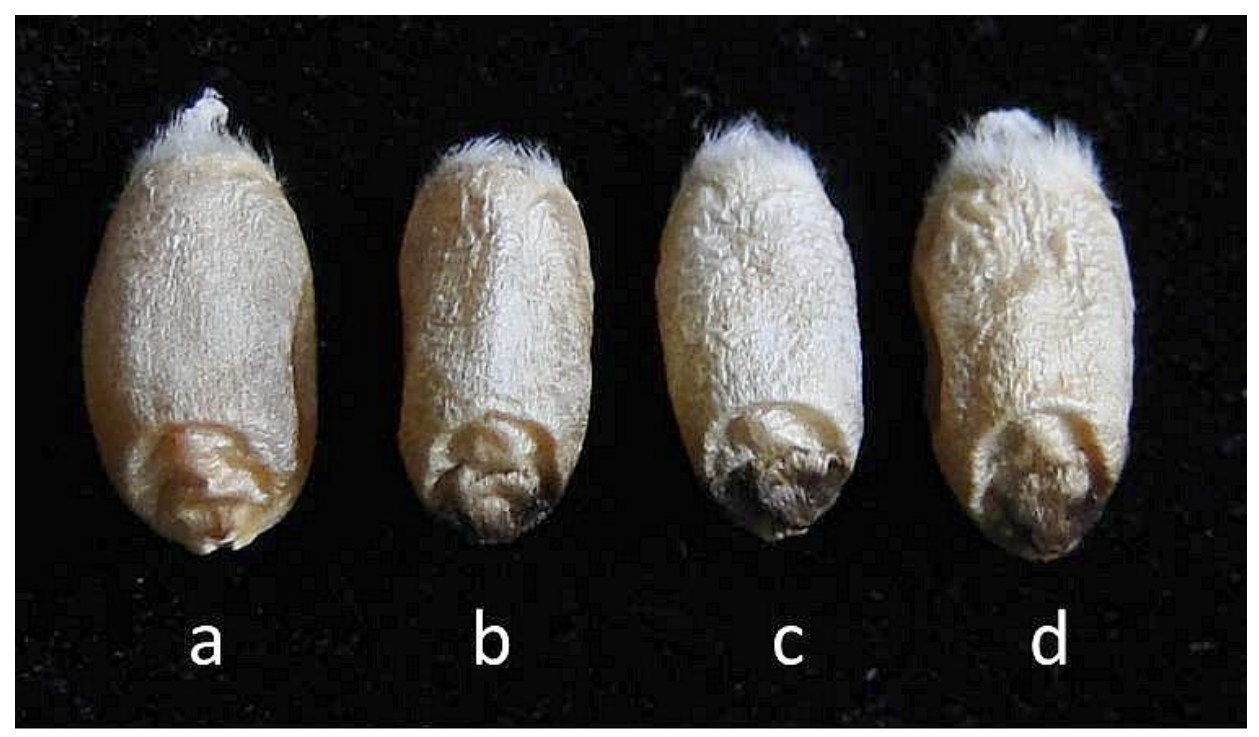

Abb. 63: Black-Point-Symptomausprägungen an Körnern von Sommerweizen (Sorte: „Tybalt“) im Gewächshaus nach Inokulation. a) Kontrolle, b) $F$. poae, c) $F$. equiseti, d) F. tricinctum. Das von F. poae hervorgerufene Symptom unterscheidet sich von dem durch $F$. equiseti und $F$. tricinctum verursachten nicht.

\section{Reisolationsraten verschiedener Fusarium-Arten aus dem Erntegut}

Zur Bestätigung der drei ersten Koch'schen Postulate, bzw. zum Nachweis, dass die während der visuellen Bonitur quantifizierten Symptome von den inokulierten FusariumIsolaten hervorgerufen wurden, erfolgten Reisolationen der Pilze aus dem Erntegut der einzelnen Versuchsvarianten, wobei diese bei symptomlosen und Black-Point-Körnern getrennt durchgeführt wurden (Tab. 26). Die Reisolationsraten der Körner mit Black-PointSymptom lagen sowohl bei der mit $F$. equiseti inokulierten, als auch bei den mit $F$. poae und F. tricinctum inokulierten Varianten bei $100 \%$. Auch die symptomlosen Körner erreichten Raten von $73 \%$ für $F$. poae und bis zu $87 \%$ für F. tricinctum. Ferner traten keinerlei Kreuzkontaminationen innerhalb der Varianten auf, sodass die Koch'schen Postulate uneingeschränkt bestätigt werden konnten. 
Tab. 26: Reisolationen der im Zuge des Pathogenitätsversuchs mit Einzelvarianten inokulierten Fusarium-Arten aus dem Erntegut. Die Reisolationen erfolgten nach Trennung der Körner mit Black-Point-Symptom (BP) von symptomlosen Körnern. Auf Grund der sehr großen Anzahl von Kümmerkörnern in der $F$.graminearum-Variante und somit wenig verfügbaren Probenmaterials, wurde in dieser Variante auf eine Reisolation verzichtet. In den Varianten 2-4 wurden die Reisolationen mit $n=15$ bei symptomlosen Körnern und $\mathbf{n}=\mathbf{1 0}$ bei Black-Point-Körnern (BP), in der Kontrollvariante mit $\mathbf{n}=\mathbf{2 5}$ durchgeführt. Sorte: „Tybalt“.

\begin{tabular}{clcl}
\hline Variante & \multicolumn{1}{c}{ Art } & $\mathrm{n}$ & Reisolation [\%] \\
\hline 1 & F. graminearum & n.d. & n.d. \\
2 & F. equiseti & 15 & 80 \\
2 & F. equiseti BP & 10 & 100 \\
3 & F. poae & 15 & 73 \\
3 & F. poae BP & 10 & 100 \\
4 & F. tricinctum & 15 & 87 \\
4 & F. tricinctum BP & 10 & 100 \\
5 & Kontrolle (Wasser) & 25 & 0 \\
\hline
\end{tabular}

\section{Anteil und Häufigkeitsverteilungen von Black-Point- und FHB-Körnern im Erntegut}

Untersuchungen des Ernteguts der einzelnen Versuchsvarianten ergaben, dass die mit F. tricinctum infizierte Variante mit einem durchschnittlichen Anteil von 23,2\% eine signifikant höhere Anzahl an Black-Point-Körnern besaß, als alle anderen Varianten (Abb. 64). Die mit F. equiseti infizierte Variante zeigte einen durchschnittlichen BlackPoint-Kornanteil von 9,6\%, die mit F. poae infizierte Variante lediglich 6,2\% Black-PointAnteil. Beide Varianten besaßen aber einen signifikant höheren Anteil als die F. graminearum-Variante, die sich mit durchschnittlich 0,5\% im Hinblick auf ihren BlackPoint-Besatz nicht signifikant von der Kontrollvariante unterschied. 


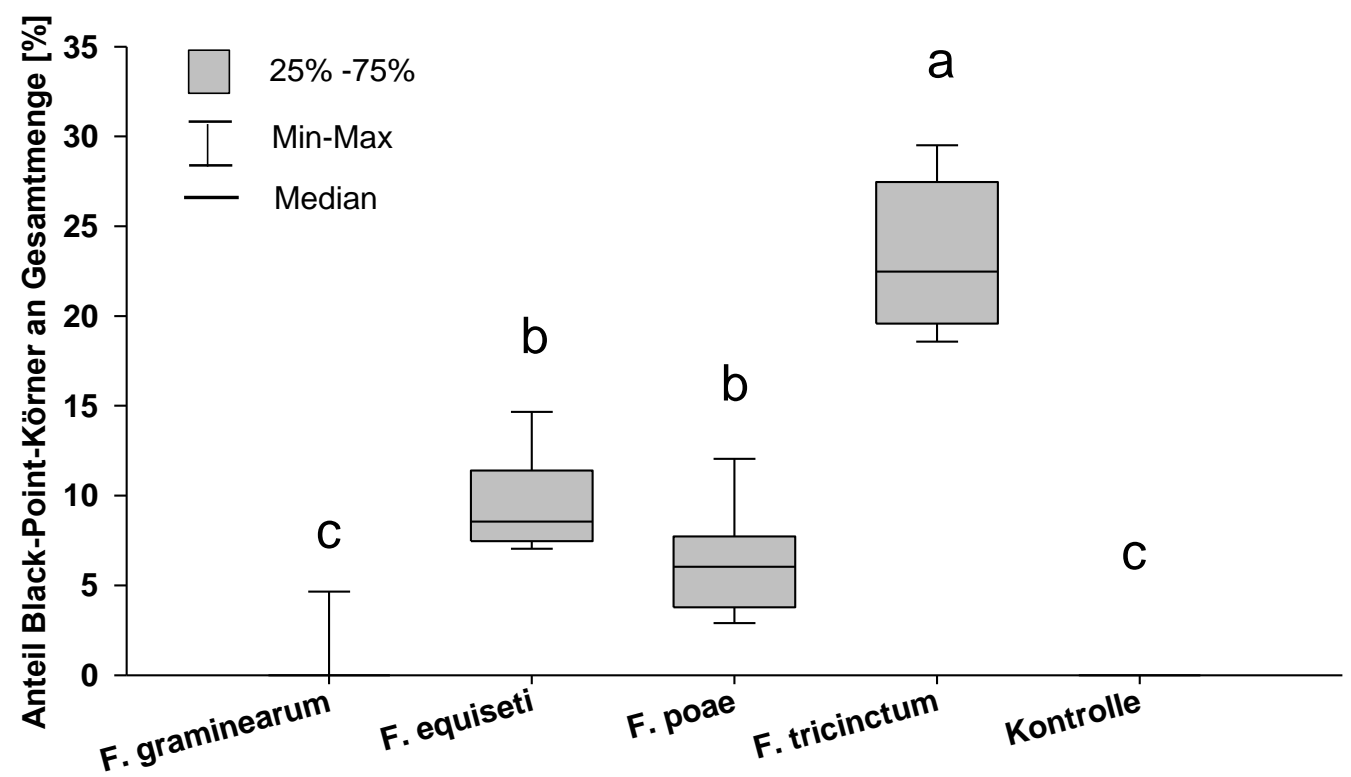

Abb. 64: Anteil von Black-Point-Körnern in den einzelnen Versuchsvarianten nach Einzelinokulation mit der jeweiligen Fusarium-Art. Darstellung als Box-Whisker-Plots mit Median. Sorte: „Tybalt“. Unterschiedliche Buchstaben kennzeichnen signifikante Unterschiede der Anteile an Black-Point-Körnern zwischen den verschiedenen Versuchsvarianten $(n=10$, mit jeweils 8 Einzelpflanzen, multipler Mittelwertvergleich nach Tukey, $\mathrm{p}<0,05)$.

Der Anteil an FHB-Körnern in Bezug auf die Gesamtmenge in den einzelnen Versuchsvarianten stellte sich dagegen anders dar. Erwartungsgemäß wies lediglich die mit dem typischen FHB-Verursacher F. graminearum infizierte Variante mit einem mittleren Anteil von 87,5\% an FHB-Körnern hohe FHB-Kornzahlen auf, die sich signifikant von allen anderen Varianten unterschieden (Abb. 65). Sowohl in der F. equiseti- als auch in der F. poae- sowie F. tricinctum-Variante lagen die durchschnittlichen FHB-Anteile bei unter $1 \%$ und unterschieden sich somit nicht signifikant von der Kontrolle. 


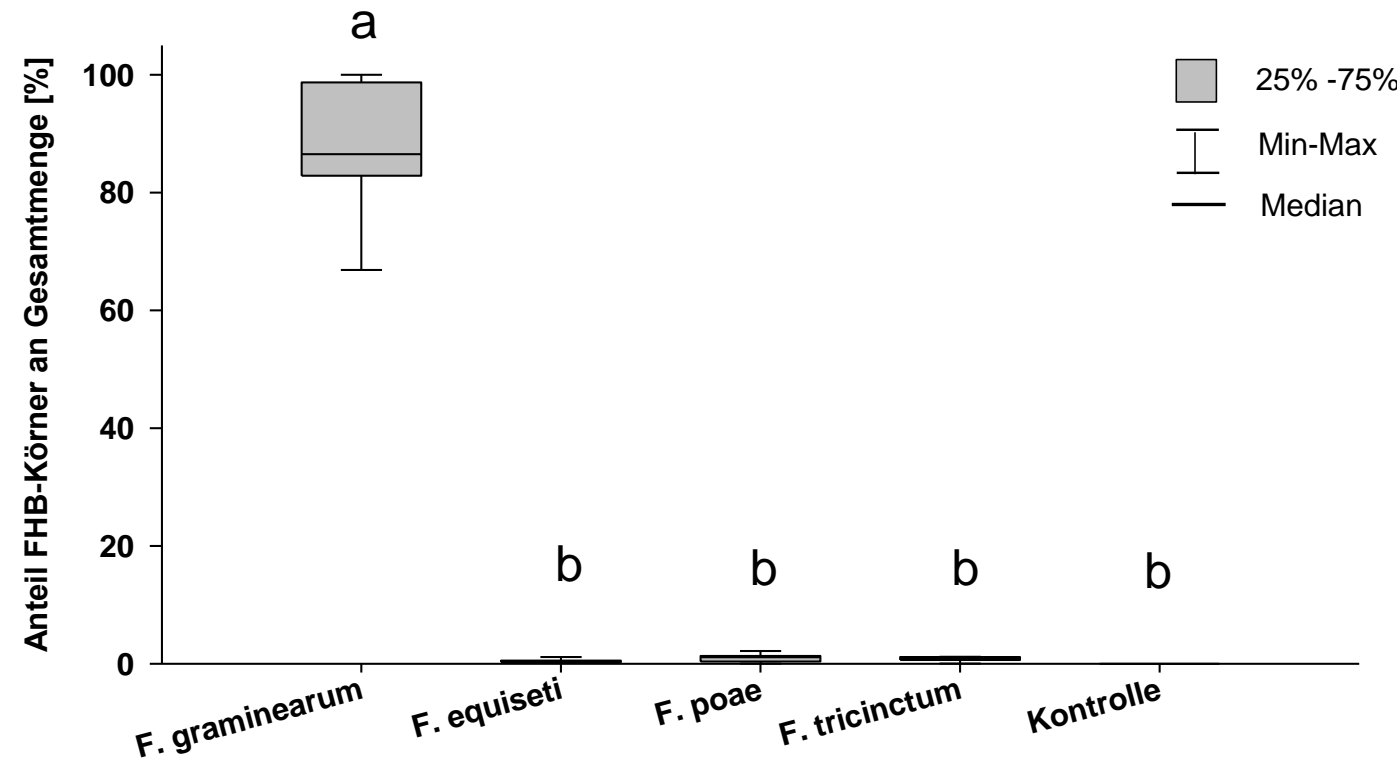

Abb. 65: Anteil von FHB-Körnern in den einzelnen Versuchsvarianten nach Einzelinokulation mit der jeweiligen Fusarium-Art. Darstellung als Box-Whisker-Plots mit Median. Sorte: „Tybalt". Unterschiedliche Buchstaben kennzeichnen signifikante Unterschiede der Anteile an FHB-Körnern zwischen den verschiedenen Versuchsvarianten ( $n=10$, mit jeweils 8 Einzelpflanzen, multipler Mittelwertvergleich nach Tukey, $p<0,05)$.

\section{TKG des Ernteguts}

Die TKG der einzelnen Versuchsvarianten sind in Tabelle 27 aufgeführt. Die F. graminearum Variante 1 brachte das niedrigste Gesamt-TKG hervor, welches sich als fünf- bis sechsmal niedriger darstellte, als in den übrigen Versuchsvarianten und sich somit signifikant von diesen unterschied. Dagegen erwies sich das Gesamt-TKG der Kontrolle mit 50,2 g als signifikant am höchsten, gefolgt von $F$. equiseti (Variante 2) mit 46,9 g. Die Gesamt-TKGs der F. poae- und F. tricinctum-Varianten (Varianten 3 und 4) unterschieden sich mit 43,4 g und 42,0 g nicht voneinander, waren aber im Vergleich zu F. equiseti signifikant niedriger.

Die TKGs der Black-Point-Fraktionen wurden lediglich in den Varianten 2-4 statistisch ausgewertet, da hier gegenüber Variante 1 genügend Daten zur Verfügung standen. Um einen mit dem Black-Point-Symptom einhergehenden etwaigen Ertragsverlust zu erfassen, wurden die TKGs der Black-Point-Fraktionen jeder Variante mit den GesamtTKGs derselben verglichen. Es zeigten sich jedoch keine signifikanten Reduktionen, im Gegenteil dazu stiegen die TKGs in den Varianten 2 und 4 sogar leicht an. In Variante 2 konnte dieses erhöhte TKG sogar als signifikant bestätigt werden. 
Tab. 27: TKG des Ernteguts der im Zuge des Pathogenitätsversuchs mit Fusarium-Arten inokulierten Einzelvarianten. Sorte: „Tybalt“. Die TKG-Bestimmungen erfolgten zunächst für das gesamte Erntegut jeder Variante sowie nach Trennung der Kornfraktion mit Black-PointSymptom (BP) separat. Unterschiedliche Buchstaben desselben Typs kennzeichnen signifikante Unterschiede der TKG zwischen Varianten bzw. Fraktionen ( $n=10$, mit Erntegut aus jeweils 8 Einzelpflanzen, multipler Mittelwertvergleich nach Tukey, $p<0,05$ ).

\begin{tabular}{cccc}
\hline Variante & Art & TKG gesamt [g] & TKG Blackpoint [g] \\
\hline 1 & F. graminearum & $8,2 \pm 3,0 \mathbf{~ d}$ & $21,7 \pm 0,0^{*}$ \\
2 & F. equiseti & $46,9 \pm 1,6$ bw & $50,2 \pm 3,6 \mathbf{~ x}$ \\
3 & F. poae & $43,4 \pm 2,3 \mathbf{~ c y}$ & $41,4 \pm 6,9 \mathbf{~ y}$ \\
4 & F. tricinctum & $42,0 \pm 2,9 \mathbf{~ c z}$ & $43,2 \pm 3,4 \mathbf{z}$ \\
5 & Kontrolle & $50,2 \pm 2,7 \mathbf{~ a ~}$ & - \\
\hline
\end{tabular}

${ }^{\text {* }}$ statistische Berechnung auf Basis eines Einzelwertes nicht möglich

\section{Mykotoxinprofile und -gehalte im Erntegut}

Mykotoxinanalysen des Ernteguts zeigten sehr hohe DON-Gehalte von über $10.000 \mu \mathrm{g} / \mathrm{kg}$ Mehl in der F. graminearum-Variante unter kontrollierten Bedingungen im Gewächshaus sowie Gehalte an glykosyliertem DON (Tab. 28). ZEA konnte jedoch im Gegensatz zum Freilandversuch (Tab. 24) nicht detektiert werden. Sowohl die F. equiseti-, als auch die F. poae-Variante wiesen Gehalte an NIV auf, welche jedoch in den Black-PointKornfraktionen der jeweiligen Arten um mehr als das Zehnfache höher lagen, als in den symptomlosen Kornfraktionen. In der Black-Point-Kornfraktion der F. poae-Variante war zudem ein sehr geringer Gehalt an BEAU gemessen worden. Im Erntegut der F. tricinctum-Variante wurden hohe Gehalte an Enniatinen detektiert. Auch hier war ein fünfmal höherer Toxingehalt in der Black-Point-Kornfraktion gegenüber der Fraktion mit symptomlosen Körnern zu erkennen. 
Tab. 28: Mykotoxinprofile und -mengen [ $\mu \mathrm{g} / \mathrm{kg}]$ in Weizenmehl des Pathogenitätsversuchs unter kontrollierten Bedingungen mit Einzelvarianten. Weizenähren der Sommerweizensorte „Tybalt" wurden mit verschiedenen Fusarium-Arten inokuliert. Die Analyse erfolgte in den entsprechenden Varianten nach Trennung der Körner mit Black-Point-Symptom (BP) von symptomlosen Körnern. DON: Deoxynivalenol; 3-ADON: 3-Acetyldeoxynivalenol; 15-ADON: 15-Acetyldeoxynivalenol; gDON: glykosyliertes Deoxynivalenol; NIV: Nivalenol; ZEA: Zearalenon; BEAU: Beauvericin; ENNIs: Enniatine A, A1, B, B1. Mykotoxinmengen unterhalb der Nachweisgrenze (LOD) sind mit "," gekennzeichnet, „“" markiert angenommene Kontaminationen. Dargestellte Werte sind Mittelwerte, berechnet aus $n=5$ Mehlproben, jeweils gepoolt aus zwei unabhängigen Wiederholungen pro Variante.

\begin{tabular}{lcccccccc}
\hline \multicolumn{7}{c}{ Mykotoxine $[\mu \mathrm{g} / \mathrm{kg}]$} \\
\multicolumn{1}{c}{ Variante } & DON & 3-ADON & 15-ADON & gDON & NIV & ZEA & BEAU & ENNIs \\
\hline F. graminearum & $>10.000$ & - & - & 2.109 & - & - & - & - \\
F. equiseti & - & - & - & - & 573 & - & - & - \\
F. equiseti BP & - & - & - & - & 6.216 & - & - & - \\
F. poae & - & - & - & - & 1.440 & $33^{*}$ & - & - \\
F. poae BP & - & - & - & - & $>10.000$ & - & $28^{*}$ & - \\
F. tricinctum & - & - & - & - & - & - & - & 3.975 \\
F. tricinctum BP & - & - & - & - & - & - & - & $>20.000$ \\
\hline
\end{tabular}

\subsubsection{Pathogenitätsversuch mit Einzel- und Mischvarianten}

Ziel dieses Versuches war es, neben Einzelvarianten von F.graminearum als Referenzpathogen sowie F.poae und F.tricinctum, Pathogenitätsversuche mit Mischvarianten durchzuführen, um ebenso die Interaktion zwischen diesen FusariumArten an der Ähre näher zu untersuchen. Der Versuch sollte es ermöglichen, etwaige Konkurrenzeffekte oder synergistische Interaktionen während des Infektionsprozesses im Hinblick auf die bereits genannten Parameter wie Symptomausprägung, FHB- bzw. BlackPoint-Besatz sowie Mykotoxinprofile des Ernteguts zu erfassen und zu beurteilen. Hierzu wurden unterschiedliche Kombinationen der bereits im Pathogenitätsversuch mit Einzelvarianten (s. 3.4.1) untersuchten Arten F. graminearum, F. poae und F. tricinctum getestet. Durch die im Versuch belassenen Einzelvarianten war ein direkter Vergleich der Effekte der Mischvarianten mit den Effekten der Einzelvarianten und somit Aussagen zu 
Interaktionen der verschiedenen Fusarium-Arten an der Ähre möglich. Auf die weitere Untersuchung von F. equiseti an der Ähre wurde in diesem Versuch auf Grund der geringen Bedeutung dieser Art in Bezug auf Ährenbefall verzichtet und der Fokus auf die weitaus relevanteren Arten F. poae und F. tricinctum gelegt.

\section{Visuelle Bonitur des Ährenbefalls}

Die visuelle Bonitur der Symptomausprägungen an der Ähre in Einzel- und Mischvarianten nach 7, 14 und $21 \mathrm{dpi}$ ergab für die ersten drei Varianten, die mit F. graminearum (Variante 1), einer Kombination von F. graminearum, F. poae und $F$. tricinctum (Variante 2) sowie einer Kombination von F. graminearum und F. tricinctum (Variante 3) inokuliert wurden, zu keinem Zeitpunkt signifikante Unterschiede zwischen den Varianten in Bezug auf ihre Disease-Indices (Tab. 29). Bereits nach 7 dpi zeichneten sich alle drei Varianten mit Disease-Indices zwischen 73,6\% für Variante 3 und $78,5 \%$ für Variante 1 durch einen sehr starken Befall der Ähre aus, welcher sich zu 14 dpi nochmals um durchschnittlich 20\% erhöhte. Zu 21 dpi lagen die Disease-Indices aller drei Varianten bei nahezu 100\% (Abb. 66). Im Gegensatz zu den ersten drei, den FHB-Bildner F. graminearum enthaltenden Varianten, wiesen die Varianten 4 (F.tricinctum und F. poae), 5 (F. tricinctum) und 6 (F.poae) zu allen drei Boniturterminen signifikant geringere Disease-Indices auf. Nach 7 dpi erreichte die mit $F$. poae inokulierte Variante mit einem Disease-Index von 52,3\% einen signifikant höheren Befall als die Varianten 4 und 5 mit 42,9\% bzw. 44,6\%. Diese glichen sich jedoch im Infektionsverlauf an, sodass zu 21 dpi mit 57,2\% für die Mischvariante 4, 61,6\% für Variante 6 und 62,0\% für Variante 5 keine signifikanten Befallsunterschiede zwischen den drei Varianten zu beobachten waren. Dennoch blieben auch zum dritten Boniturtermin die Disease-Indices der Varianten 1, 2 und 3 mit im Schnitt 40\% höheren Befällen signifikant verschieden von den Disease-Indices der ausschließlich Black-Point-Bildner enthaltenden Varianten 4, 5 und 6. 
Tab. 29: Disease-Indices [\%] im Pathogenitätsversuch mit Einzel- und Mischvarianten in der Sommerweizensorte „Tybalt“. Dargestellt ist der mittlere Disease-Index zu den drei verschiedenen Boniturterminen 7, 14 und $21 \mathrm{dpi}$, hervorgerufen durch die verschiedenen Fusarium-Arten einzeln und in Mischvarianten. Unterschiedliche Buchstaben kennzeichnen signifikante Unterschiede zwischen den Disease-Indices der Versuchsvarianten zu jedem der drei Boniturtermine (multipler Mittelwertvergleich nach Tukey mit $p<0,05$ ).

\begin{tabular}{|c|c|c|c|c|c|}
\hline \multirow[b]{2}{*}{ Variante } & \multirow[b]{2}{*}{ Arten } & \multirow[b]{2}{*}{$\mathrm{n}$} & \multicolumn{3}{|c|}{ Disease Index [\%] } \\
\hline & & & 7dpi & 14dpi & $21 \mathrm{dpi}$ \\
\hline 1 & F. graminearum & 80 & $78,5 \mathbf{a}$ & $93,9 \mathbf{a}$ & $99,1 \mathbf{a}$ \\
\hline 2 & F. gr., F. tri., F. po. & 80 & $74,0 \mathbf{a}$ & $93,1 \mathbf{a}$ & $97,2 \mathbf{a}$ \\
\hline 3 & F. gr., F. tri. & 80 & $73,6 \mathbf{a}$ & $96,0 \mathbf{a}$ & $99,0 \mathbf{a}$ \\
\hline 4 & F. tri., F. po. & 80 & $42,9 \mathrm{c}$ & 52,8 b & 57,2 b \\
\hline 5 & F. tricinctum & 80 & $44,6 \mathrm{c}$ & $55,9 \mathbf{b}$ & $62,0 \mathbf{b}$ \\
\hline 6 & F. poae & 80 & $52,3 \mathbf{b}$ & 58,4 b & $61,6 \mathbf{b}$ \\
\hline 7 & Kontrolle & 80 & $0,0 \mathbf{d}$ & $0,0 \mathbf{c}$ & $0,0 \mathbf{c}$ \\
\hline
\end{tabular}

Im Vergleich zu den Disease-Indices der Black-Point-Bildner des Pathogenitätsversuchs mit Einzelvarianten (s. 3.4.1), waren in diesem Versuch bereits zu 7 dpi wesentlich höhere Befälle zu verzeichnen (Tab. 25 und Tab. 29).

Zwischen den Varianten 1, 2 und 3, welche F. graminearum enthielten, konnten auch im Hinblick auf die Symptome an der Ähre keinerlei Unterschiede beobachtet werden (Abb. 66). In jeder der drei Varianten konnte ausschließlich das typische, mit FHB einhergehende Ausbleichen der Ähren festgestellt werden, welches die Ähren bereits nach spätestens 14 dpi nahezu vollständig erfasst hatte. In den Varianten mit Black-PointBildnern waren dagegen ausschließlich die für diese Arten typischen Spelzenverbräunungen (s. 3.4.1) zu finden. Auch hier zeigten sich keine Unterschiede in den Symptomausprägungen zwischen den Varianten. 

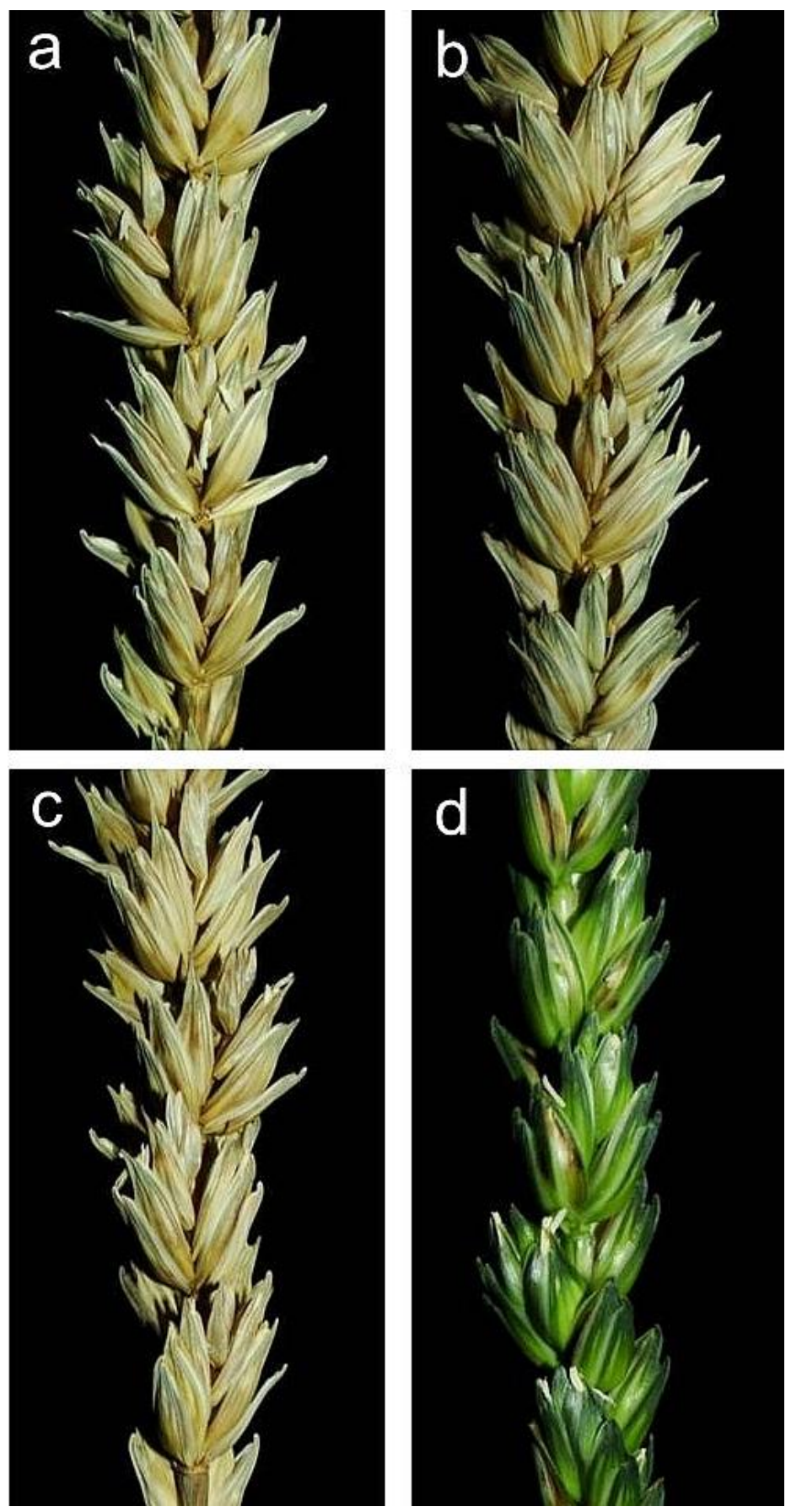

Abb. 66: Symptomausprägungen an der Ähre von Sommerweizen (Sorte „Tybalt“) nach Einzel- und Mischinokulation im Gewächshaus, hervorgerufen von a) F. graminearum nach $21 \mathrm{dpi}$, b) F. graminearum, $F$. poae und $F$. tricinctum nach $21 \mathrm{dpi}$, c) $F$. graminearum und $F$. tricinctum nach 21 dpi sowie d) F. poae und F. tricinctum nach 21 dpi. Die Symptome der Mischinokulationen b) und c) zeigen in ihrer Ausprägung keinerlei Unterschied zu a). In allen drei Varianten zeigen sich nach 21 dpi komplett abgestorbene Ähren. d) zeigt dagegen weit weniger ausgeprägte, jedoch für die Arten F.poae und F. tricinctum typische Verbräunungen der Vor-, Deck- und Hüllspelzen (s. Abb. 61 und Abb. 62). 


\section{Reisolationsraten verschiedener Fusarium-Arten aus dem Erntegut}

Wie bereits unter 3.4.1 beschrieben, musste auch in diesem Versuch in den Varianten, die F. graminearum enthielten, auf Grund der erheblichen Anzahl von Kümmerkörnern und damit verbundenen, sehr geringen Mengen an verfügbarem Erntegut auf die Reisolation zur Bestätigung der ersten drei Koch'schen Postulate verzichtet werden (Tab. 30). Zudem wurde ebenso für Mischvarianten keine Reisolation der Erreger vorgenommen. In den Varianten 5 und 6 erfolgte eine Trennung der Körner in symptomlose und Black-Point-Körner. Für symptomlose Körner konnten Reisolationsraten von $66,7 \%$ für $F$. poae und $86,7 \%$ für $F$. tricinctum erzielt werden. Die Raten der BlackPoint-Körner beliefen sich auf $100 \%$ (vgl. 3.4.1).

Tab. 30: Reisolationen der im Zuge des Pathogenitätsversuchs mit Einzel- und Mischvarianten inokulierten Fusarium-Arten aus dem Erntegut. Die Reisolationen erfolgten nach Trennung der Körner mit Black-Point-Symptom (BP) von symptomlosen Körnern. Auf Grund der sehr großen Anzahl von Kümmerkörnern in der F. graminearum-Variante und somit wenig verfügbaren Probenmaterials sowie des gemischten Befalls in den Varianten 24, wurde in diesen Varianten auf eine Reisolation verzichtet. In den Varianten 5-7 wurden die Reisolationen mit $n=15$ bei symptomlosen Körnern und $n=10$ bei Black-Point-Körnern (BP), in der Kontrollvariante mit $n=25$ durchgeführt (n.d. $=$ nicht determiniert). Sorte:"Tybalt".

\begin{tabular}{cccc}
\hline Variante & Arten & $\mathrm{n}$ & Reisolation [\%] \\
\hline 1 & F. graminearum & n.d. & n.d. \\
2 & F. gr., F. tri., F. po. & n.d. & n.d. \\
3 & F. gr., F. tri. & n.d. & n.d. \\
4 & F. tri., F. po. & n.d. & n.d. \\
5 & F. tricinctum & 15 & 86,7 \\
5 & F. tricinctum BP & 10 & 100 \\
6 & F. poae & 15 & 66,7 \\
6 & F. poae BP & 10 & 100 \\
7 & Kontrolle & 25 & 0 \\
\hline
\end{tabular}




\section{Anteil und Häufigkeitsverteilungen von Black-Point- und FHB-Körnern im Erntegut}

Abbildung 67 zeigt den Anteil von Black-Point-Körnern an der Gesamtmenge in \%. In Bezug auf die Häufigkeitsverteilungen von Black-Point-Körnern in den verschiedenen Varianten konnten keine signifikanten Unterschiede zwischen der F.graminearum Einzelvariante (Variante 1) und den Varianten 2 (F.graminearum, F. tricinctum, F. poae) und 3 (F. graminearum und F. tricinctum) ermittelt werden. Der Anteil der Black-PointKörner in diesen Varianten lag bei $0 \%$ und unterschied sich damit zudem nicht signifikant von der Kontrolle, jedoch deutlich signifikant von den übrigen Varianten. Die mit F. tricinctum inokulierte Variante wies mit 28,1\% den höchsten durchschnittlichen Anteil an Black-Point-Körnern auf und unterschied sich damit signifikant von der mit $F$. tricinctum und $F$. poae inokulierten Variante 4 mit einem durchschnittlichen Black-Point-Anteil von $22,8 \%$. Variante 6 (F. poae) verhielt sich mit 24,5\% mittlerem Anteil an Black-PointKörnern weder zu Variante 4 noch zu Variante 5 signifikant unterschiedlich.

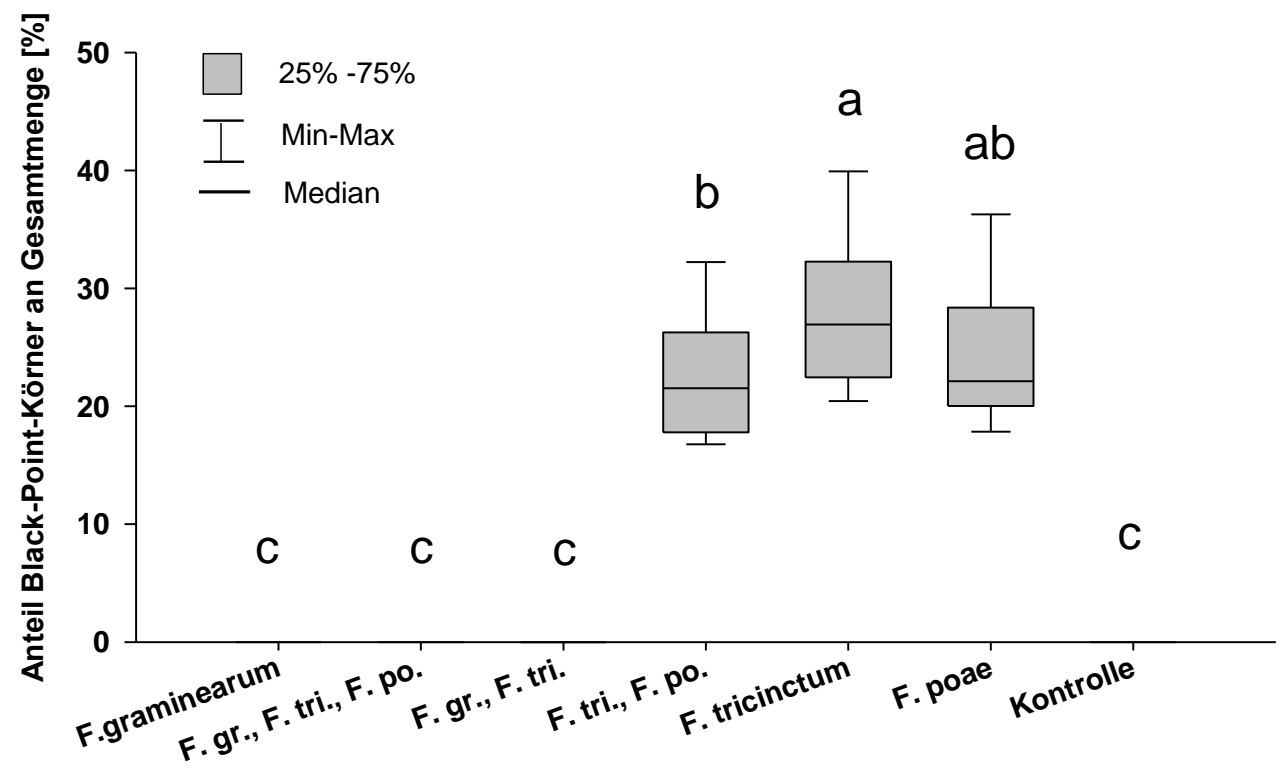

Abb. 67: Anteil von Black-Point-Körnern nach Einzel- und Mischinokulation mit den verschiedenen Fusarium-Arten. Sorte: „Tybalt“. Darstellung als Box-Whisker-Plots mit Median. Unterschiedliche Buchstaben kennzeichnen signifikante Unterschiede der Anteile an Black-Point-Körnern in den verschiedenen Versuchsvarianten $(n=10$, mit jeweils 8 Einzelpflanzen, multipler Mittelwertvergleich nach Tukey, $p<0,05$ ).

Die Betrachtung des Anteils an FHB-Körnern an der Gesamtmenge in Abbildung 68 macht die Gruppierung der Versuchsvarianten in FHB-Bildner und Nicht-FHB-Bildner deutlich. Sowohl die mit F. graminearum inokulierte Einzelvariante als auch die anteilig mit F. graminearum inokulierten Mischvarianten zeigten mit durchschnittlichen FHB-Anteilen von 94\%, dass nahezu das gesamte Erntegut FHB-Symptome aufwies. Im Gegensatz 
dazu lag der mittlere Anteil an FHB-Körnern im Erntegut der übrigen Varianten zwischen $0,5 \%$ für die mit $F$. poae inokulierte und 1,0\% für die mit $F$. tricinctum inokulierte Variante, sodass keine signifikanten Unterschiede zur Kontrollvariante beobachtet werden konnten.

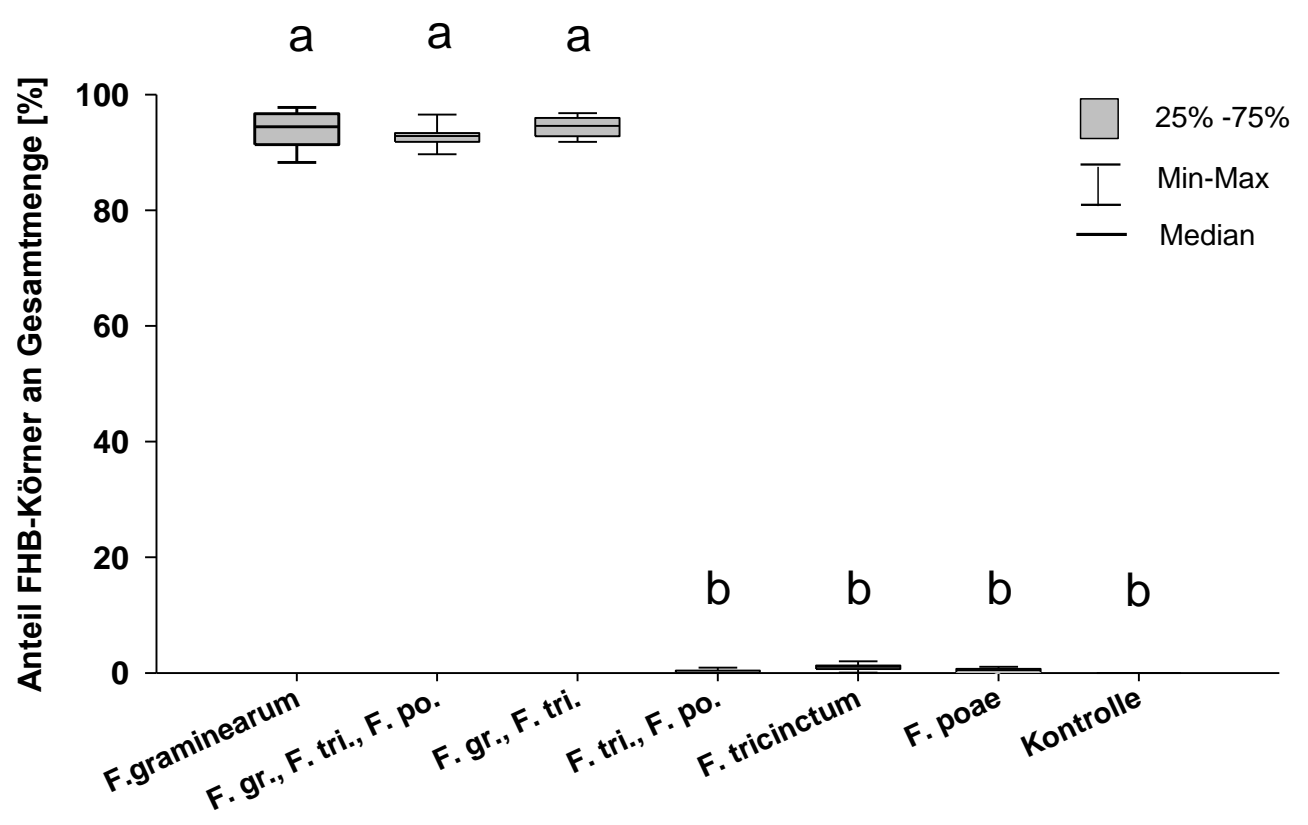

Abb. 68: Anteil von FHB-Körnern in den einzelnen Versuchsvarianten nach Einzel- und Mischinokulation mit den jeweiligen Fusarium-Arten. Sorte: „Tybalt“. Darstellung als BoxWhisker-Plots mit Median. Unterschiedliche Buchstaben kennzeichnen signifikante Unterschiede der Anteile an FHB-Körnern in den verschiedenen Versuchsvarianten $(n=10$, mit jeweils 8 Einzelpflanzen, multipler Mittelwertvergleich nach Tukey, $p<0,05$ ).

\section{TKG}

Die Ergebnisse des Pathogenitätsversuchs mit Einzel- und Mischvarianten wiesen bezüglich des TKG deutliche Parallelen zu den im Pathogenitätsversuch im Feld ermittelten TKG im Hinblick auf signifikante Unterschiede zwischen den Versuchsvarianten auf (s. 3.3.3). Auch hier zeigten die Einzel- und Mischvarianten mit F. graminearum (Varianten 1-3) mit TKGs zwischen 2,4 g und 2,6 g signifikant geringere TKGs auf, welche bis zu zwanzigmal niedriger waren, als die TKG der übrigen Varianten (Tab. 31). Die TKGs der Varianten 4 (F. tricinctum, F. poae), 5 (F. tricinctum) sowie 6 ( $F$. poae) beliefen sich auf Werte zwischen $43,0 \mathrm{~g}$ und $46,7 \mathrm{~g}$ und waren somit nur geringfügig niedriger als der für die Kontrolle ermittelte Wert von 49,4 g. Wie schon unter 3.4.1 wurden auch hier die TKGs der Black-Point-Fraktionen der Varianten 4-6 mit den Gesamt-TKGs dieser Varianten statistisch verglichen. Anders als beim Pathogenitätsversuch mit Einzelvarianten (s. 3.4.1) wiesen die TKGs der Black-Point- 
Fraktionen mit $31,5 \mathrm{~g}$ bis $38,5 \mathrm{~g}$ signifikant niedrigere Werte auf, als die Gesamt-TKGs dieser Varianten.

Tab. 31: TKG des Ernteguts der im Zuge des Pathogenitätsversuchs mit den verschiedenen Fusarium-Arten inokulierten Einzel- und Mischvarianten. Die TKG-Bestimmungen erfolgten zunächst für das gesamte Erntegut jeder Variante sowie nach Trennung der Kornfraktion mit Black-Point-Symptom (BP) separat. Unterschiedliche Buchstaben kennzeichnen signifikante Unterschiede der TKGs zwischen Varianten bzw. Fraktionen. ( $n=10$, mit Erntegut aus jeweils 8 Einzelpflanzen, multipler Mittelwertvergleich nach Tukey, $p<0,05$ ). Sorte: „Tybalt".

\begin{tabular}{cccc}
\hline Variante & Arten & TKG gesamt [g] & TKG Blackpoint [g] \\
\hline 1 & F. graminearum & $2,6 \pm 0,6 \mathbf{~ b}$ & - \\
2 & F. gr., F. tri., F. po. & $2,8 \pm 0,5 \mathbf{~ b}$ & - \\
3 & F. gr., F. tri. & $2,4 \pm 0,3 \mathbf{~ b}$ & $35,7 \pm 4,6 \mathbf{~ v}$ \\
4 & F. tri., F. po. & $43,0 \pm 4,7$ au & $38,5 \pm 2,1 \mathbf{x}$ \\
5 & F. tricinctum & $46,1 \pm 2,2$ aw & $31,5 \pm 2,4 \mathbf{z}$ \\
6 & F. poae & $46,7 \pm 3,7$ ay & - \\
7 & Kontrolle & $49,4 \pm 6,8 \mathbf{~ a}$ & \\
\hline
\end{tabular}

\section{Mykotoxinprofile und -gehalte im Erntegut}

Auch im Pathogenitätsversuch mit Einzel- und Mischvarianten zeigten sich grundsätzlich die gleichen Mykotoxinprofile, wie im Pathogenitätsversuch mit Einzelvarianten. Einzig die Produktion von NIV in den F. graminearum-Mischvarianten wich von diesem Ergebnis ab. Auch konnte in den F. poae- und F. tricinctum-Einzel- und Mischvarianten ebenso eine deutliche Erhöhung der Mykotoxinwerte in den Black-Point-Kornfraktionen festgestellt werden. Dies galt sowohl für die Gehalte an NIV, als auch für die Gehalte an Enniatinen. Beispielsweise lagen die Enniatingehalte in der F.tricinctum-Einzelvariante und der F. poae-F. tricinctum-Mischvariante bei über $40.000 \mu \mathrm{g} / \mathrm{kg}$ Mehl. Zudem konnte eine starke Reduktion der von F. poae und F. tricinctum synthetisierten Mykotoxine NIV und ENNI in den Mischvarianten mit $F$. graminearum beobachtet werden. 
Tab. 32: Mykotoxinprofile und -mengen [ $\mu \mathrm{g} / \mathrm{kg}]$ in Weizenmehl des Pathogenitätsversuchs unter kontrollierten Bedingungen mit Einzel- und Mischvarianten. Weizenähren der Sommerweizensorte „Tybalt“ wurden mit verschiedenen Fusarium-Arten inokuliert. Die Analyse erfolgte in den entsprechenden Varianten nach Trennung der Körner mit BlackPoint-Symptom (BP) von symptomlosen Körnern. DON: Deoxynivalenol; 3-ADON: 3Acetyldeoxynivalenol; 15-ADON: 15-Acetyldeoxynivalenol; gDON: glykosyliertes Deoxynivalenol; NIV: Nivalenol; ZEA: Zearalenon; BEAU: Beauvericin; ENNIs: Enniatine A, A1, B, B1. Mykotoxinmengen unterhalb der Nachweisgrenze (LOD) sind mit "," gekennzeichnet, „““ markiert angenommene Kontaminationen. Dargestellte Werte sind Mittelwerte, berechnet aus $n=5$ Mehlproben, jeweils gepoolt aus zwei unabhängigen Wiederholungen pro Variante.

\begin{tabular}{|c|c|c|c|c|c|c|c|c|}
\hline \multicolumn{9}{|c|}{ Mykotoxine $[\mu \mathrm{g} / \mathrm{kg}]$} \\
\hline Variante & DON & 3-ADON & 15-ADON & gDON & NIV & ZEA & BEAU & ENNIs \\
\hline F. graminearum & $>10.000$ & 479 & 2.192 & 2.580 & 4.360 & - & - & - \\
\hline F. gr., F. po., F. tri. & $>10.000$ & 508 & 2.421 & 2.682 & 4.558 & - & - & 1.142 \\
\hline F. gr., F.tri. & $>10.000$ & 526 & 2.851 & 4.084 & 4.625 & - & - & 1.544 \\
\hline F. po., F. tri. & - & - & - & - & 941 & - & 95 & 1.142 \\
\hline F. po, F. tri. BP & $39^{*}$ & - & - & - & 7.750 & - & 167 & $>40.000$ \\
\hline F. poae & - & - & - & - & 2.993 & - & - & - \\
\hline F. poae BP & - & - & - & - & $>10.000$ & - & - & - \\
\hline F. tricinctum & - & $27^{*}$ & - & - & - & - & - & 7.775 \\
\hline F. tricinctum BP & - & - & - & - & - & - & - & $>40.000$ \\
\hline
\end{tabular}

\subsection{Pathogenitätsversuch mit Fusarium-Arten an der Halmbasis}

Die im Rahmen des FAEN-Feldversuchs im Versuchsjahr 2010 am häufigsten an der Halmbasis von Winterweizen auftretenden Fusarium-Arten F. culmorum, F. equiseti und F. tricinctum (s. 3.2.1) sowie der in den Versuchsjahren 2010 und 2011 ausschließlich an Körnern anzutreffende F.poae, wurden mit Hilfe von Inokulationsversuchen mit Einzelvarianten an Sommerweizen („Tybalt“) einer Beurteilung ihrer Pathogenität an der Halmbasis unterzogen. F. culmorum als typischer „Fusarium-Crown“- bzw. „Foot-Rot“Erreger (Duben und Fehrmann, 1979; Cook, 1980; Clement und Parry, 1998) fungierte hierbei als Referenz für die übrigen Arten. Da F. poae 2010 an der Halmbasis nicht 
aufzufinden war, sollte durch die Untersuchung dieser Art an der Halmbasis ihre Relevanz als Halmbasispathogen geklärt werden. Die Auswahl der zur Inokulation herangezogenen Fusarium-Arten erfolgte wie unter 3.4 beschrieben. Die Fusarium-Arten wurden durch eine visuelle Bonitur zu $\mathrm{BBCH} 77$ und $\mathrm{BBCH} 92$ sowie Reisolationen aus verschiedenen Pflanzenteilen zu BBCH 77 in Bezug auf ihr Vermögen, die Pflanze zu infizieren bzw. zu kolonisieren und Symptome an der Halmbasis hervorzurufen, beurteilt.

\subsubsection{Visuelle Bonitur zu BBCH 77}

Die visuelle Beurteilung der durch die verschiedenen Fusarium-Arten an der Halmbasis hervorgerufenen Symptome wurde zunächst basierend auf einer Skala von 0-3 nach Broschewitz et al., (1999) vorgenommen. Zur grafischen Darstellung der Ergebnisse der visuellen Bonituren, wurde in Abbildung 70 die Verteilung der Boniturnoten in den einzelnen Versuchsvarianten als Box-Whisker-Plots zusammen mit den Ergebnissen der Varianzanalyse dargestellt. Die visuelle Bonitur ergab, dass $F$. culmorum gegenüber allen anderen Arten mit Abstand die signifikant stärksten Symptome an der Halmbasis hervorrief. Weder die Inokulation mit $F$. equiseti, noch mit F. poae hatte die Ausprägung von Symptomen zur Folge. Lediglich F. tricinctum war in der Lage, in einem einzigen Fall marginale Symptome hervorzurufen. Diese starke Diskrepanz bezüglich der Symptomausprägung von F.culmorum im Vergleich mit F. equiseti, F. poae sowie F. tricinctum wird auch in Abbildung 69 deutlich. 


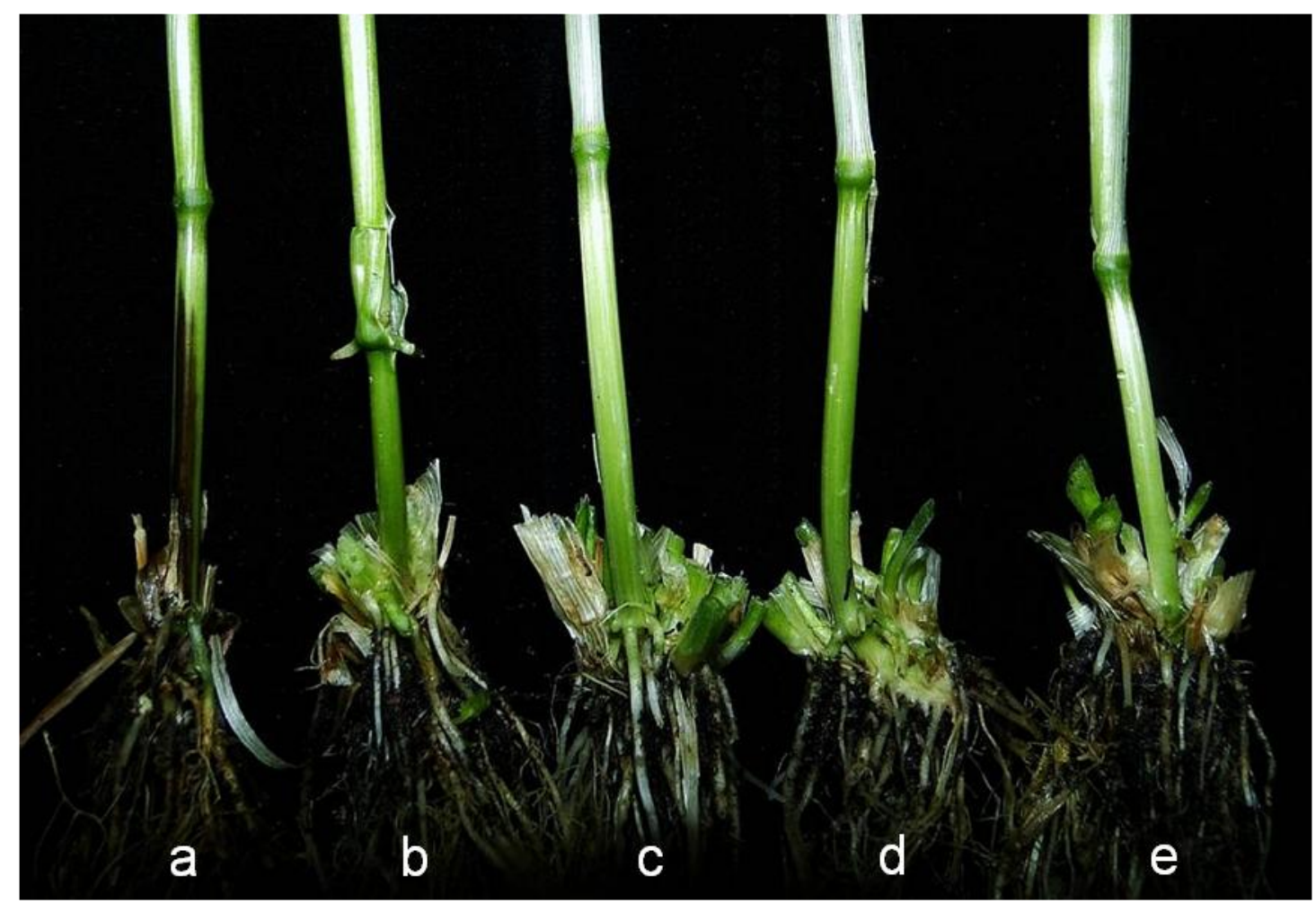

Abb. 69: Durch Tauchinokulation mit Fusarium-Arten hervorgerufene Symptome an der Halmbasis der Sommerweizensorte „Tybalt" zu BBCH 77 unter kontrollierten Bedingungen in der Klimakammer. a) F. culmorum, b) $F$. equiseti, c) $F$. poae, d) $F$. tricinctum und e) Kontrolle. Lediglich in der F. culmorum-Variante sind deutliche Halmverbräunungen zu erkennen. Bei F.equiseti, F.poae und F.tricinctum stellt sich die Kolonisierung der Halmbasis als asymptomatisch dar.

$\mathrm{Zu} \mathrm{BBCH} 77$ wurden dem Versuch nach der visuellen Bonitur die Hälfte der Pflanzen entnommen, um die Kolonisierungsraten der Fusarium-Arten in den einzelnen Versuchsvarianten zu ermitteln (s. 2.16.4). Somit wurde die in Abb. 70 ebenfalls dargestellte zweite visuelle Bonitur zu BBCH 92 mit der Hälfte der Pflanzen durchgeführt. $\mathrm{Zu}$ diesem Boniturzeitpunkt zeigte sich ein noch deutlicherer Unterschied in den Symptomausprägungen von F. culmorum verglichen mit F. equiseti, F. poae sowie F. tricinctum. Alle Pflanzen in der mit F. culmorum inokulierten Variante zeigten Vermorschungen der Halmbasis, was ausnahmslos an jeder dieser Pflanzen zu einem Boniturwert von 3 führte. Die mit $F$. poae und $F$. tricinctum inokulierten Versuchsvarianten zeigten dagegen zu BBCH 92 zwar eine signifikante Erhöhung des Befalls im Vergleich zu BBCH 77 auf, jedoch auf sehr niedrigem Niveau. Die mit F. equiseti inokulierte Versuchsvariante wies insgesamt den geringsten Befall auf und es wurde keine signifikante Erhöhung des Befalls zu $\mathrm{BBCH} 92$ gegenüber $\mathrm{BBCH} 77$ beobachtet. 


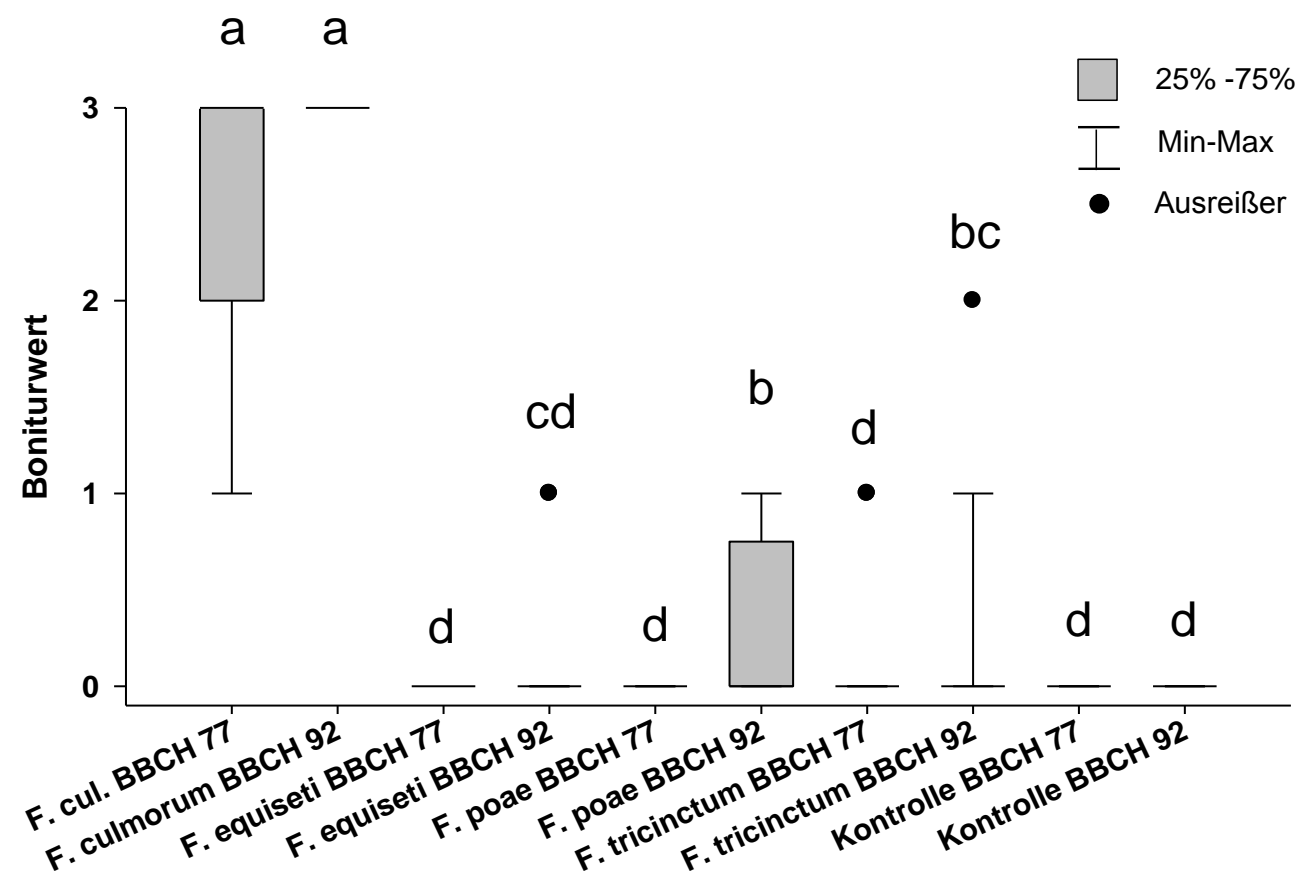

Abb. 70: Darstellung der Boniturwerte zu BBCH 77 und $\mathrm{BBCH} 92$ für die mit den verschiedenen Fusarium-Arten inokulierten Versuchsvarianten in Form von Box-WhiskerPlots. Sorte: „Tybalt“. Unterschiedliche Buchstaben kennzeichnen signifikante Unterschiede zwischen den Boniturwerten (BBCH 77: $n=80$, BBCH 92: $n=40$, statistische Auswertung nichtparametrisch mittels einfaktorieller ANOVA, $p<0,05$ ).

\subsubsection{Reisolationsraten}

Im Entwicklungsstadium der späten Milchreife zu BBCH 77 wurde dem Versuch die Hälfte der Pflanzen entnommen. Pro Variante wurden somit 40 Pflanzen auf die Besiedlung mit den verschiedenen Fusarium-Arten hin untersucht. Die Untersuchung erfolgte an vier verschiedenen Teilen des Halms der Pflanze und zwar an der Halmbasis sowie im Bereich des 1. Nodiums, des 2. Nodiums und am Pedunkel direkt unterhalb der Ähre. Diesen Bereichen des Pflanzenhalms wurden Segmente entnommen, auf PDA ausgelegt und die Reisolationsrate [\% befallene Pflanzen] pro Variante und Halmsegment erfasst. Tabelle 33 macht deutlich, dass die Reisolationsrate von F. culmorum an der Halmbasis mit 95,0\% befallener Pflanzen signifikant höher war, als in den übrigen Varianten. Die zweithöchste Rate erreichte der im Freiland nur ganz vereinzelt von der Halmbasis isolierte (s. 3.2.4) F. poae mit 42,5\%, was mehr als einer Halbierung der Besiedlung gegenüber F. culmorum entsprach. F. poae unterschied sich aber nicht signifikant von $F$. equiseti und F. tricinctum mit 37,5\% und 25,0\%. Im Bereich des ersten Nodiums war F. culmorum noch bei $85,0 \%$ der Pflanzen anzutreffen, wogegen die Reisolationsraten für $F$. poae bei $12,5 \%$ und für $F$. equiseti und $F$. tricinctum jeweils bei sehr geringen $2,5 \%$ lagen. Die Reisolationsraten der letztgenannten Fusarium-Arten unterschieden sich daher 
nicht signifikant von der Kontrolle. Lediglich F. culmorum konnte bei 22,5\% der Pflanzen aus dem Bereich des 2. Nodiums isoliert werden. In allen anderen Varianten waren die jeweiligen Fusarium-Arten nicht in der Lage, die Pflanzen über das 1. Nodium hinaus zu kolonisieren. Abgesehen von der Kontrolle war in jeder Versuchsvariante zudem ein signifikanter Rückgang der Besiedlung in akropetaler Richtung zu erkennen.

Tab. 33: Reisolationsraten zu BBCH 77 [\% befallener Pflanzen pro Variante] der verschiedenen Fusarium-Arten aus den Halmbereichen Halmbasis, 1. Nodium, 2. Nodium und Pedunkel. Sorte: „Tybalt“, $n=80$.

\begin{tabular}{lcccc}
\hline \multicolumn{1}{c}{ Art } & Halmbasis & 1. Nodium & 2. Nodium & Pedunkel \\
\hline F. culmorum & $95,0 \mathbf{a}$ & $85,0 \mathbf{a}$ & $22,5 \mathbf{a}$ & - \\
F. poae & $42,5 \mathbf{b}$ & $12,5 \mathbf{b}$ & $0,0 \mathbf{b}$ & - \\
F. equiseti & $37,5 \mathbf{b}$ & $2,5 \mathbf{b}$ & $0,0 \mathbf{b}$ & - \\
F. tricinctum & $25,0 \mathbf{b}$ & $2.5 \mathbf{b}$ & $0,0 \mathbf{b}$ & - \\
Kontrolle & $0,0 \mathbf{c}$ & $0,0 \mathbf{b}$ & $0,0 \mathbf{b}$ & - \\
\hline
\end{tabular}

\subsubsection{Trockenstressbonitur}

Um Kreuzkontaminationen durch feuchtigkeitsgesättigte Luftverwirbelungen zwischen den Versuchsvarianten innerhalb der Klimakammer zu vermeiden, wurde die Luftbefeuchtungsanlage während des Versuches nicht eingesetzt. Zudem wurden die Pflanzen zweimal für jeweils zwei Tage nicht gegossen, wodurch die Pflanzen unter Trockenstress gesetzt wurden. Zu BBCH 77 wurde ermittelt, ob in den Versuchsvarianten ein Einfluss der Inokulation mit Fusarium-Arten auf Pflanzenhöhe und Austrocknungserscheinungen der Blätter bestand.

Die Trockenstressbonitur der Blätter wurde für alle Pflanzen am Fahnblatt und dem Blatt erster Ordnung durchgeführt. Die F. culmorum-Variante wies mit durchschnittlich $86,5 \%$ einen hohen Austrocknungsgrad der Blätter auf. Der Trockenstress in Kombination mit der F. culmorum-Inokulation führte in vielen Fällen zum kompletten Absterben der Pflanzen, wie aus Abbildung 72 deutlich wird. Die übrigen Varianten zeigten einen wesentlich geringeren Austrocknungsgrad, der sich für F. poae mit 28,1\% auf dem Niveau der Kontrollvariante bewegte und daher kein Effekt des Pilzes auf das Austrocknen der Blätter 
bestätigt werden konnte. Für $F$. tricinctum und $F$. equiseti konnte im Vergleich dazu ein Effekt der Kombination Pilz-Trockenstress nachgewiesen werden, der aber für beide Varianten signifikant schwächer war, als für die F. culmorum-Variante.

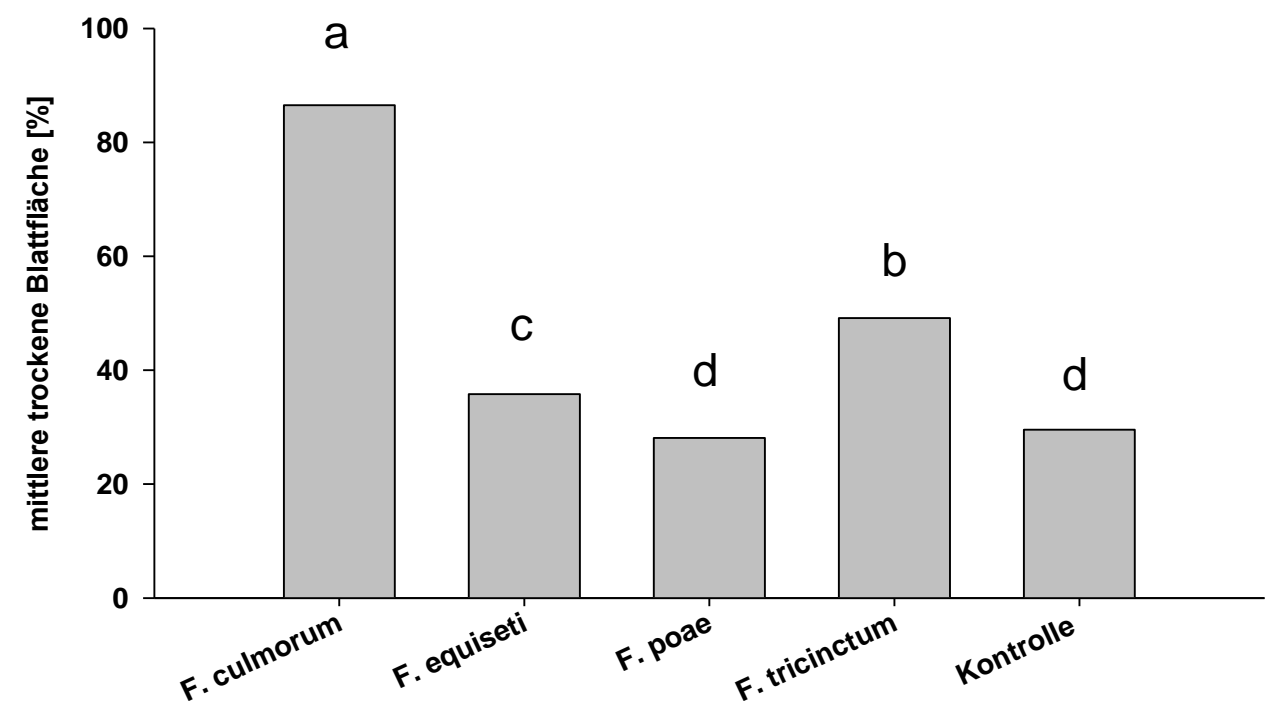

Abb. 71: Mittlere trockene Blattfläche [\%] der Sommerweizensorte „Tybalt“ in den verschiedenen mit Fusarium-Arten inokulierten Versuchsvarianten zu BBCH 77. Verrechnet wurde der prozentuale Anteil trockener Blattfläche des Fahnblattes und des Blattes 1. Ordnung jeder Pflanze pro Variante. Unterschiedliche Buchstaben kennzeichnen signifikante Unterschiede $(n=80$, statistische Berechnung mittels einfaktorieller ANOVA bei einer Irrtumswahrscheinlichkeit von $p<0,05$ ). 


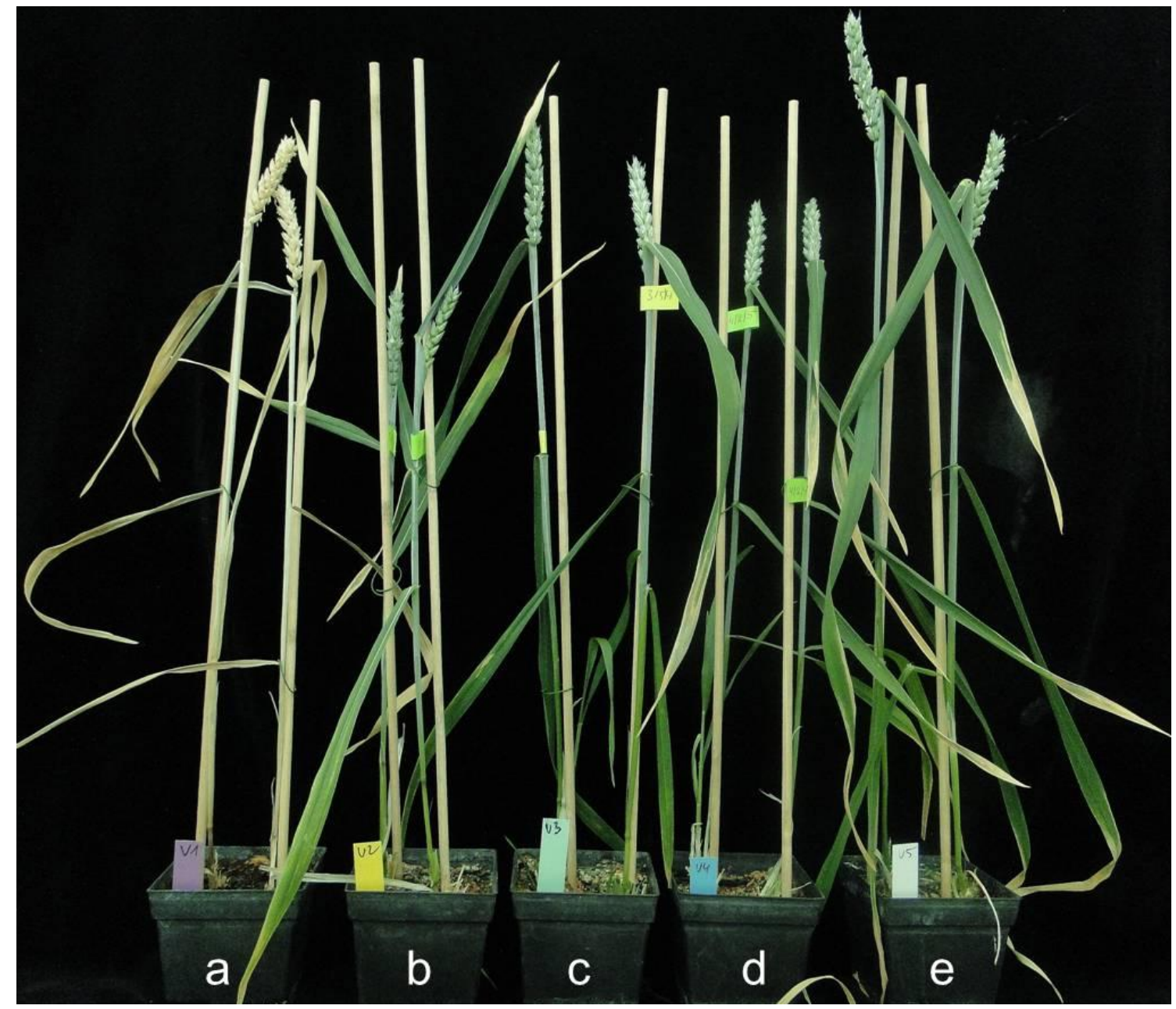

Abb. 72: Trockenstresssymptome in den verschiedenen mit Fusarium-Arten inokulierten Versuchsvarianten der Sommerweizensorte "Tybalt". a) F. culmorum, b) F. equiseti, c) F. poae, d) F. tricinctum und e) Kontrolle. Deutlich sichtbar ist der Einfluss von F. culmorum auf die Weizenpflanze. Während bei b), c), d), und e) eher schwache Trockenstresssymptome zu beobachten sind, sind die Pflanzen unter a) bereits vollkommen abgestorben.

\subsection{In vitro-Pathogenitätstest mit Fusarium-Arten an Weizen}

Zur Beurteilung der Pathogenität verschiedener Fusarium-Arten gegenüber Triticum aestivum $L$. in einem frühen Entwicklungsstadium des Weizens wurde ein In vitroPathogenitätstest durchgeführt. 

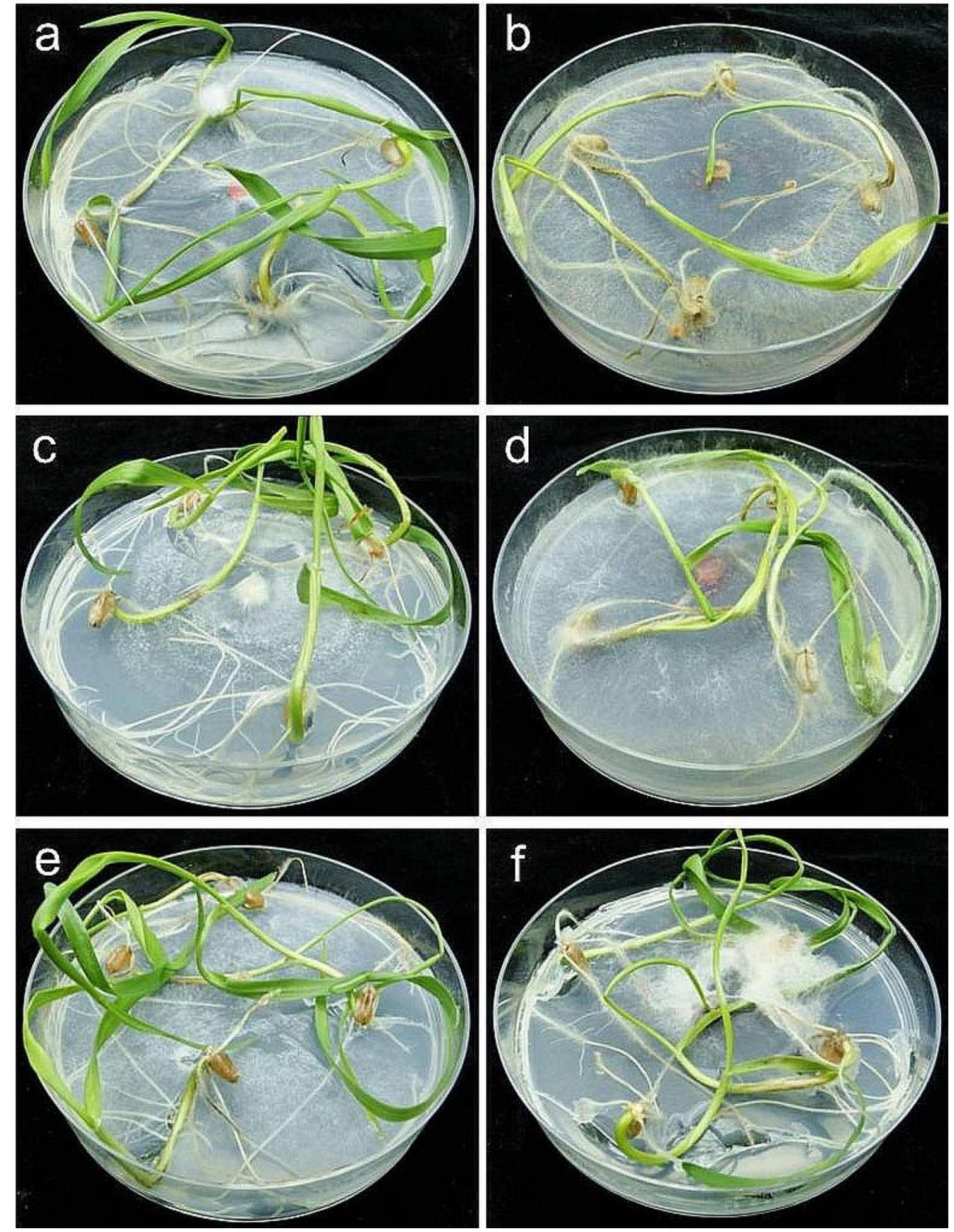

Abb. 73: Durch Fusarium-Arten während des In vitro-Pathogenitätstests hervorgerufene Symptome an Hypokotylen von Keimlingen der Winterweizensorte "Tybalt" nach 9 dpi.
a) F. avenaceum,
b) F. culmorum,
c) F. equiseti,
d) F. graminearum,
e) F. poae
und

f) F. tricinctum. 


\section{Visuelle Bonitur des Befalls}

Die Bonitur des Befalls an Weizenhypokotylen erfolgte nach Broschewitz et al., (1999). Die statistische Auswertung des In vitro-Pathogenitätstests sowie die grafische Darstellung der Ergebnisse mittels Box-Whisker-Plots sind in Abbildung 74 zu sehen. Hierfür wurden die Boniturnoten wie unter 2.18.1 beschrieben zunächst rangtransformiert und anschließend in Form von mittleren relativen Effekten der einzelnen Fusarium-Arten auf den Befall auf einer Skala von 0-1 dargestellt. Abbildung 73 zeigt die durch die unterschiedlichen, im Zuge des Versuchs getesteten Fusarium-Arten hervorgerufenen Symptome.

Die Ergebnisse machen deutlich, dass F.culmorum die mit Abstand aggressivste Fusarium-Art im Hinblick auf den Befall der Weizenhypokotylen darstellte, gefolgt von F. graminearum, da diese beiden Arten signifikant höhere mittlere relative Effekte auf den Befall hatten, als die übrigen Arten, während $F$. avenaceum moderate, mittlere relative Effekte verzeichnete. F. poae unterschied sich dagegen auf Grund der relativ großen Varianz der mittleren Befallswerte signifikant von F. avenaceum, F. tricinctum lag zwischen $F$. avenaceum und F. poae. F. equiseti wies die geringste Aggressivität auf und zeigte mittlere relative Effekte auf den Befall, die sich nicht signifikant von der Kontrolle unterschieden.

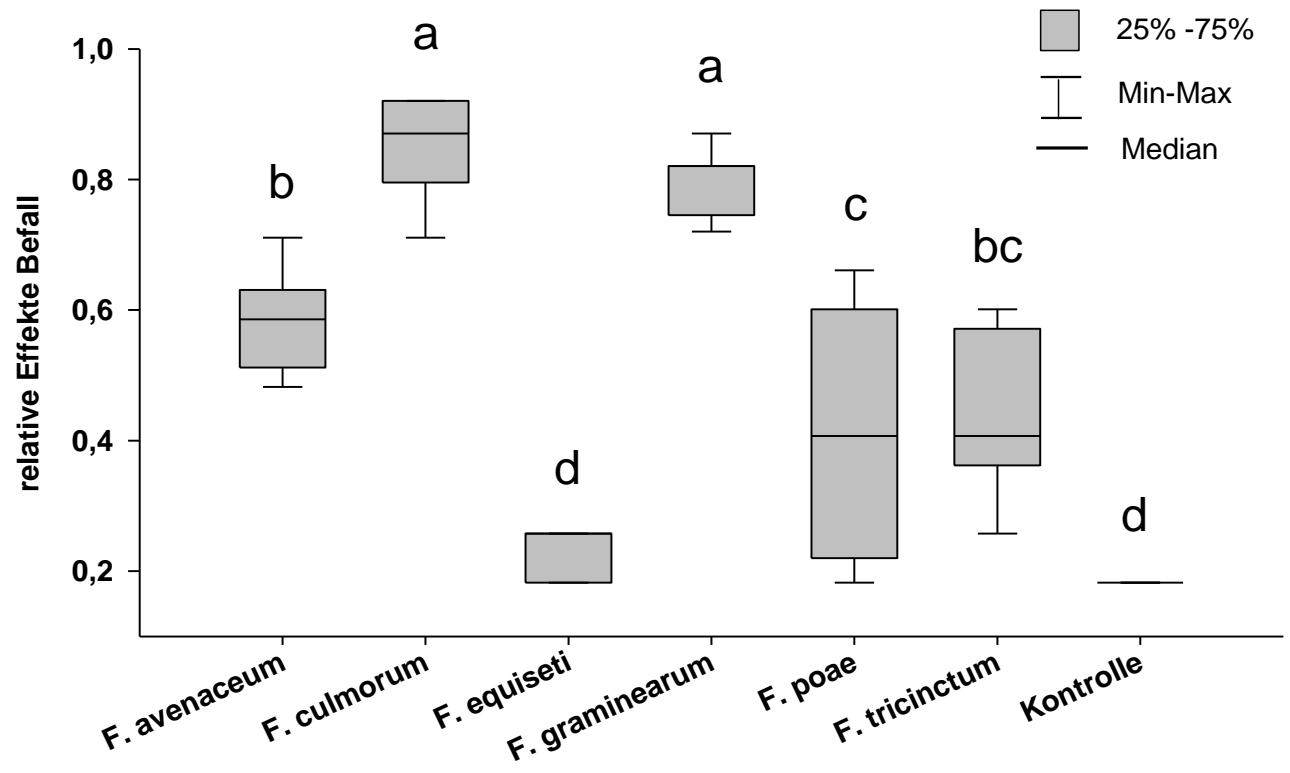

Abb. 74: Mittlere relative Effekte der verschiedenen Fusarium-Arten auf den Befall an Hypokotylen von Weizenkeimlingen. Sorte: „Tybalt“. Unterschiedliche Buchstaben kennzeichnen signifikante Unterschiede $(n=36$, statistische Berechnung nichtparametrisch mittels einfaktorieller ANOVA mit $p<0,05$ ). 


\section{$4 \quad$ Diskussion}

Im Rahmen der vorliegenden Arbeit wurden sowohl Freilandversuche als auch Versuche unter kontrollierten Bedingungen durchgeführt, um das Fusarium-Artenspektrum an Winterweizen in Abhängigkeit verschiedener Versuchsfaktoren sowie Pathogenität und agronomische Bedeutung dominierender Fusarium-Arten an Weizen zu ermitteln. Die Diskussion wird zunächst den Einfluss der einzelnen Versuchsfaktoren auf die Artenzusammensetzung sowie die Rolle verschiedener Fusarium-Arten in Abhängigkeit dieser Versuchsfaktoren näher betrachten. Eine anschließende Beurteilung der Pathogenität bedeutender Fusarium-Arten mit nachfolgender Risikobewertung gibt neben der Aufklärung interspezifischer Interaktionen Aufschluss über die agronomische Bedeutung dieser Arten, woraus sowohl eine ökologische Rolle als auch Empfehlungen zur Bekämpfung der im Zuge dieser Untersuchungen häufig aufgetretenen FusariumArten abgeleitet werden.

\subsection{Fusarium-Artenspektren und Kolonisierungsraten an Halmbasis und Körnern von Weizen in Abhängigkeit der Versuchsfaktoren}

In den Jahren 2010 und 2011 wurden im Zuge des seit 2006 existierenden FAENFruchtfolgeversuches Untersuchungen an Halmbasis und Körnern von Winterweizen durchgeführt, auf deren Basis eine Charakterisierung des Fusarium-Artenspektrums in Verbindung mit artspezifischen Kolonisierungsraten an beiden Pflanzenorganen von Weizen im Hinblick auf organspezifische Unterschiede sowie in Abhängigkeit der Versuchsfaktoren Jahr/Witterung, Probenahmezeitpunkt, Vorfrucht, Sorte und Blattfungizidbehandlung erfolgte.

\subsubsection{Einfluss des Versuchsjahres bzw. der Witterung}

Für eine unter Berücksichtigung der Vergleichbarkeit der Versuchsjahre 2010 und 2011 möglichst breit angelegte und umfassende Untersuchung des jahresbedingten Einflusses bzw. der Witterung auf die Fusarium-Artenspektren und Kolonisierungsraten der einzelnen Fusarium-Arten an Halmbasis und Körnern, wurden die artspezifischen Kolonisierungsraten der Versuchsvariante „Ritmo, unbehandelt“ an der Halmbasis der Probenahmezeitpunkte zu den Entwicklungsstadien $\mathrm{BBCH}$ 61-65 (BBCH 69 für 2011) und BBCH 71-75 (BBCH 75-77 für 2011) beider Jahre zusammengefasst (Abb. 58). Jahresbedingte Witterungseinflüsse, aus denen sich Unterschiede in Bezug auf Vor- 
frucht-, Sorten- und Fungizideffekte ergaben, werden in den jeweiligen Abschnitten 4.1.3, 4.1.4 und 4.1 .5 behandelt.

Eine erfolgreiche Infektion des Weizens durch Fusarium ist in besonderem Maße witterungsabhängig, wie bereits Andersen (1948) für das Auftreten von „Fusarium Head Blight“ (FHB) postulierte. Für eine Infektion der Halmbasis wirken besonders trockene und warme Witterungsbedingungen im Herbst während des Auflaufens des Weizens befallsfördernd (Duben, 1978; Cook, 1980; Smiley et al., 2005) auf typische Halmbasiserreger wie F.culmorum. Vergleicht man die Witterung der beiden Vegetationsperioden 2009/2010 und 2010/2011 am Versuchsstandort Torland, so waren diese jeweils zum Herbst von unterschiedlichen Witterungsereignissen geprägt (Abb. 11 und Abb. 12). Während der Herbst 2009 relativ feuchten, laut Literatur demnach wenig befallsfördernden Witterungsbedingungen unterlag, ging der Herbst 2010 dagegen im Oktober mit einer sehr trockenen, für einen Halmbasisbefall durch Fusarium günstigeren Witterung einher. Der darauffolgende November verzeichnete allerdings sehr hohe Niederschläge, was einem weiteren Befall durch Fusarium entgegengewirkt haben könnte. Bezüglich der Halmbasiskolonisierung von Weizen durch verschiedene FusariumArten in Abhängigkeit von der Witterung, brachte ein Vergleich der Versuchsjahre 2010 und 2011 sowohl qualitative als auch quantitative Unterschiede. Qualitative Unterschiede waren hinsichtlich der unterschiedlichen Anzahl der isolierten Arten zwischen den Jahren zu beobachten. Während im Versuchsjahr 2010 mit F. avenaceum, F. culmorum, F. equiseti, F. graminearum, F. oxysporum und F. tricinctum insgesamt sechs FusariumArten von der Halmbasis isoliert werden konnten (s. 3.2.1), wurde dieses Artenspektrum im darauffolgenden Jahr durch F. cerealis, F. poae, F. redolens und F. venenatum auf 10 Arten erweitert (s. 3.2.4). Dabei stellten in beiden Jahren F. culmorum, F. equiseti und F. tricinctum die drei an der Halmbasis dominierenden Arten dar, wogegen alle übrigen Arten sowohl 2010 als auch 2011 nur vereinzelt vorkamen und eine untergeordnete Rolle spielten. Aus Untersuchungen aus den 1970er Jahren hervorgehende Resultate von Duben und Fehrmann (1979), in denen neben F. avenaceum besonders F. culmorum an der Halmbasis als vorherrschende Arten identifiziert werden konnte, werden durch diese Ergebnisse bestätigt, wogegen $F$. equiseti und F. tricinctum sowohl in Deutschland, als auch in England und der Schweiz zwar von der Halmbasis isoliert werden konnten (Krampe, 1926; Bennett, 1935; Prillwitz und Bauermann, 1974), jedoch als eher unbedeutend eingestuft wurden (Duben, 1978). Ein durch die Witterungsunterschiede beeinflusster, quantitativer Unterschied war vor allem für $F$. culmorum und $F$. tricinctum zu erkennen, welcher sich in den unterschiedlich hohen Kolonisierungsraten dieser Arten zwischen den Jahren manifestierte. Die Ergebnisse zeigen, dass der jahresbedingte Witterungsunterschied zwischen 2010 und 2011 einen Einfluss auf die Diversität des Fusarium-Artenspektrums an der Halmbasis hatte. Witterungsbedingungen, die sich eher 
fördernd auf den Befall mit Fusarium auswirkten, hatten somit einen Anstieg der Artenzahl an der Halmbasis zur Folge, änderten aber nichts an der dominierenden Präsenz der Arten F. culmorum, F. equiseti und F. tricinctum. Es bestand hingegen eine signifikante Verlagerung der Kolonisierungsraten hin zu einer höheren Besiedlung mit F. culmorum, was auf die für Fusarium förderlichen Infektionsbedingungen im Herbst 2010 hindeutet. Auffallend war, dass eine verstärkte Kolonisierung der Halmbasis durch F. culmorum im Versuchsjahr 2011 offenbar eine Verdrängung der Arten F. equiseti und insbesondere F. tricinctum zur Folge hatte. F. equiseti und F. tricinctum werden unter 4.2 als an der Halmbasis apathogene, vermutlich endophytische Besiedler charakterisiert, welche keine Befallssymptome in Form von „Fusarium Foot Rot“ verursachen. Als mögliche Erklärung für eine Verdrängung der beiden Arten könnte hier demnach eine mangelnde Konkurrenzfähigkeit gegenüber der wesentlich aggressiveren, die Halmbasis des Weizens systemisch besiedelnden Art F. culmorum dienen (Snijders, 1990; Clement und Parry, 1998). Dies könnte unter Umständen an unterschiedlichen Enzymausstattungen der verschiedenen Arten liegen. Kang und Buchenauer (2002) stellten in Untersuchungen zum Infektionsprozess von F. culmorum in Weizenährchen fest, dass Hyphen von F. culmorum während des Infektionsprozesses zellwanddegradierende Enzyme wie Zellulasen, Xylanasen und Pektinasen ausscheidet, die mit starken Strukturveränderungen der Zellwandkomponenten einhergehen. Dies könnte auch an der Halmbasis der Fall sein. Überträgt man diesen Sachverhalt auf die Ergebnisse dieser Arbeit, so könnte geschlussfolgert werden, dass die Arten F. equiseti und F. tricinctum diese Enzyme wenig oder aber gar nicht produzieren, was ebenfalls die geringen Symptomausprägungen durch diese Arten erklären könnte.

Eine Ähreninfektion durch die in Deutschland mehr und mehr an Bedeutung gewinnende und mittlerweile als Hauptverursacher von FHB geltende Art F. graminearum (Brandfaß, 2006) erfolgt primär bei anhaltender feucht-warmer Witterung während der Weizenblüte (Pugh, 1933) und zeigt die starke Abhängigkeit des Pathogens von infektionsfördernden Witterungsbedingungen (Hooker et al., 2002). Halten diese Bedingungen nach der Blüte an, so kann ein signifikant höherer FHB-Befall zusammen mit verminderten Erträgen und stark erhöhten Mykotoxingehalten im Erntegut die Folge sein. Ergebnisse von Gödecke (2010) konnten an dem auch dieser Arbeit zu Grunde liegenden Versuchsstandort Torland zeigen, wie stark sich eine wie oben beschriebene, zeitliche Koinzidenz von hohen Temperaturen und anhaltendem Niederschlag während der Vollblüte und darüber hinaus in einem „Fusarium-Jahr“ auswirken kann. So setzten sich die Artenspektren an den untersuchten Körnern unter vorher genannten Witterungsbedingungen zu bis zu $90 \%$ aus F. graminearum als Leitpathogen zusammen. Der Kornbefall durch Fusarium-Arten zeigte sich im Rahmen dieser Arbeit in beiden Versuchsjahren auf Grund von Trockenheit 
zur Blüte im Monat Juni jedoch als äußerst niedrig (s. 3.1.1). So war 2010 keinerlei Niederschlag zur Blüte zu verzeichnen, 2011 fielen während der Blüte in sieben Tagen insgesamt nur $11 \mathrm{~mm}$ Niederschlag. Dies bedingte in beiden Jahren eine äußerst geringe Infektion mit $F$. graminearum und somit ein niedriges FHB-Risiko, welches sich in kaum vorhandenen FHB-Symptomen im Freiland (s. 3.1.2) und insgesamt geringen Kolonisierungsraten durch die verschiedenen Fusarium-Arten zur Ernte widerspiegelte. Beispielsweise erreichte $F$. tricinctum eine durchschnittliche Kolonisierungsrate von 7,1\% im gesamten Erntegut des Versuchsjahres, was der höchsten von einer einzelnen Fusarium-Art erreichten durchschnittlichen Kolonisierungsrate entsprach. Sowohl Versuchsjahr 2010 als auch 2011 sind daher am Standort Torland grundsätzlich nicht als sogenannte "Fusarium-Jahre" anzusehen. Dennoch konnten an den Körnern trotz der geringen Kolonisierungsraten auf Grund jahresbedingt veränderter Witterung qualitative und quantitative Unterschiede im Hinblick auf Artenspektrum und Kolonisierungsraten von Fusarium an den Körnern festgestellt werden. Im Versuchsjahr 2010 wurden insgesamt sechs Fusarium-Arten aus dem Erntegut des Versuchs isoliert: F. avenaceum, F. culmorum, F. equiseti, F. graminearum, F. poae und F. tricinctum (s. 3.2.2). Dieses Artenspektrum wurde 2011 durch die Arten F. cerealis und F. sporotrichioides erweitert, sodass sich das Artenspektrum 2011 als geringfügig diverser darstellte (s. 3.2.5). Da es sich hier jedoch sowohl für F. cerealis, als auch für F. sporotrichioides um Einzelisolate handelt, ist der Erweiterung des Artenspektrums um diese beiden Arten und somit einem qualitativen Unterschied der Artenspektren 2010 und 2011 keine große Bedeutung beizumessen. Mehrjährige Studien von Birzele et al. (2002) an verschiedenen Standorten im Rheinland zur Epidemiologie von Fusarium-Arten an Weizen wiesen dagegen auf F. avenaceum, F. poae, F. culmorum und F. graminearum als häufigste Ährenbesiedler hin, wobei $F$. avenaceum am häufigsten auftrat. Allerdings zeigte sich auch hier die starke Witterungs- und vor allem Standortabhängigkeit des Auftretens verschiedener FusariumArten. Das Jahr 2010 zeichnete nach der Blüte eine dem langjährigen Mittel gegenüber feuchtere Witterung im Juli und August aus (s. 3.1.1), durch die es zu einer sekundären Besiedlung nach der Blüte, bzw. während der Reife des Weizens bis zur Ernte gekommen sein könnte und verglichen mit 2011 in einer stärkeren Kolonisierung der Körner resultierte. F. poae und F. tricinctum stellten mit Kolonisierungsraten von 6,1\% und 7,1\% die dominierenden Arten an den Körnern dar, wogegen F. avenaceum nicht von Bedeutung war (Abb. 59). Zumindest für F. poae und F. tricinctum können die auf Basis von Nachernteuntersuchungen norwegischer Getreidearten in den Jahren 1994-1996 basierenden Ergebnisse von Kosiak et al. (2003) mit den vorliegenden Ergebnissen dieser Arbeit bestätigt werden. Die Autoren fanden neben $F$. avenaceum auch besonders häufig F. poae und F. tricinctum im Erntegut. Auch Wilcoxson et al. (1988) konnte in Minnesota nach F.graminearum als zweithäufigste Fusarium-Art F. poae von FHB- 
Weizenkörnern isolieren. Golinski et al. (1996) fanden in 78 Weizenproben von 13 verschiedenen Standorten in Polen unter allen isolierten Fusarium-Arten 64\% F. poae und $15 \%$ F. tricinctum.

Die Kolonisierungsrate von knapp 3,0\% für F. graminearum im Jahr 2010 (Abb. 59) wurde lediglich durch ein erwartungsgemäß stärkeres Auftreten des Pilzes nach Vorfrucht Mais erreicht (Abb. 27 B). Ein quantitativer Effekt im Hinblick auf unterschiedliche Kolonisierungsraten der Arten zwischen den Jahren war trotz geringer Kolonisierungsraten in beiden Jahren deutlich $\mathrm{zu}$ erkennen. So betrugen die Kolonisierungsraten von F. tricinctum und F. poae im Jahr 2011 2,6\% bzw. 3,0\% und waren somit um mehr als die Hälfte niedriger, als 2010. F. graminearum war mit weniger als $0,5 \%$ Kolonisierungsrate kaum anzutreffen (Abb. 59). Die geringeren Kolonisierungsraten im Versuchsjahr 2011 gegenüber 2010 sind jedoch nachvollziehbar. 2011 war der Juni im Schnitt zwar wesentlich feuchter im Vergleich zum langjährigen Mittel (s. 3.1.1). Dennoch war der Niederschlag zur Blüte ebenfalls sehr gering, sodass wie bereits 2010 keine primäre Infektion der Ähre durch F. graminearum stattfinden konnte. Auf den Juni folgte ein trockener Juli und trockener August (Daten für August nicht gezeigt), wodurch auch eine Besiedlung mit Arten wie F. poae, der laut Xu et al. (2005) eher warme und trockene Bedingungen bevorzugt und F. tricinctum nur schwach ausgeprägt war. Trotz witterungsbedingter Unterschiede im Hinblick auf Artenspektren und Kolonisierungsraten kann festgehalten werden, dass in beiden Jahren F. poae und F. tricinctum das Artenspektrum an den Körnern dominierten und möglicherweise im Einklang mit unter 4.2 gezogenen Schlüssen als saprophytische Sekundärkolonisierer an den Körnern von Weizen auftraten.

Auch wenn sich die Ergebnisse im Hinblick auf die Kornbesiedlung besonders im Versuchsjahr 2011 als weniger ausgeprägt darstellen als an der Halmbasis, kann am Standort Torland grundsätzlich von organspezifischen, stabilen Populationssignaturen (vgl. 4.1.3) sowohl an der Halmbasis als auch an den Körnern gesprochen werden, die eine Jahresabhängigkeit insgesamt vor allem in Bezug auf die Höhe artspezifischer Kolonisierungsraten aufwiesen.

Über einen möglichen Zusammenhang zwischen den Populationen an Halmbasis und Körnern kann im Zuge dieser Arbeit nur spekuliert werden. Auf Basis der Ergebnisse ist jedoch zu vermuten, dass es sich bei den unterschiedlichen Populationen an Halmbasis und Körnern in erster Linie um unabhängige Populationen handelt. Eine Übertragung von F. culmorum, F. equiseti, F. graminearum und F. poae von der Halmbasis auf die Körner scheint wenig wahrscheinlich. Lediglich für $F$. tricinctum, welcher durchgehend an beiden Pflanzenorganen aufzufinden war, könnte eine Abhängigkeit zwischen den beiden Populationen in Form einer Übertragung von der Halmbasis auf die Körner existieren. Ob 
ein Zusammenhang zwischen den beiden Organen in Bezug auf F. tricinctum besteht, konnte im Rahmen dieser Arbeit jedoch nicht eindeutig geklärt werden.

\subsubsection{Einfluss des Probenahmezeitpunktes}

Die Ergebnisse über den Einfluss des Probenahmezeitpunktes auf das FusariumArtenspektrum und die Kolonisierungsraten von Fusarium-Arten an Weizen beziehen sich nur auf die Halmbasis (s. 3.2.1 und 3.2.4). Hier war deutlich ein Effekt in Bezug auf die Entwicklung der Gesamtkolonisierungsraten über die Zeit nach den vier Vorfrüchten zu erkennen. In der Regel sollte nach erfolgreicher initialer Infektion durch das Pathogen bei gegebener Fähigkeit zur systemischen Kolonisierung der Pflanze im Besiedlungsverlauf eine Ausbreitung innerhalb der Pflanze erfolgen. Folglich müsste sich auch insgesamt die Zahl der Fusarium-Isolate pro Versuchsparzelle zu einem bestimmten Probenahmezeitpunkt im Vergleich zum vorherigen erhöhen. Sowohl 2010 als auch 2011 kam es jedoch teilweise zu atypischen Besiedlungsverläufen. Im Jahr 2010 (Abb. 19) waren nach allen vier Vorfrüchten zur Blüte (BBCH 61-65, Probenahmezeitpunkt 2) die Gesamtkolonisierungsraten niedriger als zum Entwicklungsstadium des Schossens (BBCH 37-39, Probenahmezeitpunkt 1). Nur nach Zuckerrübe stiegen diese zur Milchreife über die Rate des 1. Probenahmezeitpunktes an.

Im Jahr 2011 konnten zumindest nach Zuckerrübe und ÖIrettich über die Zeit kontinuierlich ansteigende Kolonisierungsraten beobachtet werden. Nach Weizen war tendenziell eine Abnahme zu verzeichnen, wogegen nach Mais die höchste Kolonisierungsrate zur Blüte ermittelt wurde. Die teilweise unregelmäßigen Besiedlungsverläufe ändern grundsätzlich nichts an der Vorfruchtbedeutung für die Halmbasisbesiedlung, (s. 4.1.3) besonders im Hinblick auf Mais und Zuckerrübe. Dennoch stellt sich die Frage, warum eine kontinuierlich steigende Besiedlung in beiden Jahren eher eine Ausnahme, als die Regel darstellte. Dieser Sachverhalt könnte mit der Tatsache erklärt werden, dass die Ergebnisse der Isolation von Fusarium-Arten aus Halmbasismaterial nicht immer exakt den tatsächlichen Besiedlungsgrad widerspiegeln. So zeigten die Ergebnisse der Halmbasisbonitur im Versuchsjahr 2011 zu BBCH 75-77 die geringsten Symptome nach Zuckerrübe (Abb. 18), wogegen die Ergebnisse der Isolation von Fusarium aus der Halmbasis zu diesem Entwicklungsstadium nach Zuckerrübe die höchste Gesamtkolonisierungsrate ergab (Abb. 19). Wegener (1996) kam bei einem Vergleich von Sichtboniturergebnissen und nachfolgender Agarisolation aus mit Fusarium besiedelten Weizenhalmbasen zu ähnlichen Ergebnissen. Eine weitere Erklärung könnte sein, dass Vorfruchtreste in der Regel ungleichmäßig auf dem Feld verteilt sind und sich dementsprechend bestimmte Hot-Spots mit erhöhter Gefahr für eine Halmbasisbesiedlung durch Fusarium-Arten ergeben haben könnten. Gleichmäßige 
Beprobungen über die gesamte Parzelle, wie sie im Zuge dieser Arbeit durchgeführt wurden, könnten unter Annahme dieses Sachverhalts Unregelmäßigkeiten der Gesamtkolonisierungsraten in der o.g. Form zwischen den drei Probenahmezeitpunkten zur Folge gehabt haben.

\subsubsection{Einfluss der Vorfrucht}

Die Wahl der geeigneten Vorfrucht ist eines der ältesten Werkzeuge des Ackerbaus und dient dazu, der Anreicherung des Inokulums bodenbürtiger Schaderreger entgegenzuwirken (Steinmann und von Tiedemann, 2006). Der sinnvolle Anbau von Zwischenfrüchten zwischen zwei Hauptkulturen in abwechselnder zeitlicher und räumlicher Dichte ist ein wichtiger Bestandteil phytosanitärer Maßnahmen zur Bekämpfung typischer Fruchtfolgekrankheiten und somit zur Sicherung des Ertrags (Keller et al., 1997). Phytosanitäre Aspekte spielen jedoch für landwirtschaftliche Betriebe in Bezug auf die Gestaltung der Fruchtfolge eine untergeordnete Rolle. Vielmehr wird die Vorfruchtwahl von betrieblichen und ökonomischen Faktoren, wie dem Betriebstyp, Lieferverträgen und der Nachfrage des Marktes bestimmt (Steinmann und von Tiedemann, 2006). So hat die in den letzten Jahren mit steigender Tendenz im Getreidebau praktizierte Einengung der Fruchtfolge zu Gunsten von Mais (Rintelen, 2000), aber auch Weizen und Raps die Diversität der Fruchtfolgen in Deutschland erheblich reduziert. Besonders in Bezug auf den Befall des Weizens mit Fusarium ist eine geeignete Fruchtfolge jedoch von großer Bedeutung, was bereits von Atanasoff Anfang der 1920er Jahre postuliert wurde. Für Mais als Vorfrucht ist ein in hohem Maße fördernder Effekt auf den Befall von Weizen mit Fusarium in Form von FHB bekannt, da die auf dem Feld verbleibenden Maisstoppeln dem Pilz eine optimale Nährstoffquelle bieten (Sutton, 1982). In diesem Kapitel rückt daher die phytopathologische Beurteilung der bisher als Gesundfrucht eingestuften Zuckerrübe als Vorfrucht im Hinblick auf eine mögliche Übertragung weizenpathogener Fusarium-Arten in den Fokus.

Die durch diese Arbeit erhaltenen Ergebnisse bestätigen die große Bedeutung des Maises als aus phytosanitärer Sicht risikoreiche Vorfrucht in Weizenfruchtfolgen (Sutton, 1982; Dill-Macky und Jones, 2000; Krauthausen et al., 2003). Jedoch zeigten die Ergebnisse der vorliegenden Arbeit auch nach Zuckerrübe zumindest bezüglich des Befalls der Halmbasis des Weizens mit Fusarium hohe Kolonisierungsraten, die die Kolonisierung nach Mais und daher den Effekt des Maises als Vorfrucht in späteren Entwicklungsstadien des Weizens noch übertraf. So lagen die Gesamtkolonisierungsraten nach Vorfrucht Zuckerrübe in beiden Versuchsjahren zum Zeitpunkt der Milchreife mit 66,7\% (Abb. 24) und 82,9\% (Abb. 38) signifikant höher, als nach Mais, Ölrettich oder Weizen. Die geringsten Kolonisierungsraten waren 2010 nach Weizen und Ölrettich zu verzeichnen, wobei sich im 
Versuchsjahr 2011 ab dem Entwicklungsstadium der Blüte die Kolonisierungsraten von durchschnittlich weniger als $20 \%$ nach Winterweizen im Vergleich zu Ölrettich sogar als signifikant niedriger darstellten. Die Vorfruchtwirkung des Weizens auf Fusarium wird in der Literatur recht kontrovers diskutiert. Laut Domsch et al. (1968) sind Fusarium-Arten typisch an Weizen und können sich besonders in Weizenmonokultur anreichern, was den Ergebnissen dieser Arbeit jedoch wiederspricht. Krauthausen et al. (2003) konnten allerdings in Weizenproben aus Betrieben und Landessortenversuchen in Rheinland-Pfalz der Jahre 1999-2002 keinen erhöhten Befall von Winterweizen nach Vorfrucht Winterweizen feststellen.

In Bezug auf den Einfluss der vier Vorfrüchte auf das Fusarium-Artenspektrum an der Halmbasis konnten über beide Versuchsjahre die Arten F. culmorum, F. equiseti und F. tricinctum als wichtigste Halmbasiskolonisierer identifiziert werden, wobei in der Literatur ausschließlich die Arten F.culmorum und F.graminearum (Duben und Fehrmann, 1979; Cook, 1980; Clement und Parry, 1998) und F. avenaceum (Duben, 1978; Smiley et al., 2005) als bedeutende Halmbasiskolonisierer genannt werden. Ein eindeutiger qualitativer Unterschied der Artenspektren im Hinblick auf vorfruchtabhängige Populationssignaturen konnte insgesamt nicht festgestellt werden. Lediglich zum Zeitpunkt der Milchreife war nach Zuckerrübe auch $F$. avenaceum häufiger vertreten. Diese Ergebnisse lassen grundsätzlich auf eine stabile Populationssignatur an der Halmbasis schließen, welche sich am Standort Torland primär aus den Arten F. culmorum, F. equiseti und F.tricinctum zusammensetzt und jahresabhängig artspezifischen Schwankungen der Kolonisierungsraten unterliegen kann (Abb. 58). Untersuchungen von Lienemann et al. (2003) zeigten das starke Auftreten von F. avenaceum an Weizenkörnern an verschiedenen Standorten im Rheinland. Als möglicher Grund dafür wurde die Anpassung des Pathogens an die speziellen Fruchtfolgen Winterweizen-Wintergerste-Zuckerrübe bzw. Winterweizen-WinterweizenZuckerrübe angegeben. Dies könnte grundsätzlich auch für Fusarium-Arten an der Halmbasis angenommen werden. Da jedoch am Standort Torland nach allen Vorfrüchten von F. culmorum, F. equiseti und F. tricinctum dominierte Populationssignaturen aufzufinden waren, muss hier eher der Standort als größter Faktor in Bezug auf die in Torland vorkommenden Arten in Betracht gezogen werden.

Die Höhe der Gesamtkolonisierungsraten nach jeder Vorfrucht war in erster Linie von erhöhten Kolonisierungsraten der oben genannten drei Haupthalmbasiskolonisierer beeinflusst, was besonders deutlich im Versuchsjahr $2010 \mathrm{zu}$ BBCH71-75 nach Zuckerrübe zu erkennen war, wo Kolonisierungsraten zwischen 28,3\% für $F$. equiseti und $35,0 \%$ für $F$. culmorum festgestellt werden konnten (Abb. 25). Die Kolonisierungsraten der übrigen Arten lagen im Gegensatz dazu bei unter 5\% oder traten gar nicht auf. Das Versuchsjahr 2011 brachte besonders nach den Vorfrüchten Mais und Zuckerrübe und 
insbesondere ab der Weizenblüte ca. 20\% höhere Gesamtkolonisierungsraten hervor (Abb. 36), was mit einer starken Dominanz von F. culmorum an der Halmbasis nach diesen Vorfrüchten zusammenhing. Diese Ergebnisse verdeutlichen die Notwendigkeit, Zuckerrübe als potenziellen Fusarium-Überträger für Weizen als Nachfrucht einzustufen, vor allem bezüglich des Auftretens toxigener Fusarium-Arten wie F. culmorum bei befallsfördernden Bedingungen. Auch Christ et al. (2011a) konnten zeigen, dass aus Zuckerrüben isolierte Fusarium-Artenspektren ähnlich divers sind, wie Artenspektren an Weizen und dass neben F. graminearum die Zuckerrübenisolate der Arten F. cerealis, F. culmorum, F. equiseti und F. tricinctum in Inokulationsversuchen unter kontrollierten Bedingungen ebenfalls an Weizen pathogen waren und Mykotoxinkontaminationen hervorrufen konnten (Christ et al., 2011b). Von der Besiedlung des Weizens mit den Arten $F$. equiseti und F. tricinctum geht dagegen nach eigenen Ergebnissen kein Risiko aus (s. 4.2.1) Zu diesem Ergebnis kam auch Duben (1978). Eine mögliche Bedeutung der Zuckerrübe als potenzieller Fusarium-Überträger durch eine Übertragung von FusariumArten auf Weizen wurde bereits von Burlakoti et al. (2007) beobachtet. Da im Zuge dieser Arbeit F.culmorum, F. equiseti und F. tricinctum jedoch in beiden Versuchsjahren besonders nach Vorfrucht Zuckerrübe zur Milchreife dominierten (Abb. 19 und Abb. 33), lässt dies hingegen den Schluss zu, dass eine Übertragung dieser Arten durch auf dem Feld verbliebene Zuckerrübenreste stattgefunden haben könnte.

Dies wirft allerdings die Frage auf, welchem Übertragungspfad Fusarium-Arten unter besonderer Berücksichtigung von F. culmorum bei der Besiedlung der Halmbasis des Weizens folgen, wenn Zuckerrübe im Vorjahr als Vorfrucht angebaut wurde. In vitroVersuche von Streit und Tillmann (2012, unveröffentlicht) zum Wachstum verschiedener Fusarium-Arten auf festen und in flüssigen auf Weizen-, Mais-, Zuckerrüben- und Ölrettichsubstrat basierenden Medien, konnten hierbei einen ersten Hinweis liefern. Die Ergebnisse erbrachten, dass bei Temperaturen zwischen $8^{\circ} \mathrm{C}$ und $24^{\circ} \mathrm{C}$ die sechs getesteten Fusarium-Arten F. avenaceum, F.culmorum, F. equiseti, F. graminearum, $F$. poae und F. tricinctum auf festem Zuckerrübensubstratmedium sowohl am schnellsten wuchsen, als auch die höchste Myzeldichte aufwiesen, dicht gefolgt von Mais. Vor allem für $F$. culmorum, F. graminearum und $F$. poae konnten signifikant höhere Wachstumsraten ermittelt werden. Nach dreiwöchiger Kultivierung in flüssigen Vorfruchtsubstratmedien wiesen zudem alle untersuchten Arten die signifikant höchste Biomasseproduktion nach Wachstum in Zuckerrübensubstratmedium auf. Die Vorzüglichkeit der beiden auf Grundlage von Zuckerrübe und Mais hergestellten Substrate liegt in ihrem Nährstoffangebot begründet. Im Rahmen der Versuche wurden u.a. die Gehalte der Substrate an gebundenem Stickstoff sowie an organischem Kohlenstoff analysiert. Das Zuckerrübensubstrat wies dabei erwartungsgemäß einen hohen Anteil an organischem Kohlenstoff in Form von Saccharose auf, während das Maissubstrat einen hohen 
Stickstoffgehalt verzeichnete (Gödecke, 2010). Diese Ergebnisse basieren auf Versuchen, welche im Labor unter artifiziellen Bedingungen durchgeführt wurden. Somit konnten Faktoren, die die Besiedlung von Vorfruchtresten im Feld zusätzlich beeinflussen können, wie z.B. interspezifische Interaktionen und Konkurrenz innerhalb der Gattung Fusarium sowie mit der übrigen Bodenflora, Temperaturschwankungen und Tag/Nacht-Rhythmen nicht simuliert werden. Aus diesen Gründen können die Ergebnisse nicht ohne Weiteres auf die Situation im Feld unter natürlichen Umweltbedingungen übertragen werden. Dennoch geben sie eine wichtige Tendenz wieder, die zeigt, dass beispielsweise das bodenbürtige Pathogen F.culmorum bei Wachstum auf Zuckerrübenresten unter natürlichen Bedingungen in der Lage sein könnte, die Kohlenhydratquellen der Zuckerrübenreste zu nutzen. Auch die hohen Kolonisierungsraten von F. culmorum an der Halmbasis nach Vorfrucht Zuckerrübe am Standort Torland in den Versuchsjahren 2010 und 2011 könnten durch diese These erklärt werden und die Annahme von Burlakoti et al. (2007) sowie von Christ et al. (2011b) bestärken, dass Zuckerrübenreste Fusarium möglicherweise als Inokulumquellen dienen. Hanse und Tijink (2010) schätzten jedoch auf Basis kürzlich durchgeführter Untersuchungen zur Vorfrucht Zuckerrübe die Menge an auf dem Feld verbleibenden Zuckerrübenresten nach der Ernte im Vergleich zu Weizen als Vorfrucht um ca. 50\% geringer ein, was einer Übertragung von Fusarium-Arten von Zuckerrübe auf Weizen als weniger wahrscheinlich erscheinen lässt, da nur wenig Vorfruchtmaterial als Inokulumquelle genutzt werden kann.

Trotzdem lässt das verstärkte Auftreten von F. culmorum an der Halmbasis von Weizen nach Zuckerrübe eine phytopathologische Neubewertung der Kulturpflanze als Vorfrucht von Weizen als erforderlich erscheinen und sollte auf Basis der im Rahmen dieser Arbeit vorliegenden Ergebnisse als Vorfrucht mit erhöhtem Risiko für eine Übertragung von Fusarium auf die Halmbasis von Weizen und dem damit verbundenen Auftreten von „Fusarium Foot Rot“ eingestuft werden. Eine agronomische Bedeutung bezüglich einer Ertragsrelevanz der Zuckerrübe als Vorfrucht konnte hingegen im Zuge dieser Arbeit nicht bestätigt werden. In beiden Versuchsjahren konnten nach Zuckerrübe mit ca. $82 \mathrm{dt} / \mathrm{ha}$ und Jahr die zweihöchsten Erträge erzielt werden, welche nur nach Ölrettich mit durchschnittlich $10 \mathrm{dt} / \mathrm{ha}$ und Jahr Mehrertrag übertroffen wurden. Zudem ergaben sich keinerlei Korrelationen der Kolonisierungsraten mit den Erträgen, sodass davon ausgegangen werden kann, dass kein Zusammenhang zwischen dem Halmbasisbefall und dem Ertrag besteht (s. 3.1.4). Zusätzlich wiesen die Halmbasen der beprobten Weizenpflanzen nach Zuckerrübe sogar die geringsten Symptome im Vergleich mit den übrigen Vorfrüchten auf (s. 3.1.5). Eine mit starker Vermorschung des Halmes verbundene Symptomausprägung durch den Befall mit an der Halmbasis pathogenen Fusarium-Arten ist jedoch essenziell für eine Ertragsminderung (s. 1.2). Ein derart starker Befall der Halmbasis tritt nach Cook (1980) hingegen in besonderem Maße nur dann auf, wenn nach 
warmen und trockenen Witterungsbedingungen während des Auflaufens des Weizens zusätzlich im Laufe der Vegetationsperiode Witterungsereignisse einsetzen, die Trockenstress im Weizen verursachen, die Pflanzen auf Grund von Vermorschung durch den Pilzbefall und Wassermangel absterben lassen und damit ein Auftreten sogenannter „white heads“ (Cook 1980; Burgess et al., 2001) verursachen. Im Pazifischen Nordwesten der USA konnte Cook (1980) mit Untersuchungen von Halmbasis und Wurzelerkrankungen an Weizen mit anschließender Ausbildung von „white heads“ belegen, dass Niederschläge von weniger als 200-400 mm notwendig waren, um derartige Symptome hervorzurufen. Bei einem Gesamtjahresniederschlag von mehr als $600 \mathrm{~mm}$, wie er am Standort Torland 2010 verzeichnet werden konnte, ist ein Befall dieses Ausmaßes aber unwahrscheinlich. Cook (1980) konnte auch zeigen, dass Niederschläge zum Beginn des Ährenschiebens $(\mathrm{BBCH} 51)$ und darüber hinaus einer durch Trockenstress verursachten, erhöhten Anfälligkeit gegenüber Fusarium effektiv entgegenwirken, sodass ein erhöhter Befall mit Fusarium nicht unweigerlich eine hohe Symptomausprägung zur Folge hat. Dies könnte auch eine Erklärung für die o. g. Diskrepanz zwischen den Ergebnissen der visuellen Bonitur der Halmbasen nach Zuckerrübe (s. 3.1.5) und den hohen Kolonisierungsraten liefern, die auch von Wegener (1996) in Versuchen zur Untersuchung des Halmbasiserregerkomplexes an Weizen beobachtet wurde. Die gemäßigten klimatischen Verhältnisse, welche in Mitteleuropa vorherrschen, lassen ein Auftreten von „Fusarium Foot Rot“ kaum zu. Vielmehr ist eine Verbreitung der Krankheit für Breitengrade mit kontinentalerem Klima, wie den Pazifischen Nordwesten der USA (Cook, 1968) oder Australien (Burgess et al., 1981) beschrieben, wo sie Ursache erheblicher Ertragsverluste darstellen kann. Im Hinblick auf den sich vollziehenden Klimawandel hin zu trockenerem und wärmerem Klima könnte es jedoch in Zukunft regional insgesamt zu verstärktem Auftreten von „Fusarium Foot Rot“ in Mitteleuropa kommen (Winter, 2012).

Auf Basis der vorliegenden Ergebnisse muss Zuckerrübe aus phytopathologischer und phytosanitärer Sicht als potenzieller Fusarium-Überträger in Weizenfruchtfolgen betrachtet werden, da davon auszugehen ist, dass auf dem Feld verbleibende Zuckerrübenreste ähnlich wie bei Mais zur Überdauerung und nachfolgender Infektion des Weizens an der Halmbasis durch Fusarium beitragen können. Für den Zuckerrübenanbau ist eine gute Wasserversorgung unerlässlich (Anonymus, 2008). Trockene klimatische Bedingungen, unter denen „Fusarium Foot Rot“ in ertragsrelevanter Stärke auftreten kann, wie beispielsweise für die großen Weizenanbaugebieten des Pazifischen Nordwestens der USA beschrieben, sind in Gebieten, die für den Zuckerrübenanbau in Mitteleuropa geeignet sind, nicht zu erwarten. Da zudem kein Zusammenhang zwischen dem Ertrag und den Kolonisierungsraten an der Halmbasis ermittelt werden konnte, ist aus 
agronomischer Sicht daher wahrscheinlich nicht von einem durch Fusarium besiedelte Zuckerrübenreste bedingten Ertragsverlust durch Halmbasisbefall im Weizen auszugehen. Anders als an der Halmbasis, war in beiden Versuchsjahren bezüglich der Gesamtkolonisierungsraten an den Körnern ein durch Zuckerrübe als Vorfrucht verursachter, deutlicher Vorfruchteffekt nicht erkennbar. Vielmehr konnte 2010 mit einer Gesamtkolonisierungsrate von 26,4\% des Ernteguts nach Vorfrucht Mais (Abb. 26) diese klassischerweise als Vorfrucht mit dem größten Effekt in Bezug auf einen Befall mit Ährenfusarium bestätigt werden (Atanasoff, 1920). Die Gesamtkolonisierungsraten nach Zuckerrübe und Ölrettich beliefen sich auf etwas über 20\%, waren damit aber signifikant niedriger, als nach Mais. Das Artenspektrum an den Körnern wurde nach den Vorfrüchten Zuckerrübe und Ölrettich mit signifikant hohen Kolonisierungsraten von bis zu knapp 13\% in besonderem Maße von den Arten F. poae und F. tricinctum dominiert (Abb. 27). Alle anderen Arten überstiegen eine Kolonisierungsrate von $2 \%$ nicht. Eine Ausnahme bildete hier die Vorfrucht Mais, für die ein qualitativer Unterschied im Artenspektrum in Form einer gegenüber den anderen Arten erhöhten Kolonisierung des Ernteguts durch F. graminearum festzustellen war. Dieses verstärkte Auftreten von F. graminearum war letztendlich maßgeblich für die vergleichsweise hohe Gesamtkolonisierungsrate nach Mais neben F. poae und F. tricinctum, wobei F. graminearum an mehr als $10 \%$ der Körner des untersuchten Ernteguts nach Vorfrucht Mais zu finden war. Dies deckt sich gut mit den für 2010 erhobenen DON-Werten. In Einzelproben wurden nach Mais in der Variante „Ritmo,

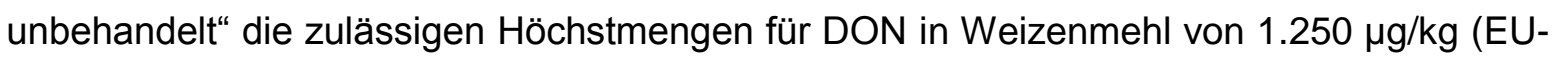
Verordnung (EG) Nr. 856/2005) überschritten, während nach den anderen Vorfrüchten kein DON detektiert werden konnte.

Die Kolonisierung der Körner erwies sich im Versuchsjahr 2011, verglichen mit den Kolonisierungsraten des Vorjahrs, als deutlich schwächer (s. 3.2.5, s. 4.1.1), dennoch gehörten auch 2011 nach allen vier Vorfrüchten F.poae und F. tricinctum zu den dominierenden Arten an den Körnern, sodass sich für Jahre mit geringem Befallsdruck unter Hinzunahme der Ergebnisse des Jahres 2010 für den Standort Torland insgesamt ein von $F$. poae und F. tricinctum dominiertes, spezifisches Artenspektrum an den Körnern ergibt. Dieses Artenspektrum unterliegt, ebenso wie das Spektrum an der Halmbasis, jahresbedingten Schwankungen der Kolonisierungsraten und unterscheidet sich signifikant von der an der Halmbasis ermittelten Populationssignatur.

Die Ergebnisse des Versuchsjahres 2010 im Hinblick auf die Bedeutung der Vorfrüchte für die Kolonisierung der Körner konnten nicht bestätigt werden, da in diesem Jahr nach Vorfrucht Winterweizen mit 15,5\% die signifikant höchste Gesamtkolonisierungsrate ermittelt wurde, nicht zuletzt durch ein vermehrtes Auftreten von F. culmorum nach Weizen (Abb. 52). 
Eine erhöhte Kolonisierung der Weizenähre durch Fusarium und dadurch bedingte Mykotoxinkontaminationen nach Vorfrucht Zuckerrübe wurden bereits beobachtet. So erbrachten Fruchtfolgeversuche in Bayern nach Vorfrucht Zuckerrübe doppelt so hohe DON-Konzentrationen, verglichen mit Vorfrüchten wie Weizen oder Gerste (Obst et al., 1997). Auch Beck und Lepschy (2000) kamen in einem 10-jährigen Monitoring in Bayern zu ähnlichen Ergebnissen. Weinert et al. (2007) konnten in einer dreijährigen, bundesweiten Studie relativ ähnliche DON-Gehalte nach Vorfrucht Zuckerrübe im Vergleich zu Vorfrucht Winterweizen nach pflugloser Bodenbearbeitung ermitteln, welche in Einzelfällen den gesetzlichen Grenzwert von $1.250 \mu \mathrm{g} / \mathrm{kg}$ DON überschritten. Dagegen berichtete Koch et al. (2006) von DON-Reduktionen um den Faktor 4,3 nach Vorfrucht Zuckerrübe im Vergleich zur Vorfrucht Weizen. Der Vorfruchteffekt von Zuckerrübe im Hinblick auf die DON-Kontamination des Weizens als Nachfrucht wird also kontrovers diskutiert.

Ein durch die Besiedlung von Vorfruchtresten hervorgerufener Vorfruchteffekt, der in sehr schwachen Befallsjahren Auswirkungen auf den Ährenbefall mit zudem nachweisbaren und grenzwertüberscheitenden DON-Kontaminationen zur Folge hatte, konnte im Rahmen der vorliegenden Arbeit weder für Zuckerrübe, noch für Weizen oder Ölrettich, sondern klassischerweise nur für die Vorfrucht Mais im Versuchsjahr 2010 nachgewiesen werden (Abb. 13) und zeigt die starke Witterungsabhängigkeit des Vorfruchteffekts. Diese wird auch durch die Ergebnisse von Gödecke (2010) verdeutlicht, welche die jahresbedingte Witterung als wichtigsten Faktor noch vor der Vorfrucht im Hinblick auf eine natürliche DON-Kontamination des Weizens herausstellten. Dabei ist jedoch die ausschließlich für DON vorgenommene Analyse des Gehaltes im Mehl des Ernteguts zu beachten. Es liegen keine Ergebnisse über eine etwaige Kontamination mit Mykotoxinen vor, welche durch F. poae oder F. tricinctum hätten hervorgerufen werden können. Allerdings wären bei relativ geringen Kolonisierungsraten, wie sie 2010 und 2011 der Fall waren, zusammen mit der durch diese Arbeit (s. 4.2) und durch die Literatur (Leslie und Summerell, 2006, Fernández-Ortuño et al., 2011) belegten geringen Pathogenität der beiden Arten, nennenswerte Mykotoxingehalte im Erntegut nicht zu erwarten. Gödecke (2010) konnte am selben Standort in Starkbefallsjahren wie 2007 und 2009 auch nach Zuckerrübe häufig F. graminearum von der Ähre isolieren. Der Autor kam aber zu dem Schluss, dass eine Überdeckung des Vorfruchteffektes in Form von luftbürtigen, regional begrenzten Infektionen in Starkbefallsjahren in Betracht gezogen werden muss. In schwachen Befallsjahren ist daher ein relevanter Vorfruchteffekt für die Besiedlung der Ähre mit grenzwertüberschreitenden DON-Kontaminationen auszuschließen. Unter Starkbefallsbedingungen kann hingegen trotz zahlreicher Berichte über erhöhte DONKonzentrationen im Erntegut nach Vorfrucht Zuckerrübe in der Literatur nicht eindeutig 
geklärt werden, ob die Besiedlung von Zuckerrübenresten mit Fusarium einen maßgeblichen Anteil am Ährenbefall hat.

\subsubsection{Einfluss der Sorte}

Neben einer sinnvollen Gestaltung der Fruchtfolge, spielt besonders die Wahl geeigneter Sorten eine große Rolle als vorbeugende Maßnahme bei der Vermeidung von Schaderregerbefall im Ackerbau. Besonders im Hinblick auf FHB ist der Anbau resistenter Sorten unerlässlich (Weinert und Wolf, 1995). Für den Weizenanbau stehen zahlreiche resistente Weizensorten zur Verfügung. Allerdings beschränken sich Resistenzeigenschaften gegenüber Fusarium-Arten im Weizen auf die Resistenz gegenüber Ährenfusarium, bzw. FHB, welche sich aus mehreren aktiven, in der Regel unabhängigen Resistenzmechanismen zusammensetzt (Mesterházy, 2003; s. 1.1.2). Resistenzen gegenüber einer Infektion der Halmbasis stehen bisher jedoch auf Grund fehlender Methoden zur Resistenztestung nicht zur Verfügung (Cook, 1980). Die im FAENFeldversuch verwendete Winterweizensorte "Centrum" besaß eine hohe Resistenz gegenüber Ährenfusarium. Welche Mechanismen dieser Resistenz zu Grunde liegen ist nicht bekannt, da hierzu keine Daten ermittelt werden konnten. Erstaunlicherweise war im Versuchsjahr 2011 an der Halmbasis zur späten Blüte (BBCH 69) und späten Milchreife (BBCH 75-77) bezüglich der Gesamtkolonisierungsraten mit Fusarium eine durchschnittlich um 8\% niedrigere Rate in der Sorte "Centrum“ ermittelt worden (Abb. 42 und Abb. 44), was einem signifikanten Sorteneffekt in der resistenten Sorte gegenüber der hochanfälligen Sorte „Ritmo“ entsprach (Tab. 21).

An den Körnern war trotz geringer Kolonisierungsraten sowohl 2010 als auch 2011 erwartungsgemäß ein signifikanter Sorteneffekt zu beobachten, der im Schnitt über beide Jahre eine um 13\% verringerte Kolonisierung der resistenten Sorte „Centrum" ausmachte und etwas stärker ausgeprägt war, als an der Halmbasis. Es ist festzuhalten, dass die Sorteneffekte an beiden Pflanzenteilen nicht von qualitativer, sondern ausschließlich quantitativer Art waren. Dies bedeutet, dass die Reduktion der Gesamtkolonisierungsraten an Halmbasis und Körnern in der resistenten Sorte durch die Reduktion der Kolonisierungsraten der am häufigsten isolierten Arten bedingt war, auf das Artenspektrum aber keinen erkennbaren Einfluss aufwies. An der Halmbasis war der Sorteneffekt somit von deutlich verringerten Kolonisierungsraten der Arten F. culmorum und F. tricinctum geprägt, jedoch weniger von F. equiseti, wogegen an der Ähre besonders die Kolonisierungsraten der Arten F.poae, F. tricinctum und 2011 auch F. culmorum in der resistenten Sorte "Centrum“ reduziert waren. In Bezug auf einen Befall des Weizens mit Ährenfusarium zeigen Ergebnisse von Mesterházy (2003), dass Resistenz in Weizen nicht artspezifisch, sondern gegenüber allen Fusarium-Arten 
wirksam ist. Demnach wäre denkbar, dass ein Resistenzmechanismus der Sorte „Centrum“ auf eine Toleranz gegenüber der Infektion der Körner (Resistenztyp III; Mesterházy, 1995) basiert. Zwar kann eine derartige Schlussfolgerung für den Sorteneffekt an der Halmbasis nicht gezogen werden. Möglich wäre jedoch eine allgemeine Resistenz der Pflanze gegenüber der Ausbreitung des Pilzes (Resistenztyp II; Schroeder und Christensen, 1963), welcher sich nicht grundsätzlich nur auf die Ähre beschränken muss und zu reduzierten Kolonisierungsraten an der Halmbasis in der Sorte „Centrum“ geführt haben könnte.

Die Ergebnisse geben Aufschluss über den restriktiven Einfluss der Sortenresistenz im Weizen gegenüber einer Kolonisierung der Weizenkörner durch Fusarium und bestätigen somit den Anbau resistenter Sorten als wirksames prophylaktisches Instrument gegenüber Ährenfusarium (Weinert und Wolf, 1995). Es konnte ebenso ein wider Erwarten aufgetretener Effekt auf die Besiedlung der Halmbasis demonstriert werden, welcher in der Literatur bisher nicht beschrieben wurde. Grundlegende Unterschiede im Artenspektrum waren zwischen den Sorten nicht zu ermitteln.

\subsubsection{Einfluss des Blattfungizids}

Es ist bekannt, dass neben den Strobilurinen auch die Azolfungizide seneszenzverzögernde Eigenschaften besitzen (Grossmann und Retzlaff, 1997; Wu und von Tiedemann, 2001). Dieser sogenannte „Greening-Effekt“ kann im Unterschied zu direkten Auswirkungen einer Ährenbehandlung im Zuge einer Fungizidbehandlung der Blätter auch indirekt Einfluss auf Pathogene an Weizen ausüben. Im Zuge des FAENFruchtfolgeversuches wurde untersucht, inwiefern eine Fungizidblattbehandlung mit einem systemisch wirkenden Triazolwirkstoff Einfluss auf das Fusarium-Artenspektrum sowie Kolonisierungsraten an Halmbasis und Körnern von Weizen nimmt. Indirekte Fungizideffekte wurden vermieden, in dem eine zweimalige Applikation von Prothioconazol, dem zurzeit gegenüber Ährenfusarium wirkungsvollsten Triazol als Blattbehandlung zu Beginn (BBCH 31-33) und Ende des Schossens (BBCH 37-39) erfolgte (s. 2.15.4).

An der Halmbasis wurden nur im Versuchsjahr 2011 zur späten Blüte (BBCH 69) und zur späten Milchreife (BBCH 75-77) Daten zur Wirkung eine Blattbehandlung mit Prothioconazol erhoben. Hier zeigten sich mit annähernd 20\% (BBCH 69) (Abb. 47) und ca. $40 \%$ (BBCH 75-77) (Abb. 48) niedrigeren Gesamtkolonisierungsraten in den behandelten Varianten ein signifikanter Einfluss des Fungizids. Wie bereits für den Sorteneffekt beobachtet (s. 4.1.4), war der Einfluss des Fungizids quantitativ und in erster Linie auf eine Reduktion der Kolonisierungsraten der drei an der Halmbasis 
dominierenden Arten F. culmorum, F. equiseti und F. tricinctum zurückzuführen. Ein qualitativer Einfluss auf das Artenspektrum war nicht zu erkennen.

Der Effekt der Blattfungizidbehandlung an den Körnern erwies sich für die Versuchsjahre 2010 und 2011 als geringfügig unterschiedlich (s. Abb. 30 und Abb. 55). Während 2010 nur ein leichter, allerdings nicht signifikanter Fungizideffekt auf die Gesamtkolonisierungsraten in der behandelten Variante verzeichnet werden konnte, war dieser 2011 signifikant. Dies konnte auch durch die Varianzanalyse der Gesamtkolonisierungsraten bestätigt werden (Tab. 22). Interessant ist jedoch die Beobachtung, dass eine Blattfungizidbehandlung in beiden Versuchsjahren keine Auswirkung auf die Kolonisierungsraten der beiden Arten F. poae und F. tricinctum hatte, jedoch $2010 \mathrm{im}$ besonderen Maße auf die Kolonisierungsrate von F.graminearum, welche in den behandelten Varianten mit ca. 4\% nur halb so hoch war, wie in den unbehandelten Varianten. Diese Ergebnisse wurden zwar nicht durch Signifikanzen belegt. Trotzdem könnte dies bedeuten, dass Azolwirkstoffe schlechter auf diese beiden Arten wirken, als auf F. culmorum und F. graminearum und somit Unterschiede in der Sensitivität verschiedener Arten gegenüber Azolen besteht. 2011 war darüber hinaus ein reduzierender Effekt auf die Kolonisierungsrate von F. culmorum erkennbar.

Dieser quantitative Effekt der Blattfungizidbehandlung, der sich primär auf die Arten $F$. culmorum und F. graminearum beschränkte unterstützt zudem die These, dass es sich bei der Kolonisierung der Körner durch die Arten F. poae und F. tricinctum um eine sekundäre, sich spät in der Vegetationsperiode ereignende (Köhl et al., 2007), saprophytische Besiedlung gehandelt haben könnte, als wahrscheinlich keinerlei Fungizidrestmengen im pflanzlichen Gewebe mehr vorhanden waren.

Gödecke (2010) nahm sogar an, dass bereits zum Zeitpunkt der Blüte (BBCH 65) nur noch sublethale Fungizidrestmengen im pflanzlichen Gewebe vorliegen, wenn zum Zeitpunkt des Schossens (BBCH 37-39) eine Blattfungizidapplikation im Feld durchgeführt wird.

Insgesamt kann auf Basis der Ergebnisse festgehalten werden, dass einer indirekten Fungizidwirkung durch eine bis zum Schossen erfolgten Blattfungizidapplikation mit Prothioconazol eine größere Bedeutung für die Reduktion der Kolonisierung durch Fusarium-Arten besonders an der Halmbasis zukommt. Der Effekt an den Körnern ist dagegen als weitaus geringer einzustufen. Das Artenspektrum wird an keinem der beiden Pflanzenorgane entscheidend beeinflusst. 


\subsection{Pathogenität, Bedeutung und Risikobewertung der untersuchten Fusarium-Arten an Halmbasis und Ähre von Weizen}

Die im Zuge des FAEN-Fruchtfolgeversuches im Jahr 2010 innerhalb der charakterisierten Fusarium-Artenspektren am häufigsten an Halmbasis und Körnern auftretenden Fusarium-Arten (s. 3.2.1 und 3.2.2) wurden nachfolgend unter kontrollierten Bedingungen untersucht. Ziel war es, eine mögliche agronomische Bedeutung hinsichtlich der Pathogenität dieser Arten zu erfassen, um eine Risikobewertung für jede Art vornehmen zu können. Zudem sollte eine ökologische Rolle dieser Arten herausgestellt und Bekämpfungsempfehlungen gegeben werden.

\subsubsection{Pathogenität, Bedeutung und Risikobewertung der untersuchten Fusarium- Arten an der Halmbasis von Weizen}

In den Versuchen zur Pathogenität an der Halmbasis unter kontrollierten Bedingungen wurde mittels Tauchinokulation von Weizenkeimlingen die Aggressivität der drei Fusarium-Arten F. equiseti, F. poae und F. tricinctum im Vergleich zu F. culmorum als Positivkontrolle überprüft. Die Untersuchungen konnten die Ergebnisse der Erfassung des Artspektrums an der Halmbasis insofern bestätigen, als dass neben dem klassischen Halmbasiserreger F. culmorum (Cook, 1968) auch F. equiseti und F. tricinctum in der Lage waren, die Halmbasis zu besiedeln (Tab. 33). Dies untermauert frühe Ergebnisse von Bennett (1935) aus England, welcher F. equiseti und F. tricinctum an der Halmbasis von Weizen nachweisen konnte. Interessanterweise konnte auch die lediglich im Versuchsjahr 2011 nur sehr vereinzelt am Halm aufgetretene Art $F$. poae die Halmbasis unter kontrollierten Bedingungen nach F. culmorum am erfolgreichsten kolonisieren. Die Ergebnisse des FAEN-Fruchtfolgeversuchs stützen die Beobachtung, dass dieser Art eine weitaus größere Bedeutung an der Ähre als Teil des FHB-Komplexes zukommt (Bottalico und Perrone, 2002; Xu et al., 2005), an der Halmbasis aber als nicht pathogen eingestuft wird (Duben, 1978) und diese kaum besiedelt (Köhl et al., 2007). Eine mögliche Erklärung für diese Diskrepanz könnte sein, dass der Pilz grundsätzlich nur eine schwach ausgeprägte Fähigkeit zur Halmbasisbesiedlung besitzt.

Diese These wird von den Resultaten der im Zuge dieser Arbeit durchgeführten In vitroPathogenitätsversuche bekräftigt. In diesem Versuch wurden verschiedenen FusariumArten nur junge Weizenkeimlinge als Nährstoffquelle angeboten. F. poae wies eine geringe Besiedlung der Keimlinge am Hypokotyl auf und brachte nur vereinzelt leichte Symptome in Form von Verbräunungen hervor (Abb. 73 und 74). Die Besiedlung war in ihrer Intensität nicht signifikant von der durch F. tricinctum verschieden, war aber 
signifikant niedriger als für die äußerst aggressiven Arten F.culmorum und F. graminearum.

Die Besiedlung der Halmbasis blieb auch in den Pathogenitätsversuchen unter kontrollierten Bedingungen in der Klimakammer bei allen drei Fusarium-Arten im Gegensatz zur weitaus aggressivsten Art F. culmorum, welche als systemischer Besiedler der Halmbasis von Weizen bekannt ist (Snijders, 1990; Clement und Parry, 1998), vergleichsweise äußerst gering, bzw. bis zur späten Milchreife (BBCH 77) (Abb. 69 und 70) symptomlos und resultierte zur Ernte (BBCH 92) in nur marginal gestiegenen Symptomausprägungen (Abb. 70). Dies entspricht zumindest für $F$. equiseti und F. tricinctum sowohl den Erfahrungen von Duben (1978) als auch den Beobachtungen von Wegener (1996), der in Reisolationsversuchen bei ca. 50\% der untersuchten, optisch symptomlosen Weizenpflanzen latente Besiedlung mit verschiedenen Fusarium-Arten feststellen konnte. Zur Milchreife wies F.culmorum die signifikant höchsten Symptomausprägungen auf, die Besiedlung durch die übrigen Arten blieb nahezu latent. Im Stadium der Ernte waren alle Pflanzen der mit F. culmorum inokulierten Variante hochgradig befallen, gegenüber im Vergleich zum Zeitpunkt der Milchreife nur leicht gestiegenen Boniturwerten der andren Arten. Dabei blieb die Besiedlung durch F. equiseti, F. poae und F.tricinctum lokal auf die Halmbasis begrenzt, wogegen F. culmorum ein signifikant höheres systemisches Wachstum aufwies. Dies ging ebenso deutlich aus den Reisolationsraten der einzelnen Fusarium-Arten hervor. So konnte F. culmorum an der Halmbasis von 95,0\% aller Pflanzen innerhalb der mit F. culmorum inokulierten Versuchsvariante isoliert werden, wodurch sich eine signifikant höhere Reisolationsrate ergab, als in den übrigen Varianten, deren höchste Reisolationsrate F. poae mit 42,5\% verzeichnete. Die Besiedlung des Halms durch F. equiseti, F. poae und F. tricinctum nahm akropetal oberhalb der Halmbasis sehr stark ab, sodass die Pilze auf Höhe des 1. Nodiums nur noch bei 2,5-12,5\% der Pflanzen isoliert werden konnten, wogegen F. culmorum sogar noch an $22,5 \%$ der Pflanzen auf Höhe des 2 . Nodiums zu finden war. Auch wenn $F$. equiseti und $F$. tricinctum immer wieder in verschiedenen Untersuchungen von der Halmbasis von Weizen isoliert wurden (Krampe,1926; Bennett, 1935; Prillwitz und Bauermann, 1974; Duben, 1978; Köhl et al., 2007), werden sie genauso wenig wie F. poae in der Literatur als Teil des „Fusarium Foot Rot“-Komplexes beschrieben. Dieser besteht laut Duben und Fehrmann (1979), Cook (1980), Clement und Parry (1998) sowie Smiley et al. (2005) hauptsächlich aus den drei Arten F. culmorum, F. graminearum und F. avenaceum. In Australien und Nordamerika wird außerdem F. pseudograminearum mit der Krankheit assoziiert (Burgess et al., 2001). F. equiseti wird dagegen primär als ubiquitär im Boden vorkommender Saprophyt betrachtet, welcher geschädigtes bzw. seneszentes Pflanzengewebe kolonisieren und ebenso als Sekundärbesiedler fungieren kann (Leslie und Summerell, 2006). Der Pilz wurde 
vereinzelt mit verschiedenen Krankheiten an Nutzpflanzen assoziiert u.a. mit Krebs an Sauerkirschbäumen (Prunus cerasus L.) (Olszak, 1994), Wurzelverbräunungen an Ginseng (Panax ginseng C. A. MEY) (Goswami et al., 2008), Krankheiten an Dattelpalmen (Phoenix sp. L.) (Abbas et al., 1991), Fäulen von Melonenpflanzen (Cucumis sp. L., Citrullus sp. (ThUnB.) MATSUM. UND NAKAI) (Adams, et al., 1987) oder Blattflecken an Rucola (Eruca sativa L.). Auch existieren Berichte über die Isolierung des Pilzes von Weizenkörnern (Langseth und Elen, 1997), mit „Fusarium Foot Rot“ an Weizen hingegen wurde F. equiseti bisher nicht assoziiert. Zudem beruhen derartige Berichte häufig auf Isolationen des Pilzes aus erkranktem Gewebe, ohne Erfüllung der Koch'schen Postulate (Leslie und Summerell, 2006).

Wie bereits zu Beginn des Kapitels erwähnt, ist F. poae vor allem mit FHB assoziiert (Bottalico und Perrone, 2002) und wird häufig von Getreidekörnern isoliert (Langseth und Elen, 1997; Logrieco et al., 2003; Kosiak et al., 2003, 2004), jedoch als schwach pathogen angesehen und nicht mit „Fusarium Foot Rot“ in Verbindung gebracht. F. tricinctum wird ebenso wie F. equiseti als Saprophyt eingestuft, allerdings kann der Pilz auch als schwach pathogener Parasit (Leslie und Summerell, 2006, Fernández-Ortuño et al., 2011) in temperaten Regionen der Erde wie Nordamerika, sowie Nord-, Mittel-, und Osteuropa an Getreide wie Weizen und Gerste auftreten (Chelkowski et al., 1989; Andersen et al., 1996; Golinski et al., 1996; Langseth und Elen, 1997; Kosiak et al., 2003). Christ et al. (2011a) konnten F. tricinctum auch häufig aus Zuckerrübe isolieren. Auch Kane (1985) isolierte F. tricinctum aus symptomatischen Halmbasen von Winterweizen. Eine Assoziierung mit „Fusarium Foot Rot“ wurde jedoch auch für diese Art bisher nicht beschrieben.

Dies führt zu der Frage, auf welche Weise eine Besiedlung der Halmbasis von Weizen durch die drei Arten F. equiseti, F. poae und F. tricinctum erfolgt. Im Rahmen des FAENFeldversuches traten die drei Arten in beiden Versuchsjahren in der Regel gemeinsam auf. Dies lässt den Schluss zu, dass eine durch F. culmorum entstandene Primärinfektion möglicherweise als Eintrittspforte für eine Kolonisierung durch die saprophytisch im Boden und auf Vorfruchtresten lebenden Arten F. equiseti und F. tricinctum als Sekundärbesiedler wie zuvor von Leslie und Summerell (2006) für $F$. equiseti beschrieben, dienen könnte. Unter kontrollierten Bedingungen war jedoch immer nur mit einer Fusarium-Art pro Variante inokuliert worden. Von einer Kolonisierung als Sekundärbesiedler ist somit weniger auszugehen, da die Weizenpflanzen des Versuchs zudem in autoklaviertem Boden angezogen worden waren und somit die gesamte Bodenflora inaktiviert worden war. Ein potenzieller Primärbesiedler des Weizens, welcher $u$. U. als Wegbereiter für eine nachfolgende Besiedlung durch die drei Fusarium-Arten hätte fungieren können, war also nicht vorhanden. Vielmehr ist ein endophytisches, latentes Wachstum der drei Fusarium- 
Arten innerhalb der Weizenpflanze, welches lokal auf die Halmbasis begrenzt bleibt, anzunehmen. Endophytisches Wachstum wurde für F. equiseti bereits 2009 von MaciáVicente et al. an Wurzeln von Gerste beobachtet und liefert einen Ansatz zur Deutung der Halmbasiskolonisierung durch die drei Fusarium-Arten F. equiseti, F.poae und F. tricinctum.

Es ist bekannt, dass geringe Niederschläge und ein damit einhergehendes niedriges Wasserpotenzial der Weizenpflanze den Befall durch F. culmorum und F. graminearum forcieren können (Cook, 1980). Ein niedriges Wasserpotenzial hat demnach erheblichen Trockenstress zur Folge, der die Pflanze schwächt und deren Anfälligkeit für eine Infektion der Halmbasis erhöht (Papendick und Cook, 1974). Ein niedriges Matrixpotenzial des Bodens von ca. -75 bis -85 bar fördert laut Cook und Papendick (1970) zudem die Chlamydosporenkeimung von F. culmorum, was einen weiteren Faktor für eine Infektion der Halmbasis bei Trockenheit darstellt. Dies steht in Einklang mit den im Zuge dieser Arbeit erhaltenen Ergebnissen. Zwar kann durch das Fehlen normalversorgter Pflanzen innerhalb des Pathogenitätsversuchs an der Halmbasis nicht mit letzter Sicherheit ausgeschlossen werden, dass F. culmorum auch ohne Trockenstress ähnlich starke Symptome hätte hervorgerufen können. Es liegt jedoch der Schluss nahe, dass der während des Versuches hervorgerufene Trockenstress in der mit F.culmorum inokulierten Variante bis zur späten Milchreife nicht nur zu einem signifikant hohen Austrocknen des Fahnenblattes und des Blattes 1. Ordnung (86,5\%) führte, sondern besonders die Koinzidenz von Trockenstress mit der Infektion der Halmbasis durch F. culmorum ein vorzeitiges Absterben der Weizenpflanzen verursacht haben könnte. (Abb. 71 und 72). Ein Austrocknen der Blätter konnte in leichter Ausprägung ebenso für $F$. equiseti und $F$. tricinctum beobachtet werden, wogegen $F$. poae keine signifikant erhöhte Austrocknung der Blätter aufwies (Abb. 71). Ein Absterben der Pflanzen blieb jedoch aus, was die sehr viel höhere Aggressivität von F.culmorum sowie den pathogenen Charakter dieser Art im Vergleich zu den an der Halmbasis als apathogen einzustufenden Arten F. equiseti, F. poae und F. tricinctum unterstreicht. Das in diesem Versuch nach Inokulation mit $F$. culmorum beobachtete frühzeitige Absterben der Pflanzen und die damit einhergehende Bildung von sogenannten „white heads“ (Mudge et al., 2007), kann unter natürlichen Bedingungen nicht nur ein geringeres TKG, sondern auch die Reduktion der Kornanzahl pro Ähre verursachen und daher Ertragseinbußen herbeiführen (Kane et al., 1987). Die Ergebnisse zeigen, dass keine der drei untersuchten Arten in der Lage ist, dieses Phänomen hervorzurufen.

Die Ergebnisse des im Zuge dieser Arbeit unter kontrollierten Bedingungen durchgeführten Inokulationsversuchs weisen auf eine ökologische Rolle der drei Arten F. equiseti, F. poae und F. tricinctum als lokal an der Halmbasis von Weizen auftretende, 
endophytische Besiedler hin, wobei diese endophytische Besiedlung vermutlich unabhängig von F. culmorum erfolgen kann.

Die Kolonisierung der Halmbasis bleibt dabei bis zum Entwicklungsstadium der späten Milchreife latent. Auch über dieses Entwicklungsstadium hinaus findet nur in äußerst geringem Maße eine Symptomausprägung an der Halmbasis statt, was mit den Ergebnissen von Duben (1978) übereinstimmt. Eine Ertragsrelevanz, wie sie für typische „Fusarium Foot Rot“ verursachende Arten wie F. culmorum in den USA (Cook, 1968) oder F. pseudograminearum in Australien (Burgess et al., 1981) beobachtet wurde, kann diesen Arten nicht zugesprochen werden, sodass ein von diesen Fusarium-Arten ausgehendes agronomisches Risiko durch Besiedlung der Halmbasis von Weizen als unbedeutend eingestuft werden muss.

\subsubsection{Pathogenität, Bedeutung und Risikobewertung der untersuchten Fusarium- Arten an der Ähre von Weizen}

In Mitteleuropa stellt „Fusarium Head Blight“ (FHB) die bedeutendste qualitätsbeinflussende Pilzkrankheit im Weizen dar und wird vor allem in den letzten Jahren in Deutschland hauptsächlich von F. graminearum als dominierende toxigene Fusarium-Art hervorgerufen (Brandfaß, 2006). Neben dieser Art treten besonders in Europa noch weitere 18 Fusarium-Arten an der Ähre von Weizen auf, welche zusammen mit F. graminearum dem sogenannten FHB-Komplex (Doohan et al., 2003; Liddell, 2003; Xu et al., 2005) angehören. Zu diesem aus größtenteils toxigenen Fusarium-Arten bestehenden Komplex werden auch F. equiseti, F. poae und F. tricinctum gezählt (Bottalico und Perrone, 2002), wobei F. poae sogar als einer der Hauptverursacher von FHB betrachtet wird und in zweijährigen Feldbeprobungen in Großbritannien, Italien und Ungarn die am häufigsten von der Ähre isolierte Art darstellte (Xu et al., 2005). Besonders in Großbritannien wurde in den frühen 1990er Jahren (Polley et al., 1991) F. poae eine dominante Rolle als FHB-Pathogen an der Ähre von Weizen zugesprochen und auch in Mitteleuropa wurde in Untersuchungen neben F. avenaceum F.poae als die bedeutendste Art an der Ähre identifiziert (Łukanowski und Sadowski, 2002). Diese Studien gehen jedoch lediglich auf PCR-basierte Untersuchungen zum Auftreten von F. poae und weiterer Fusarium-Arten an der Weizenähre zurück. Eine Evaluierung der Symptomausprägung fand nicht statt (Xu et al., 2005), sodass keine Aussagen über die Pathogenität dieser Arten gemacht werden können.

In den Versuchsjahren 2010 und 2011 wurden die im Rahmen des FAENFruchtfolgeversuchs in besonderem Maße an der Ähre aufgetretenen Arten F. poae und F. tricinctum sowie die hauptsächlich an der Halmbasis isolierte Art F. equiseti unter 
kontrollierten Bedingungen im Gewächshaus mit Hilfe von Sprühinokulationsversuchen als Einzelvarianten zunächst auf ihre Pathogenität hin an der Ähre von Weizen getestet und in Bezug zu den pathogenen Eigenschaften von F. graminearum gesetzt. Zusätzlich wurden nachfolgend unter Einbezug der Arten F. graminearum, F. poae und F. tricinctum Versuche mit Einzel- und Mischvarianten durchgeführt, die Aufschluss über Interaktionen zwischen den verschiedenen Fusarium-Arten geben und beleuchten sollten, inwiefern positive oder negative Wechselwirkungen zwischen den Arten wie z.B. synergistische Effekte, bzw. interspezifische Konkurrenz eine Rolle spielen. Parallel wurden diese Untersuchungen zusätzlich im Freiland mit Einzel- und Mischvarianten unter natürlichen Bedingungen durchgeführt.

Die Ergebnisse der Inokulationsversuche mit Einzelvarianten zeigen, dass neben $F$. graminearum auch F. equiseti, F. poae und F. tricinctum sowohl unter kontrollierten Bedingungen im Gewächshaus als auch im Freilandversuch unter natürlichen Bedingungen in der Lage waren, Symptome an der Ähre hervorzurufen. Die von den Arten F. equiseti, F. poae und F. tricinctum durch den Befall der Ähren hervorgerufenen Symptome unterschieden sich dabei in allen Versuchen in Ausprägung und Stärke signifikant von den durch F. graminearum verursachten, typischen FHB-Symptomen. Diese waren in frühen Stadien der Infektion nach 7 dpi als braune, nekrotische Flecken an Deck- und Hüllspelzen zu beobachten (Kang und Buchenauer 2000a), die im weiteren Verlauf mit dem Ausbleichen der infizierten Ährchen einhergingen (Weinert und Wolf, 1995) und nach 21 dpi ein komplettes Ausbleichen der Ähre zur Folge hatten. Alle vier Fusarium-Arten zeigten von $7 \mathrm{dpi}$ bis $21 \mathrm{dpi}$ einen stetigen Anstieg der Symptomentwicklung, jedoch verzeichnete F. graminearum im Pathogenitätsversuch mit Einzelvarianten nach 21 dpi einen Disease-Index von 98,1\%, während die Arten $F$. equiseti, F. poae und F. tricinctum signifikante, um bis zu $45 \%$ niedrigere DiseaseIndices aufwiesen (Tab. 25). Die von diesen drei Fusarium-Arten verursachten Symptome brachten eine Verbräunung der Deck- und Hüllspelzen (Palea und Lemma) hervor und waren in der Lage, an Körnern infizierter Ähren das sogenannte Black-Point-Symptom hervorzurufen. Dieses Symptom äußert sich in Form einer schwärzlichen Verfärbung des Weizenkorns in der Nähe des Embryos (Abb. 63) (Mak et al., 2006), ist aber kein typisches Symptom, welches bei Befall durch Ährenfusarium auftritt (Gödecke, 2010) und wurde bislang nur als ästhetische Beeinträchtigung ohne qualitätsmindernde Eigenschaften angesehen (Lorenz, 1986). Neben Arten der Gattung Fusarium, wie z.B. F. proliferatum (Conner et al., 1996) und F. avenaceum (Golrnski et al., 1996), werden u.a. auch Alternaria alternata und Cochliobolus sativus mit dem Symptom in Verbindung gebracht (Conner und Davidson, 1987).

Dass auch eine Infektion von Weizenkörnern unter kontrollierten Bedingungen mit $F$. equiseti und F. tricinctum dieses Symptom herbeiführen kann, wurde bereits von Christ 
et al. (2011b) im Zuge ähnlicher Inokulationsversuche an Weizen mit aus Zuckerrübe isolierten Fusarium-Arten beobachtet. Im Hinblick auf $F$. poae ist dies jedoch ein gänzlich neu beobachtetes Phänomen.

Auch die Häufigkeitsverteilungen von Black-Point- und FHB-Körnern in den mit den verschiedenen Pilzen inokulierten Einzelvarianten zeigten, dass das Black-PointSymptom von den Arten F. equiseti, F. poae und F. tricinctum verursacht wird, nicht jedoch von F. graminearum, wobei F. tricinctum mit Anteilen von durchschnittlich 23,1\% den signifikant höchsten Anteil an Black-Point-Körnern aufwies. Im Umkehrschluss waren erwartungsgemäß nur in der F. graminearum-Variante die für FHB typischen, myzelbewachsenen, weißlich-pinken Kümmerkörner (Weinert und Wolf, 1995), sogenannte „scabby kernels“ zu finden, die einen Anteil an der Gesamtmenge von 87,5\% ausmachten (Abb. 65).

Die Ergebnisse weisen auf die erheblichen Unterschiede in der Kolonisierung der Weizenähre zwischen F. graminearum und den drei übrigen Fusarium-Arten hin. Keine der drei untersuchten Arten wies eine systemische Besiedlung der Ähre auf, wie sie für F. graminearum bekannt ist (Kang und Buchenauer, 2000a, Ribichich et al., 2000). Als Erklärung für diesen Sachverhalt könnten die spezifischen Mykotoxinspektren der verschiedenen Fusarium-Arten dienen. F. poae bildet ebenso wie F. equiseti das eine im Vergleich zu DON erheblich stärkere Warmblütertoxizität aufweisende Nivalenol (Minervini et al., 2004). Bereits Joffe (1986) schätzte die Toxizität von NIV ca. zehnfach höher ein, als die toxischen Eigenschaften von DON. Neben NIV produziert F. poae aber auch DAS, wobei mittels Flüssig- und Gaschromatographieanalysen von Kulturextrakten durch Thrane et al. (2004) für einzelne Isolate auch die Bildung des T2- und des HT2Toxins beschrieben wurde. F. tricinctum wird dagegen hauptsächlich als Enniatin- und Beauvericin-Produzent charakterisiert (Thrane et al., 2004). Diese Resultate zeigen, dass keine der drei Fusarium-Arten in der Lage ist, DON zu produzieren, was mit den hier erbrachten Ergebnissen übereinstimmt. Bai, Desjardins und Plattner (2001) postulierten, dass DON nicht für die initiale Infektion der Weizenähre durch F. graminearum essenziell ist. Wahrscheinlich fungiert es jedoch als Virulenzfaktor (Proctor et al., 1995; Desjardins et al., 1996) während der systemischen Besiedlung der Ähre durch das Leitgewebe der Spindel, indem die Bildung von Zellwandappositionen in Form sekundärer Verdickungen der primären Zellwand (Jansen et al., 2005) im Zuge des von Schroeder und Christensen (1963) als Resistenztyp II beschriebenen Resistenzmechanismus unterbunden wird.

Die in der vorliegenden Arbeit beobachtete, lokale Begrenzung der Besiedlung durch F. equiseti, F. poae und F. tricinctum auf die Ährchen bzw. die Unfähigkeit, systemisch in die Ährenspindel zu wachsen und ein möglicherweise damit einhergehendes Unterbinden des Nährstoff- und Assimilattransports zu den Körnern zu verursachen, wurde auch von Christ et al. (2011b) beobachtet. Hier zeigte sich nach Sprühinokulation von Einzelähren 
mit verschiedenen Fusarium-Arten besonders für die aus DON-Chemotypen bestehenden Isolatgemische der Arten F. graminearum und F. culmorum sehr starke FHB-Symptome, die mit einer Verbräunung der Rachis einhergingen, welche auf eine sytemische Besiedlung der Spindel hindeutete, wogegen alle anderen Fusarium-Arten diese Verbräunungen der Rachis nicht aufwiesen. Die Beschränkung der Besiedlung der drei Fusarium-Arten könnte demnach auf deren Unvermögen zurückzuführen sein, DON zu produzieren.

Wie bereits erwähnt, brachte die Kolonisierung der Weizenährchen in den Pathogenitätsversuchen unter kontrollierten Bedingungen Black-Point-Körner hervor, deren Anteil an der Gesamtkornmenge in einzelnen Varianten bis zu 40\% betrug (Abb. 67), wogegen die Produktion von FHB-Kümmerkörnern ausschließlich für F. graminearum und F. graminearum-Mischvarianten zu beobachten war (Abb. 65 und Abb. 68). Die Ausprägung des Black-Point-Symptoms hatte im Pathogenitätsversuch mit Einzelvarianten keinen signifikanten Einfluss auf das TKG, wogegen im Pathogenitätsversuch mit Mischvarianten für die Variante F. tricinctum- $F$. poae eine leichte, aber dennoch signifikante Reduktion in der Black-Point-Kornfraktion nachzuweisen war (Abb. 67) und den Ergebnissen von Gödecke (2010) für F. equiseti und F. tricinctum entspricht. Dieser Unterschied lag wahrscheinlich in jahresbedingten Temperaturunterschieden im Gewächshaus begründet. Im Pathogenitätsversuch mit Mischvarianten war im Vergleich zum Pathogenitätsversuch mit Einzelvarianten nach $7 \mathrm{dpi}$ eine bereits sehr viel weiter fortgeschrittene Symptomentwicklung mit einem durchschnittlich um 36\% höheren Disease-Index in den Inokulationsvarianten ohne F. graminearum nachzuweisen (Tab. 29). Laut den Ergebnissen sorgte dies zwar nicht für einen höheren Black-Point-Besatz, führte aber zu einer stärkeren Symptomausprägung, die während der visuellen Beurteilung des Ernteguts beobachtet wurde und mit leicht geringeren TKGs einherging. Die äußerst hohe Aggressivität von F.graminearum im Zusammenspiel mit hoher Sporenkonzentration sowie der gleichmäßigen Applikation der Sporen durch Sprühinokulation unter optimalen Bedingungen, verursachte eine erhebliche Reduktion des TKG auf 2,4-2,6 g und erwies sich gegenüber den Gesamt-TKGs der übrigen Versuchsvarianten als signifikant niedriger (Tab. 31).

In Bezug auf die durch F. equiseti, F. poae und F. tricinctum verursachte Mykotoxinkontamination konnten im Pathogenitätsversuch mit Einzelvarianten in symptomlosen Körnern NIV-Gehalte von $573 \mu \mathrm{g} / \mathrm{kg}$ Mehl für $F$. equiseti festgestellt werden. Auch F. poae brachte Kontaminationen mit NIV-Gehalten von $1.140 \mu \mathrm{g} / \mathrm{kg} \mathrm{Mehl}$ in symptomlosen Körnern hervor. In der mit $F$. tricinctum inokulierten Variante lieferten Mykotoxinanalysen ENNI-Gehalte von $3.957 \mu \mathrm{g} / \mathrm{kg}$ Mehl. Die Black-Point-Fraktionen wiesen dagegen bis zu zehnfach höhere Mykotoxinwerte auf als symptomlose Körner, wie am Beispiel für NIV deutlich wird, welches mit Gehalten von $6.216 \mu \mathrm{g} / \mathrm{kg} \mathrm{bzw}$. 
$>10.000 \mu \mathrm{g} / \mathrm{kg}$ Mehl in den durch F. equiseti und F. poae besiedelten Black-PointFraktionen nachgewiesen werden konnte. Christ et al. (2011b) machten ähnliche Beobachtungen für $F$. equiseti und $F$. tricinctum. Interessanterweise konnte im Zuge dieser Arbeit ein ganz ähnliches Verhalten für $F$. poae gezeigt werden. Es erstaunt jedoch, dass auf Basis der Ergebnisse im Hinblick auf die Bildung von Black-PointKörnern F. poae als die am wenigsten pathogene Art angesehen werden muss. Die grundsätzliche Bestätigung der Pathogenität von F. equiseti, F. tricinctum und F. poae an Weizen sowie die durch sie hervorgerufene Belastung symptomloser Körner mit erheblichen Mykotoxingehalten und den im Schnitt um ein Zehnfaches höheren Toxinwerten in Black-Point-Körnern liegt zunächst der Schluss nahe, dass besonders die NIV-Produzenten $F$. equiseti und $F$. poae auch unter natürlichen Bedingungen ein potenzielles Risiko für Mensch und Tier darstellen könnten. Allerdings wiesen die Ergebnisse der Pathogenitätsversuche mit Mischvarianten unter kontrollierten Bedingungen darauf hin, dass F. graminearum die Infektion mit $F$. tricinctum und F. poae überdeckt. Die Disease-Indices der Mischvarianten $F$. graminearum- $F$. poae- $F$. tricinctum sowie F. graminearum-F. tricinctum zeigten weder nach 7 dpi noch nach 14 oder 21 dpi einen signifikanten Unterschied im Vergleich zur F.graminearum-Einzelvariante und lagen nach $21 \mathrm{dpi}$ im Schnitt bei 98\%, wobei die gesamte Ähre ausgeblichen war (Tab. 29). Zudem besaßen diese Varianten einen Anteil an FHB-Körnern von durchschnittlich 94\% und lagen somit auf dem Niveau der F. graminearum-Einzelvariante, wogegen jedoch keine Black-Point-Körner aufzufinden waren. Die Mykotoxingehalte des Ernteguts der beiden Mischvarianten wiesen dabei eindeutig durch DON dominierte Mykotoxinspektren auf, im Vergleich zu den Einzelvarianten von F. tricinctum und F. poae des Versuchs waren die Gehalte der von diesen beiden Arten synthetisierten Mykotoxingehalte extrem gering. Es muss daher davon ausgegangen werden, dass weder F. poae, noch F. tricinctum bei Anwesenheit von F.graminearum mit diesem Pathogen zu konkurrieren vermögen, was zumindest für $F$. poae die Beobachtungen von Brennan et al. (2003) und Xu et al. (2007) zur schwachen Pathogenität im Vergleich zu anderen Arten des FHB-Komplexes untermauert. Auch Gödecke (2010) berichtete, dass in Starkbefallsjahren unter natürlichen Bedingungen $F$. graminearum als Leitpathogen an der Ähre auftritt und andere Arten verdrängt werden. So waren im Jahr 2007 90\% aller Pilze, die nach Vorfrucht Mais von Winterweizenkörnern isoliert worden waren, als F. graminearum identifiziert worden.

Die F. poae-F. tricinctum Mischvariante wies im Hinblick auf den Disease-Index keinen Unterschied zu den F. poae und F. tricinctum Einzelvarianten auf, zeigte aber den niedrigsten Black-Point-Anteil, welcher aber nur im Vergleich zu F. tricinctum signifikant geringer war. Auch die Mykotoxingehalte spiegeln dies wieder (Tab. 32). Folglich kann angenommen werden, dass die beiden Arten F. poae und F. tricinctum in der Lage sind, 
nebeneinander zu koexistieren. Synergistische Interaktionen wie von Xu et al. (2005) in zweijährigen Feldstudien in mehreren europäischen Ländern u.a. für $F$. avenaceum und F. culmorum beobachtet, konnten nicht bestätigt werden, genauso wenig ist jedoch eine starke, in der Verdrängung einer der beiden Arten resultierende, interspezifische Konkurrenz anzunehmen, was zudem durch die Ergebnisse der Mykotoxinanalysen untermauert wird. So wiesen die Mischvarianten dieser Arten auf Grund niedrigerer Sporenaufwandmengen gegenüber den Einzelvarianten zwar geringere artspezifische Mykotoxingehalte auf (Tab. 29). Stark erhöhte Mykotoxinwerte zu Gunsten, bzw. stark verringerte Werte zu Lasten einer Art, welche unter Umständen auf ein größeres Konkurrenzvermögen einer Art gegenüber der anderen Art hätte hindeuten können, waren jedoch nicht zu beobachten.

Ein grundsätzliches Problem ergab sich bei der Sichtbonitur im Freilandversuch, da die Symptome von F. equiseti, F. poae und F. tricinctum nur bei sehr genauem Bonitieren sichtbar waren und sich insofern eine exakte Quantifizierung des Befalls als schwierig darstellte. Die Ergebnisse der Versuche unter kontrollierten Bedingungen im Hinblick auf Symptomausprägung und TKG konnten im Freiland jedoch eindeutig bestätigt werden. Besonders gut war hier die sehr viel höhere Pathogenität von F.graminearum im Vergleich zu den übrigen drei Fusarium-Arten anhand der Befallsstärke zu beobachten, die signifikante Unterschiede von mehr als 40\% zwischen den Einzel- und Mischvarianten von F. graminearum und den Einzel- und Mischvarianten der übrigen Fusarium-Arten aufwies (Abb. 60). In den Mischvarianten mit F. graminearum fand, wie in den Versuchen unter kontrollierten Bedingungen, eine starke Verdrängung von F. tricinctum und F. poae statt, was auch an den beispielsweise ca. zehnfach geringeren Gehalten an Enniatinen in den Mischvarianten mit $F$. tricinctum im Vergleich zu den Gehalten der Einzelvarianten im Erntegut des Feldversuches zu erkennen war. Die DON-Gehalte im Erntegut der $F$. graminearum-F. tricinctum und der F. graminearum-F. poae-F. tricinctum Mischvarianten lagen jedoch im Vergleich zur F. graminearum Einzelvariante um 1,5 bis 1,8-mal niedriger (Tab. 24). Dieser Unterschied in den DON-Gehalten im Freiland könnte eine gesteigerte Konkurrenzfähigkeit von F. poae und F. tricinctum unter Feldbedingungen gegenüber $F$.graminearum bedeuten. Die geringeren Symptomausprägungen und niedrigere Mykotoxingehalte im Erntegut, verglichen mit den Inokulationsversuchen unter kontrollierten Bedingungen für die beiden Arten lassen jedoch eher vermuten, dass der niedrigere DON-Gehalt der Mischvarianten von den im Versuchsaufbau bedingten, geringeren Sporenaufwandmengen der Mischvarianten herrührt. Die extrem hohen DONGehalte der F.graminearum Einzelvariante, welche einen Spitzenwert von 2,93 x 10 mg DON kg $^{-1}$ Mehl erreichten, verwundern zunächst. Gödecke (2010) konnte im Starkbefallsjahr 2007 am Standort Torland des FAEN-Fruchtfolgeversuchs jedoch allein durch natürlichen Befall DON-Kontaminationen von rund $80.000 \mu \mathrm{g} / \mathrm{kg}$ Mehl feststellen, 
sodass derart hohe DON-Gehalte bei künstlicher Inokulation in Abhängigkeit von Sporenaufwandmenge, Einsatz von Benetzungsmittel und günstigen Witterungsbedingungen durchaus vorstellbar sind. Im Hinblick auf den Black-Point-Besatz stimmen die Ergebnisse des Freilandversuchs nicht mit den Ergebnissen der Versuche unter kontrollierten Bedingungen überein, da im Erntegut der Einzel- und Mischvarianten ohne F. graminearum keine Black-Point-Körner zu finden waren. Es liegt der Schluss nahe, dass von den drei unter kontrollierten Bedingungen das Black-Point-Symptom hervorrufenden Fusarium-Arten F. equiseti, F. poae und F. tricinctum unter natürlichen Bedingungen keine, bzw. nur vereinzelt Black-Point-Körner gebildet werden, was Aufschluss über ihre geringe Pathogenität im Feld gibt. Es muss außerdem berücksichtigt werden, dass die für eine Inokulation im Feld durchaus günstigen, kurz vor der Vollblüte sehr trockenen Bedingungen auch zu einer geringen Hintergrundinfektion durch andere weizenpathogene Pilze führten und die inokulierten Fusarium-Arten weitestgehend ohne Konkurrenz an der Ähre verblieben. Außerdem muss erwähnt werden, dass die

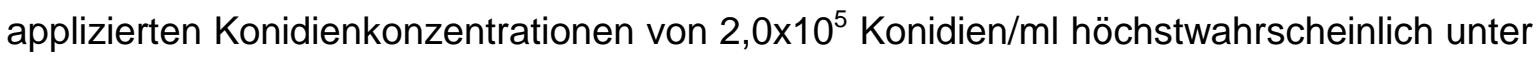
natürlichen Befallsbedingungen nicht erreicht werden.

Die geringe Konkurrenzfähigkeit der Arten $F$.poae und $F$. tricinctum gegenüber F. graminearum an der Ähre von Weizen, zusammen mit den im FAENFruchtfolgeversuch vergleichsweise insgesamt hohen Isolationsraten gegenüber den anderen von Weizenkörnern isolierten Arten wirft die Frage nach Verbreitungsmechanismus und Lebensweise dieser beiden Arten auf. Unter 4.2.1 wurde bereits die Einstufung von F. tricinctum als Saprophyt mit schwacher Pathogenität an Getreide (Leslie und Summerell, 2006; Fernández-Ortuño et al., 2011) geschildert, welcher in temperaten Regionen der Erde wie Nordamerika sowie Nord-, Mittel-, und Osteuropa weit verbreitet ist. Ebenso ist $F$. poae häufig in Nord- und Mitteleuropa anzutreffen (Jestoi et al., 2004, 2008; Uhlig et al., 2006; Gunst et al., 2005; Stenglein, 2009). Jedoch liegt auf Basis der Erkenntnisse dieser Arbeit nahe, dass es sich bei $F$. poae und $F$. tricinctum eher um Sekundärbesiedler der Ähre handelt (s. 4.1.5). Oftmals hängt der Befall durch verschiedene Fusarium-Arten und somit die Zusammensetzung auftretender FHBKomplexe von klimatischen Faktoren, bzw. Iokalen Umweltbedingungen ab (Doohan et al., 2003, Xu et al., 2005). F. graminearum kann FHB sporadisch, im Abstand mehrerer Jahre zufällig und lokal in Weizen hervorrufen (Xu, 2003). Lebenszyklus, Verbreitungsund Infektionsmechanismus dieser Art sind bekannt (Pugh, 1933; Andersen, 1948; Sutton, 1982; Jenkinson und Parry, 1994; Paul et al., 2004). Genau wie F. poae (Domsch, 1980; Köhl et al., 2007) ist wahrscheinlich auch F.tricinctum in der Lage, auf Vorfruchtresten zu überdauern. Dies konnte in In vitro-Versuchen mit festen und flüssigen Vorfruchtsubstratmedien angedeutet werden (Streit und Tillmann, 2012, unveröffentlicht). 
In Jahren mit Trockenheit zur Weizenblüte, wenn hohe Niederschläge und somit eine für F. graminearum infektionsfördernde Witterung (Hooker et al., 2002) ausbleiben, könnten F. tricinctum und F. poae die Fähigkeit haben, zwischen später Milchreife und Ernte die Weizenähre saprophytisch durch regenspritzervermittelten (Jenkinson und Parry, 1994) oder auch luftbürtigen Konidieneintrag (Markell et al., 2003) zu besiedeln, um somit als Nischenbesiedler zu fungieren.

Zusammenfassend ist festzuhalten, dass die Arten F. equiseti, F. poae und F. tricinctum über pathogene Eigenschaften an der Ähre von Weizen verfügen, wie sowohl die vorliegende Arbeit, als auch die Erkenntnisse von Christ et al. (2011) bestätigen. So sind sie befähigt, bei künstlicher Infektion die Weizenähre nicht nur zu befallen und deutliche, jedoch FHB-untypische Symptome, sondern auch hohe Mykotoxinkontaminationen hervorzurufen. Die durch diese Arbeit erhaltenen Ergebnisse zeigen indes bei künstlicher Infektion eine durch F. graminearum verursachte, deutliche Überlagerung einer lokal an den Ährchen verbleibenden Infektion der Weizenähre mit F. poae und F. tricinctum, welche als sogenannter „Konkurrenzausschluss“ („competitive exclusion“, Fitt et al., 2006) bezeichnet werden könnte. Beide Arten sind daher als nicht konkurrenzfähig gegenüber $F$. graminearum einzustufen, was auch für $F$. equiseti anzunehmen ist. Vielmehr sind sie als Sekundärbesiedler der Ähre zu bezeichnen, welche in Jahren mit Trockenheit zur Blüte und dadurch bedingtem niedrigen Auftreten von FHB eine ökologische Rolle als Nischenbesiedler einnehmen und die abreifende Weizenähre kolonisieren können. Ein potenzielles gesundheitliches Risiko für Mensch und Tier, bedingt durch grenzwertüberschreitende Mykotoxinkontaminationen des Ernteguts, ist auf Basis der Ergebnisse für diese Arten unter natürlichen Befallsbedingungen daher als wenig wahrscheinlich zu erachten, was durch Ergebnisse von Golinski et al. (1996) untermauert wird. Die Autoren fanden zwar an verschiedenen Standorten in Polen an Weizenkörnern unter allen isolierten Fusarium-Arten einen Anteil von $64 \%$ für $F$. poae und $15 \%$ für $F$. tricinctum, hingegen nur $4 \%$ für $F$.graminearum. Mykotoxinkontaminationen blieben allerdings mit Gehalten von $<100 \mu \mathrm{g} / \mathrm{kg}$ für NIV weit unter gesundheitsschädlichen Konzentrationen.

Weiterhin führte die Inokulation im Freilandversuch nicht zu einer signifikanten Reduktion des TKGs. Durch Inokulationsversuche mit Isolatgemischen von F. poae an 14 Winterweizensorten kamen auch Vogelgsang et al. (2008) zu diesem Ergebnis. Eine Besiedlung der Weizenähre durch sowohl $F$. equiseti, als auch $F$. poae und $F$. tricinctum ist daher mit keinerlei agronomischem Risiko und somit als nicht ertragsrelevant zu bewerten, was ebenso durch die Tatsache bestätigt werden kann, dass in beiden Versuchsjahren keinerlei Zusammenhang zwischen der Besiedlung der Körner und dem Ertrag ermittelt werden konnte. Eine gezielte Bekämpfung dieser Arten ist somit sowohl 
für die Halmbasis als auch für die Ähre von Weizen nicht notwendig. Maßnahmen zur Bekämpfung von Fusarium an Weizen sollten sich infolgedessen auf pathogene Arten wie F. culmorum sowie F.graminearum konzentrieren und auf Basis bekannter Kombinationen von Fruchtfolgegestaltung, Sortenwahl, Bodenbearbeitung und Fungizidbehandlung unter Berücksichtigung der Regeln des integrierten Pflanzenschutzes erfolgen. 


\section{$5 \quad$ Zusammenfassung}

Im Rahmen der vorliegenden Arbeit wurde in einem seit 2006 bestehenden Weizenfruchtfolgeversuch unter Freilandbedingungen die Zusammensetzung von Fusarium-Artenspektren an Halmbasis und Körnern von Weizen und deren Kolonisierungsraten untersucht. Ein besonderer Fokus lag hierbei auf dem Einfluss der Versuchsfaktoren (i) Jahreseffekt/Witterung, (ii) Vorfrucht, (iii) Sorte und (iv) Blattfungizidbehandlung auf Artzusammensetzung und Kolonisierung von Fusarium an den beiden Pflanzenorganen.

Der Vergleich der Fusarium-Spektren an Halmbasis und Körnern zeigte einen deutlichen Kontrast auf. So waren an der Halmbasis insgesamt besonders die Arten F. culmorum, F. equiseti und F. tricinctum anzutreffen, wogegen an den Körnern die Arten F. poae, F. tricinctum sowie 2010 F. graminearum auftraten. Dieses Ergebnis lässt vermuten, dass es sich bei den an den beiden unterschiedlichen Pflanzenorganen auftretenden Artenspektren um unabhängige Populationen handelt. Eine Übertragung von F. culmorum, F. equiseti, F. graminearum und F. poae von der Halmbasis auf die Körner scheint wenig wahrscheinlich. Lediglich für F. tricinctum, welcher durchgehend an beiden Pflanzenorganen aufzufinden war, könnte eine Abhängigkeit zwischen den beiden Populationen in Form einer Übertragung von der Halmbasis auf die Körner existieren. Ob ein Zusammenhang zwischen den beiden Organen in Bezug auf F. tricinctum besteht, kann im Rahmen dieser Arbeit jedoch nicht eindeutig geklärt werden.

Im Hinblick auf den Jahreseffekt bzw. die Witterung unterlagen die Artzusammensetzungen an Halmbasis und Körnern sowohl qualitativen als auch quantitativen Veränderungen. An der Halmbasis und auch an den Körnern führte der jahresbedingte Witterungseffekt zu einem breiteren Artenspektrum im Versuchsjahr 2011 gegenüber 2010, was zumindest für die Halmbasis mit den für eine Kolonisierung durch Fusarium günstigeren Witterungsbedingungen 2011 erklärt werden kann. Die jahresbedingten Witterungsunterschiede wirkten sich erwartungsgemäß stärker auf die Körner aus. Quantitative Diskrepanzen fanden sich an beiden Pflanzenorganen in Form von unterschiedlich hohen Kolonisierungsraten der verschiedenen Fusarium-Arten. Die Ergebnisse weisen jedoch auf eine stabile Populationssignatur an der Halmbasis hin, welche von den Arten F. culmorum, F. equiseti und F. tricinctum dominiert wird. In beiden Versuchsjahren herrschte ein geringer FHB-Befallsdruck an den Körnern, sodass die Arten F. poae und F. tricinctum grundsätzlich das Artspektrum bestimmten und eine 
relativ stabile Populationssignatur bildeten, obgleich auch andere Arten jahresabhängig auftraten, wie z.B. F. graminearum im Jahr 2010 nach Vorfrucht Mais.

In Abhängigkeit von der Vorfrucht zeigten sich große Unterschiede in der Kolonisierung der Halmbasis. So konnte zum Entwicklungsstadium der Milchreife nach Vorfrucht Zuckerrübe in beiden Versuchsjahren die höchste Gesamtkolonisierungsrate an der Halmbasis von Weizen ermittelt werden, noch vor Mais. Der Weizen wies nach Vorfrucht Weizen und Vorfrucht Ölrettich insgesamt die niedrigsten Kolonisierungsraten auf. Hauptverursacher für die erhöhte Gesamtkolonisierungsrate nach Zuckerrübe waren die Arten F. culmorum, F. equiseti und F. tricinctum. Eine hohe Relevanz kam hier der Besiedlung durch die stark pathogene Art F. culmorum zu, die besonders im Jahr 2011 häufig vertreten war. Dies konnte auch für die Vorfrüchte Mais, Weizen und Ölrettich bestätigt werden. Die Ergebnisse belegen daher, dass der Vorfruchteffekt lediglich quantitativer Art im Hinblick auf unterschiedliche Kolonisierungsraten war, die FusariumArtenzusammensetzung jedoch nicht beeinflusste.

Auf Grund der hohen Kolonisierungsraten nach Zuckerrübe sollte auf Basis der Ergebnisse dieser Arbeit die Zuckerrübe aus phytopathologischer Sicht als potenzieller Fusarium-Überträger eingestuft werden. Eine Ertragsrelevanz der Halmbasiskolonisierung an Weizen nach Zuckerrübe konnte jedoch nicht demonstriert werden.

Ein Vorfruchteffekt an den Körnern konnte dagegen nur 2010 im Zuge einer erhöhten Kolonisierung durch F. graminearum nach Vorfrucht Mais festgestellt werden, der durch Mykotoxingehalte in den Weizenkörnern verifiziert werden konnte sowie 2011 nach Weizen, bedingt durch verstärktes Auftreten von F. culmorum. Beide Effekte waren jedoch nicht reproduzierbar, was die starke Witterungsabhängigkeit des Einflusses der Vorfrucht unterstreicht.

Ein signifikanter Sorteneffekt auf die Gesamtkolonisierungsrate konnte bis auf den Probenahmezeitpunkt BBCH 37-39 2011 sowohl an der Halmbasis, als auch an den Körnern festgestellt werden, wobei der Effekt an den Körnern verglichen mit der Halmbasis zwar auf niedrigerem Niveau in Bezug auf die Kolonisierung auftrat, jedoch etwas stärker ausgeprägt war. Dieser reduzierende Effekt in der resistenten Sorte "Centrum" war in besonderem Maße auf die quantitative Reduktion der artspezifischen Kolonisierungsraten der an den jeweiligen Pflanzenorganen dominierenden FusariumArten zurückzuführen. Ein signifikant erhöhter Ertrag konnte für die resistente Sorte in beiden Jahren nachgewiesen werden, die Kolonisierungsraten von Halmbasis und Körnern korrelierten jedoch nicht mit dem Ertrag.

Die Blattfungizidbehandlung erwies sich dagegen an der Halmbasis als deutlich wirksamer bezüglich einer Reduktion der Gesamtkolonisierungsraten, als an den Körnern. Jedoch war auch hier ein quantitativer, reduzierender Effekt auf die spezifischen 
Kolonisierungsraten der an Halmbasis und Körnern dominierenden Arten zu beobachten, wobei sich dieser an den Körnern allerdings nur auf die Arten F. culmorum und F. graminearum auswirkte. Ebenso wie der Effekt der Sortenresistenz auf den Ertrag, konnte auch ein positiver Effekt des Blattfungizideinsatzes auf den Ertrag in den behandelten Varianten verzeichnet werden, wobei dieser jedoch jahresabhängig war. Auch hier wurde keine Korrelation zwischen Kolonisierungsraten an Halmbasis und Körnern und dem Ertrag beobachtet.

Darüber hinaus zeigten die Pathogenitätstests an Halmbasis und Ähre von Weizen die geringe phytopathologische und agronomische Bedeutung der Arten F. equiseti, F. poae und $F$. tricinctum. Kaum nachweisbare Symptomausprägungen nach künstlicher Infektion unter kontrollierten Bedingungen in der Klimakammer und geringe Reisolationsraten ließen den Schluss zu, dass insbesondere die Arten F. equiseti und F. tricinctum an der Halmbasis als apathogen einzustufen sind und eine ökologische Rolle als endophytische Nischenbesiedler einnehmen. An der Ähre waren alle drei Arten sowohl unter kontrollierten Bedingungen als auch im Freiland bei künstlicher Inokulation in der Lage, die Weizenkörner zu infizieren und starke Mykotoxinkontaminationen hervorzurufen. Dies ist jedoch unter natürlichen Befallsbedingungen als wenig wahrscheinlich zu erachten. Zudem wiesen die auf ihr Konkurrenzvermögen hin getesteten Arten F. poae und F. tricinctum zu keinem Zeitpunkt die Fähigkeit auf, in Anwesenheit von F. graminearum mit dieser Art zu konkurrieren. Aus diesem Grunde ist anzunehmen, dass die drei untersuchten Fusarium-Arten als Sekundärbesiedler der Ähre fungieren, welche in Jahren mit Trockenheit zur Blüte und dadurch bedingtem, niedrigen Auftreten von FHB eine ökologische Rolle als Nischenbesiedler einnehmen und die abreifende Weizenähre kolonisieren können. Ferner fand keine Reduktion des TKG unter Freilandbedingungen statt, was eine agronomische Relevanz der Kornbesiedlung durch diese drei Arten im Vergleich zu F. graminearum ausschließt. Eine Bekämpfung von Fusarium-Arten sollte sich daher klassischerweise auf pathogene, aggressive Arten wie F. culmorum sowie F. graminearum beschränken und in Form bekannter Kombinationen von Fruchtfolgegestaltung, Sortenwahl, Bodenbearbeitung und Fungizidbehandlung an Weizen unter Berücksichtigung der Regeln für den integrierten Pflanzenschutz erfolgen. 


\section{Summary}

In the present study the composition of Fusarium species spectra on stem bases and grains of wheat and their colonization rates were investigated under the conditions of a wheat crop rotation experiment existing since 2006. The influence of the experimental factors (i) year/weather, (ii) precrop, (iii) cultivar and (iv) foliar fungicide treatment on species composition and colonization rates of Fusarium species on the two plant organs was of particular interest.

Comparison of the Fusarium spectra on stem bases and grains revealed clear differences. At the stem base, mainly the species F. culmorum, F. equiseti and F. tricinctum were found, whereas on grains the species F. poae, F. tricinctum and 2010 F. graminearum occurred. This result suggests that the species spectra of the two different plant organs are independent populations. In general, a transfer of F. culmorum, F. equiseti, $F$. graminearum and F. poae from the stem base to the grains seems unlikely. A dependency between the two populations in the form of a transfer of the stem base to the grains may be possible only for F. tricinctum, which was found consistently on both plant organs. Whether a relationship between the two plant organs regarding $F$. tricinctum exists could not be conclusively clarified in this work.

With regard to the year dependent weather effects, species compositions on both, stem base and grains, were subject to qualitative as well as quantitative alterations. At both plant organs, year dependent weather effects on Fusarium resulted in a wider range of species during 2011 compared to 2010 . This can be explained at least concerning the stem base by the more favorable weather conditions for colonization by Fusarium species in 2011. As expected, year dependent differences of weather conditions had a greater effect on grains. Quantitative differences were found in both plant organs due to the different colonization rates of the various Fusarium species.

The results demonstrate a stable population signature at the stem base, which is dominated by the species F. culmorum, F. equiseti and F. tricinctum. In both years there was a low FHB infestation pressure on the grains, so that the species F. poae and F. tricinctum basically determined the species spectrum forming a relatively stable population signature, although other species occurred depending on the year, such as F. graminearum after precrop maize in 2010.

Large differences in the colonization of the stem base could be observed depending on the precrop. Thus, at milk ripeness in both years, the highest colonization rates at the stem base of wheat were determined after precrop sugar beet, even ahead of maize. Wheat and oilseed radish showed the lowest colonization. The main causes for the 
increased colonization rates after sugar beet were the species $F$. culmorum, $F$. equiseti and F. tricinctum. Especially colonization by the strongly pathogenic F. culmorum which was represented particularly in 2011 was of great importance. This has also been confirmed for the precrops maize, wheat and oil radish. The results demonstrate that the precrop effect was only quantitative in terms of different colonization rates, but did not influence Fusarium species composition.

Due to the high colonization rates after sugar beet, based on the results of this study, from a phytopathological point of view sugar beet should be considered as a potential Fusarium carrier. However, a relevance for yield could not be demonstrated for colonization of the stem base of wheat after precrop sugar beet. A precrop effect on the grains could be observed in 2010 in the form of an increased colonization after precrop maize by F. graminearum and was verified by mycotoxin contents in wheat grains. An additional precrop effect was evident in 2011 , due to increased colonization by $F$. culmorum after precrop wheat. Both effects were not reproducible, which highlights the strong climatic dependence of the precrop effect.

A distinct cultivar effect on colonization rates was found at the stem base, as well as on the grains. However, the effect on grains as compared to the stem base occurred at a much lower level in relation to the colonization of the stem base, but was slightly more pronounced. This reduction effect in the resistant cultivar 'Centrum' was due particularly to the quantitative reduction of the species-specific colonization rates of the dominant Fusarium species on the respective plant organs. A significantly increased yield could be detected for the resistant cultivar in both years. However, the colonization of stem base and grains did not correlate with the yield.

On the other hand, the foliar fungicide treatment proved to be significantly more effective at the stem base than on the grains, with respect to a reduction in colonization rates. $A$ quantitative reducing effect on the specific colonization of the dominant species on stem base and grains was observed, which also had an impact on the grains but only for the species $F$. culmorum and F. graminearum. As well as the effect of cultivar resistance on the yield, a positive but year dependent effect of foliar fungicide treatment on the yield could be observed in the treated variants. Again, no correlation between colonization of stem base and grains with the yield was observed.

In addition, pathogenicity tests at the stem base and the ear of wheat revealed low phytopathological and agronomical importance of the species F. equiseti, F. poae and F. tricinctum. Barely detectable symptoms after artificial infection under controlled conditions in the climate chamber and low reisolation rates led to the conclusion that particularly the species $F$. equiseti and $F$. tricinctum should be classified as nonpathogenic at the stem base, playing an ecological role as niche-colonizing endophytes. Both, in 
greenhouse experiments as well as under field conditions, all three species were able to infect wheat grains after artificial inoculation of ears, causing strong mycotoxin contaminations in grains. However, this is unlikely under natural infection conditions. In addition, at any time both species $F$. poae and F. tricinctum were unable to compete with F. graminearum, when this species was present. For this reason, it can be assumed that the three investigated Fusarium species act as secondary colonizers of the ear, which may colonize wheat ears in years with drought at flowering stage and therefore with a low incidence of FHB. Therefore, these species may have an ecological role as nichecolonizers. Furthermore, there was no reduction of the TGW detectable under field conditions, which excludes an agronomic relevance of grain colonization by these three species compared to $F$. graminearum. Therefore, the battle against Fusarium should target the pathogenic, aggressive species such as F. culmorum and F. graminearum, and consider known combinations of crop rotation, cultivar selection, tillage and fungicide treatment on wheat, following the rules for integrated pest management. 


\section{$6 \quad$ Literatur}

Abbas, H. K., Mouhi, M. N., Al-Roubaie, J. T., Hama, N. N. und El-Bahadli, A. H., 1991. Phomopsis phoenicola and Fusarium equiseti, new pathogens on date palm in Iraq. Mycological Research 95: 509.

Adams, G. C. Jr., Gubler, W. D. und Grogan, R. G., 1987. Seedling disease of muskmelon and mixed melons in California, USA caused by $F$. equiseti. Plant Disease 71: 370374.

Andersen, A. L., 1948. The development of Gibberella zeae head blight of wheat. Phytopathology 38: 595-611.

Andersen, B., Thrane, U., Svendsen, A. und Rasmussen, I. A., 1996. Associated field mycobiota on malt barley. Canadian Journal of Botany 74: 854-858.

Anonymus, 2005. Verordnung (EG) Nr. 856/2005 der Kommission vom 06. Juni 2005 zur Änderung der Verordnung (EG) Nr. 466/2001 in Bezug auf Fusarientoxine, ABI. EG Nr. L 143: 3.

Anonymus, 2006. Beschreibende Sortenliste 2006 Getreide, Mais, Ölfrüchte, Legumiosen, Hackfrüchte. Bundessortenamt, Hannover.

Anonymus, 2008. information.medien.agrar (i.m.a) e.V. Zuckerrüben (Beta vulgaris var. Altissima).

Anonymus, 2011. Beschreibende Sortenliste 2011 Getreide, Mais, Ölfrüchte, Legumiosen, Hackfrüchte. Bundessortenamt, Hannover.

Aoki, T. und O'Donnell, K., 1999. Morphological characterization of Gibberella coronicola sp. nov., obtained through mating experiments of Fusarium pseudograminearum. Mycoscience 40: 443-453.

Atanasoff, D., 1920. Fusarium-blight (scab) of wheat and other cereals. Journal of Agricultural Research 10: 1-33. 
Bai, G.H., Shaner, G., 1996. Variation in Fusarium graminerarum and cultivar resistance to wheat scab. Plant Disease 80: 975-979.

Bai, G.-H., Desjardins, A. E., und Plattner, R. D., 2001. Deoxynivalenol-nonproducing Fusarium graminearum causes initial infection, but does not cause disease spread in wheat spikes. Mycopathologia 153: 91-98.

Bai, G., Shaner, G., 2004. Management and resistance in wheat and barley to Fusarium head blight. Annual Review of Phytopathology 42: 135-161.

Beccari, G., Covarelli, L. und Nicholson, P., 2011. Infection process and soft wheat response to root rot and crown rot caused by F. culmorum. Plant Pathology 60: 671684.

Beck, R., und Lepschy, J., 2000. Ergebnisse aus dem Fusarium Monitoring 1989-1990 Einfluss der produktionstechnischen Faktoren Fruchtfolge und Bodenbearbeitung. LBP (Bayerische Landesanstalt für Bodenkultur und Pflanzenbau) 3: 39-47.

Becker, R., Hettwer, U., Karlovsky, P., Deising, H. B., Wirsel, S. G.R., 2010. Adaptation of Fusarium graminearum to Tebuconazole yielded descendants diverging for levels of fitness, fungicide resistance, virulence, and mycotoxin production. Phytopathology 100: 444-453.

Bennett, F. T., 1935. Fusarium species on British cereals. Annals of Applied Biology. 22: 479-507.

Bennett, J. W. und Klich, M., 2003. Mycotoxins. Clinical Microbiology Reviews 16: 497516.

Birzele, B., Meier, A., Hindorf, H., Krämer, J. und Dehne, H. W., 2002. Epidemiology of Fusarium infection and deoxynivalenol content in winter wheat in Rhineland, Germany. European Journal of Plant Pathology 108: 667-673.

Bockmann, H., 1962. Künstliche Freilandinfektionen mit den Erregern der Fuß- und Ährenkrankheiten des Weizens. I. Vorbereitung und Durchführung der Feldinfektionen sowie deren Neben- und Nachwirkungen. Nachrichtenblatt Dt. Pflanzenschutzdienst 14: 153-156. 
Boosalis, M. G., Doupnik, B. L., Wysong, D. S. und Watkins, J. E., 1983. The wheat scab epidemic of 1982. University of Nebraska. Fam. Ranch Home Quart. 29: 7-9.

Booth, C. 1971. The genus Fusarium. Commonwealth Mycological Institute, Kew, U.K.

Bosch, U. und Mirocha, C. J., 1992. Toxin production by Fusarium species from sugar beets and natural occurrence of zearalenone in beets and beet fibers. Applied Environmental Microbiology 58: 3233-3239.

Bottalico, A., und Perrone, G., 2002. Toxigenic Fusarium species and mycotoxins associated with head blight in small-grain cereals in Europe. European Journal of Plant Pathology 108: 611-624.

Brandfaß, C., 2006. Establishment and application of real-time PCR-based methods to study the epidemiology of Fusarium Head Blight. Dissertation, Universität Göttingen.

Brandfaß, C. und Karlovsky, P., 2006. Simultaneous detection of Fusarium culmorum and F. graminearum in plant material by duplex PCR with melting curve analysis. BMC Microbiology 2006, 6: 4.

Brandfaß, C. und Karlovsky, P., 2008. Upscaled CTAB-based DNA extraction and real-time PCR assays for Fusarium culmorum and F. graminearum DNA in plant material with reduced sampling error. International Journal of Molecular Sciences, 9: 2306-2321.

Brennan, J. M., Fagan, B., van Maanen, A., Cooke, B. M., Doohan, F. M., 2003. Studies on in vitro growth and pathogenicity of European Fusarium fungi. European Journal of Plant Pathology 109: 577-587.

Broschewitz, B., Frahm, J., Kakau, J., Körschenhaus, J. W., Krauthausen, H.-J., von Kröcher, C., Laermann, H.-T., Mauler-Machnik, A., Mielke, H., Puhl, T. und Steck, U., 1999. F01. Deutscher Vorschlag für eine EPPO-Richtlinie zur Prüfung der Wirksamkeit von Saatgutbehandlungsmitteln gegen luft- und bodenbürtige Krankheitserreger an Getreide. Biologische Bundesanstalt für Land- und Forstwirtschaft, Bundesrepublik Deutschland.

Brunner, E., Munzel, U., 2002. Nichtparametrische Datenanalysen. Springer Verlag, Berlin, Deutschland. 
Burgess, L. W., 1981. General ecology of the Fusaria. In: Nelson, P. E., Toussoun, T. A., Cook, R. J. (Hrsg.). Fusarium: Diseases, biology, and taxonomy. The Pennsylvania State University Press, University Park, 225-235.

Burgess, L. W., Summerell, B. A., Bullock, S., Gott, K. P. und Backhouse, D., 1994. Laboratory Manual for Fusarium Research, 3. Auflage. University of Sydney, Royal Botanic Gardens, Sydney, Australia.

Burgess, L. W., Backhouse, D., Summerell, B. A. und Swan, L., 2001. Crown Rot of Wheat, p. 271-294. In: B. A. Summerell, J. F. Leslie, D. Backhouse, W. L. Bryden und L. W. Burgess (Hrsg.) Fusarium: Paul E. Nelson Memorial Symposium. APS Press, St. Paul, Minnesota.

Burlakoti, R. R., Estrada, R., Jr., Rivera, V. V., Boddeda, A., Secor, G. A. und Adhikari, T. B., 2007. Real-time PCR quantification and mycotoxin production of Fusarium graminearum in wheat inoculated with isolates collected from potato, sugar beet and wheat. Phytopathology 97: 835-841.

Bushnell, W. R., Hazen, B. E. und Pritsch, C., 2003. Histology and physiology of Fusarium head blight. In: Fusarium Head Blight of Wheat and Barley. Edited by K. J. Leonard and W. R. Bushnell, APS Press, St. Paul, USA.

Champeil, A., Dore, T., Fourbet, J. F., 2004. Fusarium head blight: epidemiological origin of the effects of cultural practices on head blight attacks and the production of mycotoxins by Fusarium in wheat grains. Plant Science 166: 1389-1415.

Chelkowski, J., Manka, M., Kwasna, H., Visconti, A. und Golinski, P., 1989. Fusarium sporotrichioides (Sherb.), Fusarium tricinctum (Corda) Sacc. and Fusarium poae Wollenw.: Cultural characteristics, toxigenicity and pathogenicity towards cereals. Journal of Phytopathology 124: 155-161.

Christ, D. S., Märländer, B. und Varrelmann, M., 2011 (a). Characterization and mycotoxigenic potential of Fusarium species in freshly harvested and stored sugar beet in Europe. Phytopathology 101: 1330-1337. 
Christ, D. S., Gödecke, R., von Tiedemann, A. und Varrelmann, M., 2011 (b). Pathogenicity, symptom development, and mycotoxin formation in wheat by Fusarium species frequently isolated from sugar beet. Phytopathology 101: 13381345.

Clement, J. A., Parry, D. W., 1998. Stem-base disease and fungal colonization of winter wheat grown in compost inoculated with Fusarium culmorum, F. graminearum and Microdochium nivale. European Journal of Plant Pathology. 104: 323-330.

Conner, R. L. und Davidson, J. G. N., 1987. Resistance in wheat to black point caused by Alternaria alternata and Cochliobolus sativus. Canadian Journal of Plant Sciences 68: 351-359.

Conner, R. L., Hwang, S. F. und Stevens, R. R., 1996. Fusarium proliferatum: A new causal agent of black point in wheat. Canadian Journal of Plant Pathology 18: 419423.

Cook, R. J., 1968. Fusarium root and foot-rot of cereals in the Pacific Northwest. Phytopathology 58: 127-131.

Cook, R. J. und Papendick, R. I., 1970. Soil water potential as a factor in the ecology of Fusarium roseum $\mathrm{f} \mathrm{sp}$. cerealis "Culmorum". Plant Soil 32: 131-145.

Cook, R. J., 1980. Fusarium foot rot of wheat and its control in the Pacific Northwest. Plant Disease 64: 1061-1066.

Culler, M. D., Miller-Garvin, J. E. und Dill-Macky, R., 2007. Effect of extended irrigation and host resistance on deoxynivalenol accumulation in Fusarium-infected wheat. Plant Disease 91: 1464-1472.

Desjardins, A. E., Proctor, R. H., Bai, G. H., McCormick, S. P., Buechley, G. und Hohn, T. M., 1996. Reduced virulence of trichothecene-nonproducing mutants of Gibberella zeae in wheat field tests. Molecular Plant-Microbe Interactions 9: 775-781.

Desjardins, A. E., 2003. Gibberella from A (venaceae) to Z (eae). Annual Review of Phytopathology 41: 177-198.

Desjardins, A. E., 2006. Fusarium mycotoxins: chemistry, genetics and biology. APS Press, St. Paul, MN. 
Desjardins, A. E., Proctor, R. H., 2007(a). Molecular biology of Fusarium mycotoxins. International Journal of Food Microbiology 119: 47-50.

Desjardins, A. E., Busman, M., Proctor, R. H., Stessman, R., 2007(b). Wheat kernel black point and fumonisin contamination by Fusarium proliferatum. Food Additives and Contaminants 24: 1131-1137.

Dickson, J. G., Johann, H., Wineland ,G., 1921. Second progress report on the Fusarium blight (scab) of wheat. Phytopathology 11: 35.

Diehl, T., 1984. Weizenfusariosen - Zur Symptomentwicklung und Schadensanalyse bei Blatt- und Ährenbefall. Dissertation, Universität Göttingen.

Dill-Macky, R., Jones, R. K., 2000. The effect of previous crop residues and tillage on Fusarium Head Blight of wheat. Plant Disease 84: 71-76.

Domsch, K. H., Gams, W. und Weber, E., 1968. Der Einfluss verschiedener Vorfrüchte auf das Bodenpilzspektrum in Weizenfeldern. Zeitschrift für Pflanzenernährung und Bodenkunde 119: 134-149.

Domsch, K. H., Gams, W., Anderson, T.-H. 1980. Compendium of soil fungi. Academic Press, London.

Doohan, F. M., Brennan, J. und Cooke, B. M., 2003. Influence of climatic factors on Fusarium species pathogenic to cereals. European Journal of Plant Pathology 109: 755-768.

Duben, J., 1978. Untersuchungen zum Fußkrankheitskomplex an Winterweizen unter besonderer Berücksichtigung von Arten der Gattung Fusarium Lk. Dissertation, Universität Göttingen.

Duben, J., und Fehrmann, H., 1979. Occurrence and pathogenicity of Fusarium species on winter wheat in the Federal Republic of Germany. I Spectrum of species and season succession at the stem base. Zeitschrift für Pflanzenkrankheiten und Pflanzenschutz 86: 638-652. 
Fernández-Ortuño, D., Atkins, S. L., Fraaije, B. A., 2011. The use of a CYP51C gene based PCR-RFLP assay for simultaneous detection and identification of Fusarium avenaceum and $F$. tricinctum in wheat. International Journal of Food Microbiology 145: 370-374.

Fitt, B. D. L., Huang, J. Y., Van Den Bosch, F., West, J. S., 2006. Coexistence of related pathogen species on arable crops in space and time. Annual Review of Phytopathology 44: 163-82.

Gardes, M. und Bruns, T., 1993. ITS primers with enhanced specificity for basidiomycetes-application to the identification of mycorrhizae and rusts. Molecular Ecology 2: 113-118.

Gareis, M., 1994. Maskierte Mykotoxine. Übersichten zur Tierernährung 22: 104-113.

Gerlach, W. und Nirenberg, H. I., 1982. The genus Fusarium - a pictorial atlas. Mitteilungen der Biologischen Bundesanstalt für Land- und Forstwirtschaft (Berlin Dahlem) 209: 1-406.

Golinski, P., Perkowski J., Kostecki, M., Grabrarkiewicz-Szczesna, J. und Chelkowski, J., 1996. Fusarium species and Fusarium toxins in wheat in Poland: A comparison with neighbour countries. Sydowia 48: 12-22.

Golrnski, P., Kostecki, M., Lasocka, I., Wisniewska, H., Chelkowski, J. und Kaczmarek, Z., 1996. Moniliformin accumulation and other effects of Fusarium avenaceum (Fr.) Sacc. on kernels of winter wheat cultivars. Journal of Phytopathology 144: 495-499.

Goswami, R. S. und Kistler, H.C., 2004. Heading for disaster: Fusarium graminearum on cereal crops. Molecular Plant Pathology 5: 515-525.

Goswami, R. S., Dong, Y. und Punja, Z. K., 2008. Host range and mycotoxin production by Fusarium equiseti isolates originating from ginseng fields. Canadian Journal of Plant Pathology 30: 155-160.

Gödecke, R., 2010. Einflussfaktoren der Mykotoxinbildung durch Ährenbefall mit Fusarium spp. in verschiedenen Winterweizenfruchtfolgen. Dissertation, Universität Göttingen. 
Grossmann, K. und Retzlaff, G., 1997. Bioregulatory effects of the fungicidal strobilurin Kresoxim-methyl in wheat (Triticum aestivum). Pesticide Science 50: 11-20.

Gunst, L., Krebs, H., Dubois, D. und Forrer, H. R., 2005. The effect of farming system, previous crop and fertilisation on the incidence of ear diseases of wheat in the DOK trial. Proceedings of the Research conference on organic agriculture in the Germanspeaking region, Kassel, Deutschland, 117-120.

Hanse, B., Tijink, F., 2010. Harvesting losses... How to yield this hidden financial potential. Tagungsbeitrag des 72. IIRB Kongress, Copenhagen.

Hanson, L. E. und Hill, A. L., 2004. Fusarium species causing Fusarium yellows of sugarbeet. Journal of Sugar Beet Research 41: 163-178.

Hare, M. C., Parry, D. W., 1996. Observations on the maintenance and measurement of soil water in simple pot experiments and its effect on the seed-borne Fusarium culmorum seedling blight of winter wheat. The Annals of Applied Biology 129: 227235.

Hooker, D. C., Schaafsma, A. W. und Tamburic-Ilinic, L., 2002. Using weather variables pre- and post-heading to predict deoxynivalenol content in winter wheat. Plant Disease 86: 611-619.

Jansen, C., von Wettstein, D., Schäfer, W., Kogel, K.-H., Felk, A. und Maier, F. J., 2005. Infection patterns in barley and wheat spikes inoculated with wild-type and trichodiene synthase gene disrupted Fusarium graminearum. Proceedings of the National Academy of Sciences 102: 16892-16897.

Jenkinson, P. und Parry, D. W., 1994. Isolation of Fusarium species from common broadleaved weeds and their pathogenicity to winter wheat. Mycological Research 98: 776-780.

Jennings, P., Coates, M. E., Turner, J. A., Chandler, E. A., Nicholson, P., 2004. Determination of deoxynivalenol and nivalenol chemotypes of Fusarium culmorum isolates from England and Wales by PCR assay. Plant Pathology 53: 182-190. 
Jestoi, M., Rokka, M., Yli-Mattila, T., Parikkas P., Rizzo, A., Peltonen, K., 2004. Presence and concentration of the Fusarium-related mycotoxins beauvericin, enniatins and moniliformin in Finnish grain samples. Food Additives and Contaminants 21: 794802.

Jestoi, M., 2008. Emerging Fusarium-mycotoxins fusaproliferin, beauvericin, enniatins, and moniliformin - A review. Critical Reviews in Food Science and Nutrition 48: 2149.

Joffe, A. Z., 1978. Fusarium poae and F. sporotrichioides as principal causal agents of alimentary toxic Aleukia, p. 21-86. In: T. D. Wyllie und L. G. Morehouse (Hrsg.), Mycotoxic fungi, mycotoxins, mycotoxicoses, vol. 3, Marcel Dekker, New York, N.Y.

Joffe, A. Z., 1986. Fusarium Species: Their Biology and Toxicology. John Wiley \& Sons Inc., New York.

Kane, R. T., 1985. Ecology and pathogenicity of fungi associated with root and crown rot of winter wheat in New York. Dissertation. Cornell University. Ithaca. 134 pp.

Kane, R. T., Smiley, R. W. und Sorrells, M. E., 1987. Relative pathogenicity of selected Fusarium species and Microdochium bolleyi to winter wheat in New York. Plant Disease 71: 177-181.

Kang, Z. und Buchenauer, H., 1999. Immunocytochemical localization of fusarium toxins in infected wheat spikes by Fusarium culmorum. Physiological and Molecular Plant Pathology 55: 275-288.

Kang, Z. und Buchenauer, H., 2000(a). Cytology and ultrastructure of the infection of wheat spikes by Fusarium culmorum. Mycological Research 104: 1083-1093.

Kang, Z. und Buchenauer, H., 2000(b). Ultrastructure and cytochemical studies on cellulose, xylan and pectin degradation in wheat spikes infected by Fusarium culmorum. Journal of Phytopathology 148: 263-275.

Keller, R., Hanus, H., Heyland, K.-U. (Hrsg.), 1997. Handbuch des Pflanzenbaus. Band 1: Grundlagen der landwirtschaftlichen Pflanzenproduktion. Verlag Ulmer, Stuttgart. 
Kirby, E. J. M., 2002. Botany of the wheat plant. In: Curtis B. C., Rajaram, S., Gómez Macpherson, H., (Hrsg.) Bread wheat: improvement and production. Rome, Italy: Food and Agriculture Organization of the United Nations, 19-38.

Klötzel, M., Lauber, U., Humpf, H.-U., 2006. A new solid phase extraction cleanup method for the determination of 12 type $A$ and $B$ trichothecenes in cereals and cereal-based food by LC-MS/MS. Molecular Nutrition \& Food Research 50: 261-269.

Kluth, C., Buhre, C., Varrelmann, M., 2010. Susceptibility of intercrops to infection with Rhizoctonia solani AG 2-2 IIIB and influence on subsequently cultivated sugar beet. Plant Pathology 59: 683-692.

Koch, H. J., Pringas, Ch. und Märländer, B., 2006. Evaluation of environmental and management effects on Fusarium head blight infection and deoxynivalenol concentration in the grain of winter wheat. European Journal of Agronomy 24, 357366.

Kosiak, B., Torp, M. und Skierve, E., 2003. The prevalence and distribution of Fusarium species in Norwegian cereals: a survey. Acta Agriculturae Scandinavica Section BSoil and Plant Science 53: 168-176.

Kosiak, B., Torp, M., Skierve, E. und Andersen, B., 2004. Alternaria and Fusarium in Norwegian grains of reduced quality - a matched pair sample study. International Journal of Food Microbiology 93: 51-62.

Köhl, J., de Haas, B. H., Kastelein, K., Burgers, S. L. G. E. und Waalwijk, C., 2007. Population dynamics of Fusarium spp. and Microdochium nivale in crops and crop residues of winter wheat. Phytopathology 97: 971-978.

Krampe, O., 1926. Fusarium als Erreger von Fußkrankheiten am Getreide. Dissertation, Berlin.

Krauthausen, H. J., Weinert, J., Bauermann, W. und Wolf, G. A., 2003. Mehrjährige Erhebung zum Vorkommen von Ährenfusarien und dem Mykotoxin Deoxynivalenol in Getreide aus Rheinland-Pfalz. Gesunde Pflanzen 55: 136-143. 
Krska, R., Baumgartner, S. und Josephs, R., 2001. The state-of-the-art in the analysis of type-A and type-B trichothecene mycotoxins in cereals. Fresenius' Journal of Analytical Chemistry. 371: 285-299.

Kuiper-Goodman, T., 1998. Food safety: mycotoxins and phycotoxins in perspective. In: Mycotoxins and Phycotoxins - Developments in Chemistry, Toxicology and Food Safety. Hrsg.: Miraglia, M., van Edmond, H., Brera, C. und Gilbert, J., 25-48.

Kulik, T., 2008. Detection of Fusarium tricinctum from cereal grain using PCR assay. Journal of Applied Genetics 49 (3): 305-311.

Kühnel, S.-M., Krebs, D., 2012. Statistik für die Sozialwissenschaften: Grundlagen, Methoden, Anwendungen. Rowohlt Verlag.

Lancashire, P. D., Bleiholder, H., Langelüddecke, P., Stauss, R., van den Boom, T., Weber, E. und Witzenberger, A., 1991. An uniform decimal code for growth stages of crops and weeds. Annals of Applied Biology 119: 561-601.

Langseth, W. und Elen, O., 1997. The occurrence of deoxynivalenol in Norwegian cereals - differences between years and districts, 1988-1996. Acta Agriculturae Scandinavica. Section B, Soil and Plant Science 47: 176-184.

Langseth, W., Bernhoft, A., Rundberget, T., Kosiak, B., Gareis, M., 1999. Mycotoxin production and cytotoxicity of Fusarium strains isolated from Norwegian cereals. Mycopathologia 144: 103-113.

Lepschy, J., 1991. Mykotoxine, die vernachlässigten Gifte. Pflanzenschutzpraxis 4/1991: 26-28.

Lepschy, J., 1992. Fusarientoxine in Getreide - ihre Entstehung und Vorbeugungsmaßnahmen. Gesunde Pflanzen 44: 35-39.

Leslie, J. F., Summerell, B. A., 2006: The Fusarium Laboratory Manual. Blackwell Publishing, Oxford.

Liddell, C. M., 2003. Systematics of Fusarium species and allies associated with Fusarium head blight. In: Fusarium Head Blight of Wheat and Barley. Edited by K. J. Leonard and W. R. Bushnell, APS Press, St. Paul, USA. 
Lienemann, K., Oerke, E.-C. und Dehne, H.-W, 2003. Infektion und Ausbreitung von Fusarium spp. an Weizen in Abhängigkeit der Anbaubedingungen im Rheinland. Landwirtschaftliche Fakultät der Universität Bonn, Schriftenreihe des Lehr- und Forschungsschwerpunktes Usl, 104, 120 Seiten.

Link, H. F., 1809. Observationes in ordines plantarum naturales, Dissertatio I. Der Entdeckungen in der gesammten Naturkunde 3: 3-42.

Logrieco, A., Bottalico, A., Mulè, G., Moretti, A. und Bottalico, A., 2003. Epidemiology of toxigenic fungi and their associated mycotoxins for some Mediterranean crops. European Journal of Plant Pathology 109: 645-667.

Lorenz, K., 1986. Effects of blackpoint on grain composition and baking quality of New Zealand wheat. New Zealand Journal of Agricultural Research 29: 711-718.

Łukanowski, A. und Sadowski, Cz., 2002. Occurrence of Fusarium on grain and heads of winter wheat cultivated in organic, integrated, conventional systems and monoculture. Journal of Applied Genetics 43 A: 73-82.

Maciá-Vicente, J. G., Rosso, L. C., Ciancio, A., Jansson, H.-B. und Lopez-Llorca, L. V., 2009. Colonisation of barley roots by endophytic Fusarium equiseti and Pochonia chlamydosporia: Effects on plant growth and disease. Annals of Applied Biology 155: 391-401.

Mak, Y., Willows, R. D., Roberts, T. H., Wrigley, C. W., Sharp, P. J. und Copeland, L., 2006. Black point is associated with reduced levels of stress, disease- and defencerelated proteins in wheat grain. Molecular Plant Pathology 7: 177-189.

Markell, S. G. und Francl, L. J., 2003. Fusarium head blight inoculum: Species prevalence and Gibberella zeae spore type. Plant Disease 87: 814-820.

Mesterházy, Á., 1977. The effect of inoculation method on the expression of symptoms caused by Fusarium graminearum Schwabe on wheat in seedling stage. In: Z. Király (Hrsg.), Current Topics in Plant Pathology, 1975, Akad. Kiadó, Budapest, 223-232.

Mesterházy, Á., 1995. Types and components of resistance against Fusarium head blight of wheat. Plant Breeding 114: 377-386. 
Mesterházy, Á., 2002. Role of deoxynivalenol in aggressiveness of Fusarium graminearum and F. culmorum and in resistance to Fusarium head blight. European Journal of Plant Pathology. 108: 675-684.

Mesterházy, Á., 2003. Breeding wheat for Fusarium Head Blight resistance in Europe. In: Fusarium Head Blight of Wheat and Barley. Edited by K. J. Leonard and W. R. Bushnell, APS Press, St. Paul, USA.

Miller, J. D., Young, J. C., Sampson, D. R., 1985. Deoxynivalenol and Fusarium headblight resistance in spring cereals. Journal of Phytopathology 113: 359-367.

Minervini, F., Fornelli, F., Flynn, K. M., 2004. Toxicity and apoptosis induced by the mycotoxins nivalenol, deoxynivalenol and fumonisin B1 in a human erythroleukemia cell line. Toxicology in Vitro 18: 21-28.

Moretti, A. N., 2006. Taxonomy of Fusarium Genus, a continuous fight between lumpers and splitters. Proceedings For Natural Sciences, Matica Srpska Novi Sad 117: 7-13.

Mudge, A. M., Dill-Macky, R., Dong, Y., Gardiner, D. M., White, R. G. und Manners, J. M., 2006. A role for the mycotoxin Deoxynivalenol in stem colonization during crown rot disease of wheat caused by Fusarium graminearum and Fusarium pseudograminearum. Physiological and Molecular Plant Pathology 69: 73-85.

Negrutskii, B. S., El'skaya, A. V., 1998. Eukaryotic translation elongation factor 1 alpha: structure, expression, functions, and possible role in aminoacyl-tRNA channeling. Progress in Nucleic Acid Research and Molecular Biology 60: 47-78.

Nelson, P. E., Toussoun, T. A., Marasas, W. F. O., 1983. Fusarium species - an illustrated manual for identification. Pennsylvania State University Press, University Park.

Nelson, P. E., 1991. History of Fusarium Systematics. The American Phytopathological Society 81 : 1045-1048.

Nelson, P. E., Dignani, M. C., Anaissie, E. J., 1994. Taxonomy, biology, and clinical aspects of Fusarium species. Clinical Microbiology Reviews 7: 479-504. 
Nganje, W. E., Johnson, D. D., Wilson, W. W., Leistritz, F. L., Bangsund, D. A. und Tiapo, N. M., 2001. Economic Impacts of Fusarium Head Blight in Wheat and Barley: 19982000. Agribusiness and Applied Economics Report No. 464.

Nicholson, P., Simpson, D. R., Weston, G., Rezanoor, H.N., Lees, A.K., Parry, D.W. und Joyce, D., 1998. Detection and quantification of Fusarium culmorum and Fusarium graminearum in cereals using PCR assays. Physiological and Molecular Plant Pathology 109: 17-37.

Nielsen, L. K., Jensen, J. D., Nielsen, G. C., Jensen, J. E., Spliid, N. H., Thomsen, I. K., Justesen, A. F., Collinge, D. B. und Jørgensen, L. N., 2011. Fusarium Head Blight of Cereals in Denmark: Species Complex and Related Myotoxins. Phytopathology 101: 960-969.

Nitschke, E., Nihlgard, M., und Varrelmann, M., 2009. Differentiation of eleven Fusarium spp. isolated from sugar beet, applying restriction fragment analysis of polymerase chain reaction-amplified translation elongation factor $1 \alpha$ gene fragment. Phytopathology 99: 921-929.

Obst, A., Lepschy-von Gleissenthall, J., Beck, R., 1997. On the etiology of Fusarium head blight of wheat in South Germany - Preceding crops, weather conditions for inoculum production and head infection, proneness of the crop to infection and mycotoxin production. Cereal Research Communications 25: 699-703.

O’Donnell, K., Kistler, H. C., Cigelnik, E., Ploetz, R. C., 1998. Multiple evolutionary origins of the fungus causing Panama disease of banana: Concordant evidence from nuclear and mitochondrial gene genealogies. Proceedings of the National Academy of Sciences USA 95: 2044-2049.

O’Donnell, K., Kistler, H. C., Tacke, B. K. und Casper, H. H., 2000. Gene genealogies reveal global phylogenetic structure and reproductive isolation among linages of Fusarium graminearum, the fungus causing wheat scab. Proceedings of the National Academy of Sciences USA 97: 7905-7910.

O’Donnell, K., Ward, T. J., Geiser, D. M., Kistler, H. C. und Aoki, T., 2004. Genealogical concordance between the mating type locus and seven other nuclear genes supports formal recognition of nine phylogenetically distinct species within the Fusarium graminearum clade. Fungal Genetics and Biology 41: 600-623. 
Olszak., M., 1994. Aetiology of sour cherry fungal diseases in Poland. III. Pathogenicity of the isolated fungi. Journal of Fruit and Ornamental Plant Research 2: 165-184.

Papendick, R. I., und Cook, R. J. 1974. Plant water stress and development of Fusarium Foot Rot in wheat subjected to differential cultural practices. Phytopathology 64: 358-363.

Parry, D. W., Pettitt, T. R., Jenkinson, P., Lees, A. K., 1994. The cereal Fusarium complex. In: Blakeman, P., Williamson, B. (Hrsg.), Ecology of Plant Pathogens. Wallingford, UK: CAB International, 301-320.

Parry, D. W., Jenkinson, P. und McLeod, L., 1995. Fusarium ear blight (scab) in small grains - a review. Plant Pathology 44: 207-238.

Parry, D. W. und Nicholson, P., 1996. Development of a PCR assay to detect Fusarium poae in wheat. Plant Pathology 45: 383-391.

Paul, P. A., El-Allaf, S. M., Lipps, P. E., Madden, L. V., 2004. Rain splash dispersal of Gibberella zeae within wheat canopies in Ohio. Phytopathology 94: 1342-1349.

Pitt, J. I., 2000. Toxigenic fungi: which are important? Medical Mycology 38: 17-22.

Polley, R. W., Turner, J. A., Cockerell, V., Robb, J., Scudamore, K. A., Sanders, M. F., Magan, M., 1991. Survey of Fusarium species infecting winter wheat in England, Wales and Scotland, 1989-1990. Home Grown Cereals Authority Project Report 39, London: Home Grown Cereals. Authority Publication 100 pp.

Prillwitz, H. G. und Bauermann, W., 1974. Fusarien als Fußkrankheitserreger von Weizen. Jahresbericht 1974 - Landespflanzenschutzdienst, Rheinland-Pfalz 57.

Proctor, R. H., Hohn, T. M. und McCormick, S. P., 1995. Reduced virulence of Gibberella zeae caused by disruption of a trichothecene toxin biosynthetic gene. Molecular Plant-Microbe Interactions 8: 593-601.

Pugh, G. W., Johann, H., Dickinson, J.G., 1933. Factors affecting infection of wheat heads by Gibberella saubinettii. Journal of Agricultural Research 46: 771-797. 
Ribichich, K. F., Lopez, S. E. und Vegeti, A. C., 2000. Histopathological spikelet changes produced by Fusarium graminearum in susceptible and resistant wheat cultivars. Plant Disease 84: 794-802.

Rintelen, J., 2000. Ist das starke Auftreten von Gibberella zeae (Fusarium graminearum) an Getreideähren auf die Zunahme des Maisanbaus zurückzuführen? Schriftenreihe der Bayerischen Landesanstalt für Bodenkultur und Pflanzenbau: Risiken durch den Ährenparasiten Fusarium graminearum, 11-15.

Samuels, G. J, Nirenberg, H. I., Seifert, K. A., 2001. Perithecial species of Fusarium. In: Summerell, B. A., Leslie, J. F., Backhouse, D., Bryden, W. L., Burgess, L. W., (Hrsg.). Fusarium: Paul E. Nelson memorial symposium. St. Paul, Minnesota: APS Press. p 1-14.

Schroeder, H. W., Christensen, J. J., 1963. Factors affecting resistance of wheat to scab caused by Gibberella zeae. Phytopathology 53: 831-838.

Smiley, R. W., Patterson, L. M., 1996. Pathogenic fungi associated with Fusarium foot rot of winter wheat in semiarid Pacific Northwest USA. Plant Disease 80: 944-949.

Smiley, R. W., Gourlie, J. A., Easley, S. A., Patterson, L.-M., 2005. Pathogenicity of Fungi Associated with the Wheat Crown Rot Complex in Oregon and Washington. Plant Disease 89: 949-957.

Snijders, C. H. A., 1990. Systematic fungal growth of Fusarium culmorum in stems of winter wheat. Journal of Phytopathology 129: 133-140.

Snijders, C. H. A. und Perkowski, J., 1989. Effects of head blight caused by Fusarium culmorum on toxin content and weight of wheat kernels. Phytopathology 80: 566570.

Snyder, W. C., Hansen, H. N., 1940. The species concept in Fusarium. American Journal of Botany 27: 64-67.

Snyder, W. C., Hansen, H. N., 1941. The species concept in Fusarium with reference to section Martiella. American Journal of Botany 28: 738-742. 
Snyder, W. C., Hansen, H. N., 1945. The species concept in Fusarium with reference to section Discolor and other sections. American Journal of Botany 32: 657-666.

Snyder, W. C. und Nash, S. M., 1968. Relative incidence of Fusarium pathogens of cereals in rotation plots at Rothamsted. Transactions of the British Mycological Society 51 : 417-425.

Southwell, R. J., Moore, K. J., Manning, W. und Hayman, P. T., 2003. An outbreak of Fusarium head blight of durum wheat on the Liverpool Plains in northern New South Wales in 1999. Australasian Plant Pathology 32: 465-471.

Stack, R. W. und McMullen, M., 1998. A visual scale to estimate severity of Fusarium head blight in wheat. NDSU Extension Service: Small Grains Publications. Online Publication/PP-1095.

Starkey, D. E., Ward, T. J., Aoki, T., Gale, L. R., Kistler, H. C., Geiser, D. M., Suga, H., Toth, B., Varga, J. und O'Donnell, K., 2007. Global molecular surveillance reveals novel Fusarium head blight species and trichothecene toxin diversity. Fungal Genetics and Biology 44: 1191-1204.

Stein, J. M., Osborne, L. E., Bondalapati, K. D., Glover, K. D. und Nelson, C. A., 2009. Fusarium head blight severity and deoxynivalenol concentration in wheat in response to Gibberella zeae inoculum concentration. Phytopathology 99: 759-764.

Steinmann, H.-H. und von Tiedemann, A., 2006. Möglichkeiten und Grenzen der Fruchtfolgegestaltung im Ackerbau aus phytomedizinischer, ökologischer und ökonomischer Sicht. Berichte aus der Biologischen Bundesanstalt für Land- und Forstwirtschaft Berlin-Dahlem, 132: 4-9.

Stenglein, S. A., 2009. Fusarium poae: A pathogen that needs more attention. Journal of Plant Pathology 91: 25-36.

Steyn, P. S., 1995. Mycotoxins, general view, chemistry and structure. Toxicology Letters 82/83: 843-851.

Streit, S. und Tillmann, M., 2012. Wachstum und Sporulation von Fusarium-Arten auf Substratbasis verschiedener Vorfrüchte. B.Sc.-Arbeit (unveröffentlicht), Universität Göttingen. 
Summerell, B. A., Salleh, B., Leslie, J. F., 2003. An Utilitarian Approach to Fusarium Identification. Plant Disease 87: 117-128.

Sutton, J.C., 1982. Epidemiology of wheat head blight and maize ear rot caused by Fusarium graminearum. Canadian Journal of Plant Pathology 4: 195-209.

Thrane, U., Adler, A., Clasen, P. E., Galvano, F., Langseth, W., Logrieco, A., Nielsen, K. F. und Ritieni, A., 2004. Diversity in metabolite production by Fusarium langsethiae, Fusarium poae and Fusarium sporotrichioides. International Journal of Food Microbiology 95: 257-266.

Trail, F., 2009. For Blighted Waves of Grain: Fusarium graminearum in the Postgenomics Era. Plant Physiology 149: 103-110.

Turner, A. S., Lees, A. K., Rezanoor, H. N., Nicholson, P., 1998. Refinement of PCRdetection of Fusarium avenaceum and evidence from DNA marker studies for phenetic relatedness to Fusarium tricinctum. Plant Pathology 47: 278-88.

Ueno, Y., 1985. The toxicology of mycotoxins. Critical Reviews in Toxicology 14: 99-133.

Uetsuki, T., Naito, A., Nagata, S., Kaziro, Y., 1989. Isolation and characterization of the human chromosomal gene for polypeptide chain elongation factor-1 alpha. The Journal of Biological Chemistry 264: 5791-5798.

Uhlig, S., Torp, M., Heier, B. T., 2006. Beauvericin and enniatins A, A1, B, and B1 in Norwegian grain: a survey. Food Chemistry 94: 193-201.

Uhlig, S., Jestoi, M., Parikka, P., 2007. Fusarium avenaceum - The North European situation. International Journey of Food Microbiology 119: 17-24.

Visconti, A., Haidukowski, E. M., Pascale, M. und Silvestri, M., 2004. Reduction of Deoxynivalenol during durum wheat processing and spaghetti cooking. Toxicological Letters 153: 181-189.

Vogelgsang, S., Sulyok, M., Hecker, A., Jenny, E., Krska, R., Schuhmacher, R., Forrer, H. R., 2008. Toxigenicity and pathogenicity of Fusarium poae and Fusarium avenaceum on wheat. European Journal of Plant Pathology 122: 265-276. 
von Lochow, J. und Schuster, W., 1961. Anlage und Auswertung von Feldversuchen. DLG-Verlag.

Wagacha, J. M., Muthomi, J. W., 2007. Fusarium culmorum: Infection process, mechanisms of mycotoxin production and their role in pathogenesis in wheat. Crop Protection 26: 877-885.

Ward, T. J., Bielawski, J. P., Kistler, H. C., Sullivan, E., O’Donnell, K., 2002. Ancestral polymorphism and adaptive evolution in the trichothecene mycotoxin gene cluster of phytopathogenic Fusarium. Proceedings of the National Academy of Sciences USA 99: 9278-83.

Wätjen, W., Debbab, A., Hohlfeld, A., Chovolou, Y., Kampkötter, A., Edrada, R. A., Ebel, R., Hakiki, A., Mosaddak, M., Totzke, F., Kubbutat, H. G. und Proksch, P., 2009. Enniatins $A 1, B$ and $B 1$ from an endophytic strain of Fusarium tricinctum induce apoptotic cell death in H4IIE hepatoma cells accompanied by inhibition of ERK phosphorylation. Molecular Nutrition Food Research 53: 431-440.

Wegener, M., 1996. Verbreitung, Artenspektrum und Bekämpfungsmöglichkeiten von Halmbasiskrankheitserregern an Winterweizen unter besonderer Berücksichtigung der Gattung Fusarium Lk. Dissertation, Universität Göttingen.

Weinert, J. und Wolf, G. A., 1995. Gegen Ährenfusarien helfen nur resistente Sorten. Pflanzenschutzpraxis 2: 30-32.

Weinert, J., von Tiedemann, A., Kleinhenz, B., 2007. Fusarientoxine - Risiko richtig einschätzen. DLG-Mitteilungen 9: 48-51.

White, T. J., Bruns, T., Lee, S., Taylor, J., 1990. Amplification and direct sequencing of fungal ribosomal RNA genes for phylogenetics. In: Innis, M. A., Gelfand, D. H., Sninsky, J. J., Whiste, T. J., (Hrsg.) PCR Protocols: a Guide to Methods and Applications, pp. 315-322. Academic Press, New York.

Wilcoxson, R. D., Kommedahl, T., Ozmon E. A. und Windels, C. E., 1988. Occurrence of Fusarium species in scabby wheat from Minnesota and their pathogenicity to wheat. Phytopathology 78: 586-589. 
Wilcoxson, R. D., Busch, R. H. und Ozmon, E. A., 1992. Fusarium head blight resistance in spring wheat cultivars. Plant Disease 76: 658-661.

Wilson, A., Simpson, D., Chandler, E., Jennings, P. und Nicholson, P., 2004. Development of PCR assays for the detection and differentiation of Fusarium sporotrichioides and Fusarium langsethiae. FEMS Microbiology Letters 233: 69-76.

Winter, M., mündliche Mitteilung vom 09.03. 2011.

Winter, M., 2012. Halmbasis- und Wurzelkrankheitserreger an Weizen (Triticum aestivum L.) in Energiefruchtfolgen und Bedeutung des Halmbasisbefalls mit Fusarium culmorum (W. G. Smith) Sacc. und Fusarium graminearum (Schwabe) für die Mykotoxin-Kontamination der Pflanze. Dissertation, Universität Göttingen.

Wollenweber, H. W., Reinking, O. A., 1935. Die Fusarien. Ihre Beschreibung, Schadwirkung und Bekämpfung. Paul Parey Verlag, Berlin.

Wu, Y. X. und von Tiedemann, A., 2001. Physiological effects of azoxystrobin and epoxiconazol on senecence and the oxidative status of wheat. Pesticide Biochemistry and Physiology 71: 1-10.

www.wetterstation-goettingen.de. Die meteorologischen Daten wurden mit freundlicher Genehmigung von Andreas Vohl zur Verfügung gestellt.

Xu, X., 2003. Effects of environmental conditions on the development of Fusarium ear blight. European Journal of Plant Pathology 109: 683-689.

Xu, X.-M., Parry, D. M., Nicholson, P., Thomsett, M. A., Simpson, D., Edwards, S. G., Cooke, B. M., Doohan, F. M., Brennan, J. M., Moretti, A., Tocco, G., Mule, G., Hornok, L., Giczey, G. und Tatnell, J., 2005. Predominance and association of pathogenic fungi causing Fusarium ear blight in wheat in four European countries. European Journal of Plant Pathology 112: 143-154.

Xu, X. M., Monger, W., Ritieni, A. und Nicholson, P., 2007. Effect of temperature and duration of wetness during initial infection periods on disease development, fungal biomass and mycotoxin concentrations on wheat inoculated with single, or combinations of Fusarium species. Plant Pathology 56: 943-956. 
Yoder, W. T. und Christianson, L. M., 1998. Species-specific primers resolve members of Fusarium section Fusarium. Taxonomic status of the edible "Quorn" fungus reevaluated. Fungal Genetics and Biology 23: 68-80. 


\section{$7 \quad$ Anhang}

Tab. 34: Pflanzenbauliche Maßnahmen am Standort Torland im FAEN-Versuch 2010.

\begin{tabular}{|c|c|c|}
\hline Standort & Maßnahme & Datum und Art der Maßnahme \\
\hline \multirow[t]{31}{*}{ Torland } & \multicolumn{2}{|l|}{ Aussaatvorbereitung } \\
\hline & - Vorfrucht & Winterweizen, Zuckerrübe, Mais, Ölrettich \\
\hline & Stoppelbearbeitung & 04.09.2009 Grubber (IFZ) \\
\hline & - Totalherbizid & 24.09.2009 1,5kg/ha Round Up Turbo \\
\hline & - Bodenbearbeitung & 01.10.2009 Grubber (IFZ) \\
\hline & Saatbettbereitung & 01.10.2009 Kreiselegge und Walze \\
\hline & \multicolumn{2}{|l|}{ Aussaat } \\
\hline & & 02.10.2009 \\
\hline & - Technik & Scheibenschaardrillmaschine "Hassia" \\
\hline & \multirow[t]{2}{*}{ Saatgut (Menge und Sorte) } & „Centrum“ 169 kg/ha,300 Kö./m²,TKG: 53,0 g.;KF: 94\% \\
\hline & & „Ritmo“ 144 kg/ha,300 Kö./m²,TKG: 43,2 g.;KF: 90\% \\
\hline & \multirow[t]{2}{*}{ Beizung } & "Centrum": Arena C \\
\hline & & "Ritmo": Celest \\
\hline & Wege spritzen & 07.04.2010 \\
\hline & \multicolumn{2}{|l|}{ · Düngung } \\
\hline & $\cdot \mathrm{K}$ & 03.09. bzw. 29.09.2009 400 kg K2O/ha (10dt/ha 40er Kali) \\
\hline & N-min Probenahme & 09.03.2010 \\
\hline & \multirow[t]{2}{*}{$\cdot \mathrm{N}-\min$} & WW-WW: $46,1 \mathrm{~kg} \mathrm{~N} / \mathrm{ha}$; WW-M: 52,4 kg N/ha \\
\hline & & WW-ZR: 47,1 kg N/ha ; WW-ÖR: $58,6 \mathrm{~kg} \mathrm{~N} / \mathrm{ha}$ \\
\hline & . 1. N-Düngung & 18.03.2010 ES 23: $70 \mathrm{~kg} \mathrm{~N} / \mathrm{ha}$ als $\mathrm{AHL}$ \\
\hline & . 2. N-Düngung & 20.04.2010 ES 27: $60 \mathrm{~kg} \mathrm{~N} / \mathrm{ha}$ als AHL (nach WW $70 \mathrm{~kg} \mathrm{~N} / \mathrm{ha}$ ) \\
\hline & 3. N-Düngung & 04.06.2010 ES 39/41: $60 \mathrm{~kg} \mathrm{~N} / \mathrm{ha}$ als AHL \\
\hline & $\cdot \mathrm{N}_{\text {gesamt }}\left(\right.$ incl. $\left.\mathrm{N}_{\text {min }}\right)$ & nach WW: 246,1; M: 242,4; ZR: 237,1; ÖR: 248,6 kg N/ha \\
\hline & \multicolumn{2}{|l|}{ Pflanzenschutz } \\
\hline & . 1. Herbizid & 15.10.2009 ES 09: 4 I/ha Malibu \\
\hline & 2. Herbizid & 05.05.2010 ES 31: 0,5l/ha Tomigan \\
\hline & 3. Herbizid & 26.05.2010 ES39: 1,5 I/ha U-46 M fluid \\
\hline & - 1. Wachstumsregler & 15.04.2010 ES 27: 1,3 I/ha CCC 720 \\
\hline & -2. Wachstumsregler & 05.05.2010 ES 31: 0,8 I/ha CCC $720+0,3 \mathrm{I} /$ ha Moddus \\
\hline & . 1. Fungizid (nach Feldplan) & 05.05.2010 ES 31: 0,8 I/ha Proline \\
\hline & 2. Fungizid & 03.06.2010 ES 39/43: 0,8 I/ha Proline \\
\hline
\end{tabular}

10.08.2010 
Tab. 35: Pflanzenbauliche Maßnahmen am Standort Torland im FAEN-Versuch 2011.

\begin{tabular}{|c|c|c|}
\hline Standort & Maßnahme & Datum und Art der Maßnahme \\
\hline \multirow[t]{29}{*}{ Torland } & Aussaatvorbereitung & \\
\hline & - Vorfrucht & Winterweizen, Zuckerrübe, Mais, Ölrettich \\
\hline & Bodenbearbeitung & 21.09.2010 Grubber (IFZ) \\
\hline & Saatbettbereitung & 07.10.2010 Kreiselegge und Walze \\
\hline & Aussaat & \\
\hline & & 07.10 .2010 \\
\hline & - Technik & Scheibenschaardrillmaschine "Hassia" \\
\hline & Saatgut (Menge und Sorte) & „Centrum“ 146 kg/ha, 300 Kö./m²,TKG: 46,7 g.; KF: 96\% \\
\hline & & „Ritmo“ 133 kg/ha, 300 Kö./m²,TKG: 42,5 g.; KF: 96\% \\
\hline & & "Asano" 156 kg/ha, 300 Kö./m²,TKG: 51,0 g.; KF: 98\% \\
\hline & - Beizung & "Centrum": Arena C \\
\hline & & "Ritmo": Arena C \\
\hline & & "Asano" : Arena C \\
\hline & Wege spritzen & 23.03.2011 \\
\hline & · Düngung & \\
\hline & $\cdot \mathrm{K}$ & \\
\hline & N-min Probenahme & keine Probenahme \\
\hline & · 1. N-Düngung & 08.03.2011 ES 23: $70 \mathrm{~kg} \mathrm{~N} / \mathrm{ha}$ als $\mathrm{AHL}$ \\
\hline & . 2. N-Düngung & 20.04.2012 ES $30: 60 \mathrm{~kg} \mathrm{~N} / \mathrm{ha}$ als $\mathrm{AHL}$ \\
\hline & 3. N-Düngung & 25.05.2011 ES 49: $60 \mathrm{~kg} \mathrm{~N} / \mathrm{ha}$ als AHL \\
\hline & $\cdot \mathrm{N}_{\text {gesamt }}\left(\right.$ incl. $\left.\mathrm{N}_{\min }\right)$ & $190 \mathrm{~kg} \mathrm{n} / \mathrm{ha}$ ohne N-min \\
\hline & . Pflanzenschutz & \\
\hline & 1. Herbizid & $\begin{array}{l}\text { 14.10.2010 ES VA: 0,8 I/ha Bacchara forte + 0,33 I/ha Cadou } \\
\text { SC }\end{array}$ \\
\hline & 2. Herbizid & 18.05.2011 ES 39: 1,5 I/ha U-46 M-fluid + $30 \mathrm{~g} / \mathrm{ha}$ Pointer \\
\hline & 1. Wachstumsregler & 11.04.2011 ES 25: $1,3 \mathrm{l} / \mathrm{ha}$ CCC 720 \\
\hline & 2. Wachstumsregler & 04.05.2011 ES 31: $0,5 \mathrm{l} / \mathrm{ha}$ CCC $720+0,2 \mathrm{l} / \mathrm{ha}$ Moddus \\
\hline & 1. Fungizid (nach Feldplan) & 04.05.2011 ES 31: 0,8 I/ha Proline \\
\hline & 2. Fungizid & 19.05.2011 ES 39: 0,8 I/ha Proline \\
\hline & 1. Insektizid & 30.05.2011 ES 51/55: $125 \mathrm{ml} / \mathrm{ha}$ Fastac SC Super Contact \\
\hline
\end{tabular}

\section{- Ernte}


Tab. 36: Pflanzenbauliche Maßnahmen am Standort Gladebeck im FreilandInokulationsversuch 2011.

\begin{tabular}{|c|c|c|}
\hline Standort & Maßnahme & Datum und Art der Maßnahme \\
\hline \multirow[t]{25}{*}{ Gladebeck } & - Aussaatvorbereitung & \\
\hline & - Vorfrucht & Winterweizen, Zuckerrübe, Mais, Ölrettich \\
\hline & - Bodenbearbeitung & 21.09.2010 Grubber (IFZ) \\
\hline & Saatbettbereitung & 07.10.2010 Kreiselegge und Walze \\
\hline & - Aussaat & \\
\hline & & 07.10 .2010 \\
\hline & - Technik & Scheibenschaardrillmaschine "Hassia" \\
\hline & Saatgut (Menge und Sorte) & "Asano" 156 kg/ha, 300 Kö./m²,TKG: 51,0 g.; KF: 98\% \\
\hline & - Beizung & "Asano" : Arena C \\
\hline & $\begin{array}{l}\text { Fusarium-Inokulation } \mathbf{n} . \\
\text { Plan }\end{array}$ & 04.06.2011 ES 65 \\
\hline & · Düngung & \\
\hline & $\cdot \mathrm{K}$ & \\
\hline & - N-min Probenahme & keine Probenahme \\
\hline & 1. N-Düngung & 08.03.2011 ES 23: $70 \mathrm{~kg} \mathrm{~N} / \mathrm{ha}$ als $\mathrm{AHL}$ \\
\hline & 2. N-Düngung & 20.04.2012 ES $30: 60 \mathrm{~kg} \mathrm{~N} / \mathrm{ha}$ als $A H L$ \\
\hline & . 3. N-Düngung & 25.05.2011 ES 49: $60 \mathrm{~kg} \mathrm{~N} / \mathrm{ha}$ als $\mathrm{AHL}$ \\
\hline & $\cdot \mathrm{N}_{\text {gesamt }}\left(\right.$ incl. $\left.\mathrm{N}_{\min }\right)$ & $190 \mathrm{~kg} \mathrm{n} /$ ha ohne N-min \\
\hline & - Pflanzenschutz & \\
\hline & 1. Herbizid & $\begin{array}{l}\text { 14.10.2010 ES VA: 0,8 I/ha Bacchara forte }+0,33 \text { I/ha Cadou } \\
\text { SC }\end{array}$ \\
\hline & 2. Herbizid & 18.05.2011 ES 39: 1,5 I/ha U-46 M-fluid + $30 \mathrm{~g} / \mathrm{ha}$ Pointer \\
\hline & 1. Wachstumsregler & 11.04.2011 ES 25: 1,3 I/ha CCC 720 \\
\hline & 2. Wachstumsregler & 04.05.2011 ES 31: 0,5 I/ha CCC $720+0,2 \mathrm{I} /$ ha Moddus \\
\hline & . 1. Fungizid (nach Feldplan) & 04.05.2011 ES 31: 0,8 I/ha Proline \\
\hline & 2. Fungizid & 19.05.2011 ES 39: 0,8 I/ha Proline \\
\hline & 1. Insektizid & 30.05.2011 ES 51/55: $125 \mathrm{ml} / \mathrm{ha}$ Fastac SC Super Contact \\
\hline
\end{tabular}

04.08.2011 
Tab. 37: Erträge des FAEN-Fruchtfolgeversuchs Standort Torland 2010. Ertrag pro Parzelle, angegeben in $\mathrm{kg} /$ Parzelle sowie $\mathrm{dt} / \mathrm{ha}$.

\begin{tabular}{|c|c|c|c|c|c|c|c|c|c|}
\hline & \multirow[b]{2}{*}{ Parz. } & \multicolumn{2}{|c|}{ wW } & \multicolumn{2}{|c|}{ M } & \multicolumn{2}{|c|}{ ZR } & \multicolumn{2}{|c|}{ ÖR } \\
\hline & & kg/Parz. & $\mathrm{dt} / \mathrm{ha}$ & kg/Parz. & $\mathrm{dt} / \mathrm{ha}$ & kg/Parz. & $\mathrm{dt} / \mathrm{ha}$ & kg/Parz. & $\mathrm{dt} / \mathrm{ha}$ \\
\hline Centrum beh & $\mathrm{A} 1$ & 18,4 & 73,6 & 22,4 & 89,7 & 20,4 & 81,8 & 25,5 & 102,2 \\
\hline Centrum unbeh & A2 & 18,0 & 72,0 & 22,0 & 88,0 & 20,9 & 83,5 & 24,3 & 97,1 \\
\hline Centrum beh & A3 & 18,8 & 75,2 & 23,5 & 94,0 & 19,8 & 79,2 & 26,3 & 105,3 \\
\hline Ritmo beh & B1 & 17,3 & 69,2 & 24,5 & 98,1 & 22,3 & 89,1 & 26,0 & 103,9 \\
\hline Ritmo unbeh & B2 & 16,2 & 64,9 & 21,9 & 87,5 & 20,5 & 82,1 & 25,6 & 102,3 \\
\hline Ritmo beh & B3 & 17,6 & 70,5 & 24,4 & 97,7 & 20,9 & 83,7 & 24,9 & 99,6 \\
\hline Centrum unbeh & C1 & 16,2 & 64,9 & 23,2 & 92,9 & 21,3 & 85,1 & 23,5 & 94,1 \\
\hline Centrum beh & $\mathrm{C} 2$ & 17,6 & 70,6 & 24,6 & 98,4 & 21,0 & 84,1 & 24,8 & 99,2 \\
\hline Centrum unbeh & C3 & 16,6 & 66,3 & 23,0 & 91,9 & 19,9 & 79,5 & 23,8 & 95,0 \\
\hline Ritmo unbeh & D1 & 15,9 & 63,4 & 20,8 & 83,2 & 19,8 & 79,2 & 23,8 & 95,2 \\
\hline Ritmo beh & D2 & 17,8 & 71,2 & 23,1 & 92,6 & 21,7 & 86,6 & 24,1 & 96,4 \\
\hline Ritmo unbeh & D3 & 15,6 & 62,4 & 21,6 & 86,4 & 19,1 & 76,6 & 22,9 & 91,6 \\
\hline Centrum beh & $\mathrm{E} 1$ & 17,6 & 70,4 & 24,2 & 96,8 & 23,0 & 92,0 & 21,7 & 86,6 \\
\hline Centrum unbeh & E2 & 17,0 & 68,0 & 23,3 & 93,3 & 21,4 & 85,5 & 21,5 & 86,0 \\
\hline Centrum beh & E3 & 15,6 & 62,4 & 23,9 & 95,7 & 20,4 & 81,7 & 21,6 & 86,5 \\
\hline Ritmo beh & $\mathrm{F} 1$ & 17,4 & 69,4 & 24,6 & 98,3 & 21,7 & 86,8 & 24,0 & 96,1 \\
\hline Ritmo unbeh & F2 & 17,3 & 69,2 & 22,0 & 88,0 & 19,6 & 78,2 & 21,4 & 85,5 \\
\hline Ritmo beh & F3 & 13,6 & 54,5 & 24,5 & 98,1 & 18,8 & 75,2 & 23,8 & 95,2 \\
\hline Centrum unbeh & G1 & 16,5 & 66,0 & 21,6 & 86,5 & 20,3 & 81,2 & 22,5 & 90,0 \\
\hline Centrum beh & G2 & 15,2 & 60,6 & 24,1 & 96,3 & 20,4 & 81,6 & 24,4 & 97,5 \\
\hline Centrum unbeh & G3 & 13,2 & 53,0 & 22,9 & 91,4 & 17,9 & 71,7 & 21,5 & 85,8 \\
\hline Ritmo unbeh & $\mathrm{H} 1$ & 15,1 & 60,6 & 21,3 & 85,1 & 20,4 & 81,6 & 20,5 & 82,0 \\
\hline Ritmo beh & $\mathrm{H} 2$ & 15,2 & 60,7 & 25,4 & 101,4 & 22,2 & 88,9 & 24,0 & 95,8 \\
\hline Ritmo unbeh & $\mathrm{H} 3$ & 12,6 & 50,2 & 22,0 & 87,9 & 18,2 & 72,6 & 19,2 & 76,9 \\
\hline
\end{tabular}


Tab. 38: Erträge des FAEN-Fruchtfolgeversuchs Standort Torland 2011. Ertrag pro Parzelle, angegeben in $\mathrm{kg} /$ Parzelle sowie $\mathrm{dt} / \mathrm{ha}$.

\begin{tabular}{|c|c|c|c|c|c|c|c|c|c|}
\hline & \multirow[b]{2}{*}{ Parz. } & \multicolumn{2}{|c|}{ WW } & \multicolumn{2}{|c|}{ M } & \multicolumn{2}{|c|}{$\mathrm{ZR}$} & \multicolumn{2}{|c|}{ ÖR } \\
\hline & & kg/Parz. & $\mathrm{dt} / \mathrm{ha}$ & kg/Parz. & $\mathrm{dt} / \mathrm{ha}$ & kg/Parz. & $\mathrm{dt} / \mathrm{ha}$ & kg/Parz. & $\mathrm{dt} / \mathrm{ha}$ \\
\hline Centrum beh & $\mathrm{A} 1$ & 14,9 & 59,4 & 17,5 & 70,1 & 20,9 & 83,7 & 23,7 & 94,8 \\
\hline Centrum unbeh & A2 & 18,4 & 73,6 & 19,6 & 78,5 & 20,9 & 83,6 & 24,0 & 95,9 \\
\hline Centrum beh & A3 & 17,8 & 71,0 & 17,5 & 69,9 & 19,4 & 77,5 & 22,9 & 91,7 \\
\hline Ritmo unbeh & B1 & 19,9 & 79,4 & 14,9 & 59,5 & 18,3 & 73,0 & 21,9 & 87,5 \\
\hline Ritmo beh & B2 & 19,1 & 76,4 & 16,8 & 67,2 & 20,0 & 80,1 & 23,7 & 94,8 \\
\hline Ritmo unbeh & B3 & 17,4 & 69,6 & 16,4 & 65,6 & 18,1 & 72,4 & 21,5 & 86,1 \\
\hline Centrum beh & C1 & 18,7 & 74,8 & 15,7 & 62,8 & 19,5 & 78,0 & 24,4 & 97,6 \\
\hline Centrum unbeh & C2 & 17,7 & 70,7 & 14,7 & 58,7 & 21,1 & 84,2 & 23,2 & 92,7 \\
\hline Centrum beh & C3 & 18,4 & 73,5 & 16,1 & 64,4 & 19,4 & 77,5 & 23,3 & 93,4 \\
\hline Ritmo unbeh & D1 & 14,2 & 56,9 & 16,5 & 65,9 & 21,7 & 86,7 & 25,7 & 102,7 \\
\hline Ritmo beh & D2 & 16,1 & 64,4 & 14,7 & 58,7 & 20,2 & 80,7 & 22,8 & 91,1 \\
\hline Ritmo unbeh & D3 & 20,1 & 80,3 & 16,3 & 65,2 & 20,9 & 83,5 & 23,3 & 93,2 \\
\hline Centrum beh & E1 & 15,1 & 60,5 & 15,3 & 61,2 & 22,1 & 88,3 & 23,8 & 95,0 \\
\hline Centrum unbeh & E2 & 18,9 & 75,7 & 17,3 & 69,4 & 23,2 & 93,0 & 23,7 & 94,9 \\
\hline Ritmo unbeh & $\mathrm{F} 1$ & 14,3 & 57,2 & 12,2 & 48,7 & 19,2 & 77,0 & 20,9 & 83,6 \\
\hline Ritmo beh & F2 & 19,3 & 77,3 & 16,5 & 65,9 & 21,1 & 84,5 & 22,1 & 88,5 \\
\hline
\end{tabular}




\section{Danksagung}

Mein ganz besonderer Dank gilt Prof. Dr. Andreas von Tiedemann für die Überlassung des Themas sowie für die dargebotene Diskussions- und Hilfsbereitschaft.

Bei Prof. Dr. Petr Karlovsky und Prof. Dr. Elke Pawelzik möchte ich mich für die Übernahme des Korreferats und die Teilnahme am Prüfungskomitee bedanken.

Ich danke Herrn Dr. Birger Koopmann für viele konstruktive Anmerkungen die mir u.a. halfen, Ordnung in das „Fusarium-Chaos“ zu bringen.

Ganz besonders möchte ich mich bei Dr. Ruben Gödecke bedanken, der mir die Fusarien näherbrachte und mir während der gesamten Promotionszeit mit seiner Erfahrung zur Seite stand. Dr. Daniela Christ danke ich für viele kritische Anmerkungen und hilfreiche Ratschläge.

Meinen FAEN-Projektpartnern danke ich für die konstruktive und angenehme Zusammenarbeit. Manuela Filz und Christina Trümper möchte ich darüber hinaus für die vielen Stunden tatkräftiger Hilfe während des Bonitierens danken.

Vielen Dank an meine beiden Büronachbarn Dr. Tobias Wulf und Kerstin Höch für eine stets angenehme Arbeitsatmosphäre und viele anregende Gespräche.

Mein Dank gilt ferner Dagmar Tacke, Dr. Mark Winter, Dr. Nazanin Zamani-Noor und Christian Comberg. Der Austausch mit euch hat mir immer weitergeholfen.

Herzlichen Dank auch an Claudia Nordmann, die immer für mich da war, wenn ich sie brauchte.

Für umfassende Unterstützung in Labor, Gewächshaus und Feld danke ich Evelin Vorbeck, Eugen Hodyl und Hubertus Reintke. Frank Gremmes und Mark Fiebrich danke ich für technische Unterstützung jeglicher Art.

Bei Frau Martina Bode und Frau Evelin Kistner bedanke ich mich für die unbürokratische Hilfe in verwaltungstechnischen Angelegenheiten.

Sehr herzlich bedanke ich mich zudem bei André Dingelstedt und Dr. Christian Kluth für die kompetente und produktive statistische Beratung.

Ich bedanke mich ferner bei Sebastian Streit und allen studentischen Hilfskräften für die tolle Arbeit, die sie bei der Bewältigung von Arbeitsspitzen geleistet haben.

Vielen Dank auch an alle Kollegen der Abteilung Pflanzenpathologie und Pflanzenschutz für das äußerst angenehme Arbeitsklima und die stetige Hilfsbereitschaft.

Mein größter Dank gilt meinen Eltern. 
Hiermit erkläre ich, dass die vorliegende Arbeit weder in gleicher noch in ähnlicher Form bereits anderen Prüfungsbehörden vorgelegen hat.

Göttingen, 11. März 2013

Marcel Tillmann

Hiermit erkläre ich eidesstattlich, dass diese Dissertation selbstständig und ohne unerlaubte Hilfe angefertigt wurde.

Göttingen, 11. März 2013

Marcel Tillmann 
